UNIVERSIDADE DE SÃO PAULO

ESCOLA POLITÉCNICA

DANILO DE SANTANA CHUI

\title{
Identificação de chama de forno industrial através do monitoramento por visão computacional
}

São Paulo 
Danilo de Santana Chui

Identificação de chama de forno industrial através do monitoramento por visão computacional

\section{Versão Corrigida}

Tese apresentada à Escola Politécnica da Universidade de São Paulo para obtenção do título de Doutor em Ciências, no Programa: Engenharia Mecânica.

Área de Concentração: Engenharia de Controle e Automação Mecânica.

Orientador: Prof. Dr. Agenor de Toledo Fleury

São Paulo 
Autorizo a reprodução e divulgação total ou parcial deste trabalho, por qualquer meio convencional ou eletrônico, para fins de estudo e pesquisa, desde que citada a fonte.

Este exemplar foi revisado e corrigido em relação à versão original, sob responsabilidade única do autor e com a anuência de seu orientador.

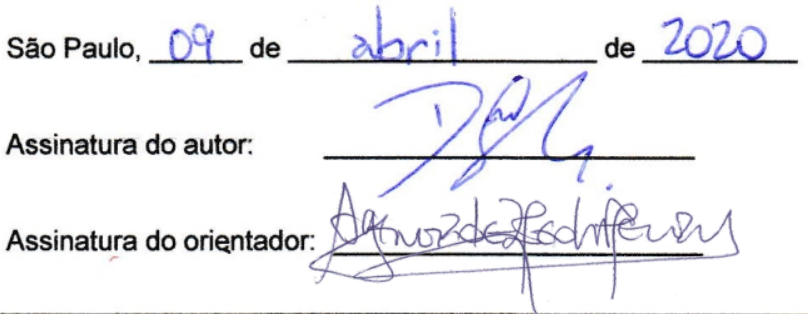

Chui, Danilo de Santana

Identificação de chama de forno industrial através do monitoramento por visão computacional / D. S. Chui -- versão corr. -- São Paulo, 2020. $174 \mathrm{p}$.

Tese (Doutorado) - Escola Politécnica da Universidade de São Paulo. Departamento de Engenharia Mecânica.

1.Identificação de sistemas 2.Sistemas dinâmicos (controle) 3.Algoritmos para imagens 4.Combustão I.Universidade de São Paulo. Escola Politécnica. Departamento de Engenharia Mecânica II.t. 
Nome: Danilo de Santana Chui

Título: Identificação de chama de forno industrial através do monitoramento por visão computacional

Tese apresentada à Escola Politécnica da Universidade de São Paulo para obtenção do título de Doutor em Ciências, no Programa: Engenharia Mecânica.

Área de Concentração: Engenharia de Controle e Automação Mecânica.

Aprovado em: 17/02/2020

\section{Banca Examinadora}

Prof. Dr. $\quad$ Agenor de Toledo Fleury

Instituição Escola Politécnica da Universidade de São Paulo (PME)

Assinatura

Prof. Dr. Flávio Celso Trigo

Instituição Escola Politécnica da Universidade de São Paulo (PME)

Assinatura

Prof. Dr. José Jaime da Cruz

Instituição Escola Politécnica da Universidade de São Paulo (PTC)

Assinatura

Prof. Dr. Paulo Roberto Gardel Kurka

Instituição Universidade Estadual de Campinas (UNICAMP)

Assinatura

Prof. Dr. Domingos Alves Rade

Instituição Instituto Tecnológico de Aeronáutica (ITA)

Assinatura 
Este trabalho é dedicado a minha amada Bia e ao pequeno Matias, pois foram, e sempre serão, a razão e a inspiração que possibilitaram sobrepujar as dificuldades desta caminhada. 


\section{AGRADECIMENTOS}

Em primeiro lugar, quero agradecer ao Prof. Dr. Agenor de Toledo Fleury, por ter aceitado a me orientar nesses longos anos, acreditando no meu potencial e sempre me incentivando. Além dos excelentes conselhos acadêmicos, agradeço também às conversas em almoços ou cafés, que vez ou outra, mesmo em hora de descontração, fazia aparecer um ensinamento sábio e valioso. Um exemplo para que levo para minha vida.

Ao Prof. Dr. Flávio Celso Trigo e ao Prof. Dr. Flavius Portella Ribas Martins, gostaria de expressar minha gratidão por não pouparem esforços para ajudar, sugerindo referências, dando conselhos, prestando comentários precisos, sempre pertinentes. Agradeço também às conversas sobre política, por me fazerem refletir e enxergar o mundo por diversos ângulos.

Ao colega de doutorado, colega de magistério e amigo Prof. Gustavo Cunha da Silva Neto, não tenho nem palavras para expressar o tamanho da gratidão, pelas conversas infindáveis, pelo apoio, pelo auxílio no rigor matemático, por ser um grande, grande amigo. Sem sua ajuda não sei como terminaria essa jornada. Muito obrigado! E conte comigo!

Ao Sr. Fausto Furnari, agradeço por não se negar em nenhum momento a ajudar a destravar os problemas encontrados nos testes experimentais. Agradeço pelo bom humor constante, conhecimento monstruoso, pontualidade britânica e habilidade didática excepcional, um dom que poucos possuem.

Aos colegas de doutorado e de DINAME, André, Adriano e Éverton desejo toda a sorte para que consigam alcançar seus objetivos. Para sempre será a equipe PoliPerfura!

Ao Instituto de Pesquisas Tecnológicas do Estado de São Paulo (IPT), agradeço por permitir a utilização do forno experimental a gás que possibilitou a aquisição das imagens que foram essenciais para a execução deste trabalho.

À Escola Politécnica da Universidade de São Paulo, agradeço pela oportunidade de realização do curso de doutorado.

À Fundação de Amparo à Pesquisa do Estado do Amazonas, agradeço pela concessão da bolsa de doutorado e pelo apoio financeiro para a realização desta pesquisa.

À Universidade Federal do Amazonas (UFAM), agradeço pela autorização de afastamento para fins desta capacitação em nível de doutorado.

Aos professores do Departamento de Engenharia Mecânica da Faculdade de Tecnologia da UFAM, agradeço pelo empenho na organização de seu plano de capacitação e pelo extraordinário comprometimento de seus membros com sua execução mesmo em face 
de inúmeras dificuldades para manter as atividades acadêmicas com quadro reduzido.

Aos amigos e familiares que me apoiaram e se solidarizaram com minhas dificuldades, mesmo não tendo condições técnicas para contribuir diretamente, prestaram suporte emocional incondicional e alimentaram a força de vontade necessária para essa empreitada. Agradeço a todos de coração, pela contribuição de cada um a seu jeito próprio.

À minha mãe, agradeço por sempre torcer, rezar por mim, e por ser essa mãe maravilhosa que é e sempre foi.

Ao meu pai e à Rita, agradeço por sempre estarem ao meu lado e respeitarem meu espaço.

A minha esposa e companheira Bia e ao meu filho Matias, agradeço por estarem sempre comigo na jornada da vida. Amo muito vocês! 
Nunca acendas um fogo que não possas apagar.

Provérbio Chinês

Os três grandes fundamentos para se conseguir qualquer coisa são, primeiro, trabalho árduo; segundo, perseverança; terceiro, senso comum.

Thomas Alva Edison

Faz-se ciência com os fatos, como se faz uma casa com pedras; mas uma acumulação de fatos não é ciência, assim como um monte de pedras não é uma casa

Jules Henri Poincaré

O sucesso é construído de $99 \%$ de fracasso.

Soichiro Honda

Blackbird singing in the dead of night

Take these broken wings and learn to fly

All your life

You were only waiting for this moment to arise

John W. Lennon \& Paul J. McCartney 


\section{RESUMO}

CHUI, D. S. Identificação de chama de forno industrial através do monitoramento por visão computacional. 2020. 174 p. Tese (Doutorado) - Escola Politécnica, Universidade de São Paulo, São Paulo, 2020.

Em fornos industriais, chamas instáveis podem levar a condições de operação potencialmente inseguras. Geralmente, sistemas supervisórios elaborados são utilizados para monitorar os parâmetros do processo para evitar esses problemas. Para aprimorar o tempo de resposta e uniformizar decisões de operadores humanos, as tendências de pesquisas atuais são realizadas com o intuito de identificar previamente comportamentos anômalos das chamas e atuar sem interferência humana para manter a chama em determinados níveis pré-estabelecidos. O desempenho do controlador está diretamente ligado à acurácia do modelo do sistema. Infelizmente, devido à complexidade do processo, os modelos físicos da dinâmica da propagação da chama não são confiáveis o suficiente para aplicações em controle de sistemas. Por outro lado, caso a dinâmica seja descrita em termos de um modelo identificado, a estratégia de controle pode ser aperfeiçoada. Este trabalho propõe uma metodologia para a identificação de um modelo para a dinâmica da chama através da evolução temporal das propriedades das imagens capturadas por uma câmera CCD em um forno a gás de escala industrial. Para tanto, utilizam-se métodos de visão computacional para processar e extrair propriedades características das imagens de chama ao longo do tempo. Então, técnicas de Análise Modal Operacional, como o método no Domínio do Tempo de Ibrahim e o algoritmo do Decremento Aleatório, identificam as características modais das propriedades com o objetivo de se obter a parte determinística do modelo. A parte aleatória do modelo é extraída de características estatísticas dos dados. A metodologia apresentada é utilizada para modelar sete condições de combustão diferentes e os dados estimados pelo modelo são comparados com dados experimentais não utilizados no processo de identificação. As respostas em frequência comparadas mostram em média uma forte correlação entre os dados estimados e experimentais, além de mostrarem um desvio espectral aceitável para os objetivos do modelo, o que valida o método de modelagem. Por fim, é proposta uma forma de unificação dos sete modelos identificados em um, o que poderia viabilizar sua aplicação num suposto projeto de controle.

Palavras-chaves: Identificação de modelo de chama. Análise modal operacional. Controle de sistemas dinâmicos. Monitoramento de chama por imagem. Método no Domínio do Tempo de Ibrahim. Algoritmo do Decremento Aleatório. 


\section{ABSTRACT}

CHUI, D. S. Identification of flames on industrial furnaces through computer vision monitoring. 2020. 174 p. Tese (Doutorado) - Escola Politécnica, Universidade de São Paulo, São Paulo, 2020.

In industrial furnaces, unstable flames can lead to potentially unsafe operating conditions. Elaborate supervisory systems are often used to monitor process parameters to avoid these problems. In order to improve response time and to standardize human operator decisions, current research trends are conducted to identify anomalous flame behavior in advance and to act without human interference to maintain the flame at certain preestablished levels. Controller performance is directly related to system model accuracy. Unfortunately, due to the complexity of the process, physical models of flame propagation dynamics are not reliable enough for control system applications. On the other hand, if the dynamics are described in terms of an identified model, the control strategy can be improved. This work proposes a methodology for the identification of a model for the flame dynamics through image features evolution in time captured by a CCD camera in an industrial scale gas furnace. For this purpose, computer vision methods are used to process and extract characteristic features of flame images over time. Then, Modal Operational Analysis techniques, such as the Ibrahim Time Domain method and the Random Decrement algorithm, identify the modal characteristics of the features in order to obtain the deterministic part of the model. The random part of the model is extracted from statistical characteristics of the data. The methodology presented is used to model seven different combustion conditions and the estimated data are compared with experimental data not used in the identification process. Compared frequency responses show on average a strong correlation between estimated and experimental data, and show an acceptable spectral deviation for the needs of the model, which validates the modelling method. Finally, it is proposed a way for unifying the seven identified models into one, which could enable its application in a supposed control design.

Keywords: Flame model identification. Operational modal analysis. Control systems. Flame imaging. Ibrahim Time Domain. Random Decrement Algorithm. 


\section{LISTA DE ILUSTRAÇÕES}

Figura 1 - Fluxograma do sistema de análise digital da imagem. . . . . . . . . . . 39

Figura 2 - Desenho ilustrativo do funcionamento do ILT CCD. . . . . . . . . . . . 40

Figura 3 - Forno vertical experimental do IPT. . . . . . . . . . . . . . . . . . . . 43

Figura 4 - Detalhamento do queimador do forno a óleo. . . . . . . . . . . 43

Figura 5 - Esquema do queimador em corte. . . . . . . . . . . . . . . 44

Figura 6 - Imagens da câmera CCD utilizada para capturar chamas no forno a óleo. 45

Figura 7 - Processo de desentrelaçamento de uma imagem com chama estável. . . 46

Figura 8 - Processo de limiarização e segmentação da figura $7(\mathrm{~b})$. . . . . . . . . 46

Figura 9 - Conjunto nebuloso associado ao conceito de "alta qualidade de nebulização". . . . . . . . . . . . . . . . . . . . . . . . . . . . 48 48

Figura 10 - Exemplos de imagens entrelaçadas de chama nas diferentes condições

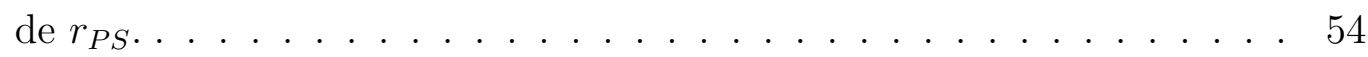

Figura 11 - Resposta das variáveis de "posição" de $\boldsymbol{x}_{\boldsymbol{r}}(t)$ às condições iniciais estipuladas . . . . . . . . . . . . . . . . . . . . . 59

Figura 12 - Resposta das variáveis de "velocidade" de $\boldsymbol{x}_{r}(t)$ às condições iniciais estipuladas . . . . . . . . . . . . . . . . . . 60 60

Figura 13 - Resposta ao controle de rastreamento de trajetória para o Modo 1 . . . 62

Figura 14 - Resposta ao controle de rastreamento de trajetória para o Modo 2 . . . 62

Figura 15 - Resposta ao controle de rastreamento de trajetória para o Modo 3 . . . 63

Figura 16 - Resposta ao controle de rastreamento de trajetória para o Modo 4 . . . 63

Figura 17 - Forno a gás experimental . . . . . . . . . . . . . . . . . . 65

Figura 18 - Extremidades do forno a gás . . . . . . . . . . . . 66

Figura 19 - Painel eletrônico de comando do forno a gás . . . . . . . . . . . . . 67

Figura 20 - Detalhamento dos blocos refrigerados . . . . . . . . . . . . . . 67

Figura 21 - Câmera CCD utilizada nos experimentos . . . . . . . . . . . . . 68

Figura 22 - Gráfico do comportamento da razão de equivalência em função do tempo de ensaio . . . . . . . . . . . . . . . . . . . . 70

Figura 23 - Fluxograma da metodologia proposta . . . . . . . . . . . . . 71

Figura 24 - Representação matricial de uma imagem $4 \times 5 . \quad \ldots . . . . .74$

Figura 25 - Amostras de imagens originais. . . . . . . . . . . . . . . . . . 75

Figura 25 - Amostras de imagens originais (continuação) . . . . . . . . . . . . . . 76

Figura 26 - Identificação de elementos da imagem sem a chama. . . . . . . . . . . . 77

Figura 27 - Posicionamento da máscara de recorte . . . . . . . . . . . . . . . 78

Figura 28 - Exemplos de imagens após o recorte . . . . . . . . . . . . . . . 79

Figura 29 - Imagem da amostra 2 da condição 2 com seu respectivo histograma. . . 80 
Figura 30 - Imagem da amostra 2 da condição 4 com seu respectivo histograma. . . 80

Figura 31 - Esquema ilustrativo de um histograma de chama a gás . . . . . . . . . 85

Figura 32 - Imagem em preto e branco da amostra 2 da condição 2 com seu respectivo histograma. . . . . . . . . . . . . . . . . . . . . . 88

Figura 33 - Imagem em preto e branco da amostra 2 da condição 4 com seu respectivo histograma. . . . . . . . . . . . . . . . . . . . 88

Figura 34 - Imagens segmentadas das amostras 2 das condições 2 e 4 . . . . . . . 89

Figura 35 - Interior do forno desligado com indicação dos eixos $x^{\prime} y^{\prime}$ e da origem $Q \quad 90$

Figura 36 - Imagens das bordas das amostras 2 das condições 2 e 4 . . . . . . . . . 91

Figura 37 - Fluxograma do algoritmo de análise de correlação da imagem. . . . . . 99

Figura 38 - Gráfico ilustrativo da seleção dos segmentos de tempo da resposta $x(t) .102$

Figura 39 - Gráfico ilustrativo da assinatura RD do exemplo da figura 38. . . . . . 103

Figura 40 - Desenho esquemático de um sistema massa-mola-amortecedor de 2 graus de liberdade. . . . . . . . . . . . . . . . . . . 115

Figura 41 - Gráficos das posições das massas 1 e 2 em função do tempo na simulação com as condições iniciais $\boldsymbol{x}_{\boldsymbol{i}}$. . . . . . . . . . . . . . . . 117

Figura 42 - Gráficos das velocidades das massas 1 e 2 em função do tempo na simulação com as condições iniciais $\boldsymbol{x}_{\boldsymbol{i}}$. . . . . . . . . . . . . . . 118

Figura 43 - Gráfico dos índices MAC entre os modos teóricos e os modos identificados via ITD com $2 n$ medidas disponíveis. . . . . . . . . . . . . . . . . . . 119

Figura 44 - Comparação de índice de sucesso para diferentes valores de $\Delta t_{1}$ e $\Delta t_{2}$. 120

Figura 45 - Ilustração esquemática de como variam as matrizes $\boldsymbol{A}_{c}^{\prime}$ e $\boldsymbol{R}_{\boldsymbol{c}}^{\prime}$ com a variação de c. . . . . . . . . . . . . . . . . . . . . . . . . . . . . . . . . . 128

Figura 46 - Ilustração esquemática da aproximação das matrizes $\boldsymbol{A}_{\boldsymbol{c}}^{\prime}$ e $\boldsymbol{R}_{\boldsymbol{c}}^{\prime}$ através de interpolação linear. . . . . . . . . . . . . . . . . . . . . . . . . . 129

Figura 47 - Comparações entre limiares para condição 1 . . . . . . . . . . . . . . 131

Figura 48 - Comparações entre limiares para condição 2 . . . . . . . . . . . . . . . 131

Figura 49 - Comparações entre limiares para condição 3 . . . . . . . . . . . . . . . 132

Figura 50 - Comparações entre limiares para condição 4 . . . . . . . . . . . . . . 132

Figura 51 - Comparações entre limiares para condição 5 . . . . . . . . . . . . . . 133

Figura 52 - Comparações entre limiares para condição 6. . . . . . . . . . . . . . 133

Figura 53 - Comparações entre limiares para condição 7 . . . . . . . . . . . . . . 133

Figura 54 - Comparação entre dados experimentais de treinamento e dados estimados sem a correção da variância (Propriedade $C_{x}$ para todas as condições). . . . . . . . . . . . . . . . . . . . . . 138

Figura 55 - Gráfico boxplot do fator de correção de variância para a condição $c=1.139$

Figura 56 - Comparação entre dados experimentais de validação e dados estimados com variância corrigida (Propriedade $C_{x}$ para todas as condições). . . . 141

Figura 57 - Espectro de frequência da propriedade $C_{x}$ na condição $c=1 \ldots$. . . . . 141 
Figura 58 - Média dos coeficientes de correlação das propriedades da imagem por cada condição de combustão. . . . . . . . . . . . . . . . . . . . . . . . 142

Figura 59 - Média dos desvios espectrais das propriedades da imagem por cada condição de combustão. . . . . . . . . . . . . . . . . . . . . . . . . . . 142

Figura 60 - Transformações da imagem da chama da amostra 1 na condição 1. . . . 154

Figura 61 - Transformações das imagens da chama das amostras 2 e 3 na condição 1.155

Figura 62 - Conjuntos das transformações das imagens da chama das amostras 1 e 2 na condição 2. . . . . . . . . . . . . . . . . . . . 156

Figura 63 - Conjuntos das transformações das imagens da chama da amostra 3 na condição 2 e da amostra 1 na condição 3. . . . . . . . . . . . . . . . . . 157

Figura 64 - Conjuntos das transformações das imagens da chama das amostras 2 e 3 na condição 3. . . . . . . . . . . . . . . . . . . . . . . 158

Figura 65 - Conjuntos das transformações das imagens da chama das amostras 1 e 2 na condição 4. . . . . . . . . . . . . . . . . . . . . . . . . . . . . . 159

Figura 66 - Conjuntos das transformações das imagens da chama da amostra 3 na condição 4 e da amostra 1 na condição 5. . . . . . . . . . . . . . . . . 160

Figura 67 - Conjuntos das transformações das imagens da chama das amostras 2 e 3 na condição 5. . . . . . . . . . . . . . . . . . . . . . . 161

Figura 68 - Conjuntos das transformações das imagens da chama das amostras 1 e 2 na condição 6. . . . . . . . . . . . . . . . . . . . . 162

Figura 69 - Conjuntos das transformações das imagens da chama da amostra 3 na condição 6 e da amostra 1 na condição 7 . . . . . . . . . . . . . . . . . 163

Figura 70 - Conjuntos das transformações das imagens da chama das amostras 2 e 3 na condição 7. . . . . . . . . . . . . . . . . . . . . . . . . . . . . 164

Figura 71 - Comparações de $C_{x}$ entre dados experimentais e dados estimados sem

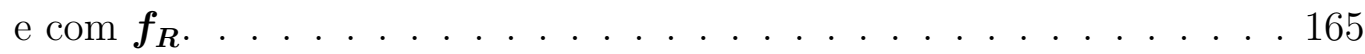

Figura 72 - Comparações de $C_{y}$ entre dados experimentais e dados estimados sem e

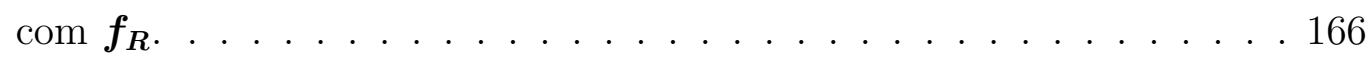

Figura 73 - Comparações de $L_{y}$ entre dados experimentais e dados estimados sem e $\operatorname{com} \boldsymbol{f}_{\boldsymbol{R}}$.

Figura 74 - Gráficos boxplot dos fatores de correção de variância para as condições $c=1$ e $c=2$.

Figura 75 - Gráficos boxplot dos fatores de correção de variância para as condições $c=3$ e $c=4$.

Figura 76 - Gráficos boxplot dos fatores de correção de variância para as condições $c=5, c=6$ e $c=7$.

Figura 77 - Comparação no domínio da frequência entre sinais dos dados experimentais de validação e dados estimados com o modelo proposto. 
Figura 77 - Comparação no domínio da frequência entre sinais dos dados experimentais de validação e dados estimados com o modelo proposto (continuação).171

Figura 77 - Comparação no domínio da frequência entre sinais dos dados experimentais de validação e dados estimados com o modelo proposto (continuação).172

Figura 77 - Comparação no domínio da frequência entre sinais dos dados experimentais de validação e dados estimados com o modelo proposto (continuação).173

Figura 77 - Comparação no domínio da frequência entre sinais dos dados experimentais de validação e dados estimados com o modelo proposto (continuação).174 


\section{LISTA DE TABELAS}

Tabela 1 - Grau de pertinência de chamas com $r_{V C}=0,21$ ao conjunto nebuloso "chamas com alta qualidade de nebulização". . . . . . . . . . . . . . . 49

Tabela 2 - Dados das diferentes condições de chama analisadas por Silva et al.

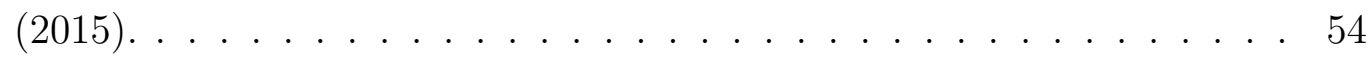

Tabela 3 - Parâmetros modais encontrados com RD/ITD e comparação com análise espectral para o caso $r_{P S}=4,00 \ldots \ldots \ldots \ldots 6$

Tabela 4 - Parâmetros modais utilizados para aplicar a estratégia controle. . . . . 57

Tabela 5 - Composição química do combustível. . . . . . . . . . . . . 66

Tabela 6 - Dados dos testes realizados para a captura das imagens em diferentes condições de combustão. . . . . . . . . . . . . . . . . . . . 69

Tabela 7 - Valores dos índices $k$ das imagens divididos entre as diferentes condições de chama. . . . . . . . . . . . . . . . . . . . . 90 90

Tabela 8 - Conceitos qualitativos do coeficiente de correlação de Pearson. . . . . . 97

Tabela 9 - Valores adotados para os pesos na equação (5.74) . . . . . . . . . . 115

Tabela 10 - Parâmetros utilizados no exemplo de 2 graus de liberdade. . . . . . . . 116

Tabela 11 - Propriedades modais do sistema (5.76) obtidas analiticamente. . . . . . 116

Tabela 12 - Propriedades modais do sistema (5.76) obtidas pelo ITD com $2 n$ medidas disponíveis. . . . . . . . . . . . . . . . . . . . . . 118

Tabela 13 - Amplitude de variação dos parâmetros $\Delta t_{1}, \Delta t_{2}$ e $\Delta t_{3}$, a fim de verificar as limitações nas suas escolha. . . . . . . . . . . . . . . . . 118

Tabela 14 - Propriedades não correlacionadas obtidas através da análise de correlação.134

Tabela 15 - Resultados da aplicação da PCA. . . . . . . . . . . . . . . . . . . 135

Tabela 16 - Resultados do algoritmo RD . . . . . . . . . . . . . . . 136

Tabela 17 - Parâmetros encontrados no processo iterativo. . . . . . . . . . . . 137

Tabela 18 - Resultados da identificação dos modelos modais para cada condição de combustão. . . . . . . . . . . . . . . . . . . 137

Tabela 19 - Resultados da determinação dos valores para $\boldsymbol{f}_{\boldsymbol{R}}$ após 200 iterações. . . 140 


\section{LISTA DE ABREVIATURAS E SIGLAS}

$\mathrm{BU}$

CCD Charge-coupled device (dispositivo de carga acoplada).

CFD Computational fluid dynamics (dinâmica dos fluidos computacional).

CMOS Complementary metal oxide semiconductor (metal-óxido-semicondutor complementar).

$\mathrm{CP}$

DBN

FCM

FFT

FIRES

ILT

IPCC

IPT

ITD

$\mathrm{KF}$

LQR Linear quadratic regulator (regulador linear quadrático).

MAC Modal assurance criterion (critério de garantia modal).

MEF Método de elementos finitos.

MLP Multilayer perceptron.

MSCC Mode shape correlation constant (constante de correlação de modos de vibrar).

MSE Mean square error (erro quadrático médio).

OMA Operational modal analysis (análise modal operacional). 
PCA Principal component analisys (análise de componentes principais).

PID Proporcional, integral e derivativo.

PPD Pinned photodiode.

qps quadros por segundo

RD Random decrement algorithm (algoritmo de decremento aleatório).

REA Razão de excesso de ar.

RGB Red, green, blue (sistema de cores vermelho, verde e azul).

RP Regime permanente.

RPS Razão de vazão ar primário por vazão de ar secundário.

RVC Razão de vazão de vapor por vazão de combustível.

SVD Singular value decomposition (decomposição em valores singulares).

VCR Video cassette recorder (gravador de videocassete).

VDT Video display terminal (terminal de exibição de vídeo). 


\section{LISTA DE SÍMBOLOS}

dada uma matriz genérica [ ], [ ]* é a sua transposta conjugada, também chamada de Hermitiana.

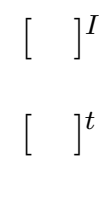

$A$

$A^{\prime}$

$\bar{A}$

$A_{c}$

$A_{c}^{\prime}$

$A_{I}$

$A_{i}$

$A_{r}$

$\boldsymbol{A}_{r, i}$

$A_{t}$

$A_{\mu}$

$A$

$a$

$a_{c}\left(P, P_{S E}\right)$ função análise de correlação das propriedades da imagem.

$a_{k}$

$\boldsymbol{B}$

$\bar{B}$

$B_{i}$

dada uma matriz genérica [ ], [ ] é a sua inversa ou pseudo-inversa.

dada uma matriz genérica [ ], [ ] é a sua transposta.

matriz do sistema (ou de estados) na representação por espaço de estados.

matriz diferença interpolada das matrizes do sistema identificadas.

matriz do sistema (ou de estados) aumentado para o controlador LQ.

matriz do sistema identificada para a condição de combustão $c$.

matriz diferença das matrizes do sistema identificadas na condição de combustão $c$.

matriz do sistema obtida através do método ITDM.

submatriz do sistema (ou de estados) para sistema de $2^{\mathrm{a}}$ ordem.

matriz do sistema (ou de estados) de referência para o controlador LQ.

submatriz do sistema (ou de estados) de referência para o controlador LQ para sistema de $2^{\text {a }}$ ordem.

matriz do sistema obtida analiticamente por um modelo teórico.

matriz média das matrizes do sistema identificadas.

área da imagem $I^{p b}$.

nível de desencadeamento do algoritmo de RD.

parte real do número complexo $e^{\lambda_{k} \Delta t_{1}}$.

matriz de entrada na representação por espaço de estados.

matriz de entrada aumentado para o controlador LQ.

submatriz de entrada para sistema de $2^{\text {a }}$ ordem. 

$\boldsymbol{B}_{r} \quad$ matriz de entrada de referência para o controlador LQ.
$\boldsymbol{B}_{r, i} \quad$ submatriz de entrada de referência para o controlador LQ para sistema de $2^{\mathrm{a}}$ ordem.
$B$ porcentagem da média de tons de cinza da imagem. quantidade de bits necessários para armazenamento do valor do tom de cinza de um pixel.
$b_{k}$ parte imaginária do número complexo $e^{\lambda_{k} \Delta t_{1}}$.
C matriz de saída na representação por espaço de estados.
$\bar{C} \quad$ matriz de saída aumentado para o controlador LQ.
$C_{\text {corr }} \quad$ conjunto de propriedades correlacionadas.
$C_{\text {corr }}^{e} \quad$ conjunto de propriedades correlacionadas de entrada.
$C_{k} \quad$ módulo do número complexo $e^{\lambda_{k} \Delta t_{1}}$.
$\boldsymbol{C}_{\boldsymbol{r}} \quad$ matriz de saída de referência para o controlador LQ.
$\boldsymbol{C}\left(t_{k}\right) \quad$ matriz de saídas do modelo de observação do filtro de Kalman.
$C_{x} \quad$ coordenada $x^{\prime}$ do centróide da área da chama.
$C_{y} \quad$ coordenada $y^{\prime}$ do centróide da área da chama.
$c$
condição de combustão.
$c_{1}$
coeficiente de amortecimento viscoso do amortecedor junto à massa 1 .
$c_{2} \quad$ coeficiente de amortecimento viscoso do amortecedor junto à massa 2.
$c_{k} \quad$ primeiro autovalor real de $\boldsymbol{A}_{\boldsymbol{I}}$ para o modo $k$.
$\boldsymbol{D}$ matriz de amortecimento de um sistema de massa-mola-amortecedor de $2^{\text {a }}$ ordem com $n$ graus de liberdade.
$D \quad$ dispersão dos pixels da imagem $I^{p b}$ em torno do centróide.
$D_{x} \quad$ componente em $x^{\prime}$ de $D$.
$\hat{D}_{x x} \quad$ função (assinatura) RD estimada.
$D_{y} \quad$ componente em $y^{\prime}$ de $D$. 


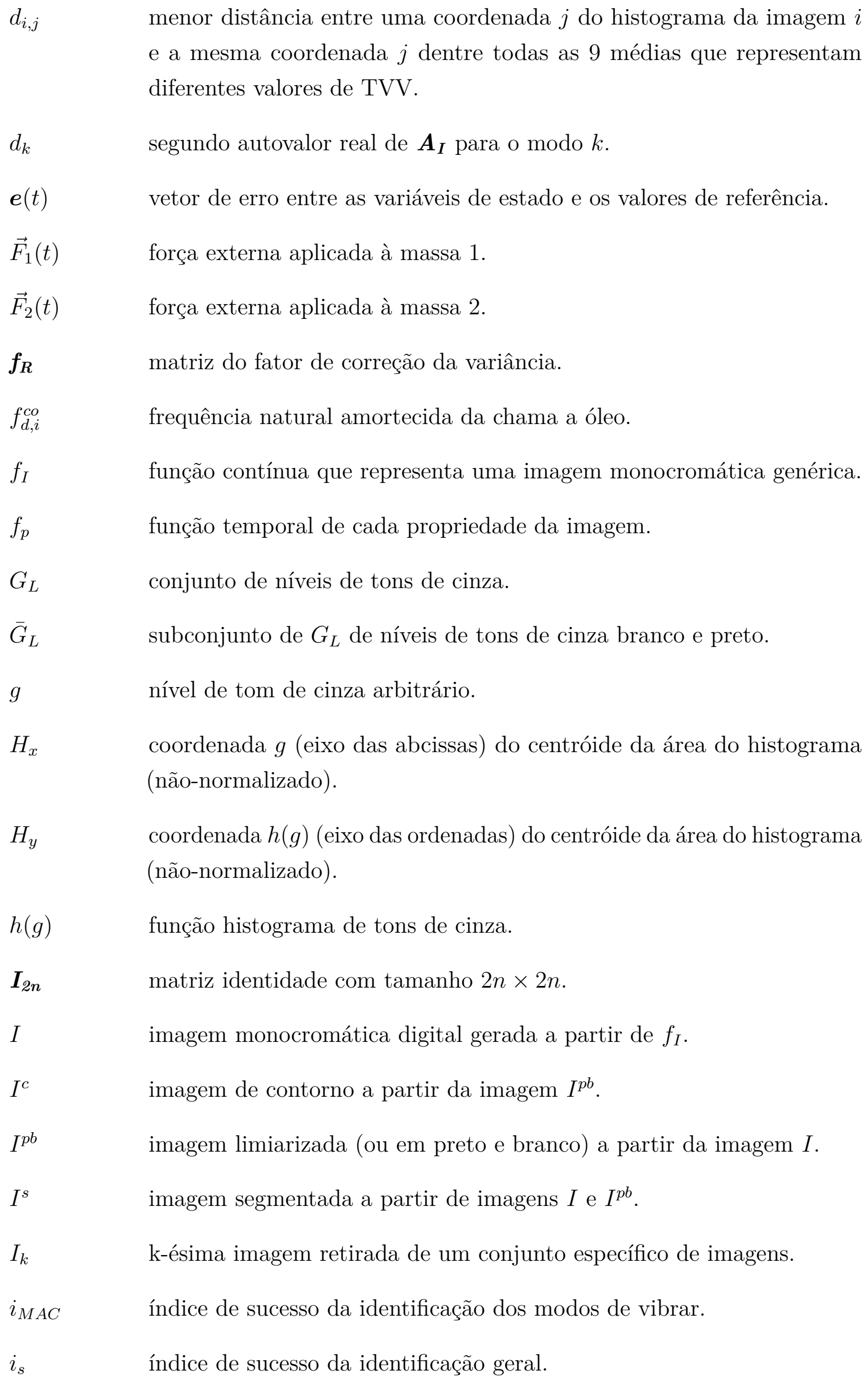




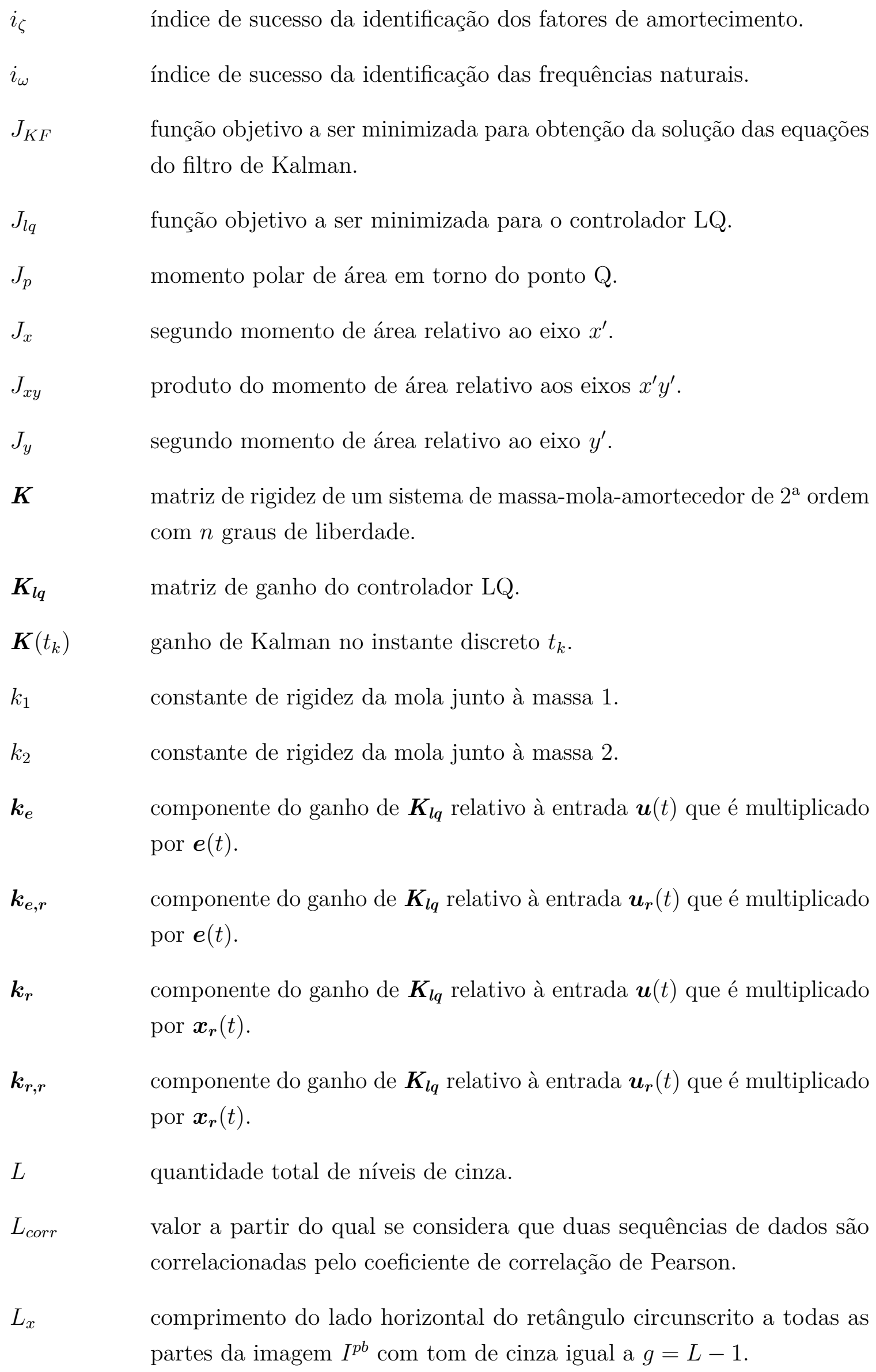


$L_{y} \quad$ comprimento do lado vertical do retângulo circunscrito a todas as partes da imagem $I^{p b}$ com tom de cinza igual a $g=L-1$.

$\boldsymbol{M} \quad$ matriz de massa de um sistema de massa-mola-amortecedor de $2^{\text {a }}$ ordem com $n$ graus de liberdade.

M número de linhas de uma matriz (ou imagem).

$M A C_{k}^{i r} \quad$ constante de correlação de modos de vibrar (MSCC), ou também chamado de índice do critério de garantia modal (MAC), entre o $k$-ésimo vetor de modo de vibrar $i$ e o $k$-ésimo vetor de modo de vibrar $r$.

m ordem do vetor de observação ou quantidade de medições.

$m_{1} \quad$ massa 1.

$m_{2} \quad$ massa 2.

N número de colunas de uma matriz (ou imagem).

$N_{1} \quad$ número múltiplo de $t_{s}$ relativo ao parâmetro de tempo $\Delta t_{1}$ do ITD.

$N_{2} \quad$ número múltiplo de $t_{s}$ relativo ao parâmetro de tempo $\Delta t_{2}$ do ITD.

$N_{3} \quad$ número múltiplo de $t_{s}$ relativo ao parâmetro de tempo $\Delta t_{3}$ do ITD.

$N_{I} \quad$ número total de imagens disponíveis.

$N_{r d} \quad$ número total de pontos de desencadeamento no algoritmo de RD.

$N_{U} \quad$ não-uniformidade dos tons de cinza de $I^{s}$.

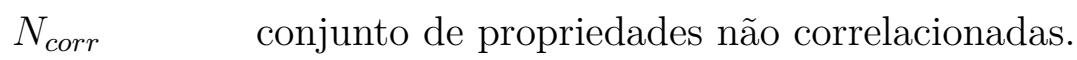

$N_{\text {corr }}^{e} \quad$ conjunto de propriedades não correlacionadas de entrada.

$N_{\text {corr }}^{s} \quad$ conjunto de propriedades não correlacionadas de saída.

n número de graus de liberdade do sistema.

$n_{c} \quad$ número de condições de combustão diferentes.

$n_{p} \quad$ quantidade de propriedades de imagens no conjunto $P_{U}$.

$n_{s} \quad$ quantidade de variáveis de estado (propriedades de imagem) selecionadas pela análise de correlação.

$n_{\tau_{c}} \quad$ quantidade total de imagens para cada condição de combustão. 


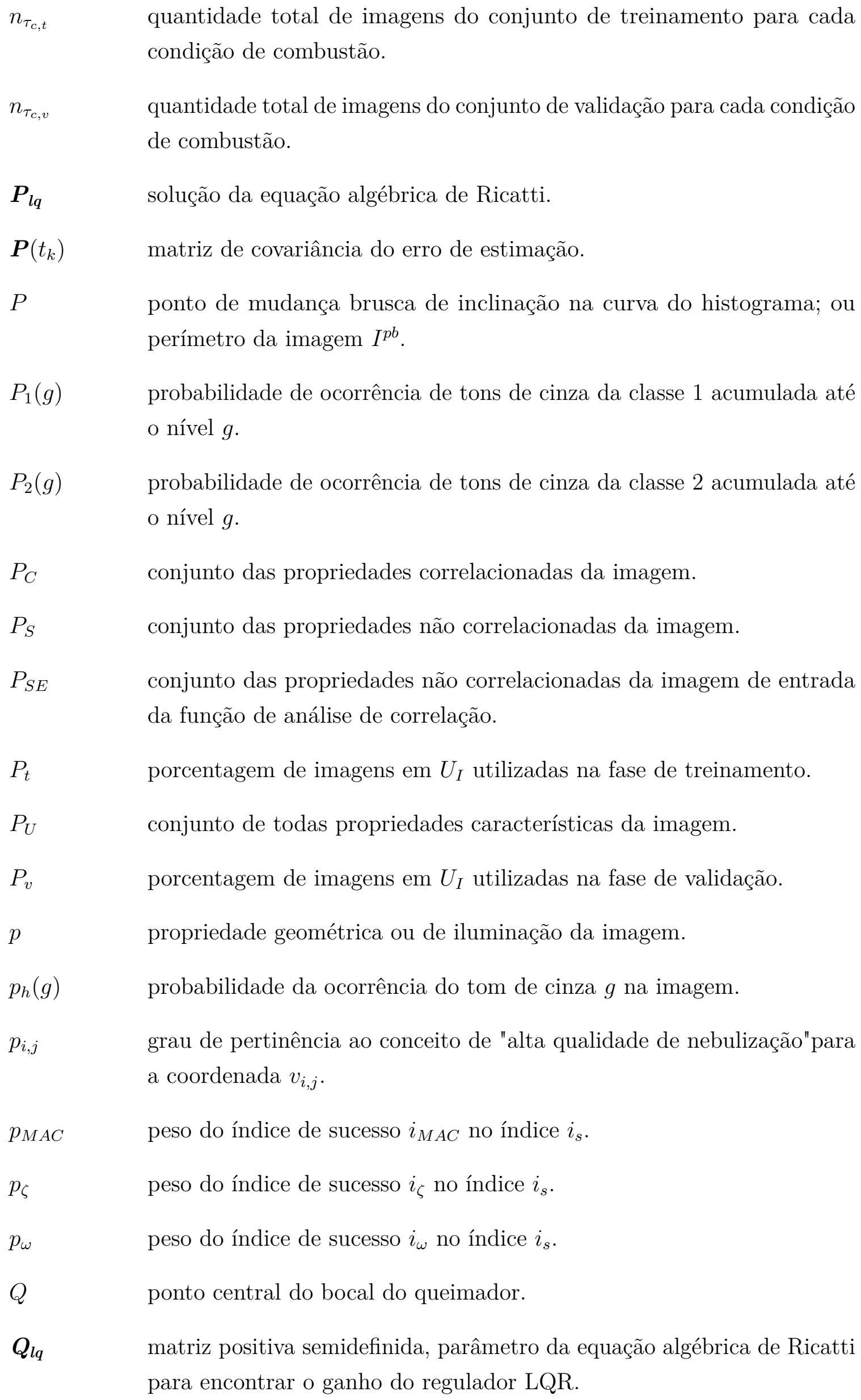
da função de análise de correlação.

$P_{t} \quad$ porcentagem de imagens em $U_{I}$ utilizadas na fase de treinamento.

$P_{U} \quad$ conjunto de todas propriedades características da imagem.

$P_{v} \quad$ porcentagem de imagens em $U_{I}$ utilizadas na fase de validação.

$p \quad$ propriedade geométrica ou de iluminação da imagem.

$p_{h}(g) \quad$ probabilidade da ocorrência do tom de cinza $g$ na imagem.

$p_{i, j} \quad$ grau de pertinência ao conceito de "alta qualidade de nebulização"para a coordenada $v_{i, j}$.

$p_{M A C} \quad$ peso do índice de sucesso $i_{M A C}$ no índice $i_{s}$.

$p_{\zeta} \quad$ peso do índice de sucesso $i_{\zeta}$ no índice $i_{s}$.

$p_{\omega} \quad$ peso do índice de sucesso $i_{\omega}$ no índice $i_{s}$.

Q ponto central do bocal do queimador.

$\boldsymbol{Q}_{l q} \quad$ matriz positiva semidefinida, parâmetro da equação algébrica de Ricatti para encontrar o ganho do regulador LQR. 


$$
\begin{aligned}
& \boldsymbol{Q}\left(\boldsymbol{x}\left(t_{k}\right)\right) \quad \text { matriz de covariância simétrica positiva e semi-definida relativa à variável } \\
& \text { estocástica } \boldsymbol{w}\left(t_{k}\right) \text {. } \\
& q_{C} \quad \text { vazão de óleo combustível. } \\
& q_{V} \quad \text { vazão de vapor nebulizado. } \\
& \boldsymbol{R}_{\boldsymbol{c}} \quad \text { matriz de correlação das propriedades da imagem para a condição de } \\
& \text { combustão } c \text {. } \\
& \boldsymbol{R}_{\boldsymbol{c}}^{\prime} \quad \text { matriz diferença das matrizes de correlação identificadas na condição } \\
& \text { de combustão } c \text {. } \\
& \boldsymbol{R}_{l q} \quad \text { matriz positiva definida, parâmetro da equação algébrica de Ricatti } \\
& \text { para encontrar o ganho do regulador LQR. } \\
& \boldsymbol{R}_{\boldsymbol{\mu}} \quad \text { matriz média das matrizes de correlação identificadas. } \\
& \boldsymbol{R}(\boldsymbol{x}(t)) \quad \text { matriz de covariância simétrica positiva semi-definida relativa à variável } \\
& \text { estocástica } \boldsymbol{\nu}(t) \text {. } \\
& \boldsymbol{R}\left(\boldsymbol{x}\left(t_{k}\right)\right) \quad \text { matriz de covariância simétrica positiva e definida relativa à variável } \\
& \text { estocástica } \boldsymbol{v}\left(t_{k}\right) \text {. } \\
& \boldsymbol{R}^{\prime}(\boldsymbol{x}(t), u) \text { matriz diferença interpolada das matrizes de correlação identificadas. } \\
& \boldsymbol{R}^{(e s t)}(\boldsymbol{x}(t)) \text { matriz de covariância dos dados estimados pelo ITD. } \\
& \boldsymbol{R}^{(e x p)}\left(\boldsymbol{x}_{t}(t)\right) \quad \text { matriz de covariância dos dados experimentais de treinamento. } \\
& \boldsymbol{r}\left(t_{k}\right) \quad \text { vetor resíduo de observação do filtro de Kalman. } \\
& r_{P S} \quad \text { razão de vazão ar primário por vazão de ar secundário. } \\
& r_{V C} \quad \text { razão de vazão de vapor por vazão de combustível. } \\
& r_{\nu}\left(t_{k}\right) \quad \text { resíduo normalizado de observação. } \\
& s \quad \text { total de instantes de tempo em que as medidas são obtidas para formar } \\
& \text { a matriz de respostas livres } \boldsymbol{\Phi} \text { do ITDM. } \\
& \text { T limiar do método de Otsu. } \\
& T^{*} \quad \text { limiar do método de Otsu modificado com influência da análise do } \\
& \text { histograma. } \\
& T_{k} \quad \text { tempo em regime permanente da condição de combustão } k \text {. } \\
& t \quad \text { tempo. }
\end{aligned}
$$




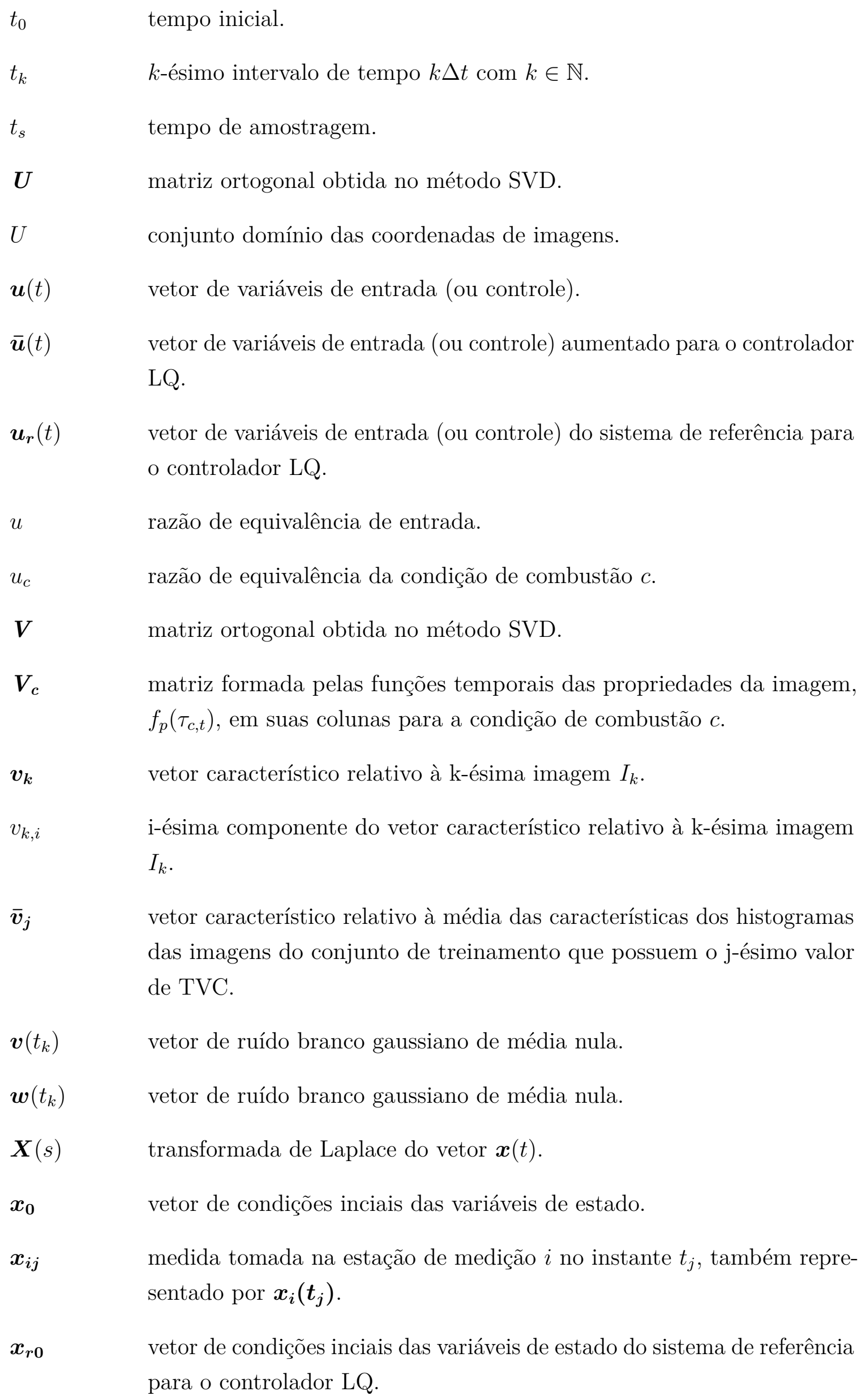
$I_{k}$.

$\overline{\boldsymbol{v}}_{\boldsymbol{j}} \quad$ vetor característico relativo à média das características dos histogramas das imagens do conjunto de treinamento que possuem o j-ésimo valor de TVC.

$\boldsymbol{v}\left(t_{k}\right) \quad$ vetor de ruído branco gaussiano de média nula.

$\boldsymbol{w}\left(t_{k}\right) \quad$ vetor de ruído branco gaussiano de média nula.

$\boldsymbol{X}(s) \quad$ transformada de Laplace do vetor $\boldsymbol{x}(t)$.

$\boldsymbol{x}_{\mathbf{0}} \quad$ vetor de condições inciais das variáveis de estado.

$\boldsymbol{x}_{\boldsymbol{i}} \quad$ medida tomada na estação de medição $i$ no instante $t_{j}$, também representado por $\boldsymbol{x}_{\boldsymbol{i}}\left(\boldsymbol{t}_{\boldsymbol{j}}\right)$.

$\boldsymbol{x}_{\boldsymbol{r} \mathbf{0}} \quad$ vetor de condições inciais das variáveis de estado do sistema de referência para o controlador LQ. 


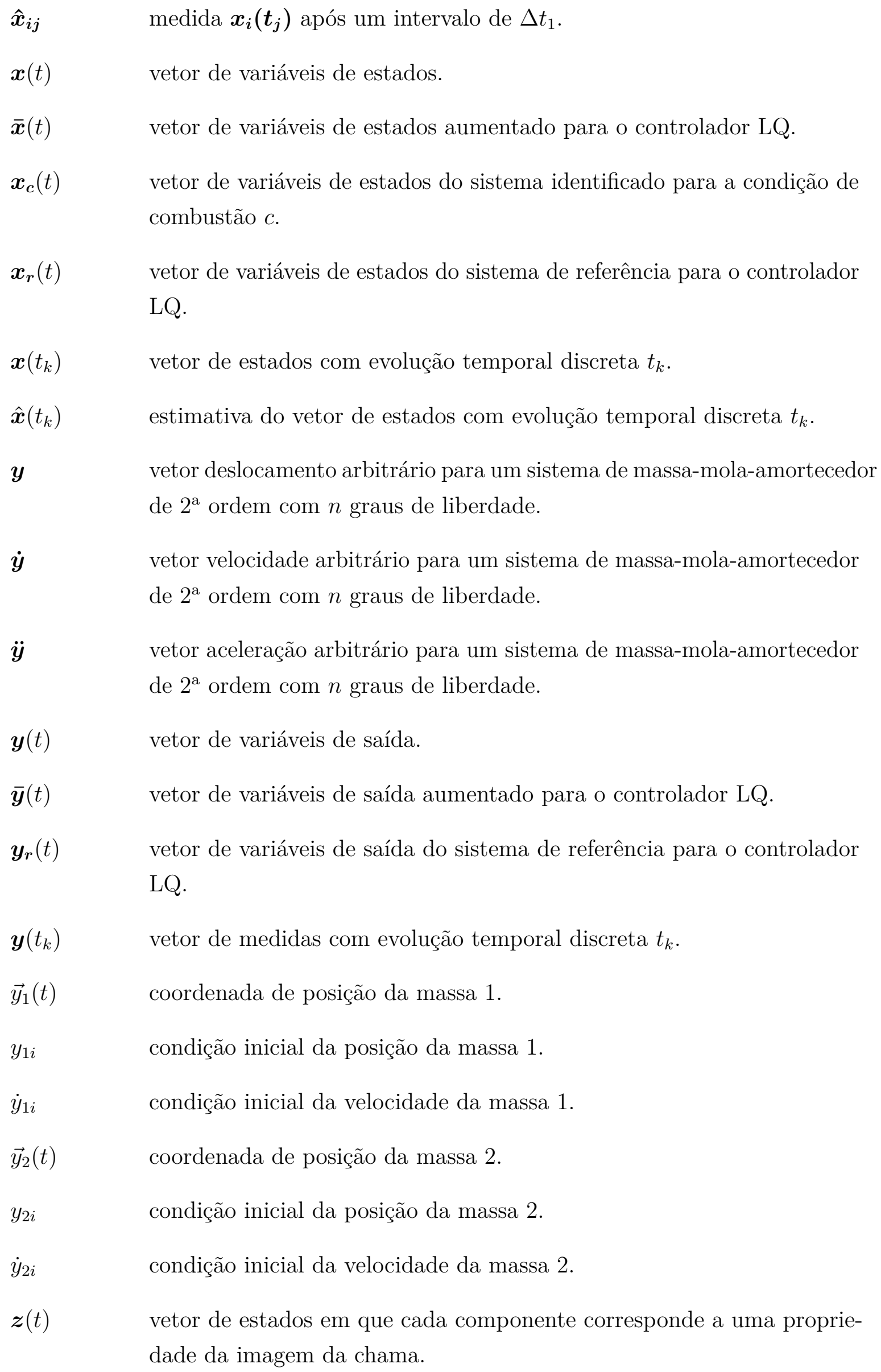




\begin{tabular}{|c|c|}
\hline$\hat{z}_{n}(t)$ & vetor normalizado de estados estimados. \\
\hline $\boldsymbol{z}_{\boldsymbol{t}}(t)$ & vetor de estados do conjunto de dados de treinamento. \\
\hline$\alpha\left(x, y, g_{l}\right)$ & índice de contagem de pixels com tom de cinza $g_{l}$. \\
\hline$\Delta g$ & intervalo de tons de cinza para derivação do histograma. \\
\hline$\Delta t$ & intervalo de tempo correspondente à taxa de amostragem da câmera \\
\hline & CCD, ou intervalo de tempo de forma genérica. \\
\hline$\Delta t_{1}$ & parâmetro de tempo do método ITDM. \\
\hline$\Delta t_{2}$ & parâmetro de tempo do método ITDM. \\
\hline$\Delta t_{3}$ & parâmetro de tempo do método ITDM. \\
\hline$\delta_{p}$ & $\begin{array}{l}\text { vetor cujas componentes armazenam a sequência temporal de uma } \\
\text { propriedade } p \text { das imagens numa determinada condição de combustão } c \text {. }\end{array}$ \\
\hline$\delta_{p}^{n}$ & vetor $\boldsymbol{\delta}_{p}$ normalizado. \\
\hline$\zeta$ & fator de amortecimento. \\
\hline$\zeta_{i}^{c o}$ & fator de amortecimento da chama a óleo. \\
\hline$\zeta_{k}$ & fator de amortecimento do $k$-ésimo modo de vibrar. \\
\hline$\zeta_{k}^{i}$ & $\begin{array}{l}\text { fator de amortecimento do } k \text {-ésimo modo de vibrar identificado (ou } \\
\text { qualquer outro que se queira comparar com uma referência). }\end{array}$ \\
\hline$\zeta_{k}^{r}$ & fator de amortecimento do $k$-ésimo modo de vibrar de referência. \\
\hline$\theta_{k}$ & ângulo do número complexo $e^{\lambda_{k} \Delta t_{1}}$. \\
\hline$\Lambda$ & matriz de exponenciais complexos. \\
\hline$\lambda$ & $\begin{array}{l}\text { autovalor da equação característica de um sistema de massa-mola- } \\
\text { amortecedor de } 2^{\text {a }} \text { ordem com } n \text { graus de liberdade. }\end{array}$ \\
\hline$\lambda_{1,2}$ & $\begin{array}{l}\text { referência às duas soluções da equação característica de } 2^{\circ} \text { grau referente } \\
\text { a um sistema de massa-mola-amortecedor de } 2^{\mathrm{a}} \text { ordem. }\end{array}$ \\
\hline$\lambda_{1, k}$ & primeiro autovalor real do $k$-ésimo modo de vibrar. \\
\hline$\lambda_{2, k}$ & segundo autovalor real do $k$-ésimo modo de vibrar. \\
\hline$\lambda_{k}$ & autovalor do $k$-ésimo modo de vibrar. \\
\hline & nédia. \\
\hline
\end{tabular}




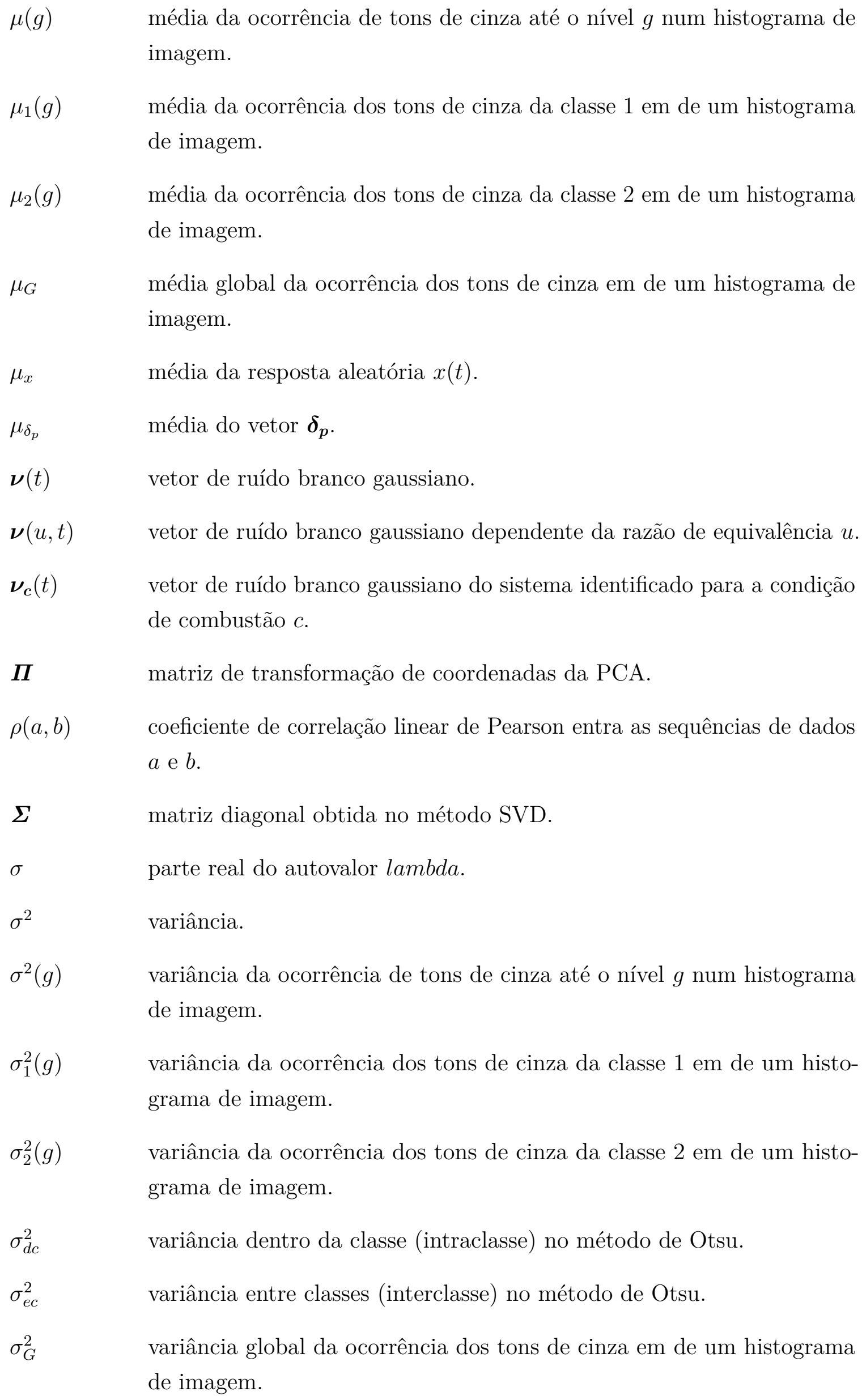
imagem.

$\mu_{1}(g) \quad$ média da ocorrência dos tons de cinza da classe 1 em de um histograma de imagem.

$\mu_{2}(g) \quad$ média da ocorrência dos tons de cinza da classe 2 em de um histograma de imagem.

$\mu_{G} \quad$ média global da ocorrência dos tons de cinza em de um histograma de imagem.

$\mu_{x} \quad$ média da resposta aleatória $x(t)$.

$\mu_{\delta_{p}} \quad$ média do vetor $\boldsymbol{\delta}_{p}$.

$\boldsymbol{\nu}(t) \quad$ vetor de ruído branco gaussiano.

$\boldsymbol{\nu}(u, t) \quad$ vetor de ruído branco gaussiano dependente da razão de equivalência $u$.

$\boldsymbol{\nu}_{\boldsymbol{c}}(t) \quad$ vetor de ruído branco gaussiano do sistema identificado para a condição de combustão $c$.

$\boldsymbol{\Pi}$ matriz de transformação de coordenadas da PCA.

$\rho(a, b) \quad$ coeficiente de correlação linear de Pearson entra as sequências de dados $a$ e $b$.

$\boldsymbol{\Sigma} \quad$ matriz diagonal obtida no método SVD.

$\sigma \quad$ parte real do autovalor lambda.

$\quad$ variância.

$\sigma^{2}(g) \quad$ variância da ocorrência de tons de cinza até o nível $g$ num histograma de imagem.

$\sigma_{1}^{2}(g) \quad$ variância da ocorrência dos tons de cinza da classe 1 em de um histograma de imagem.

$\sigma_{2}^{2}(g) \quad$ variância da ocorrência dos tons de cinza da classe 2 em de um histograma de imagem.

$\sigma_{d c}^{2} \quad$ variância dentro da classe (intraclasse) no método de Otsu.

$\sigma_{e c}^{2} \quad$ variância entre classes (interclasse) no método de Otsu.

$\sigma_{G}^{2} \quad$ variância global da ocorrência dos tons de cinza em de um histograma de imagem. 


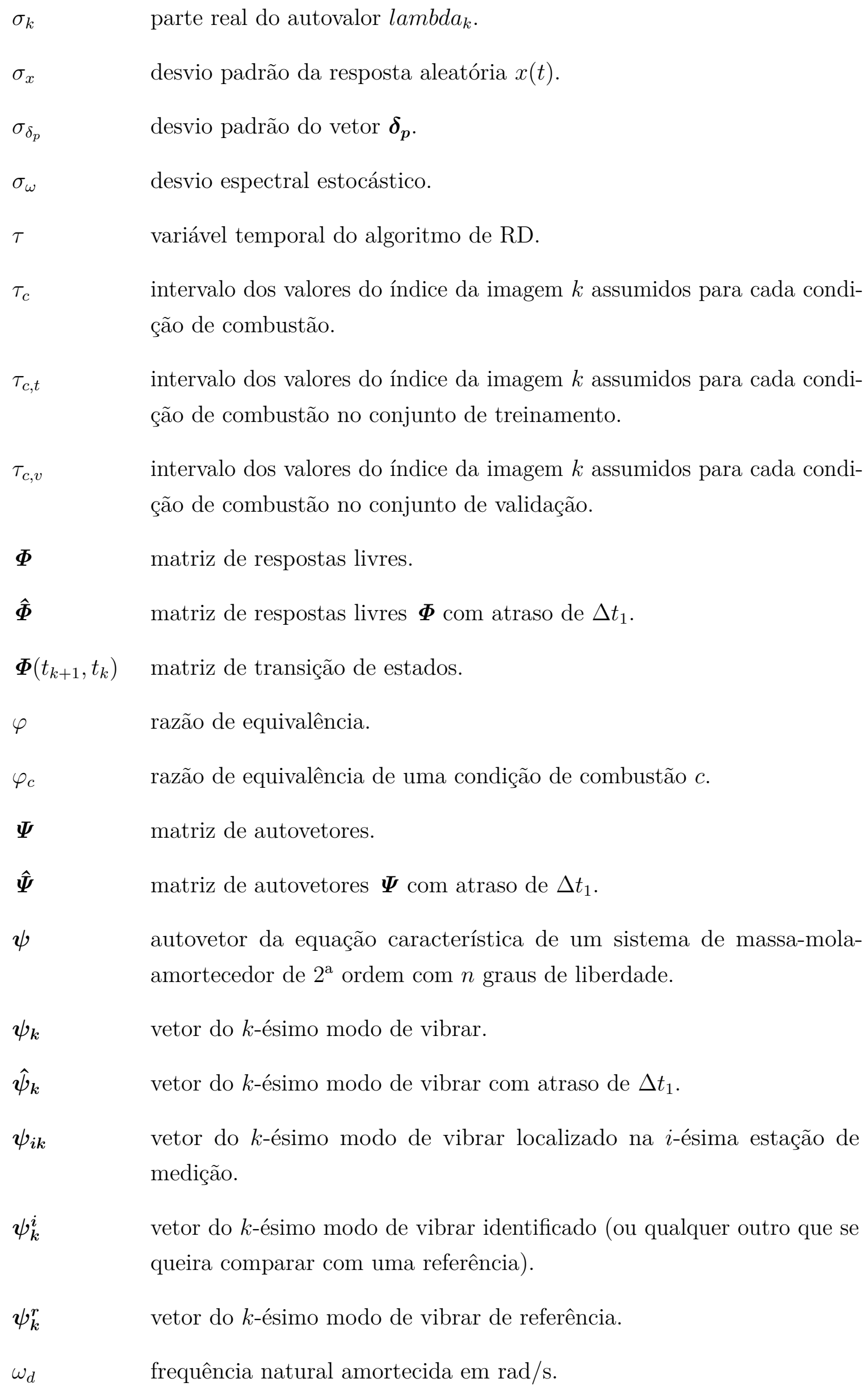


$\omega_{d, k} \quad$ frequência natural amortecida do $k$-ésimo modo de vibrar.

$\omega_{n} \quad$ frequência natural em rad/s.

$\omega_{n, i}^{c o} \quad$ frequência natural da chama a óleo.

$\omega_{n, k} \quad$ frequência natural do $k$-ésimo modo de vibrar.

$\omega_{n, k}^{i} \quad$ frequência natural do $k$-ésimo modo de vibrar identificado (ou qualquer outro que se queira comparar com uma referência).

$\omega_{n, k}^{r} \quad$ frequência natural do $k$-ésimo modo de vibrar de referência. 


\section{SUMÁRIO}

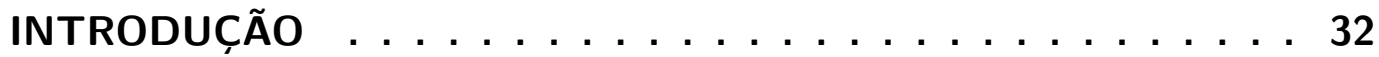

REVISÃO DA LITERATURA . . . . . . . . . . . . . . . . . . . . . 37

$2.1 \quad$ A utilização de imagens no processo de combustão . . . . . . . . . 38

$2.2 \quad$ Forno experimental de chama a óleo . . . . . . . . . . . . . . . 42

2.3 Processamento das imagens de chamas a óleo . . . . . . . . . . . 45

2.4 Identificação da qualidade de nebulização . . . . . . . . . . . 46

2.4.1 Estimação da qualidade de nebulização . . . . . . . . . . . . . . 49

2.5 Identificação da dinâmica da chama através de técnicas modais . . 53

$2.6 \quad$ Controle modal da chama com modelo identificado . . . . . . . . . 57

2.6.1 Definição da referência para os modos da chama . . . . . . . . . . . . 58

2.6.2 Regulador Linear Quadrático (LQR) . . . . . . . . . . . . . . 59

2.6.3 Resultados da simulação do LQR . . . . . . . . . . . . . . . . 61

2.7 Modelos de inferência do estado da chama . . . . . . . . . . . . 63

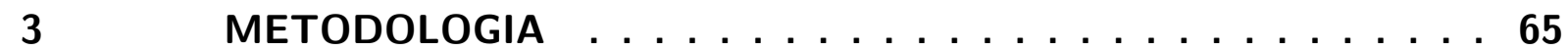

3.1 Equipamento experimental . . . . . . . . . . . . 65

$3.2 \quad$ Procedimento de aquisição das imagens . . . . . . . . . . . 68

3.3 Descrição geral do método de identificação e controle da chama . . 70

4 PROCESSAMENTO DE IMAGENS . . . . . . . . . . . . 73

$4.1 \quad$ A imagem digital . . . . . . . . . . . . . . . . . 73

4.2 As imagens de chama de forno a gás . . . . . . . . . . . . 74

$4.3 \quad$ Histograma da imagem . . . . . . . . . . . . . . . . 78

$4.4 \quad$ Limiarização . . . . . . . . . . . . . . . . . . . . . . . . 81

4.4.1 O método de Otsu . . . . . . . . . . . . . . . . . 82

4.4.2 Análise do histograma da imagem da chama . . . . . . . . . . . . . 85

$4.5 \quad$ Segmentação da imagem . . . . . . . . . . . . . . . . . . . . 87

$4.6 \quad$ Propriedades geométricas e de iluminação . . . . . . . . . . . . 89

5 IDENTIFICAÇÃO DO MODELO DE CHAMA . . . . . . . . . . . . 94

5.1 Dados de treinamento e validação . . . . . . . . . . . . . . 94

$5.2 \quad$ Análise de correlação . . . . . . . . . . . . . . . . . 95

$5.3 \quad$ Análise de componentes principais (PCA) . . . . . . . . . . 100

$5.4 \quad 0$ algoritmo de decremento aleatório (RD) . . . . . . . . . . . 101

$5.5 \quad 0$ método do domínio do tempo de Ibrahim (ITD) . . . . . . . . 103 
5.5.1 Base teórica do método do domínio do tempo de Ibrahim (ITD) . . . . . . 104

5.5 .2 Solução da matriz do sistema por SVD . . . . . . . . . . . . . . . 110

5.5.3 Aplicação do ITD para quantidade limitada de medidas disponíveis . . . . . 112

5.5.4 Ferramentas para comparar o sucesso da identificação do ITD com o modelo teórico . . . . . . . . . . . . . . . . . . . . 112

5.5.4.1 Constante de correlação de modos de vibrar/Critério de garantia modal . . . . . 113

5.5.4.2 Índices de sucesso da identificação . . . . . . . . . . . . . . . . . . . 114

5.5.5 Exemplo da aplicação do método com as $2 n$ medidas disponíveis . . . . . . 115

5.5.6 Método iterativo para obtenção de $\Delta t_{1}, \Delta t_{3}$ e $P_{t} \ldots \ldots \ldots$. . . . . 120

5.6 Identificação da dinâmica das imagens de chama . . . . . . . . 121

5.6.1 Transformação de coordenadas para propriedades da chama . . . . . . . . 123

5.6.2 Modelagem da matriz de covariância . . . . . . . . . . . . . . . 124

5.7 Validação do modelo identificado . . . . . . . . . . . . . . 125

5.8 Unificação dos modelos identificados . . . . . . . . . . . . 126

6 RESULTADOS E DISCUSSÕES . . . . . . . . . . . . . . . . . 130

6.1 Discussões sobre a coleta e o processamento das imagens de chama 130

6.2 Resultados da análise de correlação . . . . . . . . . . . . . . 134

6.3 Resultados da análise de componentes principais . . . . . . . . . . 134

$6.4 \quad$ Resultados do algoritmo RD . . . . . . . . . . . . . . . 135

$6.5 \quad$ Resultados do método ITD . . . . . . . . . . . . . . 136

6.6 Resultados da modelagem da matriz de covariância . . . . . . . . . 138

6.7 Resultados do modelo identificado . . . . . . . . . . . . . . . 140

6.8 Validação do modelo identificado . . . . . . . . . . . . . 140

7 CONCLUSÕES . . . . . . . . . . . . . . . 144

REFERÊNCIAS . . . . . . . . . . . . . . 147

APÊNDICES

APÊNDICE A - AMOSTRAS DE IMAGENS PROCESSADAS . . 154

APÊNDICE B - COMPARAÇÃO ENTRE DADOS EXPERIMENTAIS E ESTIMADOS . . . . . . . . . . 165

APÊNDICE C - FATORES DE CORREÇÃO DE VARIÂNCIA . . . 168

APÊNDICE D - COMPARAÇÕES DE SINAIS NO DOMÍNIO DA

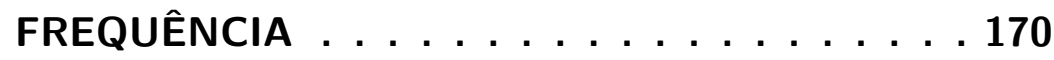




\section{INTRODUÇÃO}

O controle de chama é essencial para a otimização da eficiência térmica de um processo de combustão, o que resulta na redução do consumo de energia e menores níveis gerados de poluentes. No processo de combustão que ocorre em queimadores, normalmente utilizados em instalações industriais na aplicação de fornos, o controle da chama é responsável por regular a taxa de calor que é transferida à carga que se quer aquecer tanto por convecção como por radiação. Além disso, Santos-Victor et al. (1993) mencionam que o controle também é responsável por não deixá-la se extinguir e garantir uma certa insensibilidade a variações de combustível.

Além dessas funções primárias, o controle da chama também está relacionado com a taxa de emissão de poluentes do processo de combustão. Teoricamente, numa combustão completa de combustíveis fósseis ou biocombustíveis, todo o combustível é transformado em $\mathrm{CO}_{2}$ e $\mathrm{H}_{2} \mathrm{O}$. Isto só ocorre quando a proporção ar/combustível é estequiométrica. Quando não há estequiometria nessa proporção, ocorre uma queima incompleta do combustível e, consequentemente, há o aparecimento de poluentes, como, por exemplo, $C O, N O_{x}$ e material particulado. Hoje em dia, vale lembrar que mesmo o $\mathrm{CO}_{2}$ está sendo considerado um poluente, pois, apesar de ser encontrado inerte na natureza, seu excesso potencializa o chamado efeito estufa. O Painel Intergovernamental sobre Mudanças Climáticas (IPCC, 2014) afirma que as emissões antropogênicas de gases de efeito estufa são as mais altas da história, causando aquecimento na atmosfera e oceanos, diminuição das quantidades de neve e gelo, e aumento no nível do mar.

Ainda, ao se garantir que a chama permaneça dentro de níveis aceitáveis de operação também se protege o material refratário do forno, aumentando sua longevidade e, consequentemente, diminuindo os custos de manutenção. Portanto, o controle adequado da chama promove condições de operação necessárias para entregar o calor necessário para os fins do forno, garantir emissões dentro de limites aceitáveis e manter a integridade do material refratário.

Uma aplicação de forno industrial que possui uma preocupação especial com a qualidade da chama, quer para o controle do processo, quer para a redução de emissões, são os fornos utilizados em processos de refino de petróleo. Numa planta de refinaria de petróleo, há vários fornos para diversos processos químicos envolvidos na transformação do petróleo em seus derivados. Nesses fornos, utiliza-se uma ampla gama de sensores para medir parâmetros que afetam o processo e, assim, fechar a malha de controle com estes sinais.

Segundo Silva (2009), o tipo de controlador mais comum utilizado para controlar 
os parâmetros de fornos em refinarias de petróleo ainda é o controlador linear do tipo proporcional-integral-derivativo (PID). O controlador PID é de simples implementação e relativamente confiável e robusto, no entanto, é usualmente aplicável para sistemas de uma entrada e uma saída e não requer necessariamente de um modelo matemático do sistema. No caso dos fornos de refino, existe o controle da vazão da carga (material que entra no forno) e o controle de temperatura da carga na saída do forno. Sabendo de antemão a temperatura desejada, o controle atua através de válvulas que modificam a vazão de combustível que alimenta os maçaricos do forno. Sensores de oxigênio monitoram a qualidade da combustão, mas não é feito nenhum controle automático específico para otimizar as emissões de poluentes, por exemplo. Além disso, controladores PID lineares apresentam sérias limitações de desempenho em sistemas não-lineares, como é o caso da chama em fornos de refino. Apesar de existirem iniciativas de estudos em controladores PID não lineares, como em Armstrong, Neevel e Kusik (2001), ou PID fracionário, que se prestam a melhorar o desempenho dos controladores PID conforme revisado em Shah e Agashe (2016), essas abordagens encontram pouca aplicação na indústria. Enfim, a prática industrial atual é de se utilizar sensores para monitorar parâmetros e auxiliar na tomada de decisão sobre a atuação no processo por um especialista humano ou, onde se emprega uma maior automação, utilizar controladores PID para manter uma ou mais variáveis em torno de valores de referência.

A fim de melhorar a inteligência e desempenho dos controladores, diversas pesquisas estão sendo realizadas com o intuito de criar um modelo para a chama. Um bom modelo de chama resultaria em uma melhor predição dos estados e, consequentemente, melhores controladores do que os tradicionais PID lineares. No entanto, descrever o fenômeno de combustão de forma analítica se mostra um tarefa um tanto quanto árdua. Combustível e comburente são lançados na câmara de combustão em diferentes velocidades para interagir numa reação exotérmica que faz o ar do entorno da chama vibrar. Laera et al. (2014) citam que chamas em câmaras de combustão sofrem do problema de instabilidade termoacústica. Este fenômeno é devido à interação mútua entre ondas acústicas dentro da câmara e oscilação da liberação de calor pela chama. A pressão acústica e a velocidade das oscilações podem produzir vibrações autossustentadas que podem levar a danos aos componentes do sistema de combustão. Ainda segundo Laera et al. (2014), podem-se distinguir três tipos de abordagens para prever a ocorrência de instabilidade termoacústica, em ordem de complexidade: modelos acústicos de baixa ordem, modelos acústicos solucionados pelo Método de Elementos Finitos (MEF) e modelos por CFD (sigla em inglês para Dinâmica dos Fluidos Computacional), sendo estes dois últimos tipos de métodos de discretização. Os modelos acústicos de baixa ordem estão baseados na ideia que sistemas termoacústicos complexos podem ser representados por uma ligação de elementos em série, como por exemplo, duto de suprimento, queimador, chama, saída com restrição, etc. A chama é modelada como um elemento fino caracterizado por uma função de 
transferência que descreve a relação entre as flutuações da liberação de calor e as oscilações na velocidade na saída do queimador. Essa abordagem se torna inadequada com o aumento da complexidade da geometria do sistema. Por outro lado, os métodos de discretização citados são mais utilizados em problemas de avaliação de desempenho e comparação de certas características da chama ou sua dinâmica para diferentes tipos de combustíveis, apresentando um comportamento simulado da chama a fim de prever possíveis condições instáveis (GÓMEZ et al., 2019; JÓŹWIAK et al., 2019). Apesar de haver algum sucesso na previsão da instabilidade e de se colocarem como ótimas ferramentas para a análise de cenários do tipo "e se?", há limitações com relação ao pesado processamento computacional envolvido e que, por este motivo, tendem a ser inviáveis para situações onde se quer uma previsão em tempo real dos estados do sistema como num sistema supervisório, por exemplo.

Logo, para que se consiga aplicar um modelo em problemas de monitoramento em tempo real, o modelo deve ser conhecido de antemão. Portanto, as dificuldades em se obter um modelo para a chama em uma câmara de combustão são o foco central para o desenvolvimento deste trabalho. Mesmo na abordagem de modelos acústicos de baixa ordem já há avanços para modelos mais complexos que captam não linearidades e frequências de oscilação não harmônicas. Landau, Bouziani e Bitmead (2008) afirmam que os fenômenos de combustão podem ser explicados, na maioria dos casos, por uma chama trêmula que gera ondas de pressão pelo processo de transferência de calor, que refletem nas paredes da câmara de combustão e interagem de volta com a chama. Em outras palavras, é um acoplamento com retroalimentação positiva entre o processo de liberação de calor e a acústica da câmara. Essa interação acoplada leva a ciclos limites não lineares, que podem se manifestar em oscilações autossustentadas especialmente fortes em processos com razão de equivalência ${ }^{1}$ baixa. Observa-se que essas oscilações podem ser resultado de oscilações superpostas em diversas frequências não harmônicas. Fornos industriais se beneficiam da combustão em baixas razões de equivalência por causa de sua poluição reduzida e menor consumo de combustível, o que torna a modelagem da chama ainda mais desafiadora. É de se concordar que seria de grande valia encontrar um modelo que possua uma boa concordância com os fenômenos físicos e uma descrição matemática que mantenha sua ordem baixa, ao mesmo tempo que descreva os efeitos das oscilações não lineares. Um modelo particular a partir de uma equação diferencial ordinária de $2^{\mathrm{a}}$ ordem que combina liberação de calor pela chama e pressão acústica pelo processo de combustão dentro da câmara recebeu atenção especial nas últimas décadas. Culick (1971) propôs um modelo acústico que aproxima as equações de Navier-Stokes por uma equação diferencial ordinária de $2^{\text {a }}$ ordem que relaciona modos acústicos da chama com a taxa de liberação de calor. Peracchio e Proscia (1999) expressaram o modelo proposto por Culick (1971) com a

1 A razão de equivalência é definida na equação (3.1), na página 68, e indica se há falta ou excesso de comburente numa reação de combustão em relação a sua relação estequiométrica. 
taxa de calor da frente de chama em função da razão de equivalência e comparam com dados experimentais de um queimador de $4 \mathrm{MW}$ a diesel pré-misturado. Eles concluíram que há bom ajuste do modelo aos dados para uma razão de equivalência entre 0,45 até 0,56 e verificaram que há a ocorrência de ciclos limites cujas amplitudes variam em função da razão de equivalência e que, conforme a razão de equivalência diminui, a pressão e a liberação de calor aumentam. Em seguida, Dunstan, Bitmead e Savaresi (2001) adaptaram o modelo de Peracchio e Proscia (1999) para um queimador a gás com combustão de razão de equivalência também entre 0,45 até 0,56 e inseriram um oscilador adicional em paralelo para representar a $3^{\mathrm{a}}$ harmônica da oscilação da chama, além de filtros passa-baixas e antialiasing. Além disso, eles utilizaram técnicas de identificação de sistemas na parte linear do modelo e técnicas de ajuste de função descritiva para a parte não linear. Por fim, concluíram que o modelo foi capaz de refletir a dinâmica do fenômeno com certo nível de confiança e indicou a possível existência de uma frequência não harmonicamente relacionada, mesmo que a parte linear não apresentasse tal característica. Apesar do avanço na descrição da instabilidade da combustão trazida por Dunstan, Bitmead e Savaresi (2001), o modelo apresentado trazia algumas complicações, a saber: a presença de dois ressonadores acoplados e uma dinâmica não linear complexa devido a blocos de derivação e de atraso em série com a função descritiva. Landau, Bouziani e Bitmead (2008) simplificaram o modelo de Dunstan, Bitmead e Savaresi (2001), tornando-o mais tratável analiticamente. Trocaram os dois ressonadores acoplados por duas equações de Van der Pol acopladas e simplificaram o termo não linear retirando o atraso e uma derivação. Isso tornou o modelo muito mais tratável analiticamente, uma vez que esses autores ainda apresentaram uma solução para as duas equações de Van der Pol acopladas com o método de Krylov-Bogoliubov (KRYLOV; BOGOLIUBOV, 1949; OLIVEIRA, 2017). Um importante resultado de Landau, Bouziani e Bitmead (2008) foi de conseguir explicar a coexistência de duas frequências distintas observadas na prática. Stadlmair, Hummel e Sattelmayer (2018) propuseram uma metodologia para obter o modelo de instabilidade da chama através apenas da pressão na câmara de combustão, sem a necessidade da variável de taxa de calor. Em resumo, houve grande desenvolvimento de modelos analíticos da chama, porém a validade desses modelos ainda é apenas para uma faixa limitada de valores de razão de equivalência e, além disso, ainda persistem algumas dificuldades na obtenção dos parâmetros, que limitam suas aplicações na indústria.

Diferentemente das três metodologias de modelagem mencionadas por Laera et al. (2014), existe uma outra abordagem de pesquisa que pode ser utilizada para obter um modelo da chama que é a Identificação de Sistemas Dinâmicos, onde justamente se enquadra a proposta deste trabalho. Através da metodologia proposta, técnicas de Análise Modal Operacional (OMA, sigla em inglês) são utilizadas para relacionar o comportamento vibratório, e também assumido aqui como estocástico, da chama a um movimento oscilatório que pode ser caracterizado por modos de vibrar com respectivas 
frequências naturais e amortecimentos. Silva et al. (2015) utilizaram, pela primeira vez, o algoritmo do Decremento Aleatório (RD) em conjunto do Método no Domínio do Tempo de Ibrahim (ITD) para identificar características modais da chama de um forno industrial experimental a óleo. Este projeto de pesquisa tem a intenção de estender os resultados obtidos por Silva et al. (2015), para identificar diversas condições da chama através de imagens, em termos de modelos dinâmicos, e utilizar esses modelos para auxiliar na predição de estados da chama.

Assim, os objetivos principais desta pesquisa podem ser definidos como: identificar um sistema para as imagens da chama de um forno industrial através do monitoramento de apenas uma câmera CCD e validar os modelos identificados através da confrontação de dados estimados pelos próprios modelos com os dados experimentais.

De forma sucinta, este trabalho aplica técnicas desenvolvidas nas pesquisas anteriores não só para uma única condição de chama, mas para diversas condições, e sua contribuição original é propor uma metodologia para gerar modelos que expliquem o comportamento dinâmico das características das imagens de chama. Os múltiplos modelos obtidos podem ser, então, unificados num só, que recebe como entrada a razão de equivalência da combustão. Essa plataforma de identificação, caso atuasse num sistema supervisório de chama, monitoraria de forma contínua o estado da chama e verificaria se a razão de equivalência estimada através das imagens está de acordo com a razão de equivalência desejada. Caso houvesse divergências, um sistema de controle do tipo regulador poderia atuar no sistema para que a resposta voltasse àquela da razão de equivalência desejada.

A estrutura da tese foi pensada de forma a guiar o leitor a fim de evidenciar o cumprimento das metas estabelecidas. No capítulo 2 serão citados outros trabalhos que evidenciam as vantagens em se utilizar imagens para o monitoramento da chama em aplicações de combustão, bem como serão detalhados os trabalhos do grupo de pesquisa deste autor que estabeleceram novas abordagens para o monitoramento da chama e enveredaram para a modelagem da chama através dos dados de monitoramento por imagem combinados a técnicas de Análise Modal Operacional (OMA). A metodologia proposta para atingir os objetivos estabelecidos é apresentada no capítulo 3 , que a divide em duas partes. A primeira parte será detalhada no capítulo 4, e explora o processamento das imagens desde a imagem bruta até a transformação em informações através dos vetores característicos. A segunda parte, no capítulo 5, diz respeito ao processo de identificação do modelo a partir dos vetores característicos da imagem. Nesse capítulo são detalhadas as ferramentas utilizadas para a obtenção dos modelos, para ao final apresentar a forma unificada dos modelos das condições de chama. O capítulo 6 expõe os resultados obtidos em cada etapa da identificação, e mostra os resultados do processo de validação do modelo. Em seguida, no capítulo 7, serão apresentadas as conclusões da pesquisa, as sugestões para futuras contribuições e as considerações finais. 


\section{REVISÃO DA LITERATURA}

No capítulo 1 discutiu-se que Laera et al. (2014) enumeram três tipos de abordagens para prever a ocorrência de instabilidades na combustão: modelos acústicos de baixa ordem, modelos acústicos solucionados por MEF e modelos por CFD. Cada uma dessas abordagens se mostra incapaz de lidar com o problema que é enfrentado por este trabalho, que é conceber um modelo que possa ser utilizado em tempo real tanto para monitoramento como para, talvez, controle. MEF e CFD são modelos de discretização e não são aplicáveis para casos de monitoramento de chama em tempo real. Os modelos acústicos de baixa ordem disponíveis na literatura, apesar de promissores, ainda não descrevem o fenômeno para uma faixa de operação ampla o suficiente para aplicação industrial.

A indústria busca continuamente aumentar a eficiência, confiabilidade e flexibilidade de seus equipamentos. Com aplicações que envolvem combustão, não é diferente. A constante busca por redução no consumo de combustíveis fósseis, diminuição das emissões de gases de efeito estufa ou maior aproveitamento do calor gerado faz com que novos queimadores e novos sensores sejam desenvolvidos. Segundo Ballester e García-Armingol (2010), o monitoramento e controle da maioria dos queimadores de fins industriais são feitos pelo sistema de gerenciamento de chama e pela análise dos gases de exaustão. Com esses aparatos é possível alcançar uma razão ar-combustível desejada ou verificar níveis de emissões de poluentes fora dos limites legais. No entanto, eles se verificam insuficientes para entregar informações sobre o processo de combustão em si, impossibilitando o controle automático de variáveis do queimador de uma maneira efetiva e segura. Ballester e GarcíaArmingol (2010) ainda sugerem que a tecnologia da combustão enfrenta dois obstáculos para que métodos de controle mais avançados sejam implementados:

a) a falta de modelos de chama confiáveis que possam ser usados para predizer parâmetros de combustão com acurácia suficiente em função de condições de operação e configurações de queimadores, ou ao menos prever respostas a mudanças de variáveis manipuladas;

b) o risco de levar o sistema a regimes instáveis, que podem levar a paradas não planejadas de equipamentos ou até levar o sistema a ficar fora de controle, podendo causar danos mecânicos, térmicos e a pessoas.

Por conta disso, o método para garantir a operação de fornos ou caldeiras industriais é o monitoramento contínuo. Por outro lado, executar o monitoramento contínuo através da medição de variáveis globais como vazões de entrada de combustível e comburente, composição dos gases de emissão ou taxa de calor emitida não garante uma descrição ideal do processo de combustão que está ocorrendo dentro da câmara. Ballester e García- 
Armingol (2010) descrevem quatro estratégias para monitoramento direto de chamas que se mostram promissoras para fornecer mais informações sobre o processo de combustão dentro da câmara:

a) espectroscopia da chama;

b) captura de imagens da chama;

c) medição de flutuação de pressão;

d) técnicas de sondagem.

Neste trabalho, a estratégia de monitoramento de interesse é a captura de imagens da chama por câmeras CCD. Assim, este capítulo trata de revisar a literatura relevante para entender os tipos de pesquisas realizadas na área de forma a orientar os caminhos desta pesquisa. A seção 2.1 descreve um breve histórico sobre a utilização de imagens no monitoramento de processos de combustão. A partir da seção 2.2 é feita uma descrição dos trabalhos do grupo de pesquisa do próprio autor que culminaram nos resultados apresentados nesta tese. Primeiramente, o equipamento experimental que deu origem a imagens utilizadas em diversos artigos é descrito na seção 2.2. A seção 2.3 descreve o processamento realizado nas imagens digitais para separar a imagem da chama do seu fundo. Assim, garante-se que as informações retiradas das imagens se refiram somente ao objeto em estudo, isto é, a chama. Em seguida, a pesquisa sobre identificação da qualidade de nebulização a partir de imagens da chama é exposta na seção 2.4. A fim de estabelecer uma nova abordagem para a modelagem da chama, na seção 2.5, técnicas de OMA são aplicadas em vetores temporais gerados a partir de características das imagens que resultam na identificação de parâmetros modais que representam a característica dinâmica do sistema. Na seção 2.6, os parâmetros identificados na seção 2.5 são utilizados para a síntese de um regulador linear quadrático (LQR) que indica um caminho para se controlar a chama através do monitoramento por imagens. Por fim, a seção 2.7 faz um breve comentário sobre metodologias de inferência de estados de chama.

\subsection{A utilização de imagens no processo de combustão}

Mesmo sendo possível encontrar artigos que utilizam a captura de imagens de chama antes do advento dos dispositivos de carga acoplada (CCD), é notório como o desenvolvimento dessa tecnologia permitiu uma difusão do uso de imagens em sistemas de combustão. Christensen, Raynor e McDonald (2015) definem o que é uma inovação disruptiva e certamente os sensores CCD se enquadram nesse tipo de inovação. O advento das câmeras CCD marca uma mudança de paradigma tão abrupta na área de captura de imagens que é possível separar as pesquisas em captura de imagens de chama em pré-CCD e pós-CCD. Ao analisar, por exemplo, o trabalho de Zucherman, Kawall e Keffer (1988) 
verifica-se o quão complicado era, naquela época, a aquisição e o processamento de imagens digitais, ilustrados no fluxograma da figura 1.

Figura 1 - Fluxograma do sistema de análise digital da imagem.

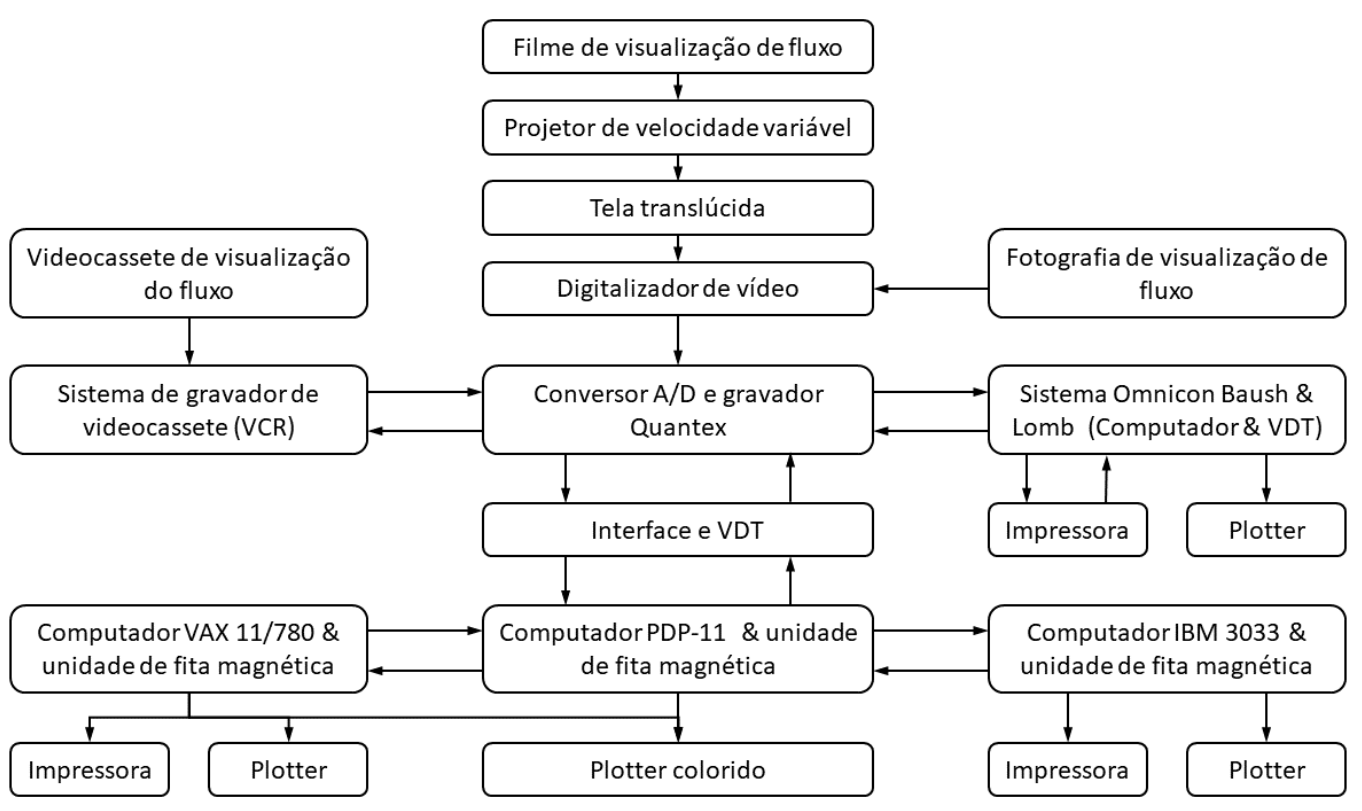

Fonte - Adaptado de Zucherman, Kawall e Keffer (1988).

Zucherman, Kawall e Keffer (1988) analisaram uma série de imagens da chama turbulenta de um bico de Bunsen, determinaram que a posição da ponta da chama é uma característica de interesse e concluíram que essa posição é uma variável aleatória gaussiana superposta com uma componente pseudoperiódica que pode ser atribuída a uma pulsação causada por convecção e uma deformação de vórtices presentes dentro da chama. É importante notar que a partir daí já se considerava que características da imagem da chama podiam ser consideradas aleatórias com distribuição gaussiana.

Outra pesquisa pré-CCD que lança mão de um equipamento de ponta para a época é o trabalho de Kurihara et al. (1986), que apresentou um sistema de estimação de emissões de $N O_{x}$ da combustão de carvão pulverizado batizado de FIRES, Flame Image REcognition System (sistema de reconhecimento de imagens de chama, em inglês). Eles utilizaram câmeras de circuito interno de televisão para observar a imagem da chama na vizinhança dos queimadores através de sondas de fibra ótica. A partir da imagem da chama foram identificadas duas áreas com alta intensidade de radiação. Parâmetros dessas áreas em relação a posição do queimador e em relação a elas próprias foram determinados para o cálculo de um índice. Comparações das concentrações do $N O_{x}$ encontradas a partir do índice obtido e de concentrações de $N O_{x}$ medidas indicaram um erro máximo de 10 ppm.

Os dispositivos de carga acoplada (CCD) foram inventados em 1969 na empresa Bell 
Labs por Boyle e Smith (1970), trabalho que lhes rendeu o prêmio Nobel de Física de 2009. Cada célula do sensor CCD (que corresponde a um pixel na imagem) tem duas funções: a primeira é converter fótons em elétrons de forma proporcional à intensidade luminosa; a segunda é de transferir essa informação para a célula adjacente de forma que a informação de toda uma rede de células possa ser lida sequencialmente para que seja interpretada como uma imagem. Os primeiros sensores CCD possuíam a chamada transferência de quadro completa. Nela, todo o sinal contido no quadro deveria chegar até as bordas do sensor para que a informação fosse interpretada. O problema dessa arquitetura era que os elétrons de uma célula que estivesse localizada longe do ponto de saída do sinal tinham que caminhar um longo caminho e as células do caminho estavam suscetíveis a sofrerem alguma excitação por fótons, o que alterava o sinal e causava manchas nas imagens.

Fossum e Hondongwa (2014) relatam que foram necessários outros dois aprimoramentos importantes para que o CCD se tornasse o sensor mais difundido em câmeras digitais que é hoje. O primeiro deles foi a transferência entrelinhas (ILT), proposto por Walsh e Dyck (1973) e ilustrado na figura 2, que incluiu dentro da mesma célula do CCD uma parte com a única função de transferir carga e outra com a função de transformar fótons em elétrons. Essas células registradoras de deslocamento separadas diminuíram o tempo em que os sinais levavam até a saída do sensor e evitavam interferência de excitações de fótons indesejadas. A arquitetura ILT CCD foi utilizada por muitos anos, mas algumas

Figura 2 - Desenho ilustrativo do funcionamento do ILT CCD.

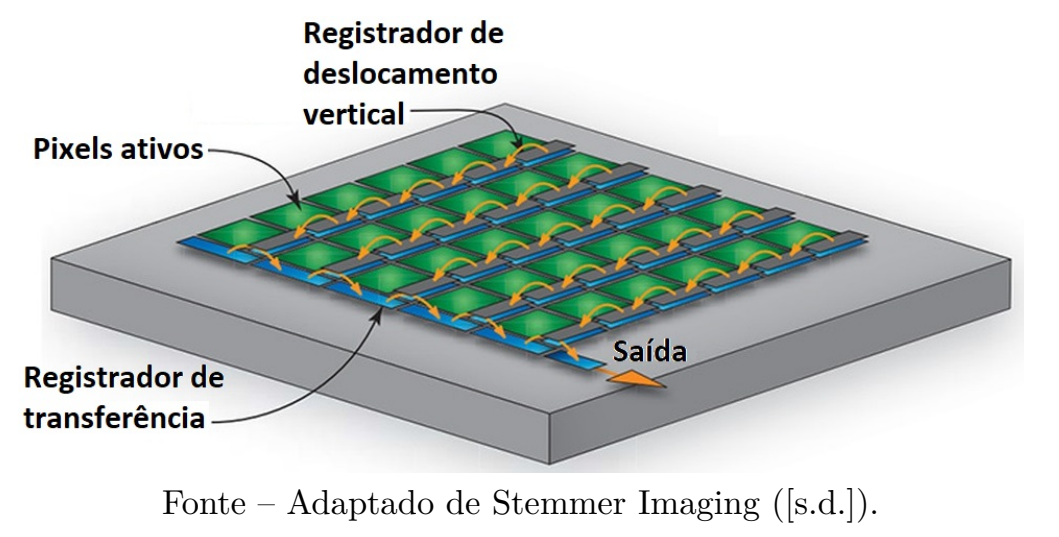

limitações técnicas não permitiam aplicações mais extensivas. Quando uma célula tem que passar a informação de um pixel bastante iluminado e, em seguida, de um pixel pouco iluminado, elétrons do pixel muito iluminado continuam se transferindo nas células subsequentes. É como se houvesse tantos elétrons a serem transferidos de uma célula para outra que nem todos conseguiam a tempo e iam se atrasando pelo caminho. Isso causava um efeito de "cauda de foguete" em câmeras de vídeo CCD. Para resolver esse problema, Teranishi et al. (1982), na empresa NEC, inventaram o fotodiodo do tipo PPD, um tipo de estrutura fotodetetora com baixo atraso, baixo ruído, alta eficiência quântica e 
baixa corrente escura ${ }^{1}$. Esse segundo avanço tecnológico permitiu que a utilização fosse expandida, no final dos anos 80, ao nível que conhecemos hoje. A tecnologia de sensores de imagem por CMOS tende a substituir a tecnologia CCD num futuro próximo, mas aí se configura não mais uma inovação disruptiva, apenas incremental.

Em um dos primeiros estudos de combustão por imagens com câmera CCD, SantosVictor et al. (1993) aplicaram visão computacional para caracterizar e classificar chamas de fornos para fabricação de vidro. Eles afirmaram que o comprimento da chama na imagem está relacionado com o ponto de operação ótimo, que geralmente é determinado pela geometria do forno. Além do comprimento da chama, os estudos mostraram indícios que características como brilho, separação do queimador, contornos e distribuição espectral também podem estar relacionados com a formação de poluentes. Para quatro classes de chama definidas por eles, que relacionam vazão de combustível e número de queimadores ativos, foram propostos dois métodos de classificação das chamas: classificação Bayesiana e classificação por redes neurais (do tipo multilayer perceptron, MLP). Ambos os classificadores se mostraram eficazes para identificar e classificar corretamente imagens de chama com a sua respectiva classe. As características de imagens utilizadas para ambos os classificadores e que proporcionaram a alta eficiência na classificação foram: comprimento da chama, momentos de área máximo e mínimo, coordenadas do centróide de área, distância dos queimadores e a área propriamente dita. Por fim, Santos-Victor et al. (1993) concluíram que o êxito na classificação das chamas através de características retiradas das imagens médias provam que há significado ou correlação entre as características das imagens e os fenômenos físicos que acontecem dentro do forno.

Hernandez e Ballester (2008) descrevem como o monitoramento de combustão pode se beneficiar da análise de imagens de chama. Eles salientam que, apesar do fato de os equipamentos para a aquisição das imagens de chama não serem tão complexos, converter imagens em informação útil não é um problema simples de se resolver.

González-Cencerrado, Peña e Gil (2012) trabalharam com imagens obtidas por uma câmera CCD num queimador em escala semi-industrial estabilizado por turbilhão para processamento de biomassa com carvão pulverizado e avaliaram a influência da razão ar-combustível na estrutura e estabilidade da chama. Chen, Chan e Cheng (2013) aplicaram análise de componentes principais (PCA) nas imagens das chamas de um processo com um queimador de óleo pesado. Para aplicar o algoritmo do PCA, cada imagem colorida RGB foi previamente representada como uma linha de matriz para formar uma grande matriz com uma imagem em cada linha. Constatou-se que as primeiras duas componentes principais representam $98.8 \%$ de toda a variância da imagem da chama. A fim de prever a temperatura da água de uma caldeira de biomassa de $3 \mathrm{MW}$, Tóth, Garami e Csordás

1 Corrente escura é o nome dado à taxa de geração de elétrons através de efeito térmico dentro da estrutura de silício do CCD. É um sinal gerado de forma independente do sinal induzido pelos fótons e fortemente dependente da temperatura do dispositivo. 
(2017) investigaram o uso de redes de crença profunda (DBN) utilizando parâmetros medidos rotineiramente com características das imagens da chama em tempo real. Eles concluíram que adicionar características de imagem aumenta a precisão das estimativas comparadas com aquelas utilizando somente dados operacionais. Sreedhanya et al. (2017) estimaram a medida de temperatura baseadas nos níveis de RGB das imagens da chama de um forno rotatório comum para fabricação de cimento utilizando o método de inferência de Mamdani e Assilian (1975).

Os trabalhos verificados convergem no seguinte ponto: existe relação entre as variáveis físicas do processo e as características geométricas e de intensidade luminosa da imagem. Mais que isso, através das características da imagem é possível inferir o estado da chama ou ainda inferir até parâmetros físicos em tempo real. Uma das características mais importantes para uma chama de forno industrial é a estabilidade. A estabilidade da chama depende de diversos fatores como tipo de combustível, razão de equivalência, estrutura da fornalha e tipo de queimador, mas apesar de toda a complexidade envolvida, ela deve ser mantida continuamente, como um requerimento essencial do processo. Uma vez que a estabilidade da chama está intimamente ligada com a eficiência da combustão e seu respectivo nível de emissões, diversas técnicas para caracterização e monitoramento de chama por câmeras CCD foram propostas a fim de garanti-la. Bertucco et al. (2000) apresentaram uma análise de monitoramento em tempo real de um processo de combustão aplicado a um incinerador de lixo baseado em redes neurais celulares. Fleury, Trigo e Martins(2010a, 2010b, 2013) também propuseram uma abordagem para monitoramento de chamas em busca da manutenção de sua estabilidade. Esses trabalhos e seus desdobramentos serão analisados com mais detalhes nas próximas seções, uma vez que possuem ligação direta com o desenvolvimento desta tese.

\subsection{Forno experimental de chama a óleo}

Diversos artigos dessa linha de pesquisa foram realizados com imagens obtidas pelo mesmo equipamento experimental. Então, antes de detalhar os resultados de cada artigo, é interessante em primeiro lugar descrever o aparato experimental utilizado na geração das imagens, já que os dados que serão analisados desses artigos vieram do mesmo lugar.

O equipamento experimental se trata de um forno vertical, mostrado na figura 3 , que está situado no Laboratório de Combustão do Instituto de Pesquisas Tecnológicas do Estado de São Paulo (IPT) e dispunha da infraestrutura necessária à coleta de dados e à regulagem dos parâmetros para executar ensaios de processos de combustão. Infelizmente, atualmente o forno encontra-se fora de operação e se tem à disposição apenas um conjunto relativamente limitado de imagens que haviam sido coletadas há alguns anos atrás.

Fleury, Trigo e Martins (2010b) descrevem que o queimador se situa na parte mais 
Figura 3 - Forno vertical experimental do IPT.

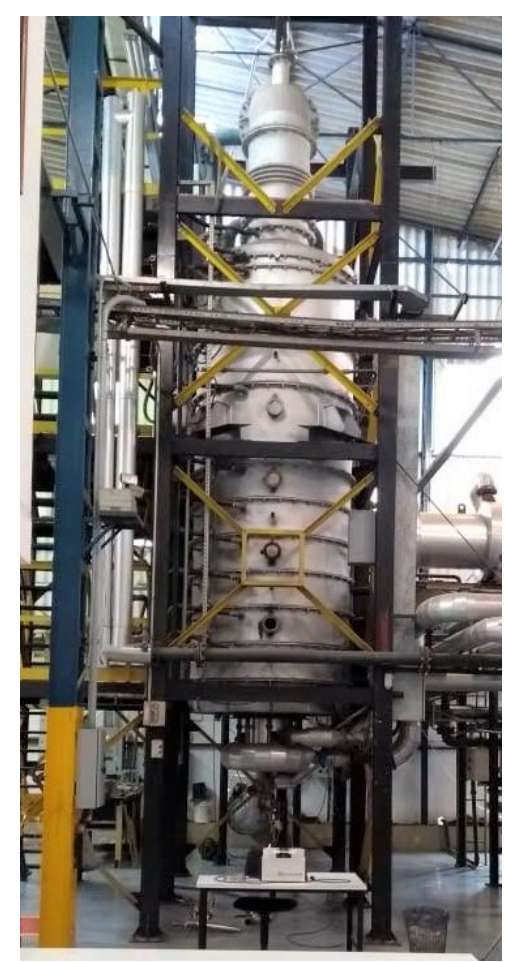

Fonte - Elaborado pelo autor.

baixa do forno, justamente a parte em evidência na figura 4 e o sistema de exaustão se localiza na parte de cima. O forno completo possui uma altura total de $4 \mathrm{~m}$, com

Figura 4 - Detalhamento do queimador do forno a óleo.

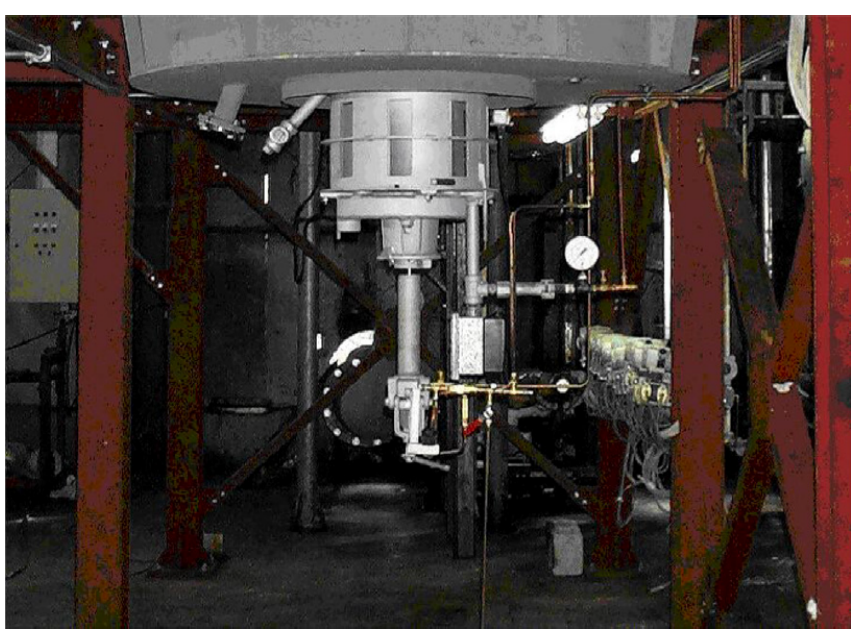

Fonte - Fleury, Trigo e Martins (2010b).

12 blocos independentes de resfriamento a água e tem capacidade de processar óleo combustível número 1 com escoamento máximo a $80 \mathrm{~kg} / \mathrm{h}$. O óleo combustível é classificado de acordo com seu ponto de fulgor, composição e aplicação numa escala que varia de 1 a 6 . Particularmente, o óleo combustível 1 possui baixa viscosidade, uma vez que é destilado, e 
é isento de resíduos sólidos e cinzas orgânicas.

Figura 5 - Esquema do queimador em corte.

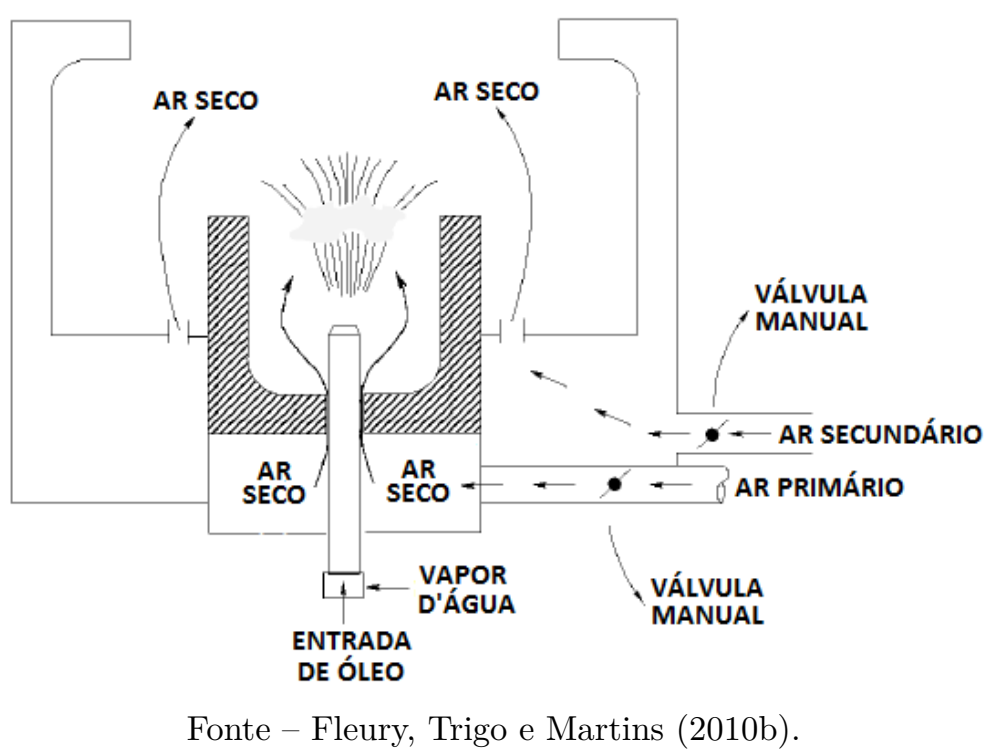

A figura 5 ilustra as partes do queimador. Neste sistema, o óleo se mistura com o vapor d'água nebulizado para formar uma mistura combustível pulverizada. O queimador ainda possui duas entradas de ar, uma primária e outra secundária, que permitem a passagem do ar através de válvulas manuais de controle de vazão.

As imagens foram geradas a partir de uma câmera CCD RS-170 monocromática padrão (modelo Marshall 1070) que utilizava uma objetiva olho de peixe com distância focal $6 \mathrm{~mm}$ e abertura máxima $f / 1$.2. Junto à objetiva era acoplado um filtro interferométrico de banda estreita $( \pm 10 \mathrm{~nm})$ no comprimento de onda de referência de $900 \mathrm{~nm}$, valor próximo ao pico de sensibilidade à luminância do sensor CCD $(750 \mathrm{~nm})$ e dentro da faixa de radiação da fuligem, que emite a maior parte da radiação de uma chama de óleo combustível típica. O conjunto óptico formado pelo sensor CCD, lente objetiva e filtro foi alojado num invólucro de aço especialmente projetado para propiciar a devida resistência mecânica e refrigeração com circulação de ar e água. O invólucro ainda contava com uma janela de vidro duplo para permitir a aquisição das imagens e garantir um isolamento térmico suficiente. A figura 6(a) ilustra o detalhamento das partes do invólucro de metal e a figura 6(b) mostra a câmera instalada num orifício apropriado para esta aplicação.

O sinal de saída de vídeo composto da câmera CCD possuía uma taxa de aquisição de $25 \mathrm{~Hz}$, ou 25 quadros por segundo (qps), que era processado através de um placa de digitalização de vídeo (frame grabber), modelo Sensoray Model 611, e era convertido em uma série de imagens entrelaçadas de $640 \times 480$ pixels. Estas imagens eram, então, armazenadas em um computador ligado à placa de aquisição. 
Figura 6 - Imagens da câmera CCD utilizada para capturar chamas no forno a óleo.

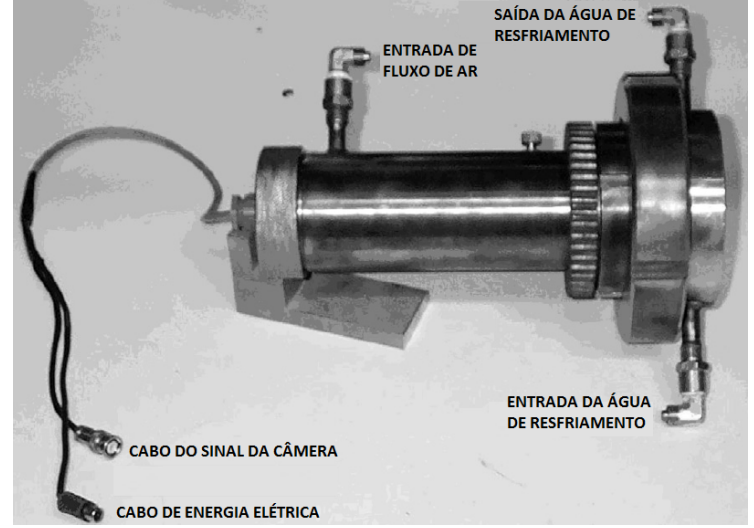

(a) Detalhamento do invólucro da câmera.

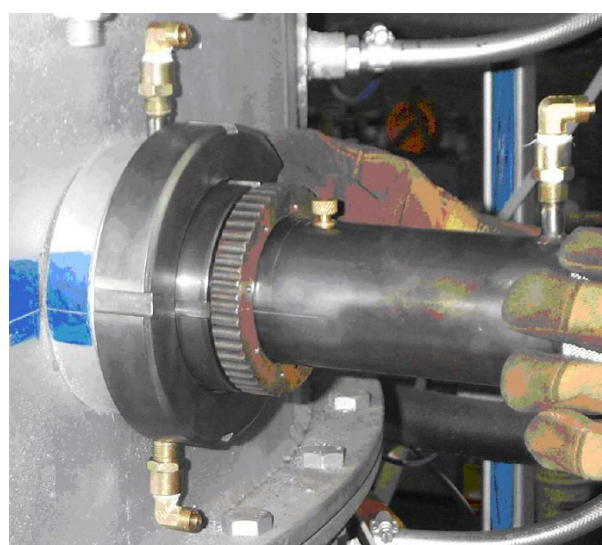

(b) Câmera CCD instalada.

Fonte - Fleury, Trigo e Martins (2010a).

\subsection{Processamento das imagens de chamas a óleo}

A técnica de varredura entrelaçada (interlaced scan) mostra-se vantajosa para mídias em vídeo uma vez que diminui à metade a largura de banda necessária para gerá-las, se aproveitando da criação de uma ilusão de ótica para o olho humano, fazendo-o parecer completo. Esse tipo de vídeo é criado a partir de um campo de linhas pares e um campo de linhas ímpares que são atualizados de forma intercalada a cada atualização do quadro. Como a taxa de atualização da câmera era de 25 qps considerando o quadro completo, então cada campo era atualizado a cada $1 / 50 \mathrm{~s}$. Uma vez que as imagens originais estavam entrelaçadas, um primeiro passo geral no processamento das imagens é o processo de desentrelaçamento. Ao se separar a parte dos campos pares e ímpares de um quadro entrelaçado, obtém-se duas imagens com metade das linhas da imagem original. Por exemplo, as imagens ímpares teriam seus pixels nas linhas $(1,3,5, \ldots, 479)$ e linhas vazias nas posições $(2,4,6, \ldots, 480)$, e as imagens pares vice-versa. Parker (2017) cita duas formas de realizar o desentrelaçamento:

a) nas imagens ímpares copiar as linhas ímpares de cima nas linhas pares abaixo, e nas imagens pares copiar as linhas pares de baixo nas linhas ímpares de cima;

b) interpolar a linha entre duas linhas adjacentes.

A figura 7 ilustra um exemplo do processo de desentrelaçamento. A partir de uma imagem original (figura 7(a)) são extraídas duas novas imagens: a imagem gerada a partir do campo ímpar (figura 7(b)) e a gerada a partir do campo par (figura 7(c)), neste caso através da forma (a) de desentrelaçar imagens.

As imagens provenientes do aparato experimental descrito na seção 2.2 (página 42) foram utilizadas em diversos trabalhos do mesmo grupo de pesquisa. As imagens desentrelaçadas serão chamadas de imagens $I_{k}$ neste capítulo, onde o índice $k$ tem como universo 
Figura 7 - Processo de desentrelaçamento de uma imagem com chama estável.

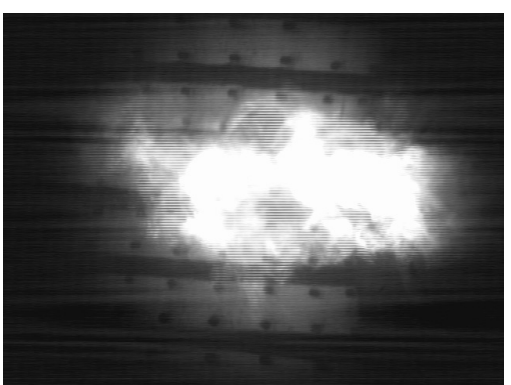

(a) Imagem original entrela-(b) çada.

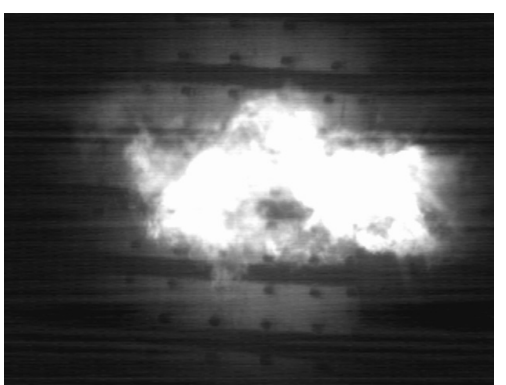

mada pelo campo ímpar.

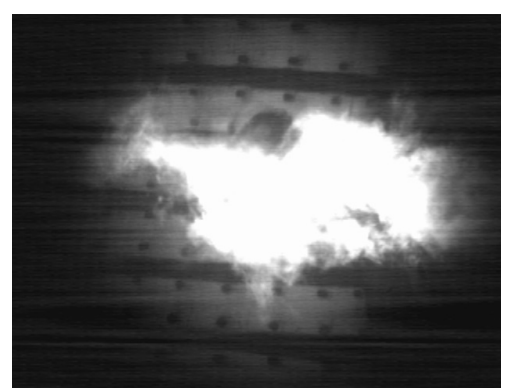

(c) Imagem desentrelaçada formada pelo campo par.

Fonte - Elaborado pelo autor.

todas as imagens disponíveis, e foram utilizadas em Fleury, Trigo e Martins (2010a, 2010b, 2013), Silva et al. (2015), Fleury et al. (2015). Em Fleury et al. (2017) as imagens $I_{k}$ passaram também por um processo de limiarização de Otsu (1979) com o objetivo de separar a chama do fundo da imagem, dando origem a imagens preto e branco $I_{k}^{p b}$. Já em Silva Neto et al. (2019) também foram obtidas imagens chamadas de segmentadas $I_{k}^{s}$. Elas são geradas utilizando as imagens $I_{k}^{p b}$ como máscara da imagem $I_{k}$, o que possibilita se ter uma imagem com a separação do fundo mas com a textura do brilho da chama. A figure 8 ilustra como fica a figura 7(b) após o processo de limiarização (figura 8(b)) e após a segmentação (figura 8(c)).

Figura 8 - Processo de limiarização e segmentação da figura 7(b)

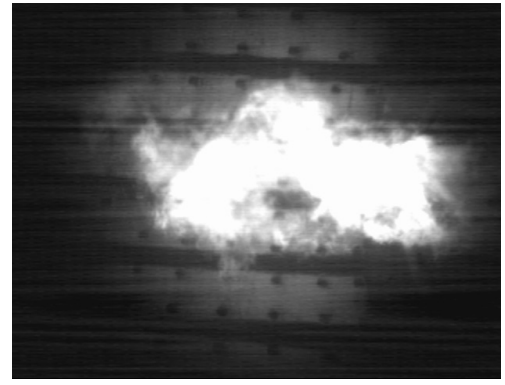

(a) Imagem desentrelaçada.

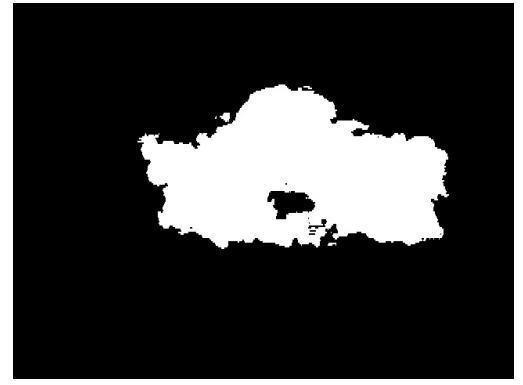

(b) Imagem em preto e branco.

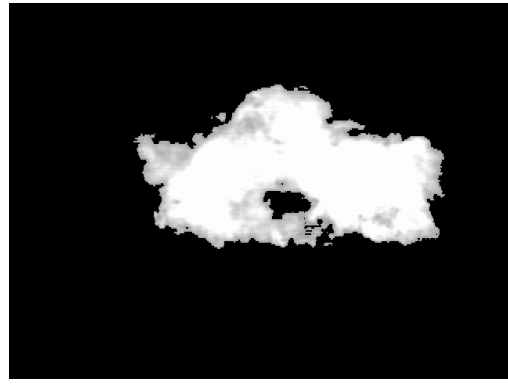

(c) Imagem segmentada.

Fonte - Elaborado pelo autor.

\subsection{Identificação da qualidade de nebulização}

A qualidade de nebulização é uma característica extremamente relevante de um processo de combustão a óleo, pois está diretamente relacionada à sua eficiência térmica, isto é, uma baixa qualidade de nebulização implica numa menor eficiência térmica do forno, que resulta numa maior emissão de material particulado. Por este motivo, Fleury, Trigo e 
Martins (2010a, 2010b, 2013) resolveram abordar o problema de diagnosticar a qualidade de nebulização para inferir sobre a qualidade do processo de combustão e, indiretamente, sobre as emissões de material particulado.

Em suas pesquisas, Fleury, Trigo e Martins (2010a, 2010b, 2013) perceberam que, embora o processo de combustão possa ser caracterizado com base em parâmetros que englobam geometria, brilho e propriedades de espectro das imagens capturadas (conforme visto na seção 2.1, página 38), a fim de atender às necessidades de um monitoramento em tempo real, a velocidade de processamento desses dados é um fator restritivo. Assim, eles escolheram parâmetros que fossem provenientes de algoritmos computacionalmente mais rápidos para formar o vetor característico de cada imagem $I_{k}$. Ainda com esse intuito, ao invés de calcular características diretamente da imagem, dez variáveis relacionadas ao histograma de tons de cinza dos pixels de cada imagem $I_{k}$ foram obtidas para formar o vetor $\boldsymbol{v}_{k}$ :

a) $v_{k, 1}$ : coordenada $x$ do centróide do histograma;

b) $v_{k, 2}$ : coordenada $y$ do centróide do histograma;

c) $v_{k, 3}$ : raio de giração em torno do eixo $x$;

d) $v_{k, 4}$ : raio de giração em torno do eixo $y$;

e) $v_{k, 5}$ : coordenada $x$ correspondente a $33 \%$ da área acumulada do histograma;

f) $v_{k, 6}$ : coordenada $x$ correspondente a $66 \%$ da área acumulada do histograma;

g) $v_{k, 7}$ : coordenada $x$ do pico máximo do histograma;

h) $v_{k, 8}$ : coordenada $y$ do pico máximo do histograma;

i) $v_{k, 9}$ : coordenada $x$ do segundo pico mais alto do histograma;

j) $v_{k, 10}$ : coordenada $y$ do segundo pico mais alto do histograma.

Após a definição do vetor característico $\boldsymbol{v}_{\boldsymbol{k}}$, foram obtidos os vetores referentes a um conjunto-treinamento de 214 imagens não-entrelaçadas de chamas, previamente classificadas entre 9 valores de razão de vazão de vapor por vazão de combustível (RVC), que é um adimensional que relaciona vazão de vapor nebulizado com vazão de óleo combustível e está intimamente relacionada com a qualidade de nebulização. Ela pode ser representada matematicamente como:

$$
r_{V C}=\frac{q_{V}}{q_{C}}
$$

onde $r_{V C}$ é a razão de vazão de vapor por vazão de combustível, $q_{V}$ é a vazão de vapor nebulizado e $q_{C}$ é a vazão de óleo combustível.

Um especialista em processo de combustão foi consultado para estabelecer uma relação entre qualidade de nebulização e RVC, o que resultou na definição de regras de lógica difusa (lógica fuzzy) para relacionar valores medidos de RVC com grau de pertinência 
a um conjunto de "chamas com alta qualidade de nebulização". A figura 9 ilustra a relação estabelecida pelo especialista. A vantagem da utilização da lógica difusa é permitir uma melhor percepção da qualidade de nebulização do que se apenas houvesse a conceituação binária de "processo normal" e "processo anormal". Essa maior variedade na conceituação da situação da chama permitiria que uma maior gama de decisões diferentes pudessem ser tomadas para cada caso.

Figura 9 - Conjunto nebuloso associado ao conceito de "alta qualidade de nebulização".

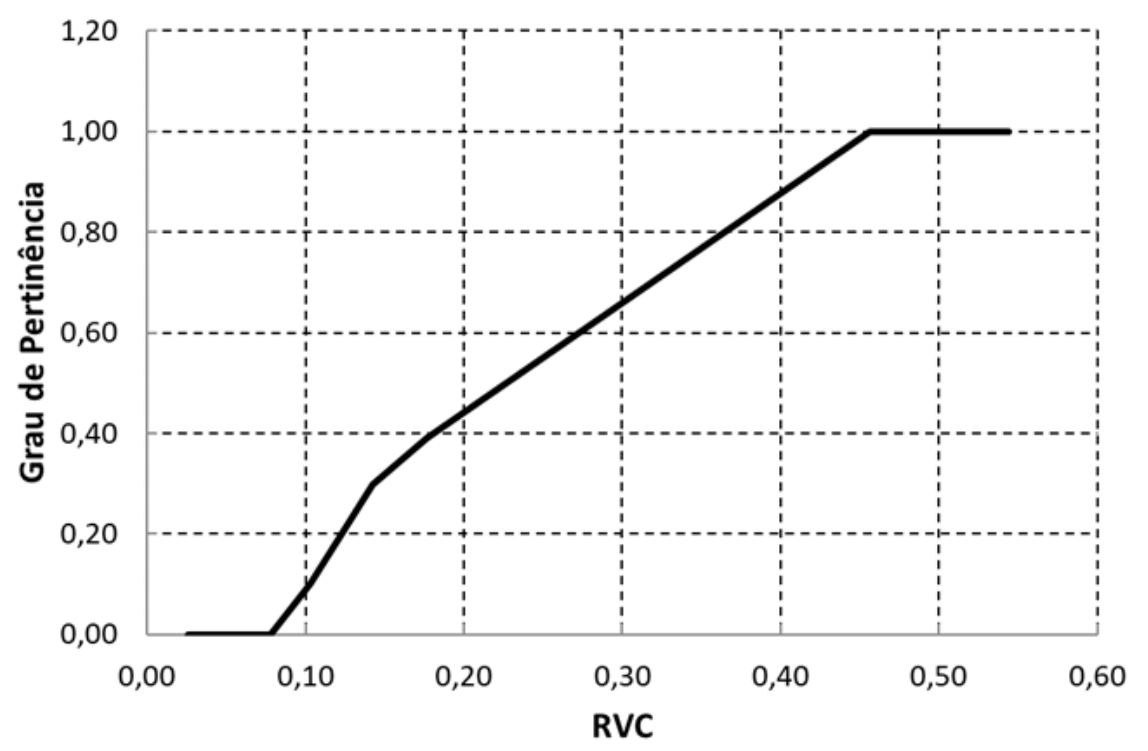

Fonte - Adaptado de Fleury, Trigo e Martins (2013).

Uma vez que esta relação havia sido efetuada, criou-se um algoritmo para classificar as imagens. Para formar as referências de comparação, obteve-se a média dos histogramas de todas as imagens que tinham sido amostradas com cada um dos 9 diferentes valores de $r_{V C}$ a saber: 0,$17 ; 0,21 ; 0,23 ; 0,26 ; 0,29 ; 0,36 ; 0,43 ; 0,50$ e 0,57. Cada histograma médio gerou um vetor característico médio $\overline{\boldsymbol{v}}_{j}$, com $j=1, \ldots, 9$. Então, para cada vetor $\boldsymbol{v}_{\boldsymbol{k}}$, com $i=k, \ldots, 214$, as distâncias entre cada uma das $i$ coordenadas do vetor $\boldsymbol{v}_{\boldsymbol{k}}$ e dos vetores $\overline{\boldsymbol{v}}_{j}$ foram calculadas. Determinou-se a distância mínima $d_{k, i}$ como a menor distância entre uma coordenada $i$ do histograma da imagem $k$ e a mesma coordenada $i$ dentre todas as 9 médias que representam diferentes valores de $r_{V C}$ :

$$
d_{k, i}=\min _{j \in[1,9]}\left(\left|v_{k, i}-\bar{v}_{j, i}\right|\right)
$$

A obtenção da distância mínima pela equação (2.2) permite estabelecer uma relação entre a imagem cuja coordenada é $v_{k, i}$ e o valor de $j$ que mais se aproxima à $r_{V C}$ da imagem $I_{k}$. A esse valor de $r_{V C}$ é relacionado um valor $p_{k, i}$ do grau de pertinência ao conceito de "alta qualidade de nebulização", onde $p_{k, i}=0$ representa nenhuma pertinência e $p_{k, i}=1$ representa pertinência total. Os valores intermediários são relacionados através do conjunto nebuloso da figura 9. 
A tabela 1 ilustra os resultados da aplicação do algoritmo proposto para 5 imagens em que a $r_{V C}=0,21$, isto é, para chamas com baixa qualidade de nebulização. Os resultados de Fleury, Trigo e Martins (2010a, 2010b, 2013) mostraram que a coordenada $v_{k, 7}$ não é uma boa medida para caracterizar a imagem, uma vez que ela é influenciada pela quantidade de pixels com o nível 253 na escala de tons de cinza. Este é um valor com grande incidência entre todas as imagens, uma vez que está relacionada à saturação do sensor e que a faixa de operação da câmera CCD é estreita. Esse fenômeno resulta num valor inesperado $p_{k, 7}=1$ para a coordenada $v_{k, 7}$, em imagens onde a $r_{V C}=0,21$ e o grau de pertinência esperado seria $p_{k, i}=0$ para $i=1, \ldots, 10$.

Tabela 1 - Grau de pertinência de chamas com $r_{V C}=0,21$ ao conjunto nebuloso "chamas com alta qualidade de nebulização".

\begin{tabular}{lrrrrrrrrrr}
\hline Imagens & $p_{k, 1}$ & $p_{k, 2}$ & $p_{k, 3}$ & $p_{k, 4}$ & $p_{k, 5}$ & $p_{k, 6}$ & $p_{k, 7}$ & $p_{k, 8}$ & $p_{k, 9}$ & $p_{k, 10}$ \\
\hline 1 & 0,0 & 0,0 & 0,0 & 0,4 & 0,0 & 0,0 & 1,0 & 0,0 & 0,1 & 0,0 \\
2 & 0,0 & 0,0 & 0,0 & 0,0 & 0,0 & 0,0 & 1,0 & 0,0 & 0,0 & 0,0 \\
3 & 0,3 & 0,3 & 0,4 & 1,0 & 0,3 & 0,3 & 1,0 & 0,4 & 0,3 & 0,0 \\
4 & 0,0 & 0,0 & 0,0 & 0,0 & 0,0 & 0,3 & 1,0 & 0,0 & 0,0 & 0,0 \\
5 & 0,0 & 0,0 & 0,0 & 0,4 & 0,0 & 0,0 & 1,0 & 0,0 & 0,0 & 0,0 \\
\hline
\end{tabular}

Até este momento, o que se tem é um algoritmo que converte uma imagem em um vetor de informações sobre essa imagem e uma relação desse vetor com a qualidade de nebulização através de uma relação de lógica nebulosa. Para que se complete a identificação do sistema, é necessário relacionar uma dinâmica a esses dados de qualidade de nebulização.

\subsubsection{Estimação da qualidade de nebulização}

Obter um modelo teórico sobre o comportamento da combustão já não é tarefa fácil, ainda mais quando o estado do sistema está expresso em propriedades geométricas do histograma de tons de cinza de imagens de chamas. Para superar estas dificuldades Fleury, Trigo e Martins (2010a, 2010b, 2013) utilizam um modelo de passeio aleatório, que é usualmente utilizado quando se tem pouco conhecimento sobre o processo e consiste num modelo de um processo estocástico onde o caminho do processo se constitui de uma sucessão de passos aleatórios num determinado espaço. O modelo de estados pode ser expresso pela equação de diferenças (2.3), que representa um processo estocástico genérico em tempo discreto:

$$
\boldsymbol{x}\left(t_{k+1}\right)=\boldsymbol{\Phi}\left(t_{k+1}, t_{k}\right) \boldsymbol{x}\left(t_{k}\right)+\boldsymbol{w}\left(t_{k+1}\right)
$$


onde $\boldsymbol{x}\left(t_{k}\right) \in \mathbb{R}^{n}$ é o vetor de estados da qualidade de nebulização com evolução temporal discreta $t_{k}, t_{k}$ é o $k$-ésimo intervalo de tempo $k \Delta t \operatorname{com} k \in \mathbb{N}, \Delta t$ é o intervalo de tempo relacionado à taxa de amostragem da câmera CCD, $n$ é a ordem do sistema, $\boldsymbol{\Phi}\left(t_{k+1}, t_{k}\right) \in \mathbb{R}^{n \times n}$ é a matriz de transição de estados e $\boldsymbol{w}\left(t_{k}\right) \sim N\left(0, \boldsymbol{Q}\left(\boldsymbol{x}\left(t_{k}\right)\right)\right) \in \mathbb{R}^{n}$ é o ruído de processo definido por um vetor de ruído branco gaussiano de média nula que possui matriz de covariância simétrica positiva semidefinida $\boldsymbol{Q}\left(\boldsymbol{x}\left(t_{k}\right)\right) \in \mathbb{R}^{n \times n}$.

No caso específico do modelo de passeio aleatório, a matriz de transição de estados $\boldsymbol{\Phi}\left(t_{k+1}, t_{k}\right)$ é igual à matriz identidade $\boldsymbol{I}_{n}$, e a equação (2.3) se torna:

$$
\boldsymbol{x}\left(t_{k+1}\right)=\boldsymbol{x}\left(t_{k}\right)+\boldsymbol{w}\left(t_{k+1}\right)
$$

O modelo de observação considera que o algoritmo de classificação de lógica difusa insere incertezas no cálculo do vetor de estados, e que estas incertezas possam ser representadas por um ruído de medida que corrompe o vetor de estados. A equação (2.5) expressa o modelo de observação:

$$
\boldsymbol{y}\left(t_{k}\right)=\boldsymbol{C}\left(t_{k}\right) \boldsymbol{x}\left(t_{k}\right)+\boldsymbol{v}\left(t_{k}\right)
$$

onde $\boldsymbol{y}\left(t_{k}\right) \in \mathbb{R}^{m}$ é o vetor de observação com evolução temporal discreta $t_{k}, m$ é a ordem do vetor de observação, $\boldsymbol{C}\left(t_{k}\right) \in \mathbb{R}^{m \times n}$ é a matriz de saídas e $\boldsymbol{v}\left(t_{k}\right) \sim N\left(0, \boldsymbol{R}\left(\boldsymbol{y}\left(t_{k}\right)\right)\right) \in \mathbb{R}^{m}$ é um vetor de ruído branco gaussiano de média nula que possui matriz de covariância simétrica positiva definida ${ }^{2} \boldsymbol{R}\left(\boldsymbol{y}\left(t_{k}\right)\right) \in \mathbb{R}^{m \times m}$. As sequências de ruído branco $\boldsymbol{w}\left(t_{k}\right)$ e $\boldsymbol{v}\left(t_{k}\right)$ são consideradas, por hipótese, mutuamente independentes, e, portanto, são nãocorrelacionadas, uma vez que são distribuições gaussianas.

O problema é intencionalmente proposto de tal forma a se ajustar com os requisitos para aplicação do filtro de Kalman (KF), a fim de que a estimação da qualidade de nebulização seja realizada. Jazwinski (2007) mostra que as equações do KF são desenvolvidas a partir da minimização da função objetivo $J_{K F}$, expressa na equação (2.6) e sujeita à restrição (2.4).

$$
\begin{aligned}
J_{K F} & =\frac{1}{2}\left(\boldsymbol{x}\left(t_{k}\right)-\hat{\boldsymbol{x}}\left(t_{k}\right)\right)^{T} \boldsymbol{P}\left(t_{k}\right)^{-1}\left(\boldsymbol{x}\left(t_{k}\right)-\hat{\boldsymbol{x}}\left(t_{k}\right)\right)+ \\
& +\frac{1}{2}\left(\boldsymbol{y}\left(t_{k}\right)-\boldsymbol{C}\left(t_{k}\right) \boldsymbol{x}\left(t_{k}\right)\right)^{T} \boldsymbol{R}^{-1}\left(\boldsymbol{y}\left(t_{k}\right)\right)\left(\boldsymbol{y}\left(t_{k}\right)-\boldsymbol{C}\left(t_{k}\right) \boldsymbol{x}\left(t_{k}\right)\right)+ \\
& +\frac{1}{2} \boldsymbol{w}^{T}\left(t_{k}\right) \boldsymbol{Q}^{-1}\left(\boldsymbol{x}\left(t_{k}\right)\right) \boldsymbol{w}\left(t_{k}\right)
\end{aligned}
$$

onde $\hat{\boldsymbol{x}}\left(t_{k}\right)$ é a estimativa de $\boldsymbol{x}\left(t_{k}\right)$ e $\boldsymbol{P}\left(t_{k}\right)$ é a matriz de covariância do erro de estimação.

Fleury, Trigo e Martins (2010a, 2010b) definem que a ordem do vetor de observação $m$ é igual à ordem do sistema $n$, isto é, todos os estados são medidos. Isto é natural uma vez que os estados coincidem com as características retiradas das imagens medidas. Assim,

2 As matrizes de covariância são sempre simétricas e positivas semidefinidas. Quando as variáveis que a formam são linearmente independentes entre si, elas serão positivas definidas. 
a matriz $\boldsymbol{C}\left(t_{k}\right) \in \mathbb{R}^{n \times n}$ é definida como a matriz identidade $\boldsymbol{I}_{n}$, e a equação (2.5) se torna:

$$
\boldsymbol{y}\left(t_{k}\right)=\boldsymbol{x}\left(t_{k}\right)+\boldsymbol{v}\left(t_{k}\right)
$$

Jazwinski (2007) apresenta o teorema 2.1 que resume o funcionamento do filtro de Kalman para sistemas discretos, sabendo que os sobrescritos (p) e (a) referem-se a valores na fase de propagação (ou previsão) e valores imediatamente após a fase de atualização, respectivamente.

Teorema 2.1 (adaptado de Jazwinski (2007)). O filtro ótimo (variância mínima) para sistemas discretos (2.4), (2.7) consiste nas equações de diferença para a média condicional e a matriz de covariância. Entre as observações,

$$
\begin{aligned}
& \hat{\boldsymbol{x}}^{(p)}\left(t_{k+1}\right)=\boldsymbol{\Phi}\left(t_{k+1}, t_{k}\right) \hat{\boldsymbol{x}}^{(a)}\left(t_{k}\right) \\
& \boldsymbol{P}^{(p)}\left(t_{k+1}\right)=\boldsymbol{\Phi}\left(t_{k+1}, t_{k}\right) \boldsymbol{P}^{(a)}\left(t_{k}\right) \boldsymbol{\Phi}^{T}\left(t_{k+1}, t_{k}\right)+\boldsymbol{Q}\left(\boldsymbol{x}\left(t_{k}\right)\right)
\end{aligned}
$$

Nas observações,

$$
\begin{aligned}
& \hat{\boldsymbol{x}}^{(a)}\left(t_{k+1}\right)=\hat{\boldsymbol{x}}^{(p)}\left(t_{k+1}\right)+\boldsymbol{K}\left(t_{k+1}\right)\left(\boldsymbol{y}\left(t_{k+1}\right)-\boldsymbol{C}\left(t_{k+1}\right) \hat{\boldsymbol{x}}^{(p)}\left(t_{k+1}\right)\right) \\
& \boldsymbol{P}^{(a)}\left(t_{k+1}\right)=\left(\boldsymbol{I}_{n}-\boldsymbol{K}\left(t_{k+1}\right) \boldsymbol{C}\left(t_{k+1}\right)\right) \boldsymbol{P}^{(p)}\left(t_{k+1}\right)
\end{aligned}
$$

onde

$$
\boldsymbol{K}\left(t_{k+1}\right)=\boldsymbol{P}^{(p)}\left(t_{k+1}\right) \boldsymbol{C}^{T}\left(t_{k+1}\right)\left[\boldsymbol{C}\left(t_{k+1}\right) \boldsymbol{P}^{(p)}\left(t_{k+1}\right) \boldsymbol{C}^{T}\left(t_{k+1}\right)+\boldsymbol{R}\left(\boldsymbol{y}\left(t_{k+1}\right)\right)\right]^{-1}
$$

é o ganho de Kalman. Predições para $t>t_{k+1}$ indicadas por $\left(\hat{\boldsymbol{x}}^{(p)}(t), \boldsymbol{P}^{(p)}(t)\right)$ são calculadas através de (2.8) e (2.9) com condições iniciais $\left(\hat{\boldsymbol{x}}^{(a)}\left(t_{k+1}\right), \boldsymbol{P}^{(a)}\left(t_{k+1}\right)\right)$.

Chega a ser intrigante a maneira que essa metodologia funciona, uma vez que o modelo não se relaciona diretamente, através das equações de diferenças, com as imagens das chamas. Pois se verificarmos o comportamento da chama, mesmo mantendo-se um valor constante de $r_{V C}$ há variações perceptíveis nas características geométricas das imagens ao longo do tempo. E o modelo de passeio aleatório escolhido afirma, a grosso modo, que o estado futuro da chama será igual ao estado passado com a diferença de um ruído no estado. De forma perspicaz, Fleury, Trigo e Martins (2010a, 2010b) inserem a relação entre o modelo e os vetores adquiridos das imagens através das matrizes de covariância dos ruídos de medição $\boldsymbol{Q}\left(\boldsymbol{x}\left(t_{k}\right)\right)$ e $\boldsymbol{R}\left(\boldsymbol{y}\left(t_{k}\right)\right)$. Ou seja, na medida em que se fornece a covariância do erro do estado e da saída ao filtro de Kalman, ele estima os estados futuros como se essa covariância fosse a própria variação das condições físicas que influenciam na chama em si.

Jazwinski (2007) afirma que a convergência estatística do processo de estimação só pode ser garantida através da inspeção dos resíduos de observação. Sabendo que o resíduo 
de observação, $\boldsymbol{r}\left(t_{k}\right)$, é a diferença entre a medida efetiva e o valor calculado pelo filtro na última estimativa disponível:

$$
\begin{aligned}
& \boldsymbol{r}\left(t_{k}\right)=\boldsymbol{y}\left(t_{k}\right)-\boldsymbol{C}\left(t_{k}\right) \hat{\boldsymbol{x}}^{(p)}\left(t_{k}\right) \\
& \boldsymbol{r}\left(t_{k}\right)=\boldsymbol{y}\left(t_{k}\right)-\hat{\boldsymbol{x}}^{(p)}\left(t_{k}\right)
\end{aligned}
$$

onde $\boldsymbol{C}\left(t_{k}\right)=\boldsymbol{I}_{n}$ (já discutido na equação 2.7), Rios Neto e Kuga (1985) definem o resíduo normalizado de observação, $r_{\nu}\left(t_{k}\right)$, dado por (2.14),

$$
r_{\nu}\left(t_{k}\right)=\frac{1}{m \sigma_{\nu}} \sum_{i=1}^{m} r_{i}\left(t_{k}\right)
$$

onde $m$ é a dimensão do vetor de medidas, $\sigma_{\nu}$ é o desvio padrão do ruído medido e $r_{i}\left(t_{k}\right)$ é a i-ésima componente de $\boldsymbol{r}\left(t_{k}\right)$. Caso o resíduo de observação $r_{\nu}\left(t_{k}\right)$ for uma sequência branca, gaussiana de média nula, cujo desvio-padrão se situe entre $-3 \sigma_{\nu}$ e $3 \sigma_{\nu}$, Fleury (1985) explica que o processo pode ser considerado convergente.

Os resultados de Fleury, Trigo e Martins (2010a, 2010b) mostram que, para conjuntos-treinamento em que se sabia a priori o valor de $r_{V C}$, a estimação pela metodologia proposta converge, após um pequeno número de iterações, para situações de baixa, média qualidade de nebulização. Para o valor testado referente a alta qualidade de nebulização, o critério não é satisfeito, mas a tendência é que essa convergência tivesse sido garantida caso estivesse disponível um número maior de medidas experimentais, segundo os autores.

Fleury, Trigo e Martins (2013) validaram esta metodologia de identificação da qualidade de nebulização aplicando-a a sequências de imagens em que os valores de $r_{V C}$ não são conhecidos a priori, para comprovar que a metodologia é uma ferramenta útil para o diagnóstico de características de um processo de combustão. Para isso, os pesquisadores estenderam o filtro de Kalman utilizado anteriormente com uma regularização de Tikhonov. Este tipo de regularização visa verificar se ao longo das iterações o método converge para a solução desejada. O filtro estima um valor para a qualidade de nebulização e a regularização de Tikhonov irá forçar um certo valor para a qualidade de nebulização. Se o filtro funciona corretamente, o valor só irá convergir para os casos que combinarem com a qualidade de nebulização forçada pela regularização, para os outros casos, não haverá convergência. Os resultados demonstram exatamente esse comportamento do filtro, comprovando a eficácia do método de classificação.

Fleury, Trigo e Martins (2010a, 2010b, 2013) sugerem que este sistema pode ser utilizado para o monitoramento em tempo real da qualidade de nebulização de chamas de fornos de refino com as seguintes vantagens:

a) a instrumentação necessária para o forno consiste apenas em uma câmera CCD;

b) as medidas são propriedades simples do histograma de tons de cinza das imagens instantâneas facilitando o processamento da imagem; 
c) o diagnóstico leva em consideração a evolução temporal do processo e, portanto, leva em consideração a dinâmica do sistema.

O fato de utilizar apenas uma câmera CCD como sensor possibilitaria uma redução na complexidade da instrumentação necessária na operação do forno, e consequentemente uma possível redução no custo da operação, ou então, caso outros sensores não sejam eliminados, haveria redundância de informações com diferentes medidas, o que também não deixa de ser útil para fornecer maior robustez ao monitoramento.

As principais contribuições de Fleury, Trigo e Martins (2010a, 2010b, 2013) podem ser resumidas como:

a) propor uma metodologia de monitoramento através de imagens de chama que indica quando há problemas físicos reais, no caso, problemas na qualidade de nebulização;

b) demonstrar que, uma vez que houve convergência no diagnóstico da qualidade de nebulização, o modelo do passeio aleatório descreve razoavelmente bem a parte estocástica (desconhecida) do processo, e o filtro de Kalman pode ser utilizado como complemento para a convergência das estimativas.

\subsection{Identificação da dinâmica da chama através de técnicas modais}

Silva et al. (2015) continuaram a estudar o problema de deteç̧ão de instabilidades no comportamento do processo de combustão através das imagens de chamas obtidas no mesmo equipamento experimental descrito na seção 2.2 (página 42). Diferentemente de Fleury, Trigo e Martins (2010a, 2010b, 2013), onde a preocupação estava em garantir a eficiência térmica do processo de combustão, Silva et al. (2015) relacionaram a aparência visual das chamas com a razão de vazão de ar primário por vazão de ar secundário (RPS), que tem grande influência na turbulência da chama. A RPS pode ser calculada da seguinte forma:

$$
r_{P S}=\frac{q_{A P}}{q_{A S}}
$$

onde $r_{P S}$ é a razão de vazão de ar primário $\left(q_{A P}\right)$ por vazão de ar secundário $\left(q_{A S}\right)$, e os valores dos parâmetros das condições analisadas estão descritos na tabela 2 .

Nas figuras 10(a)-(c) são exibidas amostras de imagens em cada uma das condições de $r_{P S}$, onde pode ser verificado que suas aparências visuais apresentam diferenças significativas umas das outras. Então, foram calculadas 13 características da imagem para formar o vetor característico $\boldsymbol{v}_{\boldsymbol{k}}$ de cada imagem $I_{k}$, mas com características diferentes daquelas utilizadas na seção 2.4 (página 46), que são definidas a seguir:

a) $v_{k, 1}$ : a média dos níveis de cinza dos pixels;

b) $v_{k, 2}$ : a entropia da imagem; 
Tabela 2 - Dados das diferentes condições de chama analisadas por Silva et al. (2015).

\begin{tabular}{lcccc}
\hline Condição & $\begin{array}{c}q_{A P} \\
{\left[\mathrm{~m}^{3} / \mathrm{h}\right]}\end{array}$ & $\begin{array}{c}q_{A S} \\
{\left[\mathrm{~m}^{3} / \mathrm{h}\right]}\end{array}$ & $r_{P S}$ & $\begin{array}{c}\text { Descrição } \\
\text { da chama }\end{array}$ \\
\hline 1 & 500 & 500 & 1,00 & Chama estável \\
2 & 650 & 350 & 1,86 & Chama trêmula \\
3 & 800 & 200 & 4,00 & Chama instável \\
\hline \multicolumn{4}{c}{ Fonte - Elaborado pelo autor. }
\end{tabular}

Figura 10 - Exemplos de imagens entrelaçadas de chama nas diferentes condições de $r_{P S}$.

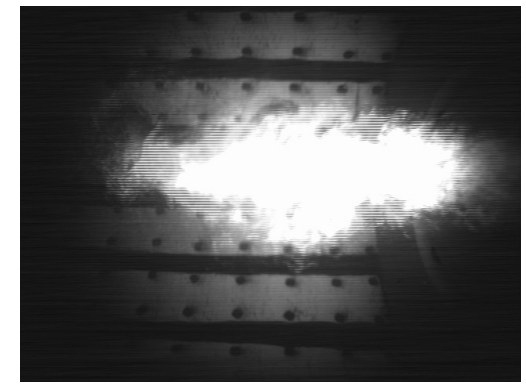

(a) $r_{P S}=1,00$

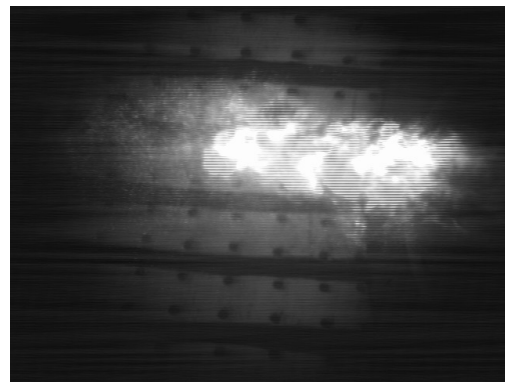

(b) $r_{P S}=1,86$

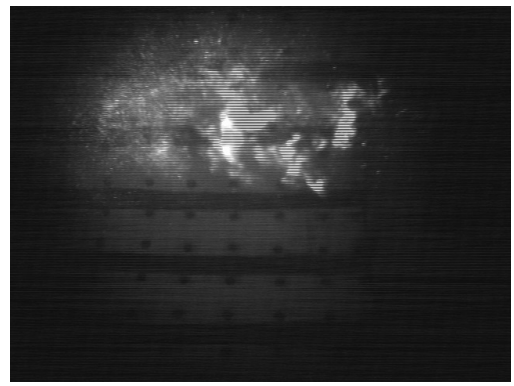

(c) $r_{P S}=4,00$

Fonte - Elaborado pelo autor.

c) $v_{k, 3}$ : a média das diferenças locais máximas dos níveis de cinza de janelas 3x3 a partir de uma varredura completa da imagem;

d) $v_{k, 4}$ : a média dos desvios padrão locais dos níveis de cinza de janelas 3x3 a partir de uma varredura completa da imagem.

As características $v_{k 5}$ a $v_{k 13}$ são baseadas na matriz de co-ocorrência definidas em Gonzalez e Woods (2001) da imagem $I_{k}$, e são relativas a dois pixels horizontalmente vizinhos cujos níveis de cinza estão separados por 1, 3 ou 5 unidades. Esclarecido esse ponto, as definições ${ }^{3}$ seguem:

e) $v_{k, 5}$ : índices de correlação do número de ocorrências das sequências de dois pixels cujos níveis de cinza estão separados por 1 unidade;

f) $v_{k, 6}$ : índices de correlação do número de ocorrências das sequências de dois pixels cujos níveis de cinza estão separados por 3 unidades;

g) $v_{k, 7}$ : índices de correlação do número de ocorrências das sequências de dois pixels cujos níveis de cinza estão separados por 5 unidades;

3 Para detalhamento do algoritmo de obtenção da matriz de co-ocorrência, ou dos cálculos do índice de correlação, valor de contraste e valor de homogeneidade, verificar em Gonzalez e Woods (2001) e Silva et al. (2015). 
h) $v_{k, 8}$ : valores de contraste do número de ocorrências das sequências de dois pixels cujos níveis de cinza estão separados por 1 unidade;

i) $v_{k, 9}$ : valores de contraste do número de ocorrências das sequências de dois pixels cujos níveis de cinza estão separados por 3 unidades;

j) $v_{k, 10}$ : valores de contraste do número de ocorrências das sequências de dois pixels cujos níveis de cinza estão separados por 5 unidades;

k) $v_{k, 11}$ : valores de homogeneidade do número de ocorrências das sequências de dois pixels cujos níveis de cinza estão separados por 1 unidade;

l) $v_{k, 12}$ : valores de homogeneidade do número de ocorrências das sequências de dois pixels cujos níveis de cinza estão separados por 3 unidades;

m) $v_{k, 13}$ : valores de homogeneidade do número de ocorrências das sequências de dois pixels cujos níveis de cinza estão separados por 5 unidades;

De posse dos vetores característicos das imagens $I_{k}$, onde os dados foram dispostos de forma a evidenciar a evolução de cada característica no tempo, Silva et al. (2015) pretendiam aplicar métodos de OMA para extrair dos dados das imagens os parâmetros modais da chama. O primeiro método seria o algoritmo do Decremento Aleatório (RD), que, por hipótese, assume que um sinal de resposta aleatória é composto por uma resposta em degrau devido a condições iniciais, uma resposta ao impulso devido à taxa de variação do sinal e uma resposta aleatória. Uma varredura no sinal de forma a coletar dados por um período fixo de tempo, com condições iniciais iguais, e derivada com sinal alternante, é realizada o maior número de vezes possível para trechos diferentes do sinal. Ao se calcular a média dos dados coletados nesses períodos, a parte aleatória tende a zero, as respostas ao impulso tendem a se cancelar, uma vez que se coletam os dados com derivada alternante, restando apenas a resposta ao degrau, que é a resposta livre do sistema. Em seguida, a partir desta resposta livre, o método no Domínio do Tempo de Ibrahim (ITD) extrairia os parâmetros modais do sistema da chama (frequências naturais, fatores de amortecimento e modos de vibrar). Em termos gerais, o ITD monta duas matrizes de respostas com as medidas dos sinais, uma é deslocada no tempo em relação à outra. Como as duas respostas são do mesmo sistema, a relação entre elas se dá por sua própria dinâmica. Essa relação leva à identificação dos parâmetros modais ${ }^{4}$. No entanto, Silva et al. (2015) se depararam com uma limitação no número de amostras de imagens, que não permitia a convergência num resultado confiável do RD. Para ultrapassar este obstáculo, Silva et al. (2015) concatenaram as 13 sequências temporais das características das imagens numa única longa sequência, processo que foi nomeado de vetorização dos dados. Dessa forma, teriam muito mais dados para aplicar o algoritmo do RD. Por outro lado, perderiam a

4 Como os métodos do RD e ITD fazem parte da metodologia apresentada nesta tese, seu detalhamento matemático será deixado para o capítulo 5 (página 94), o que não interfere na descrição do trabalho de Silva et al. (2015). 
noção de que grandeza exatamente se tratava aquela sequência de dados. A vetorização, de acordo com Silva et al. (2015), podia ser aplicada pelas seguintes razões:

a) foi assumida a hipótese de estacionariedade para que o RD pudesse ser aplicado, o que implica que os dados representam um processo estocástico estacionário;

b) as componentes de cada vetor característico $\boldsymbol{v}_{\boldsymbol{k}}$ são obtidas da mesma imagem $I_{k}$ através de algoritmos estritamente determinísticos;

c) as imagens $I_{k}$ contêm informação de todo o processo num determinado instante. Logo, já que o processo é assumido estacionário, ele mantém os dois primeiros momentos estatísticos. Mais ainda, como as componentes dos vetores vêm de cálculos determinísticos, se todos eles forem normalizados, a variância e média se manterão uma vez que vieram dos mesmos dados, e, portanto, o processo de vetorização não alterará os dois primeiros momentos.

Após o processo de vetorização, aplicaram-se os métodos combinados do RD e ITDM para obter os parâmetros modais do comportamento das imagens para a condição $r_{P S}=4,00$, que são exibidos na tabela 3. Para fins de comparação, obteve-se também a FFT dos sinais vetorizados.

Tabela 3 - Parâmetros modais encontrados com RD/ITD e comparação com análise espectral para o caso $r_{P S}=4,00$.

\begin{tabular}{lcccc}
\hline $\begin{array}{l}\text { Modos } \\
\text { de } \\
\text { vibrar }\end{array}$ & $\begin{array}{c}\text { Frequência natural } \\
\text { amortecida obtida } \\
\text { por RD/ITD [Hz] }\end{array}$ & $\begin{array}{c}\text { Fator de } \\
\text { amortecimento } \\
\text { obtido por RD/ITD }\end{array}$ & $\begin{array}{c}\text { Frequência natural } \\
\text { amortecida obtida } \\
\text { por FFT [Hz] }\end{array}$ & $\begin{array}{c}\text { Diferença } \\
\text { percentual nas } \\
\text { frequências [\%] }\end{array}$ \\
\hline 1 & 1,88 & 0,072 & 1,88 & 0,0 \\
2 & 2,41 & 0,740 & 2,88 & 19,5 \\
3 & 3,60 & 0,791 & 3,40 & $-5,5$ \\
4 & 5,03 & 0,005 & 5,07 & $-0,8$ \\
\hline
\end{tabular}

Fonte - Adaptado de Silva et al. (2015).

Silva et al. (2015) não mostraram como ficaram os parâmetros modais estimados para $r_{P S}=1,00$ e $r_{P S}=1,86$, mas alegaram utilizar essas informações para viabilizar a validação da metodologia. Eles definiram um critério de garantia modal (MAC) próprio e demonstraram com esse critério que existem diferenças entre as características modais das três condições. Logo, os modelos identificados para as diferentes condições apresentam características distintas, provando que essa metodologia de identificação de modelos de chama é viável. Por outro lado, essa metodologia proposta apresenta pelo menos duas desvantagens: 
a) a perda da noção de qual grandeza física está sendo representada pelo modelo, apesar de ser uma grandeza estatisticamente comparável às características retiradas da imagem;

b) a falta de ligação do modelo proposto com grandezas físicas, principalmente no que diz respeito às entradas do modelo.

Em resumo, a principal contribuição do trabalho de Silva et al. (2015) foi apresentar com sucesso uma metodologia inovadora para a identificação de um sistema para a chama que seria capaz de inferir sobre a extinção da chama.

\subsection{Controle modal da chama com modelo identificado}

Fleury et al. (2015) aproveitaram os parâmetros modais identificados em Silva et al. (2015) para $r_{P S}=4,00$ e vislubraram, com grande participação deste autor, uma estratégia de controle modal que evitasse que a chama fosse extinta. Acrescentam-se, na tabela 4, os valores das frequências naturais em rad/s ao que já havia sido exibido na tabela 3. Uma vez que houve a identificação de quatro modos de vibrar, e que cada modo

Tabela 4 - Parâmetros modais utilizados para aplicar a estratégia controle.

\begin{tabular}{lccc}
\hline $\begin{array}{l}\text { Modos } \\
\text { de vibrar }\end{array}$ & $\begin{array}{c}\text { Frequência natural } \\
\text { amortecida } f_{d, i}^{c o}(\mathrm{~Hz})\end{array}$ & $\begin{array}{c}\text { Frequência natural } \\
\omega_{n, i}^{c o}(\mathrm{rad} / \mathrm{s})\end{array}$ & $\begin{array}{c}\text { Fator de } \\
\text { amortecimento } \zeta_{i}^{c o}\end{array}$ \\
\hline 1 & 1,88 & 11,84 & 0,072 \\
2 & 2,41 & 22,51 & 0,740 \\
3 & 3,60 & 36,97 & 0,791 \\
4 & 5,03 & 31,60 & 0,005 \\
\hline
\end{tabular}

Fonte - Adaptado de Fleury et al. (2015).

pode ser modelado como um grau de liberdade de um sistema de $2^{\text {a }}$ ordem, considera-se que os modos são desacoplados entre si e que o sistema pode ser escrito como:

$$
\begin{aligned}
& \dot{\boldsymbol{x}}(t)=\boldsymbol{A x}(t)+\boldsymbol{B} \boldsymbol{u}(t) \\
& \boldsymbol{y}(t)=\boldsymbol{C} \boldsymbol{x}(t)
\end{aligned}
$$

onde o sistema de equações das variações de estado de (2.16) é formado por 8 equações dife-

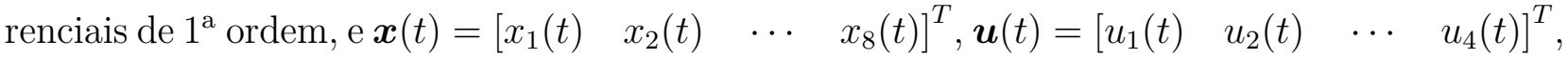




$$
\boldsymbol{y}=\left[\begin{array}{llll}
y_{1}(t) & y_{2}(t) & \cdots & y_{8}(t)
\end{array}\right]^{T} \mathrm{e}
$$

$$
\begin{aligned}
\boldsymbol{A} & =\operatorname{diag}\left(\boldsymbol{A}_{\mathbf{1}}, \boldsymbol{A}_{2}, \boldsymbol{A}_{3}, \boldsymbol{A}_{4}\right) \\
\boldsymbol{A}_{\boldsymbol{i}} & =\left[\begin{array}{cc}
0 & 1 \\
-\left(\omega_{n, i}^{c o}\right)^{2} & -2 \zeta_{i}^{c o} \omega_{n, i}^{c o}
\end{array}\right] \\
\boldsymbol{B} & =\operatorname{diag}\left(\boldsymbol{B}_{1}, \boldsymbol{B}_{2}, \boldsymbol{B}_{3}, \boldsymbol{B}_{4}\right) \\
\boldsymbol{B}_{\boldsymbol{i}} & =\left[\begin{array}{c}
0 \\
\left(\omega_{n, i}^{c o}\right)^{2}
\end{array}\right]
\end{aligned}
$$

com $i=1,2, \ldots, 4$.

Sem perda de generalidade, a saída $\boldsymbol{y}(t)$ foi escolhida de forma a ser igual ao vetor de estados $\boldsymbol{x}(t)$. Para outros casos, pode-se projetar um observador para obter o vetor de estados de forma completa. Assim, considera-se que $\boldsymbol{C}=\boldsymbol{I}_{8}$. O sistema (2.16) descreve a dinâmica da chama, de acordo com os modos obtidos a partir das imagens da câmera CCD para $r_{P S}=4,00$.

Cada subsistema é um sistema de $2^{\text {a }}$ ordem subamortecido clássico, cujas respostas decaem a zero na ausência de um sinal de entrada permanente. Recorrendo-se ao sistema da chama, a ausência de oscilações significa que a chama foi extinta. Então, uma maneira para manter a chama ativa é excitando-a com uma entrada apropriada de forma que todos os quatro modos nunca se estabilizem assintoticamente a uma posição. A estratégia é, dessa forma, manter o sistema em um movimento oscilatório, garantindo as características da chama para o tempo requerido. Esse comportamento pode ser obtido se uma referência apropriada for definida e um simples regulador linear quadrático (LQ) for sintetizado para seguir esta referência.

\subsubsection{Definição da referência para os modos da chama}

A referência será definida de acordo com o comportamento desejado para o sistema (2.16). Ao se analisar esse sistema, basta apenas uma pequena modificação nos fatores de amortecimento para propiciar uma característica oscilatória, fazê-los iguais a zero $\left(\zeta_{i}^{c o}=0\right)$. Isso faria com que os subsistemas se comportassem como sistemas de segunda ordem não amortecidos. Assim, considera-se o seguinte sistema de referência:

$$
\begin{aligned}
& \dot{\boldsymbol{x}}_{\boldsymbol{r}}(t)=\boldsymbol{A}_{\boldsymbol{r}} \boldsymbol{x}_{\boldsymbol{r}}(t)+\boldsymbol{B}_{\boldsymbol{r}} \boldsymbol{u}_{\boldsymbol{r}}(t) \\
& \boldsymbol{y}_{\boldsymbol{r}}(t)=\boldsymbol{C}_{\boldsymbol{r}} \boldsymbol{x}_{\boldsymbol{r}}(t)
\end{aligned}
$$

onde $\boldsymbol{x}_{\boldsymbol{r}}(t)=\left[\begin{array}{llll}x_{r, 1}(t) & x_{r, 2}(t) & \cdots & x_{r, 8}(t)\end{array}\right]^{T}, \boldsymbol{u}_{\boldsymbol{r}}(t)=\left[\begin{array}{llll}u_{r, 1}(t) & u_{r, 2}(t) & \cdots & u_{r, 4}(t)\end{array}\right]^{T}$, $\boldsymbol{B}_{r}=\boldsymbol{B}, \boldsymbol{C}_{r}=\boldsymbol{C}=\boldsymbol{I}_{8} \mathrm{e}$

$$
\begin{aligned}
\boldsymbol{A}_{r} & =\operatorname{diag}\left(\boldsymbol{A}_{r, 1}, \boldsymbol{A}_{r, 2}, \boldsymbol{A}_{r, 3}, \boldsymbol{A}_{r, 4}\right) \\
\boldsymbol{A}_{r, i} & =\left[\begin{array}{cc}
0 & 1 \\
-\left(\omega_{n, i}^{c o}\right)^{2} & 0
\end{array}\right]
\end{aligned}
$$


com $i=1,2, \ldots, 4$.

Para a completa definição da trajetória de referência, é necessário estipular uma condição inicial para o sistema de referência, $\boldsymbol{x}_{\boldsymbol{r} \mathbf{0}}=\left[\begin{array}{llllllll}1,5 & 0,0 & 1,5 & 0,0 & 1,5 & 0,0 & 1,5 & 0,0\end{array}\right]^{T}$, e definir as entradas, para todo o tempo $t \geq 0, \boldsymbol{u}_{r}=\left[\begin{array}{llll}0 & 0 & 0 & 0\end{array}\right]^{T}$. Essas condições podem ser interpretadas de forma análoga a um sistema mecânico massa-mola, com uma posição inicial em 1,5 m, com velocidade inicial da massa igual zero para cada subsistema de (2.18). Além disso, a posição de equilíbrio desses subsistemas massa-mola é também escolhida de forma arbitrária a uma posição 1,0 m. Conforme esperado, as respostas do sistema de referência são compostas por um conjunto de movimentos oscilatórios mostrados nas Figuras 11 e 12.

Figura 11 - Resposta das variáveis de "posição" de $\boldsymbol{x}_{\boldsymbol{r}}(t)$ às condições iniciais estipuladas

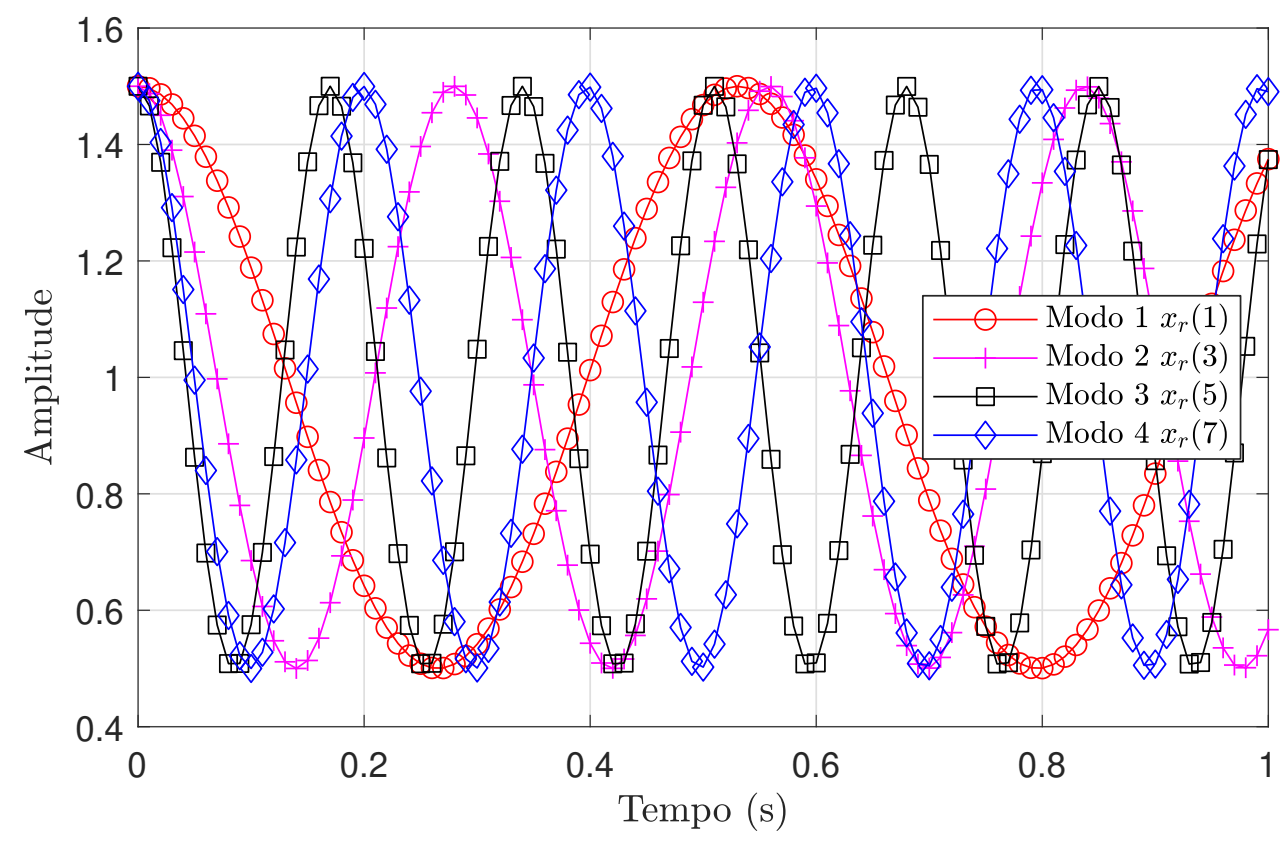

Fonte - Adaptado de Fleury et al. (2015).

\subsubsection{Regulador Linear Quadrático (LQR)}

Um regulador é um controlador que leva o estado para zero. Para sintetizar um controlador que siga uma referência, basta definir o erro de estado como sendo a diferença entre o estado real e o estado desejado, e projetar um regulador para esse erro. Assim, define-se o vetor de erros $\boldsymbol{e}(t)$ como sendo o erro do sistema:

$$
\boldsymbol{e}(t)=\boldsymbol{x}(t)-\boldsymbol{x}_{\boldsymbol{r}}(t)
$$


Figura 12 - Resposta das variáveis de "velocidade" de $\boldsymbol{x}_{\boldsymbol{r}}(t)$ às condições iniciais estipuladas

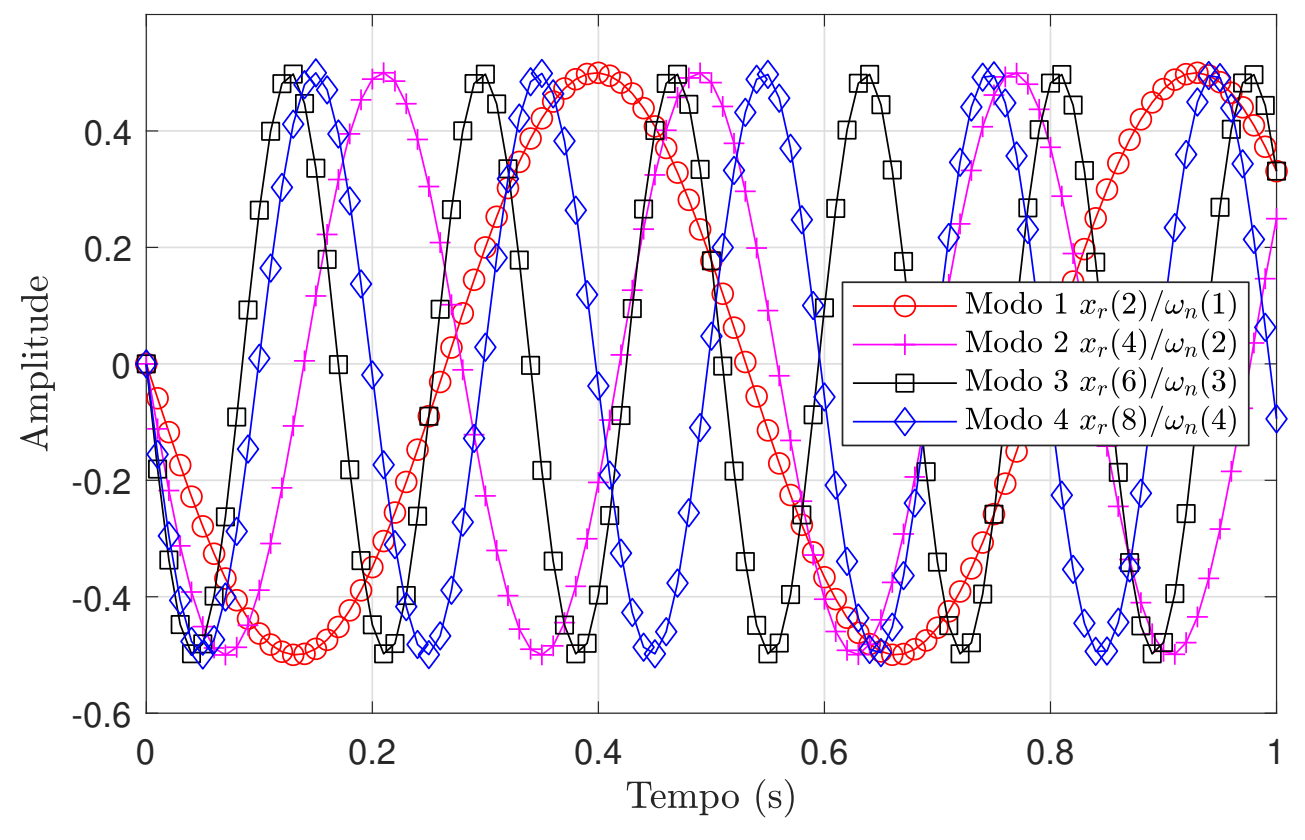

Fonte - Adaptado de Fleury et al. (2015).

Então,

$$
\begin{aligned}
\dot{\boldsymbol{e}}(t) & =\dot{\boldsymbol{x}}(t)-\dot{\boldsymbol{x}}_{\boldsymbol{r}}(t)=\boldsymbol{A} \boldsymbol{x}(t)+\boldsymbol{B} \boldsymbol{u}(t)-\boldsymbol{A}_{r} \boldsymbol{x}_{\boldsymbol{r}}(t)-\boldsymbol{B}_{r} \boldsymbol{u}_{r}(t) \\
\dot{\boldsymbol{e}}(t) & =\boldsymbol{A}\left(\boldsymbol{e}(t)+\boldsymbol{x}_{\boldsymbol{r}}(t)\right)+\boldsymbol{B} \boldsymbol{u}(t)-\boldsymbol{A}_{r} \boldsymbol{x}_{\boldsymbol{r}}(t)-\boldsymbol{B}_{r} \boldsymbol{u}_{\boldsymbol{r}}(t) \\
\dot{\boldsymbol{e}}(t) & =\boldsymbol{A} \boldsymbol{e}(t)+\left(\boldsymbol{A}-\boldsymbol{A}_{\boldsymbol{r}}\right) \boldsymbol{x}_{\boldsymbol{r}}(t)+\boldsymbol{B} \boldsymbol{u}(t)-\boldsymbol{B}_{r} \boldsymbol{u}_{\boldsymbol{r}}(t)
\end{aligned}
$$

Agora, define-se o vetor de variáveis de estado aumentado $\overline{\boldsymbol{x}}(t)=\left[\begin{array}{ll}\boldsymbol{e}(t) & \boldsymbol{x}_{\boldsymbol{r}}(t)\end{array}\right]^{T}$ e o vetor de entradas aumentado $\overline{\boldsymbol{u}}(t)=\left[\begin{array}{ll}\boldsymbol{u}(t) & \boldsymbol{u}_{\boldsymbol{r}}(t)\end{array}\right]^{T}$ que devem satisfazer o sistema dinâmico seguinte:

$$
\begin{aligned}
\dot{\overline{\boldsymbol{x}}}(t) & =\overline{\boldsymbol{A}} \overline{\boldsymbol{x}}(t)+\overline{\boldsymbol{B}} \overline{\boldsymbol{u}}(t) \\
\overline{\boldsymbol{y}}(t) & =\overline{\boldsymbol{C}} \overline{\boldsymbol{x}}(t)
\end{aligned}
$$

onde

$$
\begin{aligned}
\bar{A} & =\left[\begin{array}{cc}
A & A-A_{r} \\
\boldsymbol{O}_{8 \times 8} & A_{r}
\end{array}\right] \\
\bar{B} & =\left[\begin{array}{cc}
B & -B_{r} \\
\boldsymbol{O}_{8 \times 4} & \boldsymbol{B}_{r}
\end{array}\right] \\
\bar{C} & =\left[\begin{array}{ll}
C & C_{r}
\end{array}\right]
\end{aligned}
$$

Se o erro $\boldsymbol{e}(t)$ for a zero significa que o sistema (2.16) está seguindo o sistema (2.18). A fim de se fechar a retroação do sistema e perseguir um erro que tende a zero, uma entrada 
linear $\overline{\boldsymbol{u}}(t)$ é definida para o sistema (2.22) como sendo:

$$
\begin{aligned}
\overline{\boldsymbol{u}}(t) & =-\boldsymbol{K}_{l q} \overline{\boldsymbol{x}}(t) \\
{\left[\begin{array}{c}
\boldsymbol{u}(t) \\
\boldsymbol{u}_{\boldsymbol{r}}(t)
\end{array}\right] } & =\left[\begin{array}{cc}
-\boldsymbol{k}_{e} & -\boldsymbol{k}_{\boldsymbol{r}} \\
-\boldsymbol{k}_{e, r} & -\boldsymbol{k}_{\boldsymbol{r}, \boldsymbol{r}}
\end{array}\right]\left[\begin{array}{c}
\boldsymbol{e}(t) \\
\boldsymbol{x}_{\boldsymbol{r}}(t)
\end{array}\right]
\end{aligned}
$$

A matriz de ganho $\boldsymbol{K}_{l q}$ é determinada através do método para regulador LQ. Esse método minimiza o índice de performance $J_{l q}$ :

$$
\begin{aligned}
& J_{l q}=\int_{0}^{\infty}\left(\overline{\boldsymbol{x}}(t)^{T} \boldsymbol{Q}_{l q} \overline{\boldsymbol{x}}(t)+\overline{\boldsymbol{u}}(t)^{T} \boldsymbol{R}_{l q} \overline{\boldsymbol{u}}(t)\right) d t \\
& J_{l q}=\int_{0}^{\infty} \overline{\boldsymbol{x}}(t)^{T}\left(\boldsymbol{Q}_{l q}+\boldsymbol{K}_{l q}^{T} \boldsymbol{R}_{l q} \boldsymbol{K}_{l q}\right) \overline{\boldsymbol{x}}(t) d t
\end{aligned}
$$

onde $\boldsymbol{Q}_{l q}$ é uma matriz positiva semidefinida e $\boldsymbol{R}_{l q}$ é uma matriz positiva definida e são definidas conforme segue:

$$
\begin{aligned}
\boldsymbol{Q}_{l q} & =\left[\begin{array}{cc}
\boldsymbol{Q}_{l q}^{\prime} & 0_{8 \times 8} \\
0_{8 \times 8} & 0_{8 \times 8}
\end{array}\right] \\
\boldsymbol{Q}_{l q}^{\prime} & =\operatorname{diag}\left(1,30,1,10^{4}, 1,2 \times 10^{4}, 1,10\right) \\
\boldsymbol{R}_{l q} & =\boldsymbol{I}_{\boldsymbol{8}}
\end{aligned}
$$

A matriz de ganhos $\boldsymbol{K}_{\boldsymbol{l} \boldsymbol{q}}$ pode ser encontrada através da equação (2.27) com a solução $\boldsymbol{P}_{\boldsymbol{l q}}$ da equação algébrica de Ricatti:

$$
\boldsymbol{K}_{l q}=\boldsymbol{R}_{l q}{ }^{-1} \overline{\boldsymbol{B}}^{T} \boldsymbol{P}_{l q}
$$

onde a equação algébrica de Ricatti pode ser expressa por (2.28)

$$
\overline{\boldsymbol{A}}^{T} \boldsymbol{P}_{l q}+\boldsymbol{P}_{l q} \overline{\boldsymbol{A}}-\boldsymbol{P}_{l q} \overline{\boldsymbol{B}} \boldsymbol{R}_{l q}^{-1} \overline{\boldsymbol{B}}^{T} \boldsymbol{P}_{l q}+\boldsymbol{Q}_{l q}=\boldsymbol{O}
$$

e $\boldsymbol{P}_{l q}$ é uma matriz simétrica $8 \times 8$.

\subsubsection{Resultados da simulação do LQR}

A simulação foi realizada considerando que a chama estava acesa em uma posição arbitrária e o controle é repentinamente ligado para mantê-la. O vetor de condições iniciais foi arbitrariamente escolhido a partir de realizações aleatórias de distribuições gaussianas com média $\mu=1$ e $\mu=0$ respectivamente para "posição" e "velocidade", e variância $\sigma^{2}=1$ para todas as variáveis de estado.

Como pode ser observado nas Figuras 13 a 16, a ação do regulador foi capaz de fazer com que a dinâmica do sistema seguisse a referência desejada dentro de alguns segundos.

Portanto, Fleury et al. (2015) mostram que é possível manter a oscilação da chama atuando em características de imagens. A questão que se coloca é como chegar num 
Figura 13 - Resposta ao controle de rastreamento de trajetória para o Modo 1

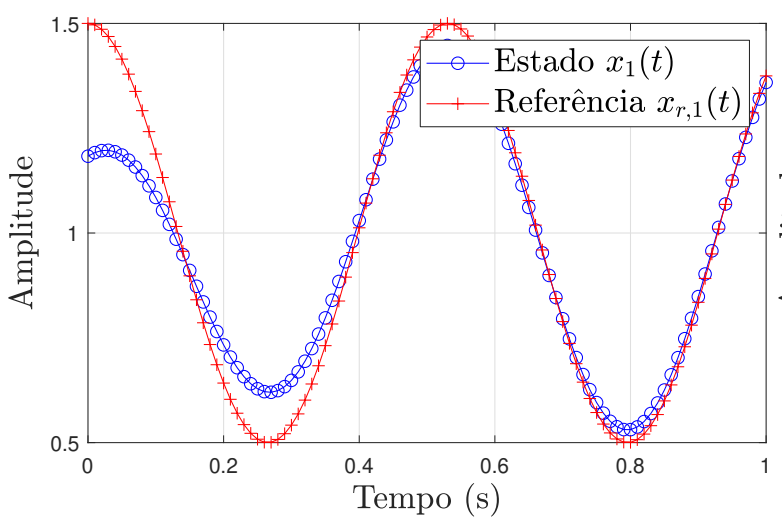

(a) Variável de "posição" do modo 1

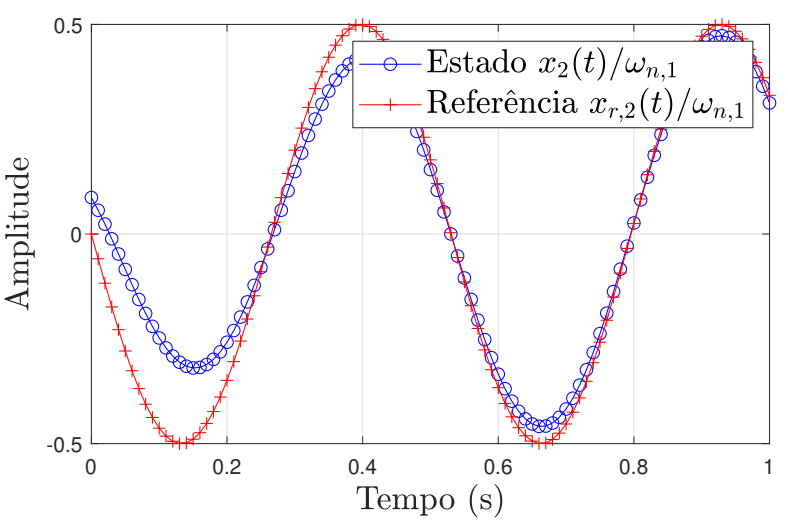

(b) Variável de "velocidade" do modo 1

Fonte - Adaptado de Fleury et al. (2015).

Figura 14 - Resposta ao controle de rastreamento de trajetória para o Modo 2

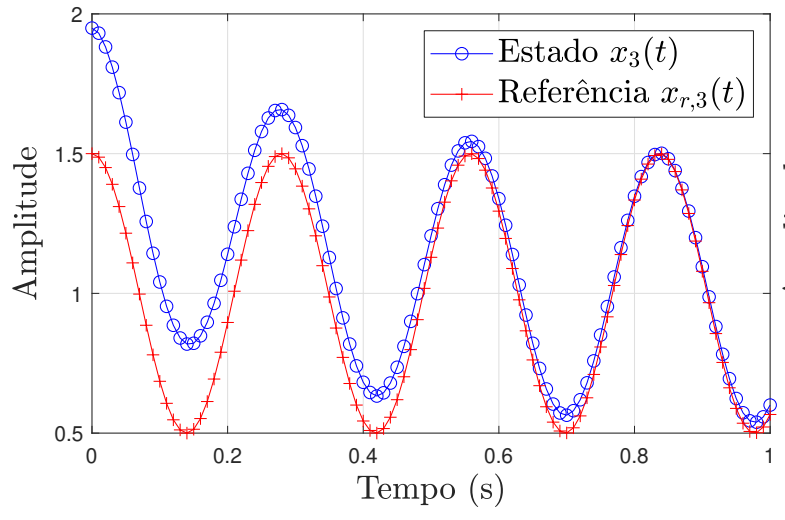

(a) Variável de "posição" do modo 2

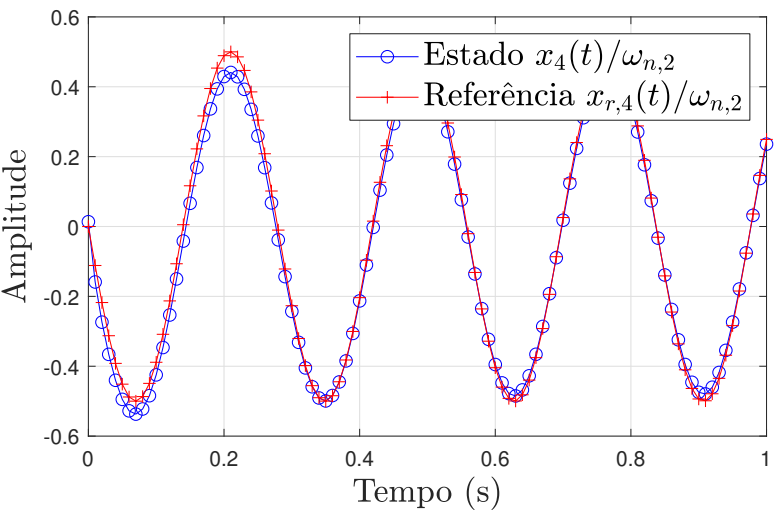

(b) Variável de "velocidade" do modo 2

Fonte - Adaptado de Fleury et al. (2015).

ponto onde será possível obter esta resposta sobre imagens e transformá-la em uma ação física nos atuadores do sistema? Pois, uma vez que os modos do sistema são retirados de características das imagens de chama, não há uma relação direta entre as respostas apresentadas aqui e as entradas dos atuadores do sistema. É necessário relacionar, de forma mais direta, as imagens com variáveis que atuem fisicamente na chama, de forma que uma ação de controle em termos de características da imagem seja facilmente transformada num sinal para atuadores da chama.

O método apresentado por Silva et al. (2015) para estimar a matriz do sistema certamente possui incertezas que podem prejudicar o desempenho desse tipo de controlador. Para lidar com tais incertezas, a inclusão de partes adaptativas no controlador pode ser um caminho viável. 
Figura 15 - Resposta ao controle de rastreamento de trajetória para o Modo 3

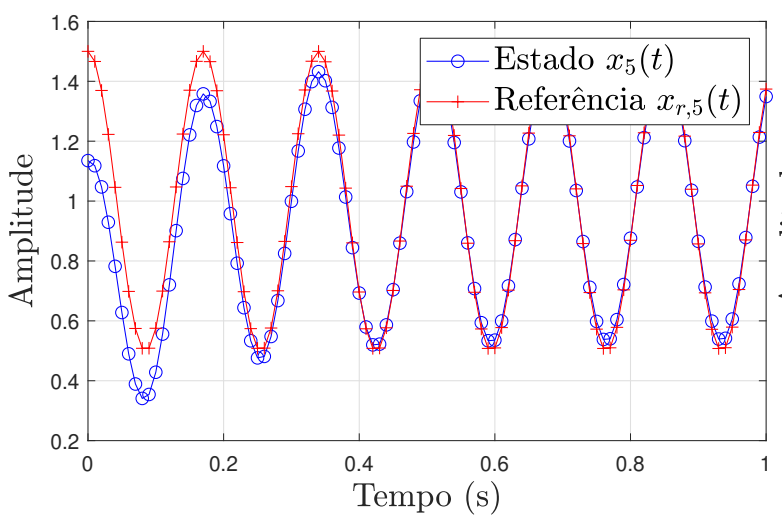

(a) Variável de "posição" do modo 3

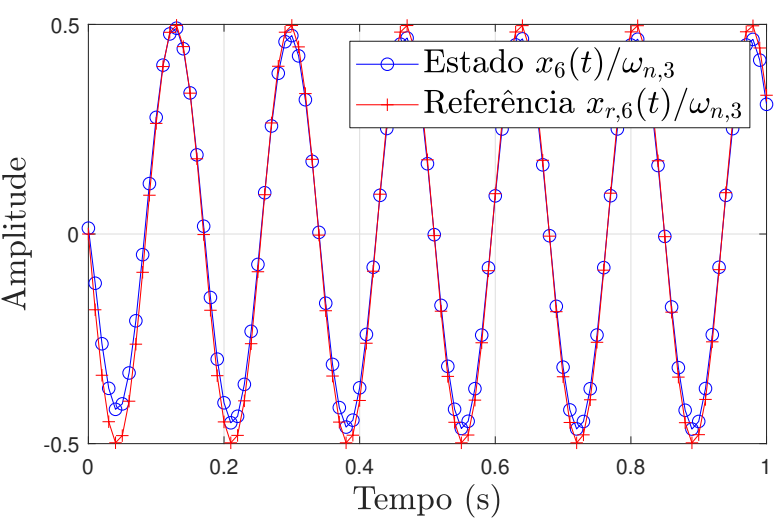

(b) Variável de "velocidade" do modo 3

Fonte - Adaptado de Fleury et al. (2015).

Figura 16 - Resposta ao controle de rastreamento de trajetória para o Modo 4

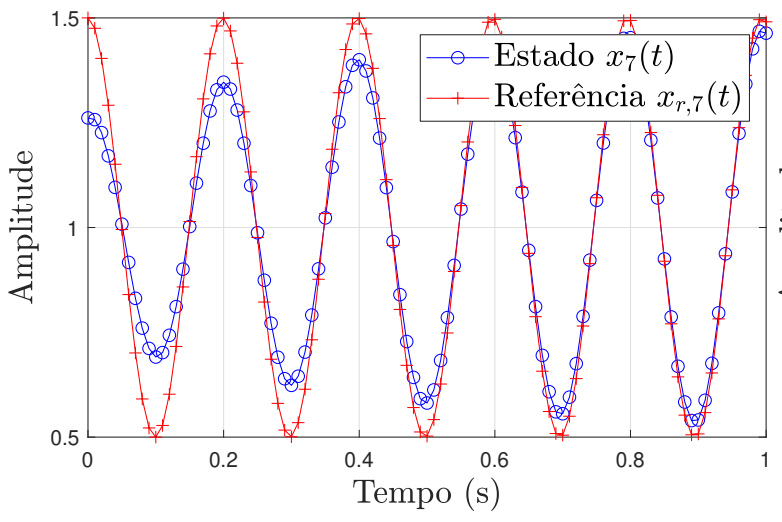

(a) Variável de "posição" do modo 4

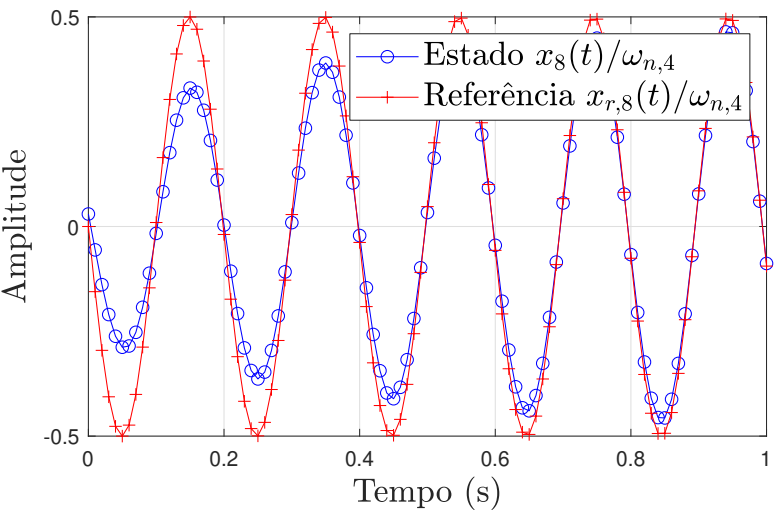

(b) Variável de "velocidade" do modo 4

Fonte - Adaptado de Fleury et al. (2015).

\subsection{Modelos de inferência do estado da chama}

Fleury et al. (2017) propuseram um modelo de inferência para correlacionar 33 características de imagem de chama com estados físicos da combustão em uma fornalha a óleo, a mesma da seção 2.2 (página 42), a fim de montar um sistema supervisório para o monitoramento da estabilidade da chama classificando-a em 9 categorias. Esse mecanismo de inferência, baseado nos conceitos de crença e plausibilidade do método de inferência de Dempster-Shafer (ZADEH, 1986), foi capaz de reconhecer a maioria das mudanças bruscas no processo de combustão, resultantes da modificação de parâmetros físicos.

Já o trabalho de Silva Neto et al. (2019), com a contribuição deste autor, faz desenvolvimentos adicionais nos resultados de Fleury et al. (2017): em vez de usar o método de Dempster-Shafer, utilizou-se o método de inferência de Mamdani baseado em onze características da imagem da chama para, além de classificar a combustão em cinco 
categorias de estado da chama, inferir valores de duas variáveis físicas, a saber, razão de vazão de vapor por vazão de combustível (RVC) e razão vazão de ar primário por vazão de ar secundário (RPS). 


\section{METODOLOGIA}

Este capítulo tem por objetivo descrever a metodologia adotada neste trabalho tendo em vista os objetivos descritos no capítulo 1 (página 32), e apresenta uma visão geral da metodologia proposta, bem como descreve os equipamentos envolvidos nos experimentos. Capítulos posteriores apresentarão os detalhamentos de tópicos específicos da metodologia que é mencionada aqui. A seção 3.1 descreve o aparato experimental utilizado para a aquisição das imagens de chama, essenciais para o desenvolvimento deste trabalho. A forma como os experimentos para a aquisição das imagens foram realizados é descrita na seção 3.2. Por fim, a seção 3.3 dá um panorama geral da metodologia deste projeto.

\subsection{Equipamento experimental}

Os experimentos foram realizados em um forno a gás experimental de escala industrial que está localizado no Instituto de Pesquisas Tecnológicas do Estado de São Paulo (IPT). O forno possui um corpo cilíndrico de $6 \mathrm{~m}$ de comprimento e $2 \mathrm{~m}$ de diâmetro conforme ilustrado na figura 17. O queimador está localizado no centro de uma das faces

Figura 17 - Forno a gás experimental

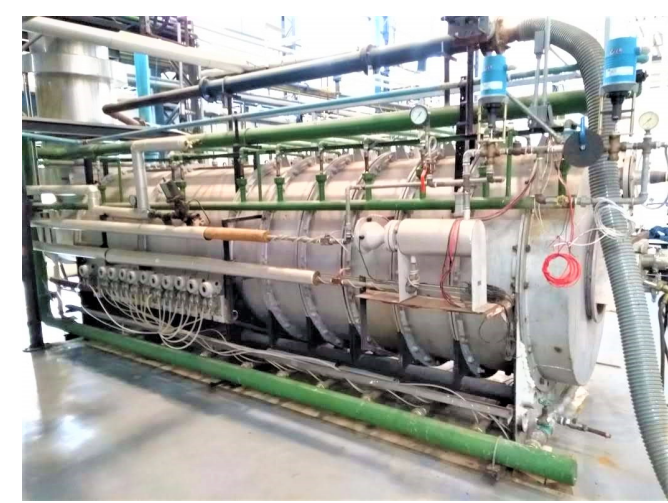

(a) visão da lateral esquerda do forno

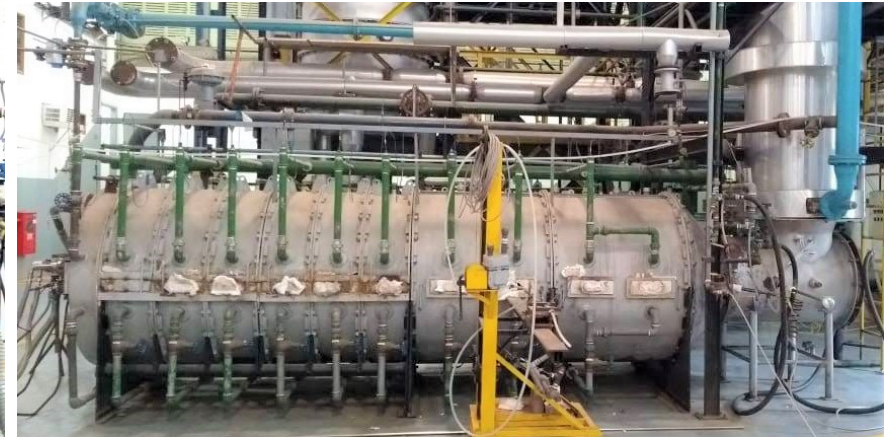

(b) visão da lateral direita do forno

Fonte - Elaborado pelo autor.

circulares, conforme figura 18(a). Na outra extremidade, gases de exaustão são expelidos para o ambiente externo num duto na parte de cima. Há uma pequena vigia no centro da face circular oposta ao queimador, onde a câmera é posicionada para captar as imagens das chamas emitidas pelo processo de combustão, mostrada na figura 18(b).

O combustível utilizado no experimento é gás natural, cuja composição está descrita na tabela 5. As porcentagens mássica e molar das substâncias químicas estão em base úmida (BU). E o gás oxigênio puro foi utilizado como comburente. 
Figura 18 - Extremidades do forno a gás

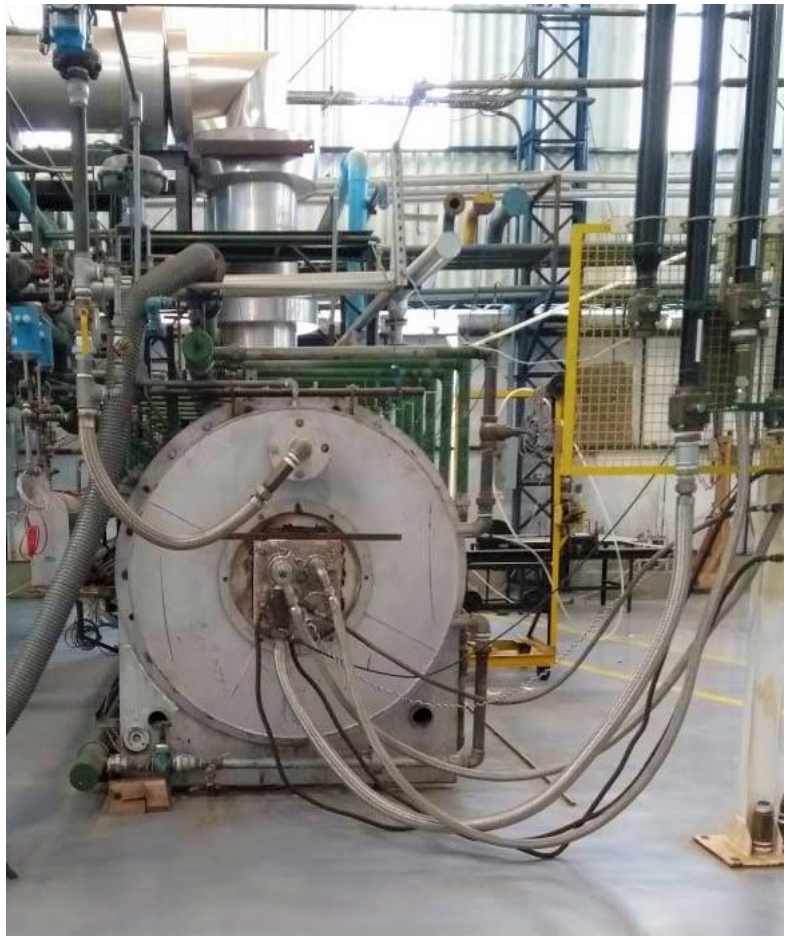

(a) extremidade do queimador

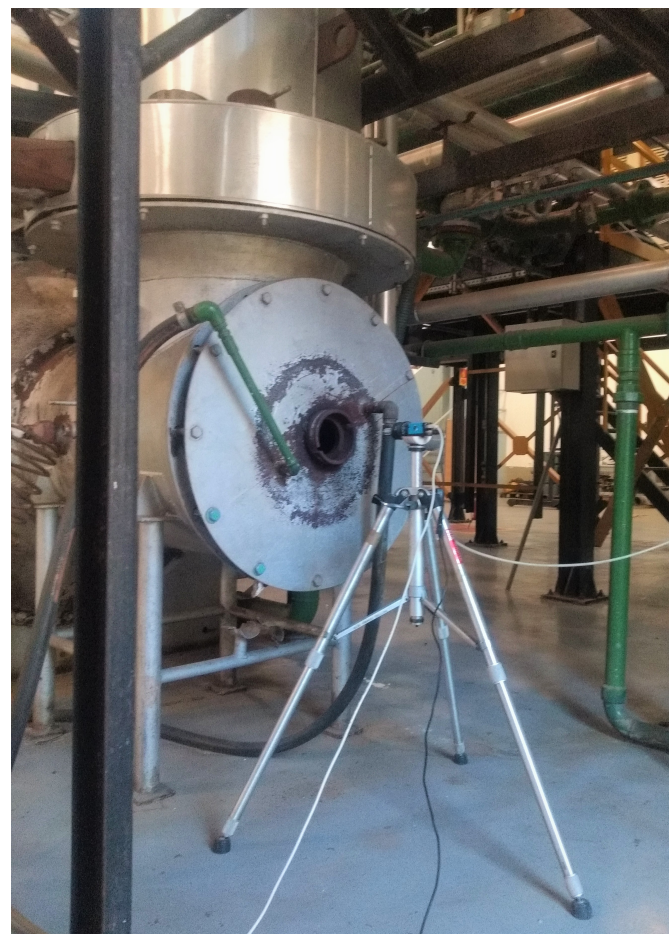

(b) extremidade da vigia com a câmera

Fonte - Elaborado pelo autor.

Tabela 5 - Composição química do combustível.

\begin{tabular}{llcc}
\hline Nome & Fórmula & $\%$ molar $(\mathrm{BU})$ & $\%$ mássica $(\mathrm{BU})$ \\
\hline Etano & $\mathrm{C}_{2} H_{6}$ & 8,03 & 13,63 \\
Gás Carbônico & $\mathrm{CO}_{2}$ & 0,48 & 1,19 \\
Metano & $\mathrm{CH}_{4}$ & 89,35 & 80,94 \\
n-Butano & $\mathrm{C}_{4} H_{10}$ & 0,07 & 0,23 \\
n-Pentano & $C_{5} H_{12}$ & 0,01 & 0,04 \\
Nitrogênio & $N_{2}$ & 1,28 & 2,02 \\
Propano & $C_{3} H_{8}$ & 0,78 & 1,94 \\
\hline
\end{tabular}

Fonte - Elaborado pelo autor. 
Um painel eletrônico de comando controla as vazões de gás natural e do comburente que pode ser ar comprimido ou oxigênio puro (figura 19). Além disso, a figura 20 ilustra

Figura 19 - Painel eletrônico de comando do forno a gás

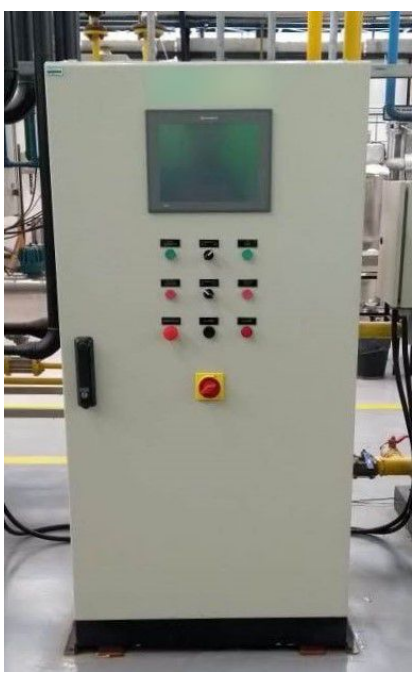

(a) painel de comando

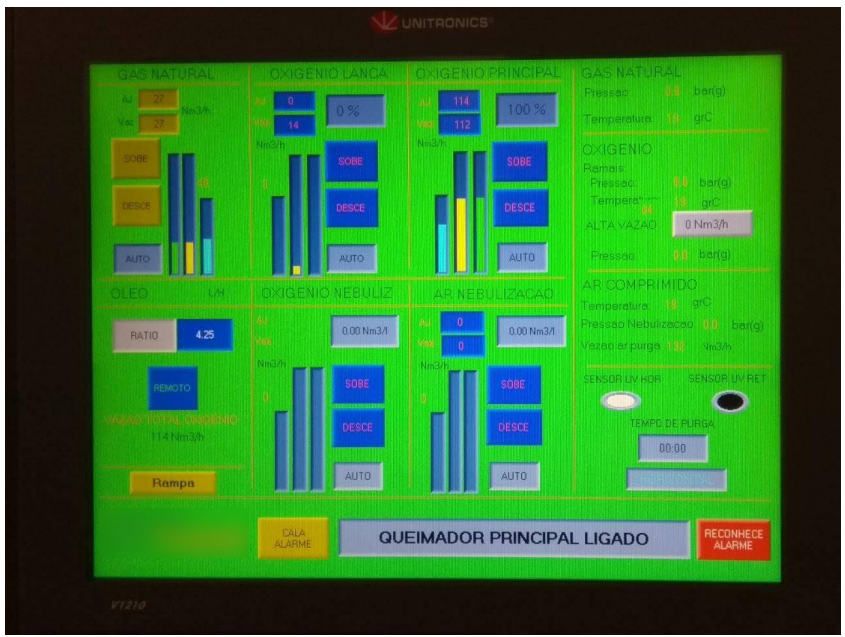

(b) tela do painel de comando

Fonte - Elaborado pelo autor.

que o forno é subdividido em 10 blocos refrigerados de forma independente com água, cujas medidas de temperatura e vazão na saída de cada bloco são adquiridas. Um analisador de gases Horiba PG-350E foi usado para medir as concentrações dos gases de exaustão na taxa de $1 \mathrm{~Hz}$, compreendendo os seguintes gases: $\mathrm{O}_{2}, \mathrm{CO}, \mathrm{CO}_{2}, \mathrm{SO}_{2}$ and $\mathrm{NO}_{x}$. Ademais, são tomadas as medidas de temperatura de água para refrigeração na entrada do forno antes do fluxo de água ser dividido para cada bloco e também a temperatura dos gases de escape.

Figura 20 - Detalhamento dos blocos refrigerados
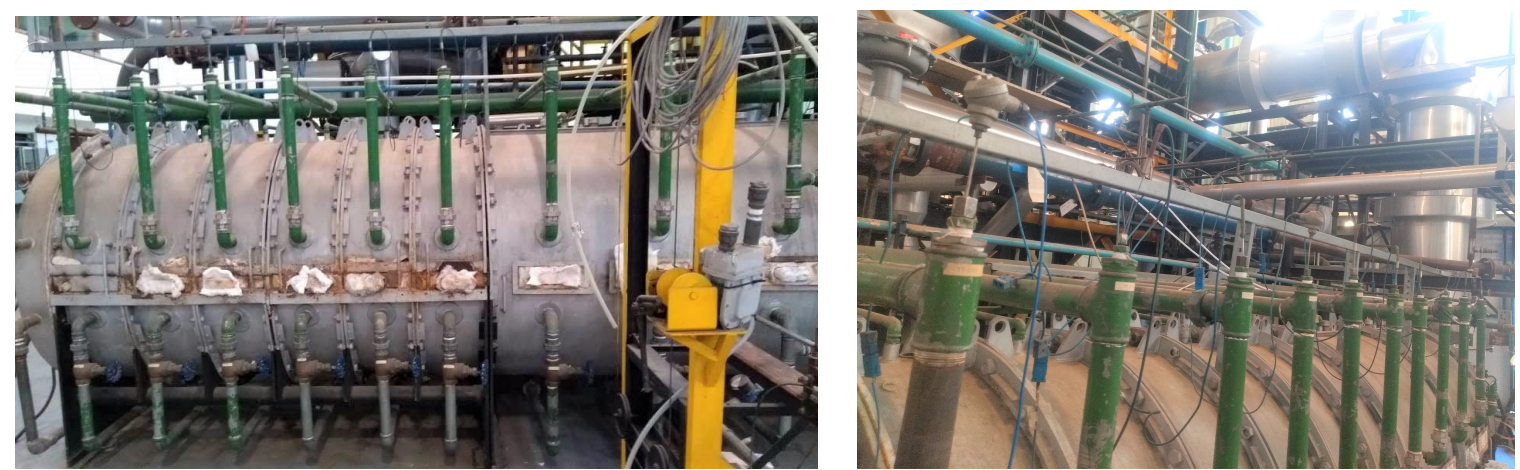

(a) detalhe das divisões dos blocos e alimentação (b) detalhe da tomada de temperatura de da água de refrigeração saída da água de refrigeração

Fonte - Elaborado pelo autor. 
As chamas foram capturadas por uma câmera CCD monocromática, modelo DMK 23G618 da Imaging Source, equipada com lentes objetivas (12 mm, f1.2), mostradas na figura 21. O sinal de saída de vídeo foi amostrado a uma taxa de $30 \mathrm{~Hz}$ (podendo chegar a uma taxa máxima de $120 \mathrm{~Hz}$ ) de quadros progressivos no formato $640 \times 480$ e com resolução de 0.3 megapixel.

Figura 21 - Câmera CCD utilizada nos experimentos

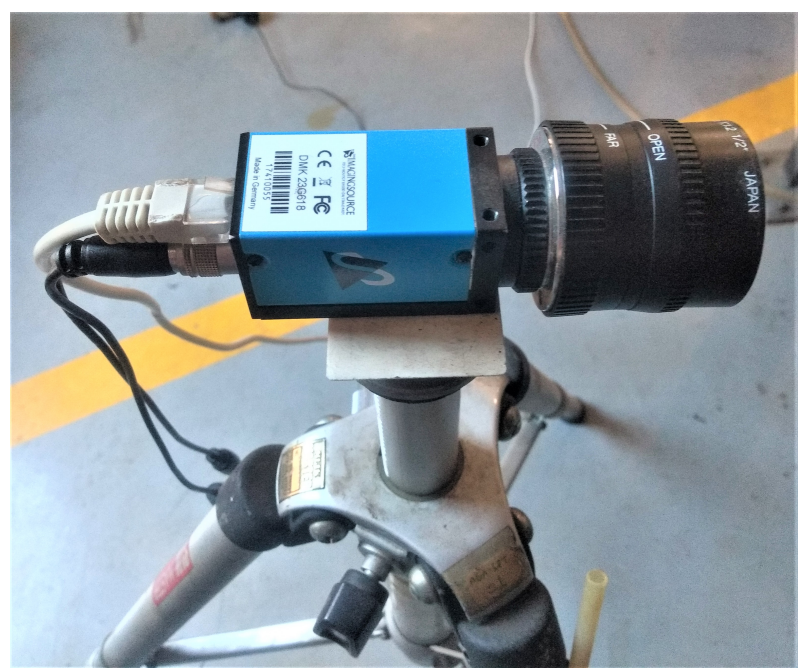

Fonte - Elaborado pelo autor.

\subsection{Procedimento de aquisição das imagens}

A estratégia de aquisição foi cobrir uma quantidade suficiente de condições de combustão diferentes para que os modelos identificados representassem uma ampla faixa de operação do forno. Nos testes experimentais, cada condição de combustão diferente era caracterizada por um valor de razão de equivalência distinto.

A razão de equivalência é uma medida normalizada da relação entre quantidade de combustível e quantidade de comburente na reação de combustão. Uma vez que cada combustível possui uma relação estequiométrica diferente com o gás oxigênio, a razão de equivalência normaliza essa medida para indicar se há falta ou excesso de combustível na reação de combustão, considerando sua própria relação estequiométrica. Dessa forma, a razão de equivalência $\varphi$ pode ser definida como:

$$
\varphi=\frac{r_{A C}^{r e a l}}{r_{A C}^{e s t e q}}
$$

onde $r_{A C}^{r e a l}$ é a razão ar-combustível real e $r_{A C}^{e s t e q}$ é a razão ar-combustível estequiométrica. Nota-se que em uma reação de combustão com relação estequiométrica, a razão de equivalência é igual a unidade. Quando houver excesso de ar (ou falta de combustível) a 
razão de equivalência será menor que 1 e, de forma inversa, quando houver falta de ar (ou excesso de combustível) a razão de equivalência será maior que 1.

Assim, decidiu-se por dividir as condições de combustão em $n_{c}=7$ valores diferentes de razão de equivalência, $\varphi_{c}=\left\{\varphi_{1}, \varphi_{2}, \ldots, \varphi_{n_{c}}\right\}$. Os valores escolhidos de razão de equivalência, os tempos totais das aquisições, os tempos em regime permanente e a quantidade de imagens obtidas em regime permanente são exibidos na tabela 6 . As

Tabela 6 - Dados dos testes realizados para a captura das imagens em diferentes condições de combustão.

\begin{tabular}{lcccc}
\hline Condição & $\begin{array}{c}\text { Razão de } \\
\text { Equivalência } \\
c\end{array}$ & $\begin{array}{c}\text { Tempo total } \\
\text { do ensaio } \\
\varphi_{c}\end{array}$ & $\begin{array}{c}\text { Tempo em regime } \\
\text { permanente }(\mathrm{RP})\end{array}$ & $\begin{array}{c}\text { Quantidade } \\
\text { de imagens } \\
T_{c}[\mathrm{~s}]\end{array}$ \\
\hline 1 & 1,12 & 303 & 243 & em RP \\
2 & 0,85 & 296 & 236 & 7.290 \\
3 & 0,70 & 302 & 242 & 7.080 \\
4 & 0,60 & 300 & 240 & 7.260 \\
5 & 0,50 & 301 & 241 & 7.230 \\
6 & 0,42 & 267 & 207 & 6.210 \\
7 & 1,05 & 140 & 80 & 2.400 \\
\hline
\end{tabular}

Fonte - Elaborado pelo autor.

primeiras seis condições foram gravadas por aproximadamente 5 min cada. A sétima e última condição foi uma condição configurada no processo de desligamento do forno e, por isso, foi mantida por 2 min $20 \mathrm{~s}$. Ou seja, não foi uma condição planejada, mas mesmo assim optou-se por incorporar suas imagens na metodologia. É por este motivo que sua razão de equivalência não segue a ordem decrescente das demais condições. A tabela 6 mostra a informação sobre as condições do experimento na ordem cronológica de aquisição dos dados.

Foi observado através de inspeção visual que, a partir da alteração da razão de equivalência para o início de cada condição, o período transitório levou menos de um minuto para cada condição, logo se convencionou em 1 min os períodos transitórios para todas as condições para fins de padronização. O gráfico da figura 22 ilustra o comportamento da razão de equivalência durante o tempo de ensaio, e mostra que considerar o período transitório de 1 min para cada condição é razoável. A taxa de amostragem das imagens obtidas foi de $30 \mathrm{~Hz}$ e a gravação foi realizada sem interrupções.

As chamas foram gravadas a partir de uma abertura na extremidade do forno com uma visão direta ao bocal do queimador, conforme já foi explicado na seção 3.1 (página 65). 
Figura 22 - Gráfico do comportamento da razão de equivalência em função do tempo de ensaio

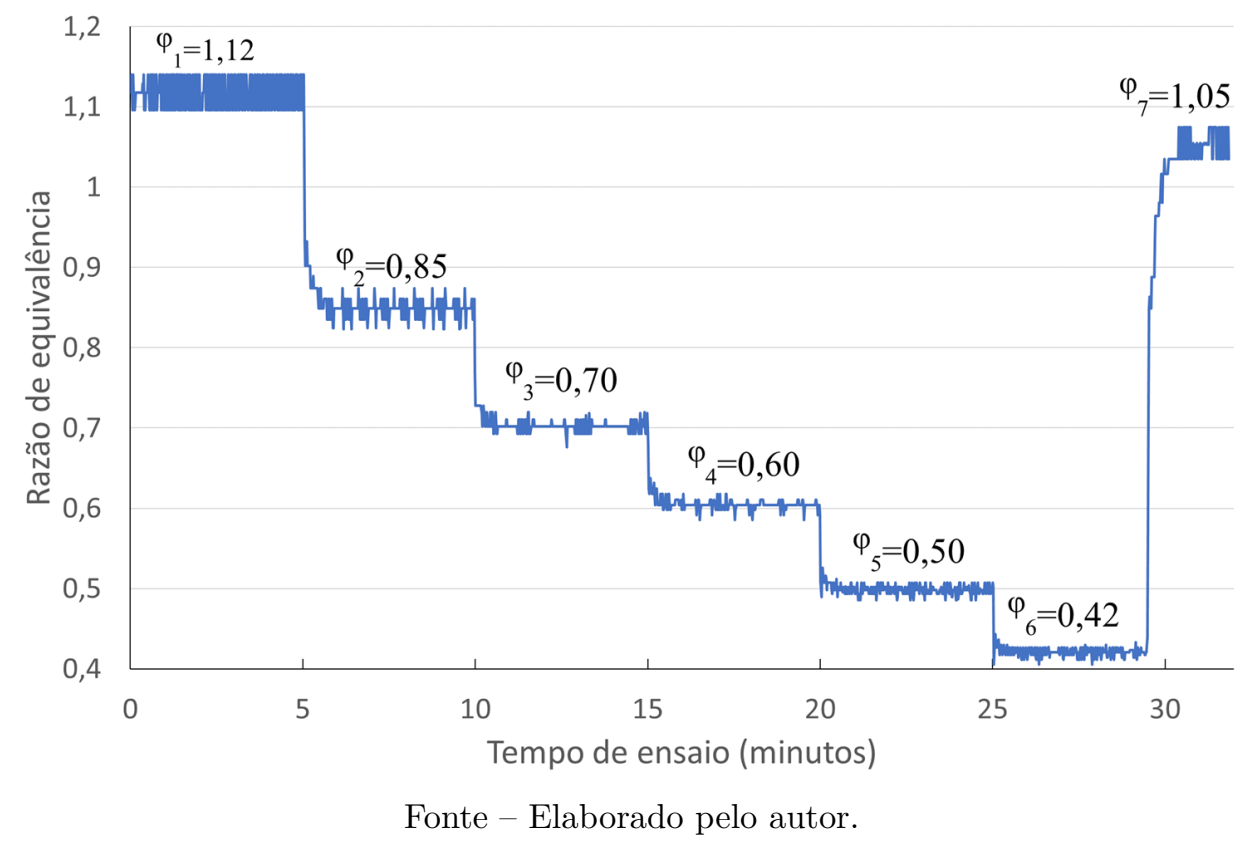

Dessa forma, as imagens de chama resultantes foram capturadas numa visão frontal em relação ao bocal do queimador. A razão para esta posição de filmagem era para que a câmera não sofresse danos devidos ao calor, uma vez que ela não possuía nenhuma proteção térmica ou sistema de refrigeração.

O equipamento experimental disponível não seria capaz de acompanhar um monitoramento em tempo real pois não havia um digitalizador de vídeo (frame grabber) para transformar o vídeo em imagens com alta taxa de amostragem. No entanto, mesmo sem esse equipamento, é possível chegar a modelos de chama separando-se o vídeo em imagens em momento posterior à aquisição do vídeo através de softwares específicos. Assim, uma vez que se disponha do digitalizador de vídeo, os modelos identificados por esta metodologia permaneceriam aplicáveis para o monitoramento em tempo real.

\subsection{Descrição geral do método de identificação e controle da chama}

Obtidas as imagens, a metodologia proposta a fim de se obter o modelo de chama pode ser dividida em duas grandes partes, ilustradas na figura 23. Nela também está contida uma terceira parte que seria uma evolução natural do trabalho, que está fora do escopo desta tese, mas é ilustrada a fim de fornecer ao leitor uma visão mais ampla:

a) processamento das imagens: compreende a separação da chama e seu fundo, cálculo das propriedades características da imagem da chama e criação dos vetores característicos; 
Figura 23 - Fluxograma da metodologia proposta

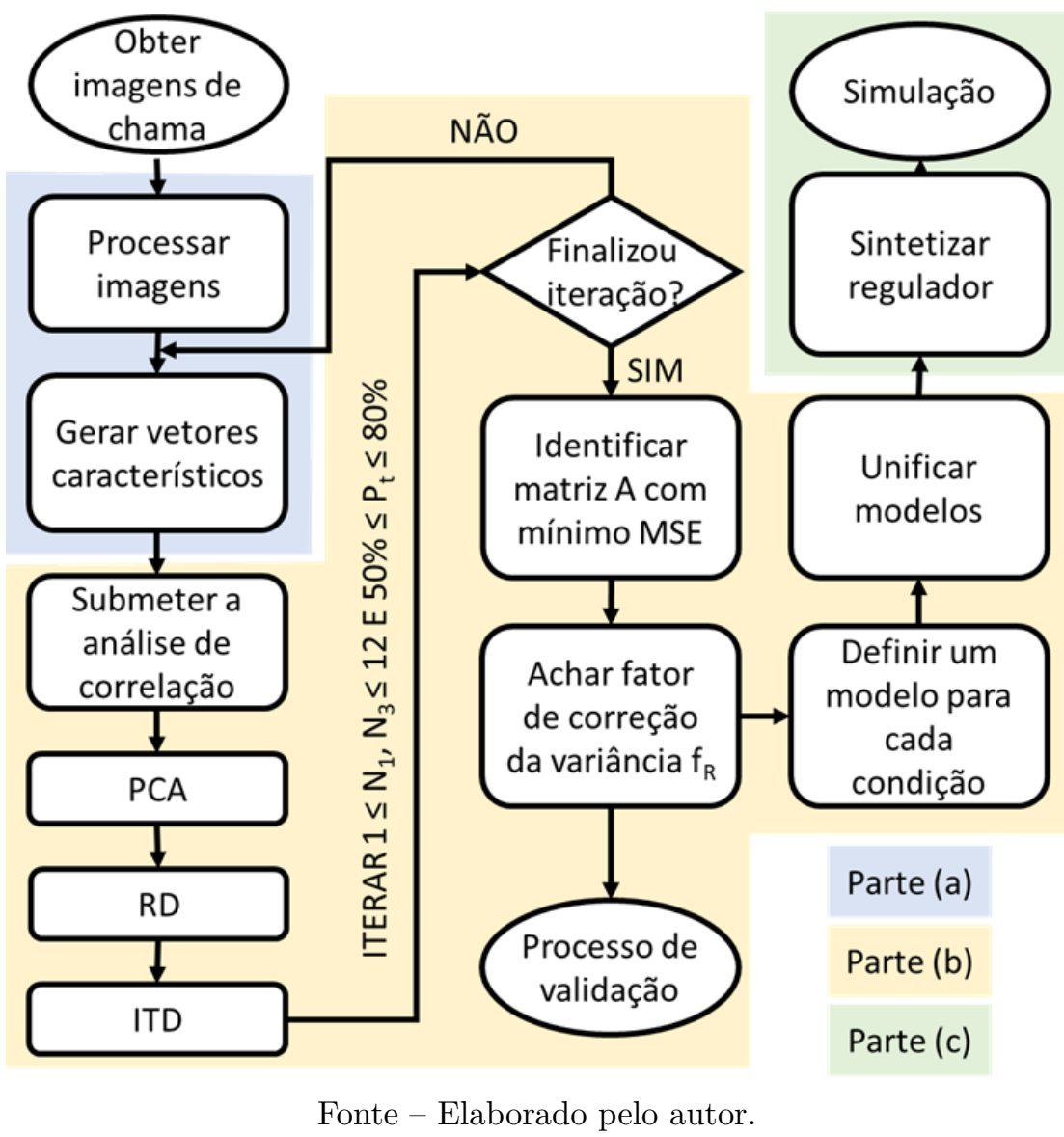

b) identificação do modelo: processamento dos vetores característicos como variáveis temporais, identificação dos modelos para cada condição de chama através da aplicação da análise de correlação, análise de componentes principais (PCA), algoritmo do decremento aleatório (RD) e método do domínio do tempo de Ibrahim (ITD) e modelagem da parte estocástica do modelo. Nesta parte ainda está incluído um processo iterativo para escolher o modelo mais adequado para cada condição, através da minimização de um índice de erro quadrático médio (MSE), para uma gama de parâmetros dos métodos utilizados. Por fim, é realizada a unificação dos modelos através da introdução da razão de equivalência como entrada do modelo;

c) controle da chama: sintetização do regulador para manter a chama estável e simulação.

O processo de validação, na parte (b) tem o objetivo de verificar se os dados obtidos com os modelos são compatíveis com os dados experimentais. Tanto a parte (a) quanto a parte (b) serão detalhados em capítulos dedicados a seguir.

Com o desenvolvimento das partes (a) e (b), viabiliza-se naturalmente a oportuni- 
dade de pesquisa da parte (c), que é vista como um dos objetivos a serem perseguidos pelo grupo de pesquisa para tornar a tecnologia viável em aplicações industriais, e que certamente será tema de trabalhos futuros por este autor. 


\section{PROCESSAMENTO DE IMAGENS}

Neste capítulo os procedimentos do processamento digital de imagens são abordados desde a imagem bruta até sua transformação em informações que serão utilizadas para a identificação do sistema de chama. A seção 4.1 apresenta uma definição matemática para imagem digital. Na seção 4.2 amostras de imagens de chama são exibidas e o processo de recorte das imagens é explicado. Nas seções 4.3 e 4.4 são definidos o histograma e o processo de limiarização para separar na imagem a chama do seu fundo. As imagens segmentadas são obtidas na seção 4.5 unindo em uma só imagem a chama sem o fundo com as diferentes tonalidades de cinza que a formam. Finalmente, as propriedades geométricas e de iluminação são definidas na seção 4.6 com o objetivo de se construir o vetor característico da imagem, que a sumariza e a representa.

\subsection{A imagem digital}

Uma imagem monocromática genérica pode ser definida como uma função $f_{I}=$ $f_{I}(x, y) ; f_{I}: \mathbb{R}^{2} \rightarrow \mathbb{R}$ que representa a reflexão de luz no espaço $\mathbb{R}^{2}$, ou seja, assume um valor de intensidade de luz para cada coordenada $(x, y)^{1}$.

Martins (2014) explica que uma imagem monocromática digital $I$ é gerada a partir de $f_{I}$ através dos processos de amostragem e quantização. A amostragem consiste em estabelecer uma discretização no domínio $\mathbb{R}^{2}$ de forma que $I$ seja uma representação discretizada de $f_{I}(x, y)$ em $U \subset \mathbb{N}^{2}$ e que, por exemplo, o valor assumido por $I(a, b)$ seja uma amostra representativa dos infinitos valores que $f_{I}(x, y)$ pode assumir com $a \leq x<a+1$ e $b \leq y<b+1$, com $a, b \in \mathbb{N}$. Por outro lado, a quantização é a discretização do conjunto imagem de $f_{I}$, ou seja, enquanto $f_{I}$ pode assumir infinitos valores de intensidade luminosa, $I$ assume um número finito de níveis de cinza. Portanto, pode-se definir uma imagem monocromática digital da seguinte forma:

Definição 4.1 Uma imagem monocromática digital I é uma representação gráfica do mapeamento $I=I(x, y) ; I: U \subset \mathbb{N}^{2} \rightarrow g$ em que as variáveis independentes $x$ e y são em geral coordenadas espaciais, e o conjunto imagem de $I$ em $G_{L}=\{0,1, \ldots, L-1\}$ define o tom de cinza da imagem em cada $(x, y) \in U$.

1 Assume-se um abuso de linguagem entre as coordenadas $(x, y)$ de $f_{I}$ e $(x, y)$ de $I$. Enquanto as primeiras estão em $\mathbb{R}^{2}$, as segundas estão em $\mathbb{N}^{2}$. No entanto, uma vez que o uso de $f_{I}$ está restrito à contextualização para a definição de $I$, não haverá mistura de notação, e no restante do documento as coordenadas $(x, y)$ referentes a uma imagem estarão sempre em $\mathbb{N}^{2}$. 
O conjunto $G_{L}$ representa o conjunto de níveis de tons de cinza que $I(x, y)$ pode assumir, que normalmente está no intervalo $\left[0, L-1\right.$ [, onde $L=2^{b}$ é o total de níveis de tons de cinza e, geralmente, é representado pelo número de combinações de $b$ bits necessários para armazenamento de cada pixel, também chamado de profundidade da imagem. Um valor padrão para $b$ largamente utilizado é 8 , que resulta num total de $2^{8}=256$ níveis de cinza, onde o tom zero define a cor preta e o tom 255 (ou $2^{8}-1$ ) define a cor branca.

A definição 4.1 permite que a imagem $I$ possa ser interpretada como uma matriz $M \times N \operatorname{com} M, N \in \mathbb{N}$, onde cada elemento $I(x, y)$ é chamado de pixel (picture element):

$$
I(x, y)=\left[\begin{array}{cccc}
I(0,0) & I(0,1) & \cdots & I(0, N-1) \\
I(1,0) & I(1,1) & \cdots & I(1, N-1) \\
\vdots & \vdots & \ddots & \vdots \\
I(M-1,0) & I(M-1,1) & \cdots & I(M-1, N-1)
\end{array}\right]
$$

onde $y \in[0, M[\subset \mathbb{N}$ e $x \in[0, N[\subset \mathbb{N}$.

A figura 24 exibe uma representação matricial para o caso de uma imagem $4 \times 5$ pixels. É interessante notar a notação admitida para os eixos coordenados $x y$, onde o zero coincide com o canto superior esquerdo da imagem, o eixo $x$ está na horizontal com sentido para a direita e o eixo y está na vertical com sentido para baixo. Essa convenção para a direção dos eixos na imagem é padrão na literatura de processamento de imagens ${ }^{2}$.

Figura 24 - Representação matricial de uma imagem $4 \times 5$.

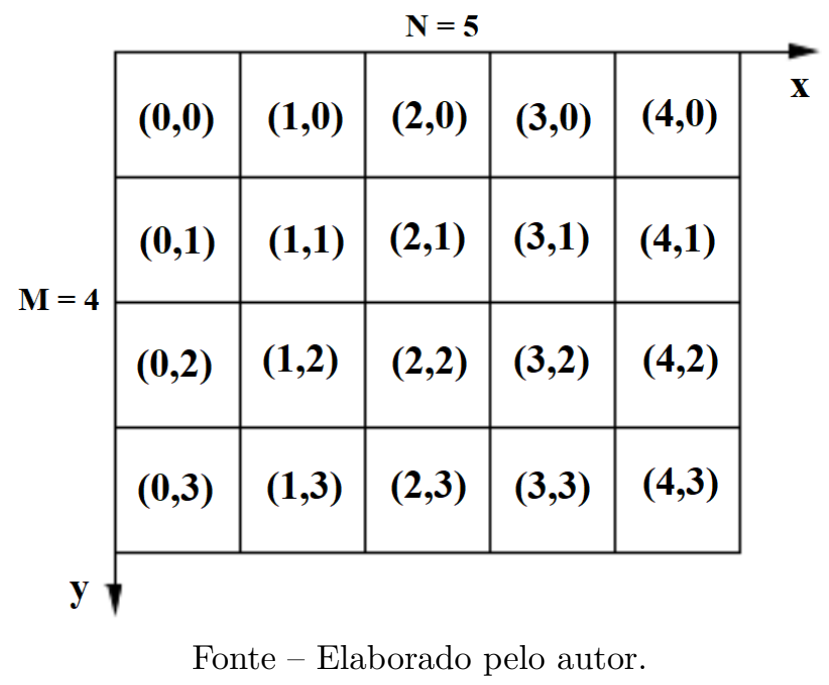

\subsection{As imagens de chama de forno a gás}

A tabela 6 da seção 3.2 (página 69) já indicou que foram capturadas milhares de imagens para cada condição. Não faz sentido exibir todas elas aqui, no entanto, para

2 Essa escolha de referência é explicada em Gonzalez e Woods (2001). 
Figura 25 - Amostras de imagens originais.

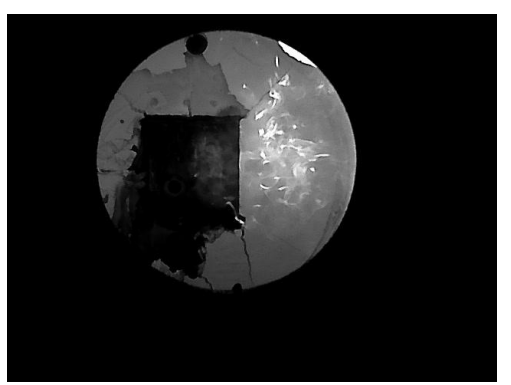

(a) Condição 1 - Amostra 1.

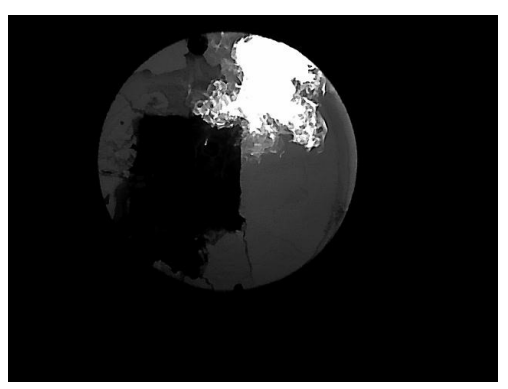

(d) Condição 2 - Amostra 1.

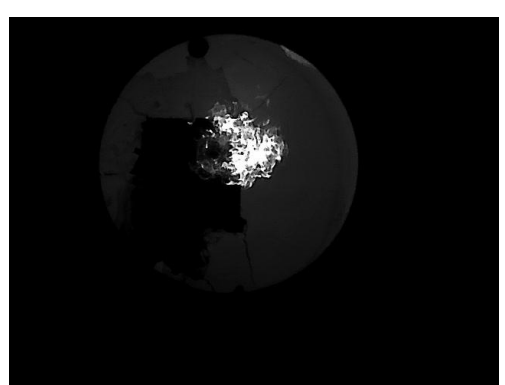

(g) Condição 3 - Amostra 1.

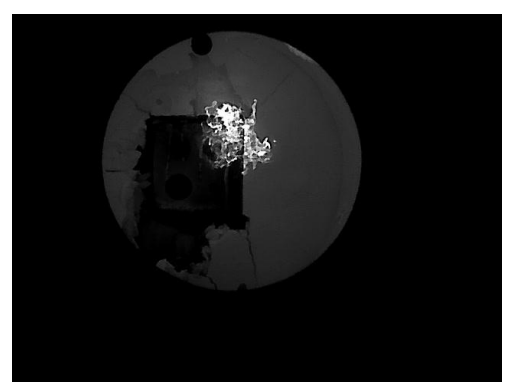

(j) Condição 4 - Amostra 1.

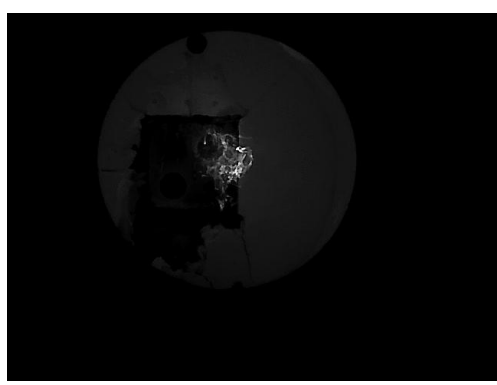

(m) Condição 5 - Amostra 1.

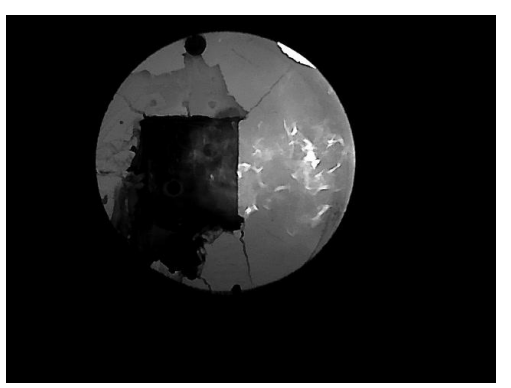

(b) Condição 1 - Amostra 2.

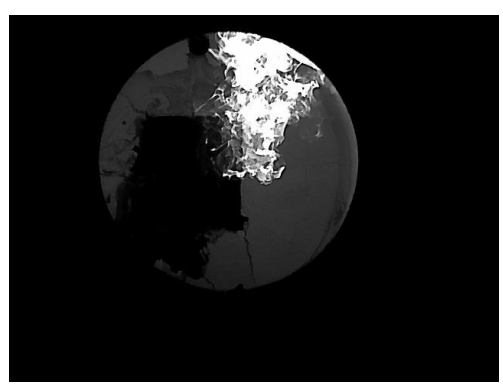

(e) Condição 2 - Amostra 2.

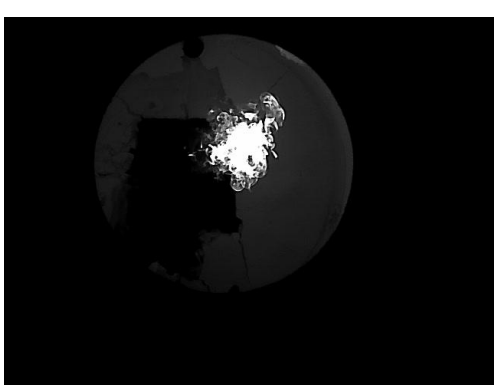

(h) Condição 3 - Amostra 2.

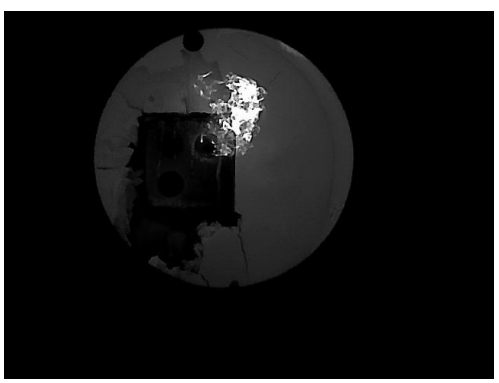

(k) Condição 4 - Amostra 2.

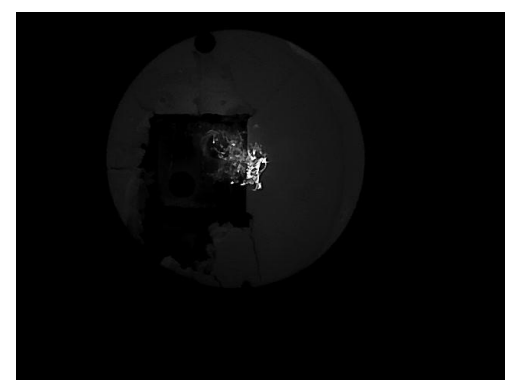

(n) Condição 5 - Amostra 2.

Fonte - Elaborado pelo autor.

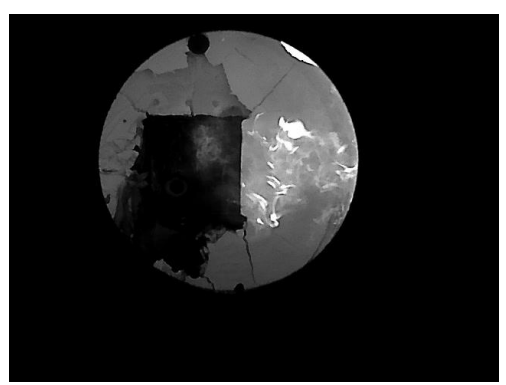

(c) Condição 1 - Amostra 3.

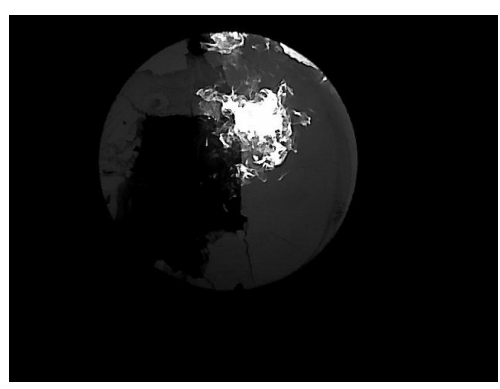

(f) Condição 2 - Amostra 3.

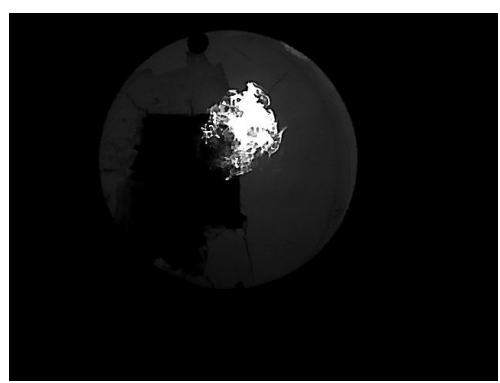

(i) Condição 3 - Amostra 3.

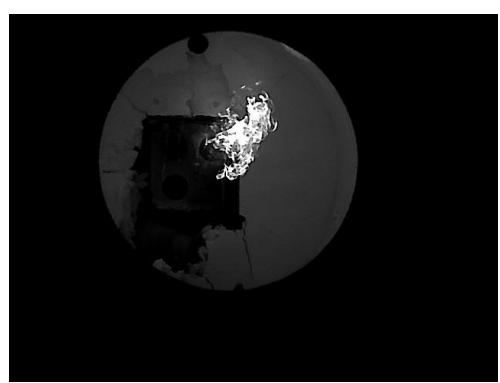

(l) Condição 4 - Amostra 3.

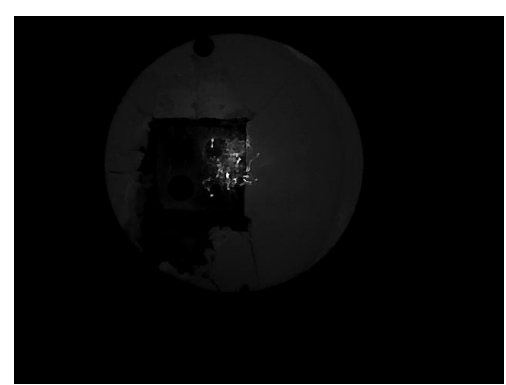

(o) Condição 5 - Amostra 3. 
Figura 25 - Amostras de imagens originais (continuação).

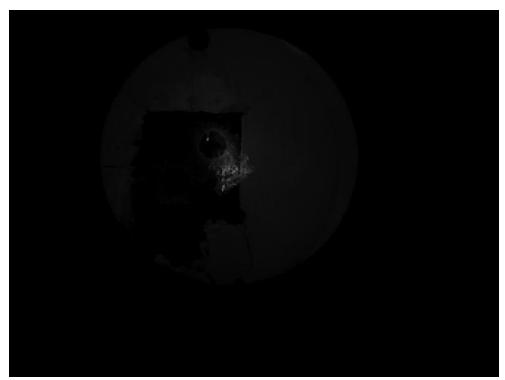

(p) Condição 6 - Amostra 1.

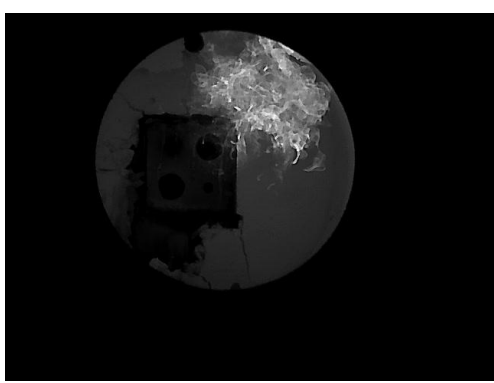

(s) Condição 7 - Amostra 1.

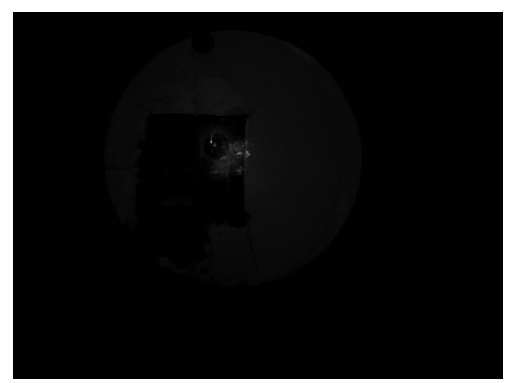

(q) Condição 6 - Amostra 2.

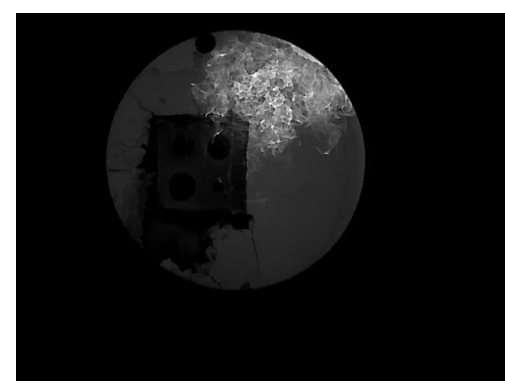

(t) Condição 7 - Amostra 2.

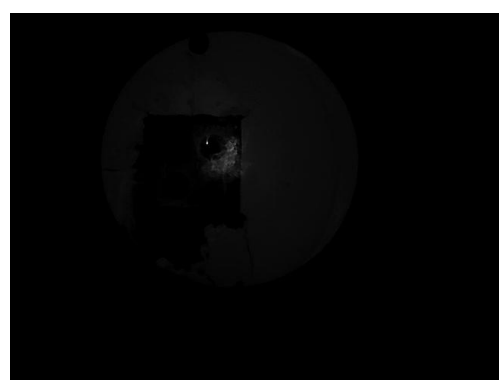

(r) Condição 6 - Amostra 3.

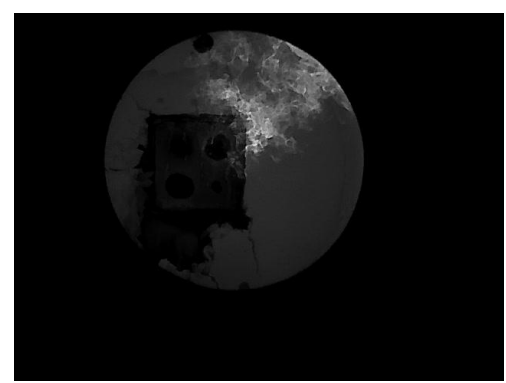

(u) Condição 7 - Amostra 3.

Fonte - Elaborado pelo autor.

se ter uma ideia da metodologia do processamento das imagens, para cada condição serão mostradas, na figura 25, três amostras que representam o estado das chamas, uma vez que, em regime permanente, o aspecto geral da imagem não varia muito apesar da dinâmica natural da chama. É importante mencionar que as três imagens exibidas de cada condição ilustram uma sequência de imagens obtidas com a diferença de tempo definida pela taxa de aquisição do equipamento, isto é, elas estão em sequência temporal. Além disso, se uma comparação entre condições for realizada, fica clara a diferença das chamas, o que demonstra o potencial para a identificação de sistemas diferentes para as diversas condições.

Antes de iniciar os passos de processamento das imagens, alguns elementos da imagem serão descritos qualitativamente para que fique clara a forma de interpretar as imagens mostradas na figura 25. A figura 26 destaca alguns elementos da imagem que são captados quando a chama está desligada. Nota-se que boa parte da imagem é ocupada pelo entorno da janela de vigia, em cor preta, em que a câmera foi posicionada. A região cinza mais claro refere-se à cobertura de fibra cerâmica que o forno possui para isolamento térmico. O bloco refratário é onde o queimador é instalado e quando a chama está acesa ele fica num tom de cinza escuro, próximo ao preto, devido à sua característica de absorção de calor. Na região abaixo do bloco refratário, a fibra cerâmica foi danificada, deixando a parte refratária do próprio forno à mostra. Por isso, é uma região que também fica escura quando há chama. O queimador é posicionado na região laranja da figura 26, e é nessa 
Figura 26 - Identificação de elementos da imagem sem a chama.

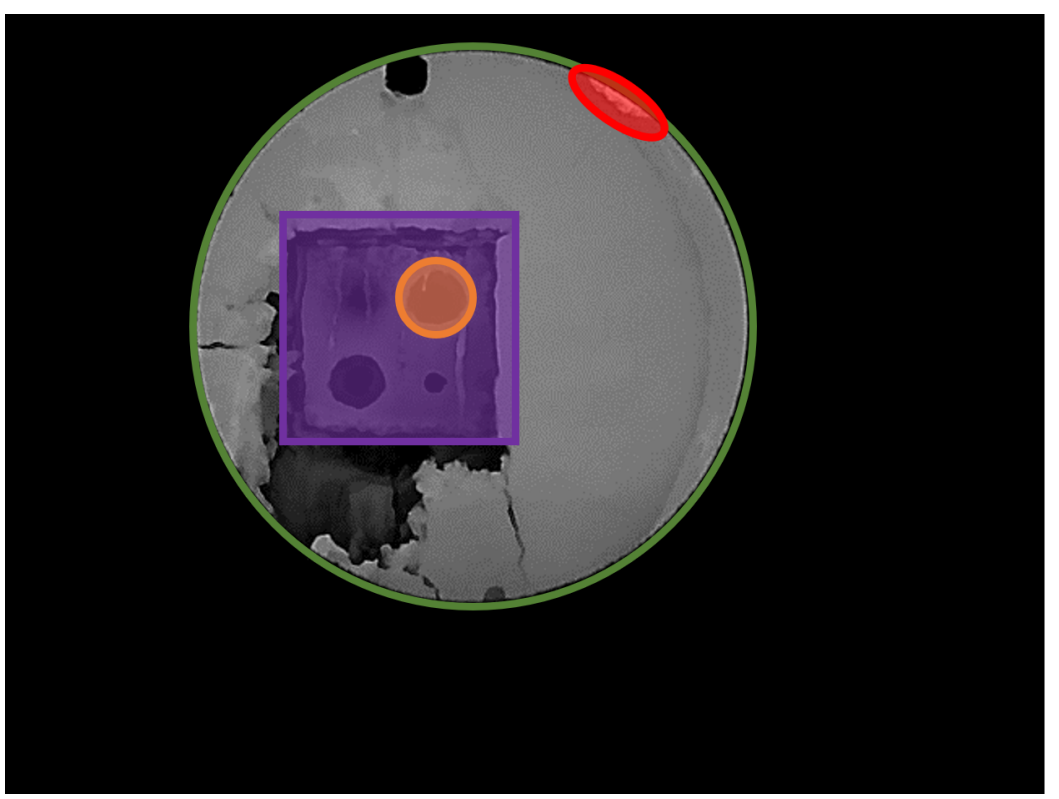

Janela de vigia
Fibra cerâmica
Bloco refratário
Bocal do queimador
Mancha branca

Fonte - Elaborado pelo autor.

posição que a chama tem sua origem. Além disso, existe uma mancha branca no canto superior direito da janela que se refere a uma parte da fibra cerâmica que fica em volta da vigia, e, por não fazer parte da chama, pode influenciar no resultado. É possível verificar, por exemplo, na figura $25(\mathrm{f})$, que a mancha branca se confunde com a chama.

As características a serem extraídas das imagens são calculadas através da análise completa da imagem, que é realizada com varreduras sucessivas na imagem inteira. Consequentemente, a parte externa à janela de vigia que é composta apenas por pixels em tom preto não acrescenta nenhuma informação sobre a chama ou o fundo do forno, e só agregaria mais tempo de processamento. Por esse motivo e a fim de otimizar tempo de processamento computacional para o cálculo das características, foi realizado um processo de recorte da imagem, para que a imagem seja composta quase completamente pela visão do interior do forno, e também para que aquela pequena mancha branca fosse retirada.

Ajustou-se, então, uma máscara circular de 320 pixels de diâmetro e com centro em $(x, y)=(288,192)$ na imagem original de tamanho $640 \times 480$ pixels, considerando os eixos coordenados conforme ilustrado na figura 24. A nova imagem foi formada com essa imagem circular circunscrita num quadrado de tamanho $320 \times 320$ pixels. As bordas fora da máscara circular foram definidas com o tom preto. A escolha por uma máscara circular ao invés de uma quadrada se deu para que se pudesse retirar a mancha branca anteriormente descrita com o mínimo de perda de porções úteis da imagem. A figura 27 ilustra a posição da máscara circular na imagem original.

A fim de ilustrar os resultados de cada passagem do processamento de imagens, serão mostradas apenas as transformações sobre as figuras $25(\mathrm{e})$ e $25(\mathrm{k})$ com o intuito de 
Figura 27 - Posicionamento da máscara de recorte

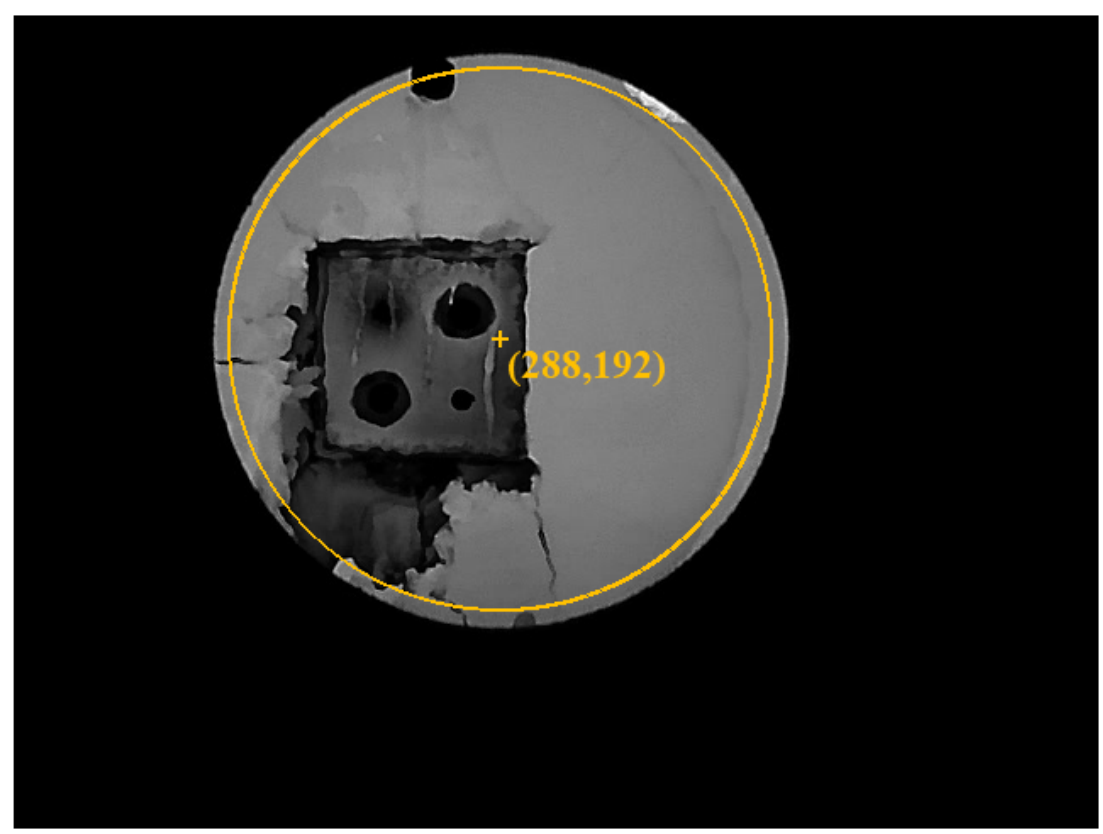

Fonte - Elaborado pelo autor.

não poluir o texto com imagens em demasia ${ }^{3}$. Portanto, a figura 28 ilustra como ficam as figuras $25(\mathrm{e})$ e $25(\mathrm{k})$ após o processo de recorte. Além disso, os eixos $x y$ são redefinidos de forma análoga ao exibido na figura 24 para as imagens recortadas, isto é, a partir de agora, a notação dos eixos $x y$ deverá entendida como eixos das imagens com dimensão $320 \times 320$, conforme indicado na figura 28 (a), com origem no canto superior esquerdo.

\subsection{Histograma da imagem}

O histograma de uma imagem, além de ser relativamente simples de ser construído, é capaz de evidenciar características na imagem que seriam difíceis de verificar apenas pela imagem em si como, por exemplo, mostrar mais claramente o comportamento do contraste da imagem. Essa versatilidade o torna uma ferramenta poderosa na análise e no processamento de imagens, sendo de extrema importância no processo de limiarização que será visto adiante.

O índice de contagem de pixels com tom de cinza $g, \alpha(I(x, y), g)$, irá auxiliar na definição de diversas propriedades da imagem e é definido como:

$$
\alpha(I(x, y), g)= \begin{cases}0, & \text { se } I(x, y) \neq g \\ 1, & \text { se } I(x, y)=g\end{cases}
$$

onde a função $I(x, y)$ havia sido definida na equação (4.1) e $g \in G_{L}$ é um nível de cinza qualquer.

3 As imagens das transformações das figuras 25(a) a 25(u) decorrentes do processamento de imagens realizado podem ser encontradas no Apêndice A (página 154). 
Figura 28 - Exemplos de imagens após o recorte

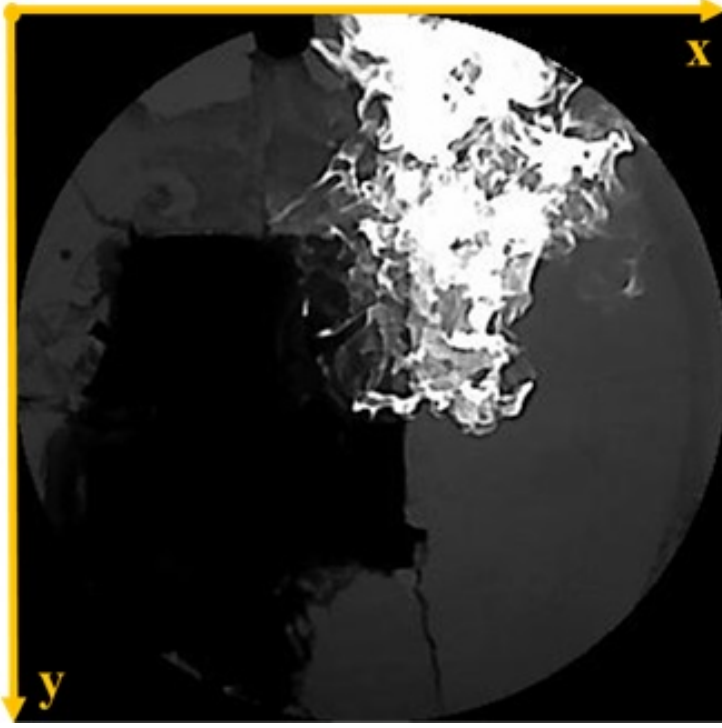

(a) Condição 2 - Amostra 2.

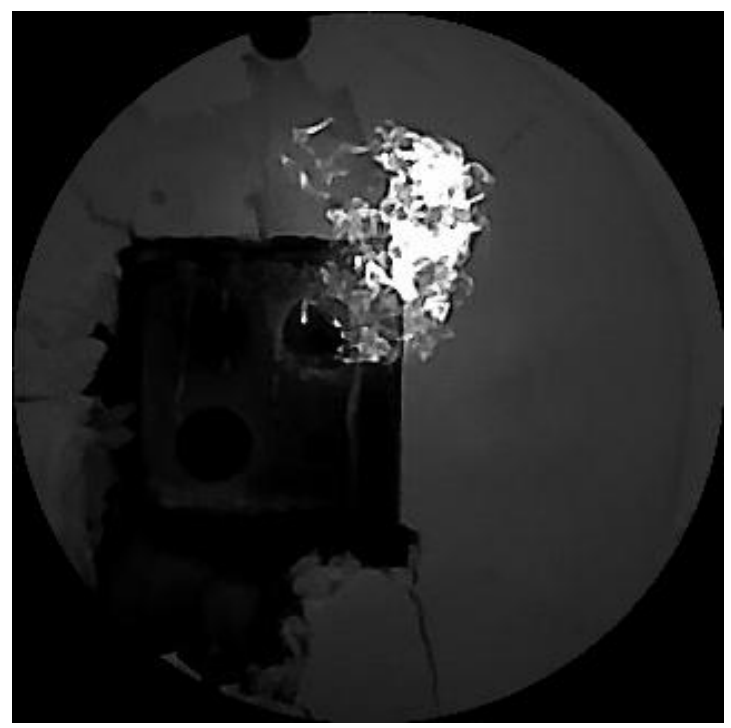

(b) Condição 4 - Amostra 2.

Fonte - Elaborado pelo autor.

O histograma nada mais é que uma função discreta $h(g)$ que indica a quantidade de pixels da imagem $I$ com determinado tom de cinza $g$ :

$$
h(g)=\sum_{x=0}^{N-1} \sum_{y=0}^{M-1} \alpha(I(x, y), g)
$$

No entanto o histograma é mais comumente observado em sua forma normalizada, conforme Definição 4.2.

\section{Definição 4.2 (Histograma, adaptado de Marques Filho e Vieira Neto (1999)).}

O histograma de uma imagem é um conjunto de números indicando o percentual de pixels naquela imagem que apresentam um determinado nível de cinza. Estes valores são normalmente representados por um gráfico de barras que fornece para cada nível de cinza o percentual de pixels correspondentes na imagem. Para uma imagem de tamanho $M \times N$, cada elemento deste conjunto é calculado através da seguinte expressão:

$$
p_{h}(g)=\frac{h(g)}{M N}
$$

em que $h(g)$ representa a quantidade de pixels da imagem que possuem o tom de cinza $g \in G_{L}$ e $p_{h}(g)$ representa a probabilidade da ocorrência do tom de cinza g na imagem.

As figuras 29 e 30 ilustram as imagens das amostras 2 da condição 2 e da condição 4 , respectivamente. A condição 2 , por ser uma condição mais estável da chama do que a condição 4, apresenta uma chama maior e mais brilhante, o que se reflete na comparação 
Figura 29 - Imagem da amostra 2 da condição 2 com seu respectivo histograma.

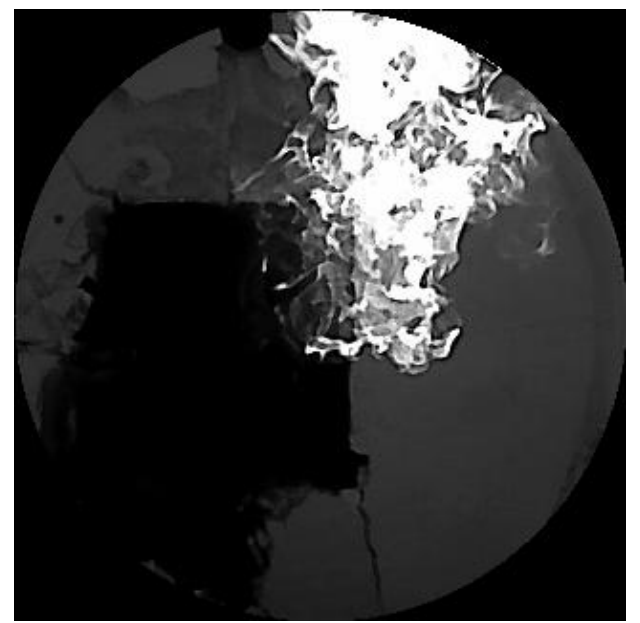

(a) Imagem da chama.

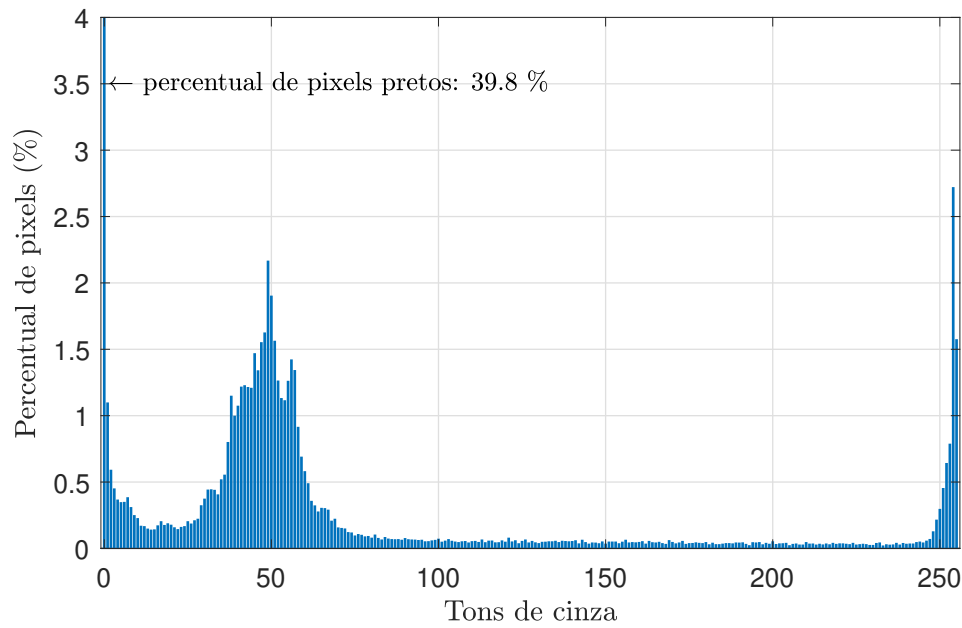

(b) Histograma da imagem.

Fonte - Elaborado pelo autor.

dos histogramas das figuras 29(b) e 30(b). Nota-se que há mais pixels com tons de cinza próximo ao tom branco (255) na chama da condição 2 do que a da condição 4 . O percentual de ocorrência do tom preto (zero) é muito mais alto que os outros e destoa em todas as imagens e, por isso, foi cortado da escala. Para compensar, indicou-se textualmente nos gráficos o percentual referente a esse tom.

Figura 30 - Imagem da amostra 2 da condição 4 com seu respectivo histograma.

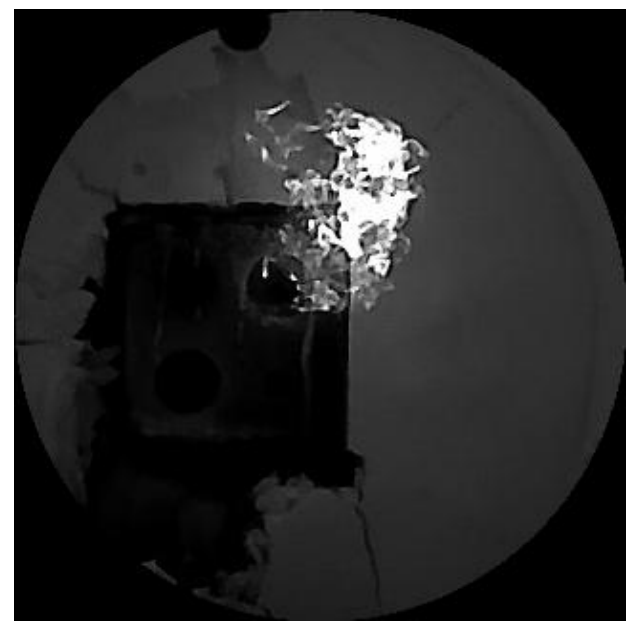

(a) Imagem da chama.

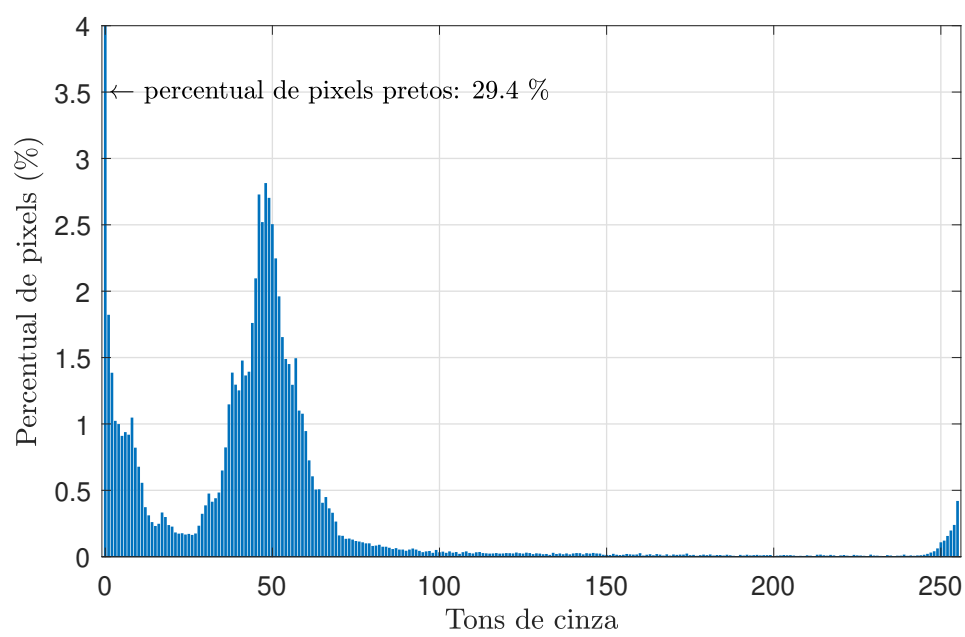

(b) Histograma da imagem.

Fonte - Elaborado pelo autor. 


\subsection{Limiarização}

A limiarização consiste em separar uma ou mais regiões de interesse em uma imagem. Quando há mais de uma região de interesse, o processo de limiarização se torna muito mais complicado, logo, na maioria dos casos onde a limiarização é aplicada, há o interesse em separar apenas uma região do restante da imagem, isto é, separar o objeto de interesse do fundo.

Nas imagens monocromáticas, a limiarização é efetuada definindo-se um valor limite (threshold), ou seja, um valor de tom de cinza $T$ que representa, no histograma, a segregação entre a classe de pixels com tons de cinza mais escuros que $T$ da classe de pixels com tons de cinza mais claros que $T$, de forma que um dos grupos coincida o máximo possível com o objeto de interesse na imagem.

Definição 4.3 (Limiarização). Seja uma imagem em tons de cinza representada pela imagem do operador $I=I(x, y) ; I: U \subset \mathbb{N}^{2} \rightarrow G_{L}=\{0,1, \ldots, L-1\}$. Dado um limiar $T \in G_{L}$, a limiarização (global) é definida pelo operador $I^{p b}=I^{p b}(x, y)$, chamado de imagem em preto e branco, dado por:

$$
I^{p b}(x, y)= \begin{cases}a, & \text { se } I(x, y) \geq T \\ b, & \text { se } I(x, y)<T\end{cases}
$$

em que $a, b \in G_{L}$.

A definição 4.3 é genérica ao estipular os dois níveis de cinza $a$ e $b$ da imagem resultante da limiarização $I^{p b}$. No entanto, no algoritmo utilizado neste trabalho, denominase a imagem $I^{p b}$ como imagem em preto e branco com $a=L-1$, referente ao objeto, e $b=0$, referente ao fundo.

Marques Filho e Vieira Neto (1999) afirmam que a forma mais simples de limiarização consiste na bipartição do histograma e é uma operação trivial quando o histograma possui uma característica bimodal. No entanto, mesmo nesses casos, quando o histograma apresenta dois picos e um vale, os resultados obtidos com diferentes valores de $T$ nesse vale podem ser substancialmente diferentes. As imagens de chama são especialmente interessantes para a aplicação da limiarização uma vez que a chama tem um brilho alto e o fundo naturalmente é mais escuro, uma vez que um forno é formado por material refratário, o que, supostamente, resultaria numa característica bimodal.

Consequentemente, devido à variabilidade entre as imagens, encontrar um método automático de determinação do limiar é necessário. Gonzalez e Woods (2001) citam dois métodos: um utiliza médias móveis mas possui algumas limitações em seu desempenho e outro chamado método de Otsu será discutido mais profundamente (ver seção 4.4.1) pois será utilizado neste trabalho. Além disso, Gonzalez e Woods (2001) mostram maneiras 
de pré-processar imagens de forma a aprimorar os resultados de um posterior processo de limiarização como, por exemplo, suavização através do cálculo de janelas de média, que substituem os valores dos pixels em determinada janela pelo valor da média de todos os pixels da janela, ou identificação e utilização das bordas dos objetos para gerar um histograma bimodal, cujo limiar também é representativo na imagem original.

\subsubsection{O método de Otsu}

O método de Otsu (1979) se fundamenta na ideia que classes (objeto ou fundo) com boa limiarização devem possuir valores de tons de cinza claramente distintos. Por outro lado, esses valores dentro de uma mesma classe devem ser similares. Gonzalez e Woods (2001) explicam que o método de Otsu é ótimo pois maximiza a variância entre as classes (ou interclasses) e minimiza a variância dentro de cada classe (ou intraclasses). A grande vantagem desse método é que ele pode ser calculado inteiramente a partir do histograma da imagem, uma vez que ele representa a distribuição de probabilidades de ocorrência dos tons de cinza em uma imagem.

A média acumulada até o tom de cinza $g$ e sua variância são dados por:

$$
\begin{aligned}
\mu(g) & =\sum_{i=0}^{g} i p_{h}(i) \\
\sigma^{2}(g) & =\sum_{i=0}^{g}(i-\mu(g))^{2} p_{h}(i)
\end{aligned}
$$

onde $p_{h}(g)$ é o histograma da imagem $I$ e foi definido na equação (4.4). A partir das equações (4.6) e (4.7) pode-se calcular $\mu_{G}=\mu(L-1)$, a média global, e $\sigma_{G}^{2}=\sigma^{2}(L-1)$, a variância global dos tons de cinza da imagem inteira, respectivamente.

Algoritmo 4.1 (Método de Otsu). O algoritmo do método de Otsu pode ser descrito da seguinte forma:

a) calcular histograma $p_{h}(g)$, conforme equação (4.4);

b) determinar o menor valor de $g \in G_{L}$ cujo valor de $p_{h}(g) \neq 0$;

c) calcular as probabilidades de ocorrência de cada classe:

$$
\begin{aligned}
& P_{1}(g)=\sum_{i=0}^{g} p_{h}(i) \\
& P_{2}(g)=\sum_{i=(g+1)}^{L-1} p_{h}(i)=1-P_{1}(g) ;
\end{aligned}
$$

d) calcular as médias de tons de cinza acumulados de cada classe:

$$
\begin{aligned}
& \mu_{1}(g)=\frac{1}{P_{1}(g)} \sum_{i=0}^{g} i p_{h}(i)=\frac{\mu(g)}{P_{1}(g)} \\
& \mu_{2}(g)=\frac{1}{P_{2}(g)} \sum_{i=(g+1)}^{L-1} i p_{h}(i)=\frac{\mu_{G}-\mu(g)}{1-P_{1}(g)}
\end{aligned}
$$


e) calcular as variâncias de tons de cinza acumulados de cada classe:

$$
\begin{aligned}
\sigma_{1}^{2}(g) & =\frac{1}{P_{1}(g)} \sum_{i=0}^{g}\left(i-\mu_{1}(g)\right)^{2} p_{h}(i) \\
\sigma_{2}^{2}(g) & =\frac{1}{P_{2}(g)} \sum_{i=(g+1)}^{L-1}\left(i-\mu_{2}(g)\right)^{2} p_{h}(i)
\end{aligned}
$$

f) calcular a variância dentro da classe (intraclasse):

$$
\sigma_{d c}^{2}(g)=P_{1}(g) \sigma_{1}^{2}(g)+P_{2}(g) \sigma_{2}^{2}(g)
$$

g) incrementar g e repetir o algoritmo a partir de (b) até encontrar $T$ tal que

$$
T=\arg \min _{0 \leq g \leq L-1} \sigma_{d c}^{2}(g)
$$

(se T não for único, calcular a média entre os candidatos), e este será o limiar ótimo, segundo Otsu (1979);

O Algoritmo 4.1 recalcula os termos $P_{1}(g), P_{2}(g), \mu_{1}(g), \mu_{2}(g), \sigma_{1}^{2}(g)$ e $\sigma_{2}^{2}(g)$ para cada iteração de $g$. Otsu (1979) explica que é possível obter o valor do limiar com uma menor quantidade de termos, o que resultaria num ganho de processamento computacional. Para isso, ele demonstrou que o limiar ótimo que minimiza a variância intraclasse é o mesmo que maximiza a variância interclasse, que pode ser definida por:

$$
\sigma_{e c}^{2}(g)=P_{1}(g)\left(\mu_{1}(g)-\mu_{G}\right)^{2}+P_{2}(g)\left(\mu_{2}(g)-\mu_{G}\right)^{2}
$$

A partir das equações (4.8) e (4.9) pode-se concluir que:

$$
\begin{aligned}
P_{1}(g)+P_{2}(g) & =1 \\
\mu(g) & =P_{1}(g) \mu_{1}(g) \\
\mu(g) & =\mu_{G}-P_{2}(g) \mu_{2}(g) \\
\mu_{G} & =P_{1}(g) \mu_{1}(g)+P_{2}(g) \mu_{2}(g)
\end{aligned}
$$

E utilizando as relações (4.14) a (4.17) em (4.13) é possível deduzir que:

$$
\begin{aligned}
\sigma_{e c}^{2}(g) & =P_{1}(g) P_{2}(g)\left(\mu_{1}(g)-\mu_{2}(g)\right)^{2} \\
& =\frac{\left(P_{1}(g) \mu_{G}-\mu(g)\right)^{2}}{P_{1}(g)\left(1-P_{1}(g)\right)}
\end{aligned}
$$

Com todas essas relações, Otsu (1979) também deduziu que a soma da variância entre as classes com a variância dentro da classe é constante e igual à variância global dos tons de cinza da imagem:

$$
\sigma_{d c}^{2}(g)+\sigma_{e c}^{2}(g)=\sigma_{G}^{2}
$$


Essa relação comprova que encontrar $T=g$ que minimiza $\sigma_{d c}^{2}(g)$ significa também encontrar $T=g$ que maximiza $\sigma_{e c}^{2}(g)$, já que $\sigma_{G}^{2}$ é uma constante da imagem. Além disso, comparando a equação (4.11) com a equação (4.19), nota-se que a segunda requer muito menos parâmetros, apenas $P_{1}(g)$ e $\mu(g)$ e uma constate $\mu_{G}$, o que causa um impacto no esforço computacional, uma vez que o processo é iterativo.

Assim, o Algoritmo 4.1 pode ser levemente alterado para o Algoritmo 4.2:

Algoritmo 4.2 (Método de Otsu modificado). O algoritmo do método de Otsu pode ser descrito da seguinte forma:

a) calcular histograma $p_{h}(g)$, conforme equação (4.4);

b) executar os passos (b) a (e) do Algoritmo 4.1;

c) calcular a variância entre as classes, de acordo com a equação (4.19);

d) incrementar $g$ e repetir o algoritmo a partir de (b) até encontrar $T$ tal que

$$
T=\arg \max _{0 \leq g \leq L-1} \sigma_{e c}^{2}(g)
$$

(se T não for único, calcular a média entre os candidatos), e este será o limiar ótimo, segundo Otsu (1979);

Através de uma estimativa bem superficial, é possível comparar o tempo computacional entre os algoritmos 4.1 e 4.2. Considera-se, primeiramente, que as probabilidades $P_{1}(g)$ e $P_{2}(g)$ da equação (4.8) são calculadas com o mesmo tempo computacional $\Delta t_{c}^{P}$ para uma imagem completa, ou seja, com a iteração de $g$ entre zero e $L-1$, uma vez que as equações de $P_{1}(g)$ e $P_{2}(g)$ são muito parecidas. Essas hipóteses são utilizadas de forma análoga para as médias de tons de cinza $\mu_{1}(g)$ e $\mu_{2}(g)$ e para as variâncias de tons de cinza $\sigma_{1}^{2}(g)$ e $\sigma_{2}^{2}(g)$, de forma que $\Delta t_{c}^{\mu}$ e $\Delta t_{c}^{\sigma}$ são os intervalos de tempo que as equações (4.9) e (4.10) levam para serem calculadas para a imagem toda. Além disso, observa-se que as equações (4.9) e (4.10) possuem aproximadamente o mesmo número de operações matemáticas, do que se infere que os tempos $\Delta t_{c}^{\mu}$ e $\Delta t_{c}^{\sigma}$ possuem a mesma ordem de grandeza. A equação (4.8) possui menos operações algébricas que as outras duas, e portanto $\Delta t_{c}^{P}$ é certamente menor que $\Delta t_{c}^{\mu}$ e $\Delta t_{c}^{\sigma}$. Então, se for considerado, de forma aproximada, que:

$$
\begin{aligned}
& \Delta t_{c}^{\mu}=\Delta t_{c}^{\sigma}=\Delta t_{c} \\
& \Delta t_{c}^{P}=0,3 \Delta t_{c}
\end{aligned}
$$

O algoritmo 4.1 necessitaria dos cálculos de $P_{1}(g), P_{2}(g), \mu_{1}(g), \mu_{2}(g), \sigma_{1}^{2}(g)$ e $\sigma_{2}^{2}(g)$ e, então, levaria $4,6 \Delta t_{c}$. E o algoritmo 4.2 necessitaria dos cálculos de $P_{1}(g)$ e $\mu(g)$ e, portanto, levaria $1,3 \Delta t_{c}$. Conclui-se, assim, que o algoritmo 4.2 é, aproximadamente, pelo menos três vezes mais rápido que o algoritmo 4.1 . 


\subsubsection{Análise do histograma da imagem da chama}

A princípio tentou-se utilizar apenas o limiar obtido pelo método de Otsu, conforme descrito na seção 4.4.1. Entretanto percebeu-se que ora detalhes importantes da chama eram perdidos, ora parte do fundo era considerado como chama. Para aperfeiçoar o desempenho obtido com o método de Otsu, decidiu-se analisar os histogramas da chama e notou-se que em todas as condições de chama o histograma tem a mesma característica: um pico muito alto no tom zero, seguido de um vale e outro pico que varia de altura e largura conforme a condição de combustão, e depois um longo vale com uma porção na pixels na parte dos tons mais claros, que também varia de acordo com a condição. Esse perfil do histograma pode ser observado nas figuras 29(b) e 30(b) (bem como no Apêndice A), e está esquematizado na figura 31.

Figura 31 - Esquema ilustrativo de um histograma de chama a gás

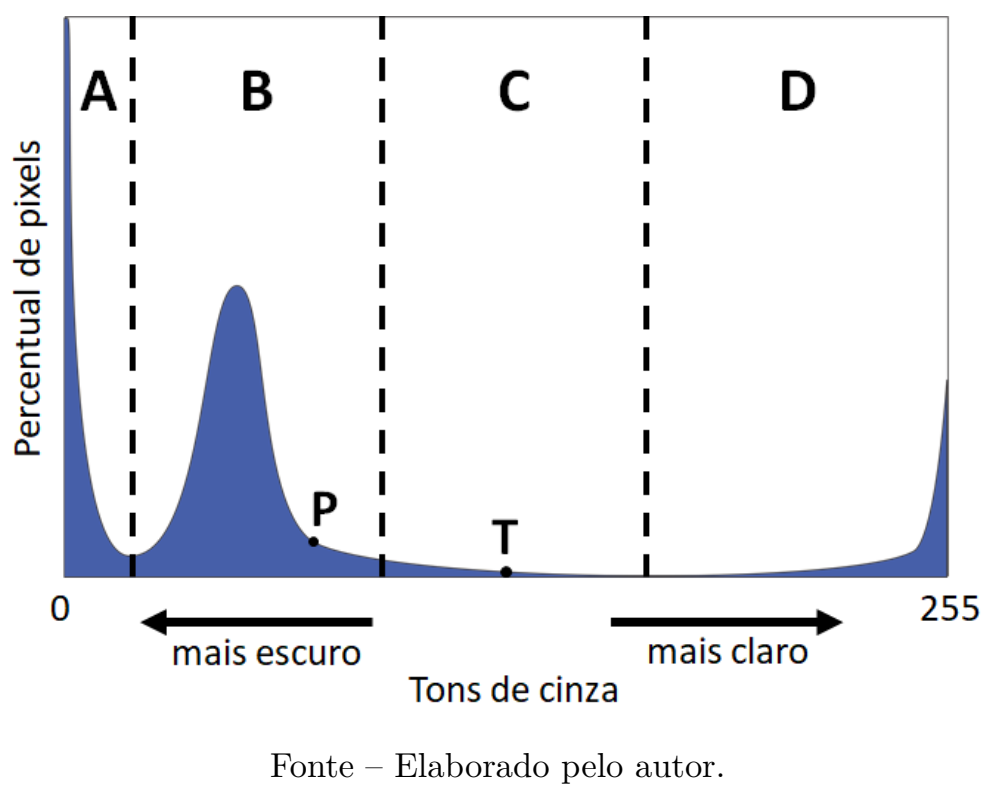

O esquema da figura 31 mostra diversas regiões características das imagens de chama. A região A compreende os pixels das bordas do círculo que completam a área do quadrado da imagem, bem como áreas mais escuras do forno, como o bloco refratário de encaixe do queimador, por exemplo. A área B também é composta pela região do fundo, mas é uma área que já reflete mais a luz produzida pela chama. A região D, quando existente $^{4}$, mostra a região da chama propriamente dita e é facilmente detectável pelo método de Otsu. No entanto, na medida que a condição da combustão torna-se mais pobre e a chama emite menos luz, a porção dos pixels relativos à chama se move para a região C. Na região C também se localizam pixels das bordas da chama, locais de interesse para uma correta identificação do sistema.

4 A região D está presente quando as chamas possuem regiões bem iluminadas. Quando a condição de combustão não permite boa queima, a chama fica mais fraca e a câmera a capta com tons mais cinzentos. Consequentemente, a quantidade de pixels na região D do histograma é pequena ou inexistente. 
O método de Otsu sabidamente entrega bons resultados em histogramas bimodais conforme discutido anteriormente no início da seção 4.4 ou em Marques Filho e Vieira Neto (1999) e Gonzalez e Woods (2001). No entanto, o vale entre as regiões A e B impede que o histograma seja bimodal. A primeira ação então foi identificar o último pico na região B antes do vale que segue nas regiões C e D. Se o histograma sob o Algoritmo 4.2 começar a partir desse pico, haverá uma característica parcialmente bimodal do histograma. Mesmo após essa consideração, o método de Otsu consistentemente perdia detalhes importantes da chama, principalmente em suas bordas onde seu brilho é menor.

Nota-se então que existe uma dificuldade em se identificar com precisão o tom de cinza que representaria o limiar ideal, pois há uma área em torno da divisão entre a área $\mathrm{B}$ e a área $\mathrm{C}$ em que existem tanto pixels do fundo quanto pixels da chama. O método de Otsu resultava, em geral, num valor de $T$ em torno do centro da região $\mathrm{C}$, marcado de forma ilustrativa na figura 31, mas invariavelmente corta uma porção importante da chama.

Assim sendo, o desejável seria trazer o limite $T$ mais próximo do entorno da divisão entre as regiões B e C. Um ponto próximo que é identificável via algoritmo sobre o histograma seria o ponto $P$ identificado sobre a figura 31 . Este ponto tem por característica a mudança da inclinação na base da curva. Identificando-se o ponto $P$, o valor do novo limiar é determinado como o valor de tom de cinza médio entre $T$ e $P$.

Algoritmo 4.3 Este algoritmo analisa o histograma de acordo com características observadas nas imagens de chama em todas as condições para aperfeiçoar o resultado da limiarização:

a) calcular a primeira e a segunda derivadas do histograma em função dos tons de cinza;

- o intervalo de derivação da primeira derivada $\Delta g$ é um parâmetro admitido inicialmente como oito ${ }^{5}$.

b) determinar os tons de cinza que são os zeros da primeira derivada em conjunto com valores negativos da segunda derivada, isto é, determinar os pontos de máximos locais do histograma;

c) caso não se encontrem máximos locais, diminuir o valor de $\Delta g$ e voltar para o passo (a);

d) entre todos os máximos locais, escolher o último grande pico entre aqueles que ficam supostamente na região $B$ da figura 31;

5 O valor de $\Delta g$ foi determinado com a análise de algumas amostras de cada condição de combustão. Não podia ser um número alto a ponto de pular um possível candidato a máximo local, nem pequeno a ponto de achar que qualquer irregularidade no histograma fosse um máximo local. O valor escolhido satisfez esses requisitos. 
- os limites de onde se inicia e onde termina a região $B$ são definidos de forma que garantam nem que os picos da região A nem da região $D$ estejam dentro dessa janela de busca, mas certamente uma boa parte da região $C$ ainda está inserida nela.

e) encontrar o ponto $P$ na base do pico encontrado no passo (d);

- calcula-se a diferença da primeira derivada do histograma entre o tom de cinza atual e o tom de cinza $\Delta g / 2$ tons a frente. O valor inicial do tom de cinza atual é o tom de cinza do último grande pico encontrado no passo (d),

- caso essa diferença for menor que dez $z^{6}$, escolhe-se o tom de cinza atual como ponto $P$.

- caso contrário, incrementa-se o tom de cinza atual em um tom e retorna-se ao primeiro item do passo (e). Como se sabe que a região $C$ existe, um ponto $P$ sempre será encontrado.

f) executar o Algoritmo 4.2 para encontrar o ponto $T$;

- o valor do tom de cinza relativo ao pico encontrado no passo (d) será o limite inferior do histograma analisado pelo Algoritmo 4.2.

g) encontrar o novo limiar $T^{*}$ fazendo a média dos valores de tons de cinza dos pontos $T$ e $P$.

Após encontrar o limiar $T^{*}$, basta que se aplique a equação (4.5), com $a=L-1$, $b=0$ e $T=T^{*}$ para se obter a imagem em preto e branco $I^{p b}$. As figuras 32 e 33 ilustram o resultado do processo de limiarização conforme Algoritmo 4.3. Os valores dos limiares obtidos estão anotados nos histogramas 32(b) e 33(b), bem como a barra deste tom de cinza está realçada na cor vermelha e indicada com uma pequena flecha ${ }^{7}$.

\subsection{Segmentação da imagem}

A segmentação é o passo final no processamento da imagem antes do processo de cálculo das propriedades geométricas e de iluminação. Em termos gerais, a segmentação é a consolidação da separação da imagem da chama do seu fundo, de forma a restabelecer os tons de cinza originais apenas para ela.

Definição 4.4 (Segmentação). Seja uma imagem em tons de cinza representada pela imagem do operador $I=I(x, y) ; I: U \subset \mathbb{N}^{2} \rightarrow G_{L}=\{0,1, \ldots, L-1\}$. E seja a imagem em

$\overline{6}$ O valor do parâmetro de parada igual a 10 foi determinado através da análise de imagens cujo último grande pico eram menos íngremes. Esse valor foi suficiente para que um ponto próximo à base da curva fosse selecionado.

7 Mais uma vez, caso o leitor queira verificar as imagens das etapas de processamento das imagens de amostras das condições de combustão, inclusive com a possibilidade de comparar mais rapidamente a imagem original com a imagem em preto e branco, consultar o Apêndice A. 
Figura 32 - Imagem em preto e branco da amostra 2 da condição 2 com seu respectivo histograma.

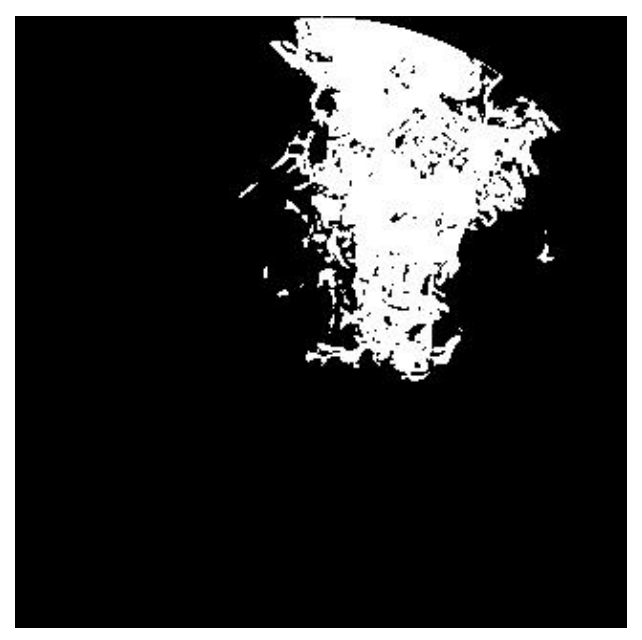

(a) Imagem da chama.

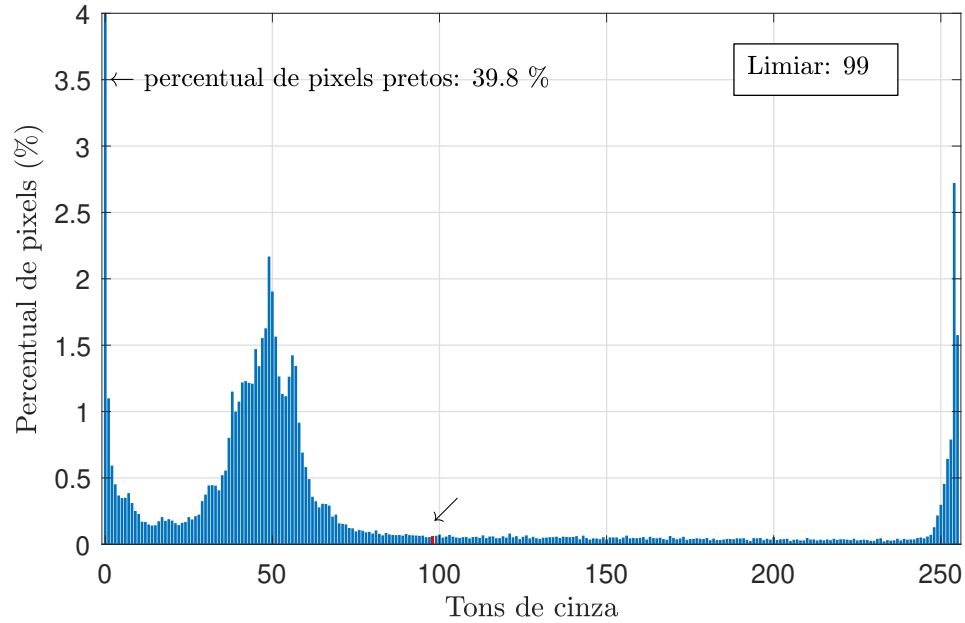

(b) Histograma da imagem.

Fonte - Elaborado pelo autor.

Figura 33 - Imagem em preto e branco da amostra 2 da condição 4 com seu respectivo histograma.

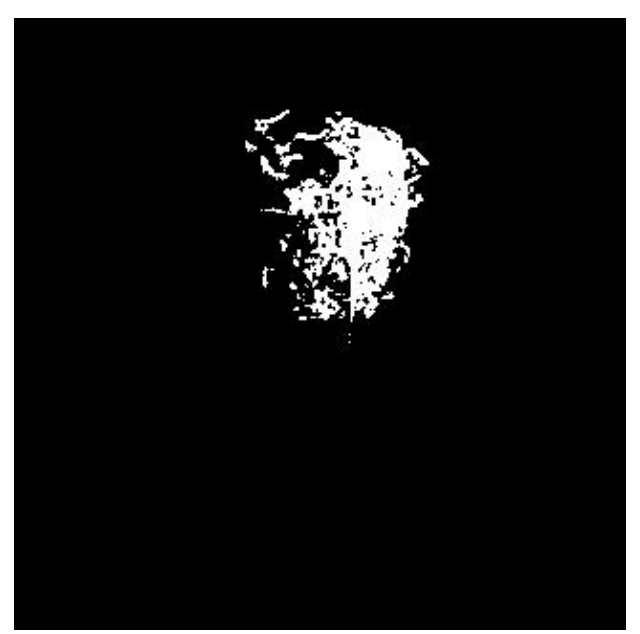

(a) Imagem da chama.

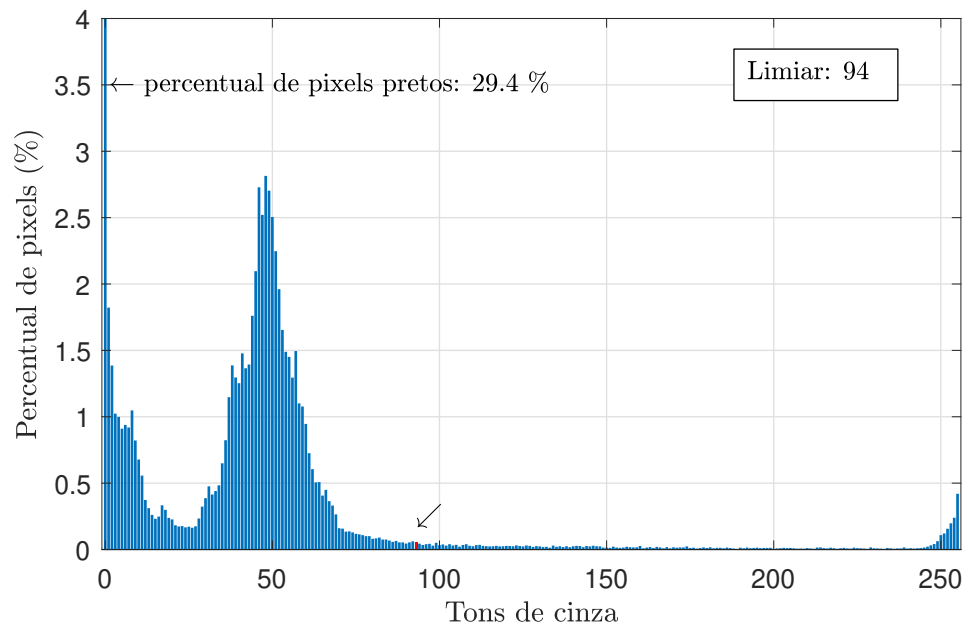

(b) Histograma da imagem.

Fonte - Elaborado pelo autor. 
preto e branco de $I$ representada pela imagem do operador $I^{p b}=I^{p b}(x, y) ; I^{p b}: U \subset \mathbb{N}^{2} \rightarrow$ $\bar{G}_{L} \in G_{L}$, onde $\bar{G}_{L}=\{0, L-1\}$. A segmentação é definida pelo operador $I^{s}=I^{s}(x, y)$ dado por:

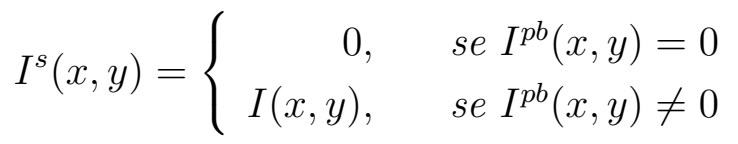

A figura 34 ilustra como ficam as imagens das amostras 2 das condições 2 e 4, após a execução do processo de segmentação descrito na Definição 4.4.

Figura 34 - Imagens segmentadas das amostras 2 das condições 2 e 4

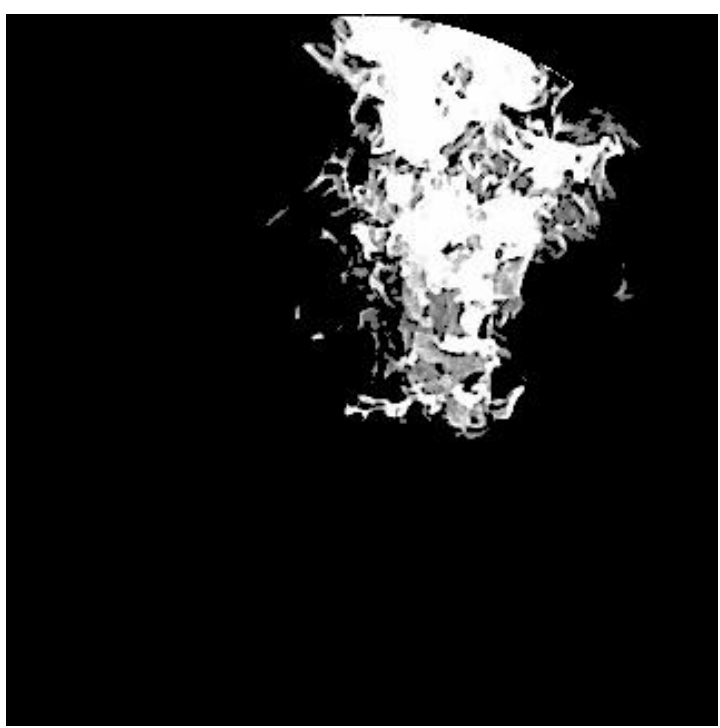

(a) Condição 2 - Amostra 2.

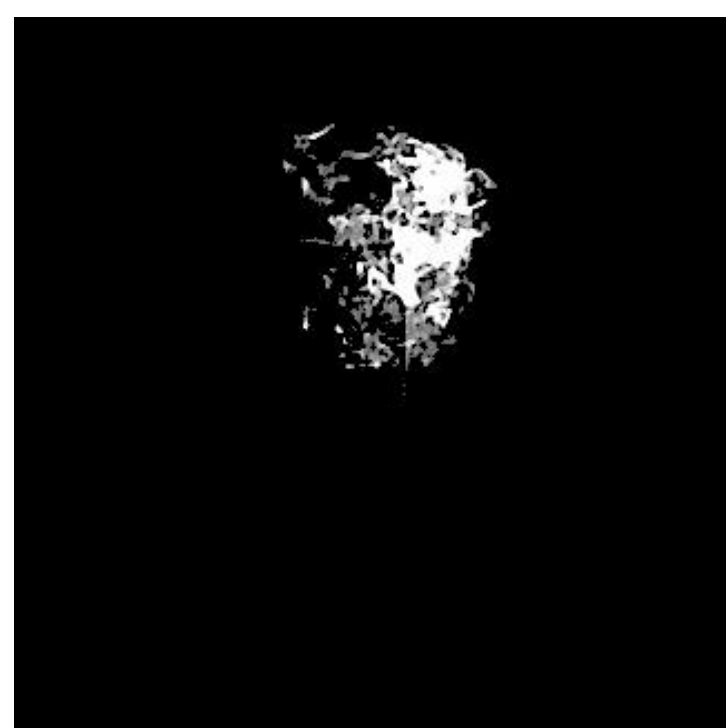

(b) Condição 4 - Amostra 2.

Fonte - Elaborado pelo autor.

\subsection{Propriedades geométricas e de iluminação}

Nesta seção são apresentadas as propriedades geométricas e de iluminação que serão utilizadas para formar o vetor característico da imagem. Até agora, as imagens foram referidas de forma genérica e independente e, por isso, elas foram denominadas imagens $I$. Porém, é preciso inseri-las no contexto da sequência temporal do conjunto de imagens existentes, chamando-as de imagens $I_{k}$, onde o índice $k$ denota uma imagem específica entre todo o universo de imagens. A tabela 7 mostra a quantidade total de imagens para cada condição de chama, $n_{\tau_{c}}$, e o intervalo $\tau_{c}$, que indica os valores de $k$ assumidos para cada condição de combustão.

Definição 4.5 (Imagens processadas de chama). Dada uma imagem monocromática $I_{k}$ onde $k=\left\{1,2, \ldots, N_{I}\right\}$ com $N_{I}=44.670$ (conforme tabela 7 ) sendo a quantidade total 
Tabela 7 - Valores dos índices $k$ das imagens divididos entre as diferentes condições de chama.

\begin{tabular}{lcl}
\hline $\begin{array}{l}\text { Condição de } \\
\text { combustão, } c\end{array}$ & $\begin{array}{c}\text { Quantidade de } \\
\text { imagens, } n_{\tau_{c}}\end{array}$ & $\begin{array}{c}\text { Intervalo de } k, \\
\tau_{c}\end{array}$ \\
\hline 1 & 7.290 & {$[1,7.290]$} \\
2 & 7.080 & {$[7.291,14.370]$} \\
3 & 7.260 & {$[14.371,21.630]$} \\
4 & 7.200 & {$[21.631,28.830]$} \\
5 & 7.230 & {$[28.831,36.060]$} \\
6 & 6.210 & {$[36.061,42.270]$} \\
7 & 2.400 & {$[42.271,44.670]$} \\
\hline
\end{tabular}

Fonte - Elaborado pelo autor.

de imagens disponíveis após a aquisição através do experimento descrito na seção 3.2. A imagem em preto e branco $I_{k}^{p b}$ da imagem $I_{k}$ é obtida a partir do processo de limiarização, conforme Definição 4.3, escolhendo $a=L-1$ e $b=0$. E a imagem segmentada $I_{k}^{s}$ é formada com as imagens $I_{k}$ e $I_{k}^{p b}$ de acordo com a Definição 4.4 .

Algumas características geométricas dependem de um ponto ou eixos de referência para a chama. O ponto $Q$, definido como o ponto central do bocal do queimador e origem dos eixos coordenados $x^{\prime} y^{\prime}$, será adotado quando necessário. A figura 35 ilustra a posição do ponto $Q=\left(x_{Q}, y_{Q}\right)$. Como se trata apenas de uma translação dos eixos $x y$, os eixos

Figura 35 - Interior do forno desligado com indicação dos eixos $x^{\prime} y^{\prime}$ e da origem $Q$

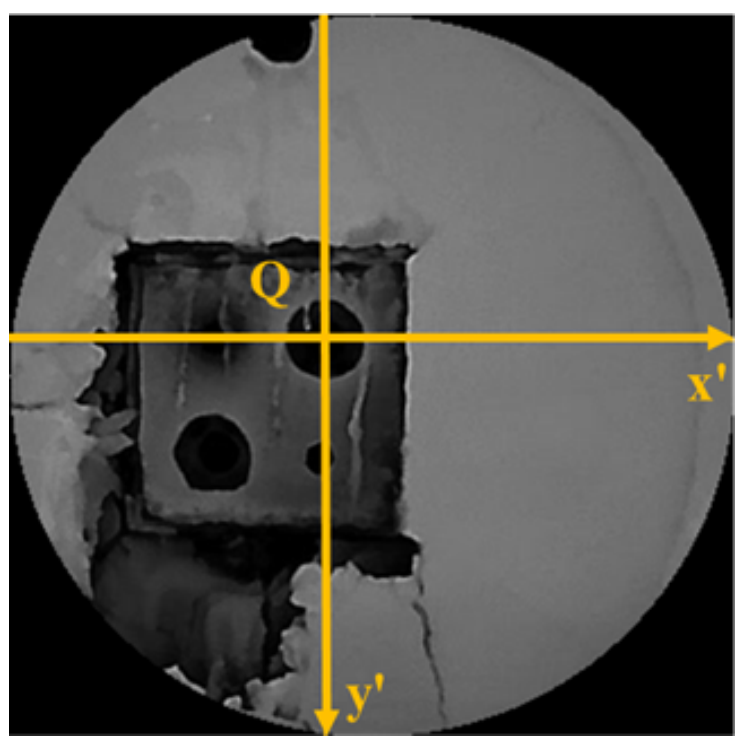

Fonte - Elaborado pelo autor. 
$x^{\prime} y^{\prime}$ podem ser descritos como:

$$
\begin{aligned}
& x^{\prime}(x)=x-x_{Q} \\
& y^{\prime}(y)=y-y_{Q}
\end{aligned}
$$

onde $\left(x_{Q}, y_{Q}\right)=(140,145)$.

Além disso, antes de se definir as propriedades do vetor característico $\boldsymbol{v}_{\boldsymbol{k}}(p)$, a metodologia para se obter o perímetro da imagem é apresentada juntamente com a Definição 4.6.

Definição 4.6 (Imagem de contorno). A imagem de contorno de $I^{p b}$ em tons de cinza representada pela imagem do operador $I^{c}=I^{c}(x, y) ; I^{c}: U \subset \mathbb{N}^{2} \rightarrow \bar{G}_{L}=\{0, L-1\}$ é a imagem que registra somente a borda da imagem $I^{p b}$ com pixels de tom branco $g=L-1 e$ apenas um pixel de largura. O restante dos pixels da imagem possui tom preto $g=0$.

A imagem $I^{c}$ é obtida através da operação morfológica de dilatação ${ }^{8}$ em $I^{p b}$ com o elemento estruturante sendo um disco de raio um pixel ${ }^{9}$, com subsequente subtração da imagem resultante pela própria imagem $I^{p b}$, resultando apenas no contorno da imagem. A figura 36 ilustra as imagens de contorno nas amostras 2 das condições 2 e 4.

Figura 36 - Imagens das bordas das amostras 2 das condições 2 e 4

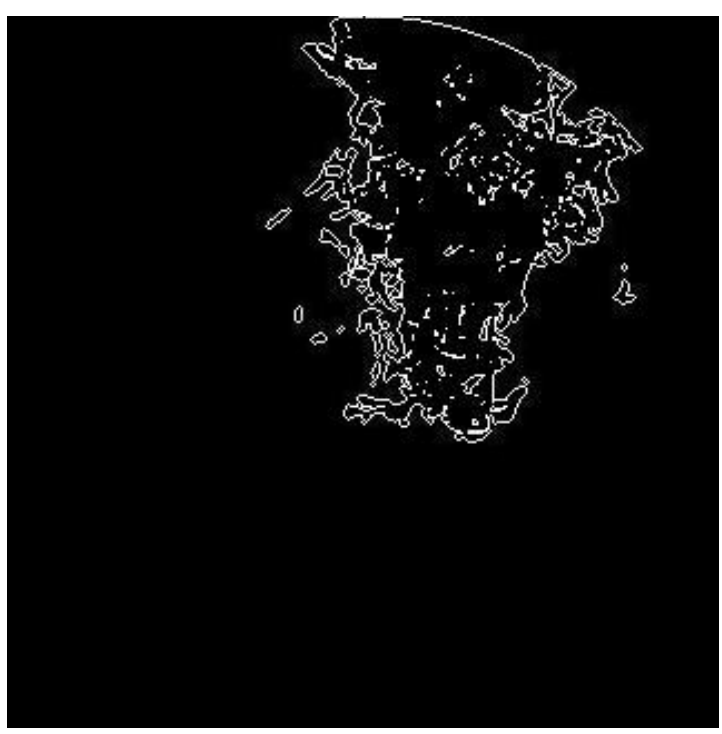

(a) Condição 2 - Amostra 2.

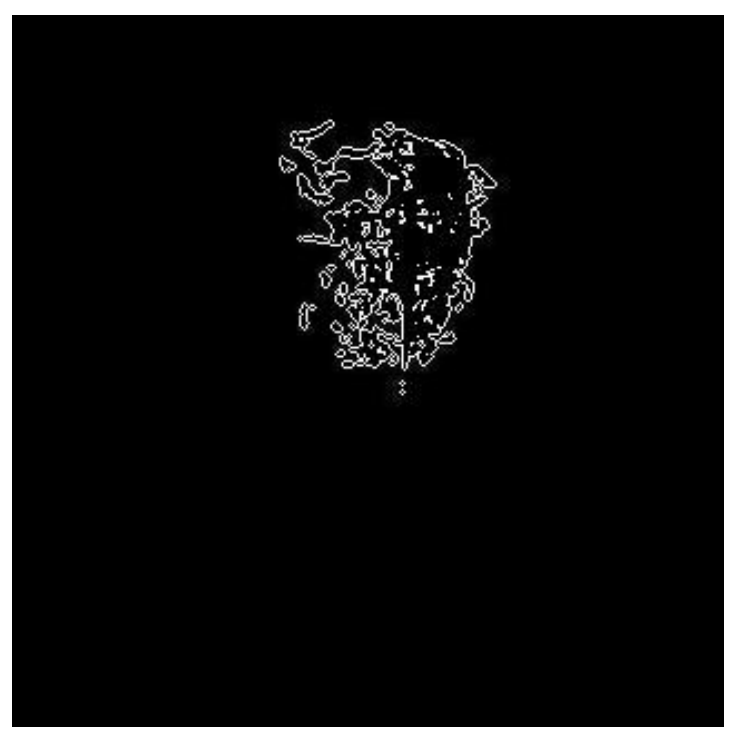

(b) Condição 4 - Amostra 2.

Fonte - Elaborado pelo autor.

8 Operações morfológicas de imagens são um tema denso e vasto no processamento digital de imagens, fugindo do escopo deste trabalho este detalhamento. Recomenda-se como referências o capítulo 9 de Gonzalez e Woods (2001) ou o capítulo 5 de Marques Filho e Vieira Neto (1999).

9 Um elemento estruturante em forma de disco com raio de 1 pixel equivale a um quadrado $3 \times 3$ onde não fazem parte do elemento estruturante os quatro pixels dos cantos, isto é, um elemento estruturante que se assemelha a uma pequena cruz. 
Para cada conjunto de imagens $I_{k}^{p b}, I_{k}^{s}$ e $I_{k}^{c}$ provenientes da imagem $I_{k}$, o vetor característico $\boldsymbol{v}_{\boldsymbol{k}}(p)$ é calculado considerando as propriedades $p \in P_{U}=\left\{1,2, \ldots, n_{p}\right\}$, com $n_{p}=15$, descritas a seguir:

a) $v_{k}(1)$ : área da imagem $I_{k}^{p b}$ em pixels, dada a equação

$$
A=\sum_{x=0}^{N-1} \sum_{y=0}^{M-1} \alpha\left(I_{k}^{p b}(x, y), L-1\right)
$$

onde a imagem $I_{k}^{p b}(x, y)$ é de tamanho $M \times N$ e $\alpha(I(x, y), g)$ foi definida na equação (4.2);

b) $v_{k}(2)$ : segundo momento de área relativo ao eixo $x^{\prime}$

$$
J_{x}=\sum_{x=0}^{N-1} \sum_{y=0}^{M-1}\left(y^{\prime}(y)\right)^{2} \alpha\left(I_{k}^{p b}(x, y), L-1\right)
$$

c) $v_{k}(3)$ : segundo momento de área relativo ao eixo $y^{\prime}$

$$
J_{y}=\sum_{x=0}^{N-1} \sum_{y=0}^{M-1}\left(x^{\prime}(x)\right)^{2} \alpha\left(I_{k}^{p b}(x, y), L-1\right)
$$

d) $v_{k}(4)$ : produto de inércia de área relativo aos eixos $x^{\prime} y^{\prime}$

$$
J_{x y}=\sum_{x=0}^{N-1} \sum_{y=0}^{M-1} x^{\prime}(x) y^{\prime}(y) \alpha\left(I_{k}^{p b}(x, y), L-1\right) ;
$$

e) $v_{k}(5)$ : momento polar de área em torno do ponto $Q$

$$
J_{p}=J_{x}+J_{y}
$$

f) $v_{k}(6)$ : coordenada $x^{\prime}$ do centróide da área da chama

$$
C_{x}=\frac{1}{A} \sum_{x=0}^{N-1} \sum_{y=0}^{M-1} x^{\prime}(x) \alpha\left(I_{k}^{p b}(x, y), L-1\right)
$$

g) $v_{k}(7)$ : coordenada $y^{\prime}$ do centróide da área da chama

$$
C_{y}=\frac{1}{A} \sum_{x=0}^{N-1} \sum_{y=0}^{M-1} y^{\prime}(y) \alpha\left(I_{k}^{p b}(x, y), L-1\right)
$$

h) $v_{k}(8)$ : perímetro da imagem $I_{k}^{p b}$, que é calculado a partir da imagem de contorno $I_{k}^{c}$

$$
P=\sum_{x=0}^{N-1} \sum_{y=0}^{M-1} \alpha\left(I_{k}^{c}(x, y), L-1\right)
$$

i) $v_{k}(9)$ : comprimento $L_{x}$ do lado horizontal (paralelo ao eixo $x$ ) do retângulo circunscrito a todas as partes da imagem $I_{k}^{p b}$ com tom de cinza igual a $g=L-1$; 
j) $v_{k}(10)$ : comprimento $L_{y}$ do lado vertical (paralelo ao eixo $y$ ) do retângulo circunscrito a todas as partes da imagem $I_{k}^{p b}$ com tom de cinza igual a $g=L-1$;

k) $v_{k}(11)$ : porcentagem da média de tons de cinza da imagem $I_{k}^{s}$, pode ser chamada de brilho médio

$$
B=\frac{1}{A} \sum_{x=0}^{N-1} \sum_{y=0}^{M-1}\left(I_{k}^{s}(x, y) /(L-1)\right) \alpha\left(I_{k}^{p b}(x, y), L-1\right) \times 100 ;
$$

l) $v_{k}(12)$ : não-uniformidade dos tons de cinza de $I_{k}^{s}$. Pode ser considerada uma medida de desvio do brilho médio $B$

$$
N_{U}=\sum_{x=0}^{N-1} \sum_{y=0}^{M-1}\left|\left(I_{k}^{s}(x, y) /(L-1)\right) \times 100-B\right| \alpha\left(I_{k}^{p b}(x, y), L-1\right)
$$

m) $v_{i}(13)$ : dispersão $D$ da imagem $I_{k}^{p b}$, que é uma medida do quão espalhados estão os objetos da imagem ao redor do centróide.

$$
\begin{aligned}
D_{x} & =\sqrt{\frac{1}{A} \sum_{x=0}^{N-1} \sum_{y=0}^{M-1}\left(x^{\prime}(x)-C_{x}\right)^{2} \alpha\left(I_{k}^{p b}(x, y), L-1\right)} \\
D_{y} & =\sqrt{\frac{1}{A} \sum_{x=0}^{N-1} \sum_{y=0}^{M-1}\left(y^{\prime}(y)-C_{y}\right)^{2} \alpha\left(I_{k}^{p b}(x, y), L-1\right)} \\
D & =\frac{D_{x}+D_{y}}{2}
\end{aligned}
$$

n) $v_{k}(14)$ : coordenada $g$ (eixo das abcissas) do centróide da área do histograma (não normalizado), $H_{x}$

$$
H_{x}=\frac{\sum_{g=1}^{L-1}(g+0.5) \cdot h(g)}{\sum_{g=1}^{L-1} h(g)}
$$

o) $v_{k}(15)$ : coordenada $h(g)$ (eixo das ordenadas) do centróide da área do histograma (não normalizado), $H_{y}$

$$
H_{y}=\frac{\sum_{g=1}^{L-1} h(g)^{2} / 2}{\sum_{g=1}^{L-1} h(g)}
$$

As últimas duas propriedades estão relacionadas com o histograma não normalizado $h(g)$ da imagem $I_{k}^{s}$. Nota-se que não são considerados os pixels de tom preto $(g=0)$ no cálculo delas, uma vez que $g$ inicia-se em 1 nas somatórias.

Por fim, considera-se que o vetor $\boldsymbol{v}_{\boldsymbol{k}}$ é obtido para todas as imagens $I_{k}$, e a partir daqui a análise se dará sobre os vetores característicos das imagens, que tem por função representá-las. 


\section{IDENTIFICAÇÃO DO MODELO DE CHAMA}

Neste capítulo, a metodologia utilizada para identificar os modelos de chama a partir dos vetores característicos das imagens é explicada. Primeiramente, na seção 5.1, os dados são separados numa parte para treinamento e outra parte para validação. O procedimento realizado para verificar a correlação entre as propriedades características de chama é apresentado na seção 5.2. Depois, na seção 5.3, descreve-se a análise de componentes principais. O próximo passo é aplicar o algoritmo do decremento aleatório (RD), explicado na seção 5.4, para se obter as respostas livres das variáveis submetidas a excitação aleatória. Em seguida, a seção 5.5 detalha os fundamentos do método no domínio do tempo de Ibrahim (ITD). Na seção 5.6, lança-se mão de todas as ferramentas apresentadas anteriormente para que a identificação do modelo de chama propriamente dita seja apresentada. A seção 5.7 descreve o método de validação do modelo identificado. Por fim, a seção 5.8 propõe uma metodologia para unificar os modelos de chama.

\subsection{Dados de treinamento e validação}

O conjunto de imagens (ou vetores característicos de imagens) de cada condição de combustão deve ser dividido para que uma parte seja usada para o treinamento, isto é, para a identificação dos modelos propriamente dita, e outra parte chamada de conjunto de validação, que será utilizada para testar se o modelo identificado é coerente com amostras que não foram utilizadas para a própria identificação.

O fluxograma da metodologia mostrado na figura 23 do capítulo 3 (página 71) mostra o processo iterativo existente para a identificação dos sistemas. Um dos parâmetros de iteração é justamente a porcentagem, em relação à quantidade total, de imagens a serem usadas como dados de treinamento $P_{t}$. É importante ressaltar que para cada condição de chama, uma porcentagem diferente é definida pelo método iterativo, que será detalhado na seção 5.5.6.

O limite mínimo foi definido para que não houvesse mais dados de validação do que de treinamento. O limite máximo foi definido de forma a não deixar um valor muito reduzido de imagens para validação, um valor mínimo de 1/5 de dados de validação foi considerado razoável. Então, os limites mínimo e máximo para $P_{t}$ são de $50 \%$ e $80 \%$ dos dados de cada condição de combustão, respectivamente. Por sua vez, o valor da 
porcentagem de dados de validação, $P_{v}$, é o complementar de $P_{t}$, ou seja

$$
P_{v}=1-P_{t}
$$

Consequentemente, o intervalo do índice de tempo $\tau_{c}$ (ver tabela 7, página 90) também é dividido para cada condição de combustão $c$ em um intervalo $\tau_{c, t}$ para os dados de treinamento e $\tau_{c, v}$ para os dados de validação. Dessa forma, o índice $k$ da imagem $I_{k}$ não irá somente determinar a condição de chama $c$ da imagem, mas também classificá-la entre dados de treinamento ou validação para cada condição $c$.

O valor total de imagens em cada conjunto pode ser calculada com base no total de imagens em cada condição de combustão $n_{\tau_{c}}$, também definido na tabela 7 :

$$
\begin{aligned}
& n_{\tau_{c, t}}=P_{t} \cdot n_{\tau_{c}} \\
& n_{\tau_{c, v}}=P_{v} \cdot n_{\tau_{c}}
\end{aligned}
$$

onde os resultados dessas equações são convenientemente arredondados, uma vez que $n_{\tau_{c, t}}, n_{\tau_{c, v}} \in \mathbb{N}$ e $n_{\tau_{c}}=n_{\tau_{c, t}}+n_{\tau_{c, v}}$.

\subsection{Análise de correlação}

Em princípio, é esperado que a evolução de cada propriedade da imagem no tempo apresente algum grau de correlação com a dinâmica da chama. Partindo dessa hipótese, o vetor característico $\boldsymbol{v}_{\boldsymbol{k}}$ de cada imagem $I_{k}$, onde $k=1,2, \ldots, N_{I}$ (citado na Definição 4.5, página 89) remete ao total de imagens, é calculado e também organizado em ordem temporal de forma que a sequência de cada componente $\boldsymbol{v}_{\boldsymbol{k}}(p)$ no tempo descreva a dinâmica de cada propriedade. Além disso, a dinâmica de cada componente $\boldsymbol{v}_{\boldsymbol{k}}(p)$ varia com a razão de equivalência $\varphi_{c}$. O intervalo de tempo $\tau_{c, t}$ compreende os índices $k$ de imagens do conjunto de treinamento de cada condição de combustão $c$. Logo, a função temporal de cada propriedade para cada condição de combustão pode ser definida como $f_{p}=f_{p}\left(\tau_{c, t}\right)$.

Definição 5.1 Seja $\tau_{c, t}$ o intervalo do índice temporal $k$, definido para cada condição de combustão $c=1,2, \ldots, n_{c}$. A função $f_{p}=f_{p}\left(\tau_{c, t}\right)$ exprime a evolução de uma propriedade $p \in P_{U}=\left\{1,2, \ldots, n_{p}\right\}^{1}$ no intervalo de tempo $\tau_{c, t}$ (definido na seção 5.1). A função $f_{p}$ pode ser definida como:

$$
f_{p}\left(\tau_{c, t}\right)=\boldsymbol{\delta}_{p}
$$

onde as componentes do vetor $\boldsymbol{\delta}_{p}$ podem ser determinados por:

$$
\delta_{p}(i)=\boldsymbol{v}_{k}(p), \forall k \in \tau_{c, t}
$$

onde $i=1,2, \ldots, n_{\tau_{c, t}}$.

\footnotetext{
1 As propriedades da imagem foram definidas nas páginas 92 a 93 .
} 
Nota-se que há uma sutil diferença entre o índice $i$ e o índice $k$, apesar de os dois índices tratarem da contagem de imagens ao longo do tempo. Sabendo-se, hipoteticamente, que se trata da condição de combustão 3 e que $P_{t}=100 \%$ (para tornar o exemplo menos complicado), $\delta_{p}(i)=\boldsymbol{v}_{\boldsymbol{k}}(p), \operatorname{com} i=1,2, \ldots, 7.260$ e $k=14.371,14.372, \ldots, 21.630$.

Pode-se definir também o cálculo da média do vetor $\boldsymbol{\delta}_{p}, \mu_{\delta_{p}}$, e do seu desvio padrão, $\sigma_{\delta_{p}}$, como:

$$
\begin{aligned}
\mu_{\delta_{p}} & =\frac{1}{n_{\tau_{c, t}}} \sum_{i=1}^{n_{\tau_{c, t}}} \delta_{p}(i) \\
\sigma_{\delta_{p}} & =\sqrt{\frac{1}{n_{\tau_{c, t}}} \sum_{i=1}^{n_{\tau_{c, t}}}\left(\delta_{p}(i)-\mu_{\delta_{p}}\right)^{2}}
\end{aligned}
$$

onde $\delta_{p}(i)$ são componentes do vetor $\boldsymbol{\delta}_{\boldsymbol{p}}$ e $n_{\tau_{c, t}}$ é o número total de amostras de imagens do conjunto de treinamento para a condição $c$.

A análise de correlação cruzada entre as propriedades da imagem tem o intuito de garantir que as propriedades escolhidas para a identificação do modelo não possuam alto grau de correlação, e consequentemente, para que não haja redundância nas informações extraídas das imagens. Para cada um dos intervalos $\tau_{c, t}$, a matriz $\boldsymbol{V}_{\boldsymbol{c}}$ é formada colocando as funções $f_{p}\left(\tau_{c, t}\right)$ nas suas colunas, $\forall p \in P_{U}$. Supõe-se, como exemplo, que as propriedades $p=a$ e $p=b$ dão origem aos vetores $f_{a}\left(\tau_{c, t}\right)=\boldsymbol{\delta}_{\boldsymbol{a}}$ e $f_{b}\left(\tau_{c, t}\right)=\boldsymbol{\delta}_{\boldsymbol{b}}$, com médias $\mu_{\delta_{a}}$ e $\mu_{\delta_{b}}$, e desvios padrão $\sigma_{\delta_{a}}$ e $\sigma_{\delta_{b}}$, respectivamente, conforme equações (5.6) e (5.7).

De acordo com Pearson e Galton (1895), o coeficiente de correlação linear de Pearson $\rho(a, b)$ entre as colunas $\boldsymbol{\delta}_{\boldsymbol{a}}$ e $\boldsymbol{\delta}_{\boldsymbol{b}}$ é definido como:

$$
\rho(a, b)=\frac{\operatorname{cov}\left(\boldsymbol{\delta}_{\boldsymbol{a}}, \boldsymbol{\delta}_{\boldsymbol{b}}\right)}{\sigma_{\delta_{\boldsymbol{a}}} \sigma_{\delta_{b}}}
$$

e pode ser calculado da seguinte maneira:

$$
\rho(a, b)=\frac{\sum_{i=1}^{n_{\tau_{c, t}}}\left(\delta_{a}(i)-\mu_{\delta_{a}}\right)\left(\delta_{b}(i)-\mu_{\delta_{b}}\right)}{\sqrt{\sum_{i=1}^{n_{\tau_{c, t}}}\left(\delta_{a}(i)-\mu_{\delta_{a}}\right)^{2} \sum_{i=1}^{n_{\tau_{c}, t}}\left(\delta_{b}(i)-\mu_{\delta_{b}}\right)^{2}}}
$$

Este coeficiente definido nas equações (5.8)-(5.9) assume valores $-1 \leq \rho(a, b) \leq 1$ onde 1 representa correlação linear positiva total, -1 representa correlação linear negativa total e zero representa nenhuma correlação linear². Evans (1996) sugere, conforme mostrado na tabela 8, uma classificação qualitativa do nível de correlação com o valor do módulo do coeficiente de Pearson, $\|\rho(a, b)\|$. Um algoritmo foi criado para comparar a correlação das propriedades duas a duas de forma a descartar aquelas com $\|\rho(a, b)\|>L_{\text {corr }}$, onde $L_{\text {corr }}$ é o valor limite que determina se as propriedades serão ou não consideradas correlacionadas. O valor escolhido para $L_{\text {corr }}$ leva em consideração os conceitos da tabela 8. Adotando-se

$\overline{2}$ Correlação linear positiva indica que as grandezas são proporcionais, correlação linear negativa indica que as grandezas são inversamente proporcionais. 
Tabela 8 - Conceitos qualitativos do coeficiente de correlação de Pearson.

\begin{tabular}{ll}
\hline Intervalo de $\|\rho\|$ & Conceito qualitativo \\
\hline $0,80-1,00$ & Muito forte \\
$0,60-0,79$ & Forte \\
$0,40-0,59$ & Moderado \\
$0,20-0,39$ & Fraco \\
$0,00-0,19$ & Muito fraco \\
\hline
\end{tabular}

Fonte - Adaptado de Evans (1996).

$L_{\text {corr }}=0,40$, descartam-se as propriedades com correlação moderada, forte ou muito forte, restando apenas as propriedades com correlação fraca ou muito fraca.

A matriz de correlação é uma matriz quadrada com dimensão $n_{p} \times n_{p}$, onde cada elemento da matriz indica o coeficiente $\|\rho(a, b)\|$ de uma propriedade indicada na linha $a$ da matriz com uma propriedade indicada na sua coluna $b$. Assim, essa matriz é naturalmente simétrica com os elementos da diagonal principal iguais a um, uma vez que a correlação de uma propriedade com ela mesma é um. É uma ferramenta excelente para resumir a informação dos coeficientes de correlação de Pearson para mais de duas variáveis.

Definição 5.2 (Matriz de correlação). Seja a matriz $\boldsymbol{V}_{\boldsymbol{c}} \in \mathbb{R}^{n_{\tau_{c, t}} \times n_{p}}$ formada pelas funções $f_{p}$ em suas colunas, $\forall p \in P_{U}$. A matriz de correlação $\boldsymbol{R}_{\boldsymbol{c}} \in \mathbb{R}^{n_{p} \times n_{p}}$ é uma matriz simétrica, onde cada elemento da matriz

$$
R_{c}(i, j)=\left\|\rho\left(f_{i}\left(\tau_{c, t}\right), f_{j}\left(\tau_{c, t}\right)\right)\right\|
$$

para $i=1,2, \ldots, n_{p}$ e $j=1,2, \ldots, n_{p}$.

Para determinar quais propriedades estão correlacionadas e quais não estão correlacionadas, segue-se o Algoritmo 5.1.

Algoritmo 5.1 Este algoritmo determina, a partir de uma matriz de correlação $\boldsymbol{R}_{\boldsymbol{k}}$, quais propriedades em $\boldsymbol{R}_{k}$ são correlacionadas entre si, $\|\rho\| \geq L_{\text {corr }}$, e quais não são correlacionadas entre si, $\|\rho\|<L_{\text {corr }}$ :

a) Determinar a quantidade $n_{\text {corr }}(j) \in \mathbb{N}$ de elementos com $\|\rho\| \geq L_{\text {corr }}$ existentes em cada coluna $j$ de $\boldsymbol{R}_{k}$;

b) Relacionar os indices $j$ das colunas de $\boldsymbol{R}_{\boldsymbol{k}}$ aos vetores temporais de cada propriedade, $\boldsymbol{\delta}_{j}$.

c) Separar os vetores em dois grupos: um grupo de propriedades correlacionadas $\left(C_{\text {corr }}\right)$, isto é, aquelas em que $n_{\text {corr }}(j)>1$, e um grupo de propriedades não correlacionadas 
$\left(N_{\text {corr }}\right)$, onde $n_{\text {corr }}(j)=1$ (a correlação de uma propriedade com ela mesma será sempre igual a 1 e, portanto, maior que $\left.L_{\text {corr }}\right)$;

O Algoritmo 5.2 de análise de correlação entre as propriedades da imagem proposto tem uma característica recursiva, isto é, é um algoritmo que chama ele mesmo até que uma condição de parada seja alcançada. Para explicitar essa característica, além da descrição do algoritmo, a figura 37 exibe um fluxograma desse algoritmo.

Algoritmo 5.2 (Análise de correlação entre propriedades da imagem). Este algoritmo recebe como entradas um conjunto de propriedades que a princípio se supõe correlacionadas $C_{\text {corr }}^{e}$, e um conjunto de propriedades não correlacionadas $N_{\text {corr }}^{e}$, e devolve como saída um novo conjunto de propriedades não correlacionadas $N_{\text {corr }}^{s}$. Enquanto o algoritmo não chegar no critério de parada, que é quando $C_{c o r r}=\emptyset$, ele continua iterando com subconjuntos do $C_{\text {corr }}^{e}$ original:

a) iniciar o algoritmo com $C_{\text {corr }}^{e}=P_{U}$ e $N_{\text {corr }}^{e}=\emptyset$;

b) calcular a matriz de correlação $\boldsymbol{R}_{k}$ de $C_{\text {corr }}^{e}$ conforme Definição 5.2;

c) executar o Algoritmo 5.1 para a matriz $\boldsymbol{R}_{\boldsymbol{k}}$, que resulta nos conjuntos $C_{\text {corr }}$ e $N_{\text {corr }}$;

d) verificar se $C_{\text {corr }}=\emptyset$, em caso positivo, pular para o item (j), em caso negativo, continuar na sequência;

e) verificar se $N_{c o r r}=\emptyset$, em caso positivo, continuar na sequência, em caso negativo, pular para o item $(h)$;

f) identificar a propriedade mais correlacionada $p^{*}$ em $C_{c o r r}$, que será aquela que, durante o Algoritmo 5.1, obteve o maior valor de $n_{\text {corr }}(j)$, isto é:

$$
p^{*}=\left(\arg \max _{j} n_{c o r r}(j)\right)
$$

g) descartar a propriedade $p^{*}$ de $C_{\text {corr }}$;

h) executar novamente este Algoritmo 5.2 a partir do item (a), mas redefinindo as entradas para essa nova instância como $\bar{C}_{\text {corr }}^{e}=C_{\text {corr }}$ e $\bar{N}_{\text {corr }}^{e}=N_{\text {corr }}$, onde a barra denota conjuntos da nova instância;

i) redefinir o conjunto $N_{\text {corr }}$ como sendo igual a $\bar{N}_{\text {corr }}^{s}$;

j) verificar, para cada propriedade $i$ em $N_{\text {corr }}$, se sua correlação com cada propriedade $j$ de $N_{\text {corr }}^{e}$ de fato possui $\|\rho(i, j)\|<L_{\text {corr }}$. Caso $\|\rho(i, j)\| \geq L_{\text {corr }}$, descartar a propriedade $i$;

k) montar um conjunto $N_{\text {corr }}^{s}$ unindo as propriedades de $N_{\text {corr }}^{e}$ às propriedades não descartadas de $N_{\text {corr }}$ no item (j);

l) entregar como saída o conjunto $N_{\text {corr }}^{s}$; 
Figura 37 - Fluxograma do algoritmo de análise de correlação da imagem.

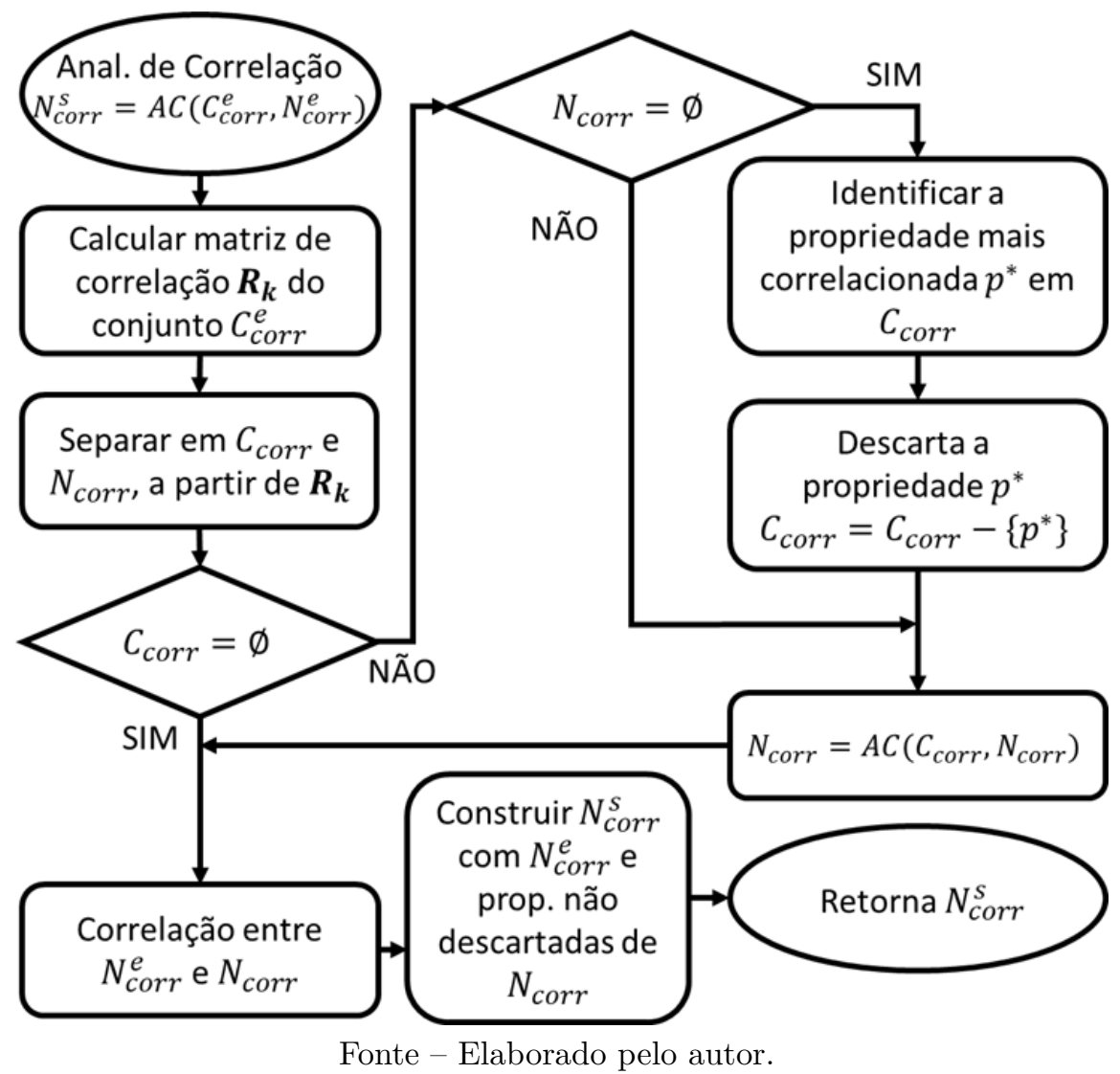

Em resumo, o Algoritmo 5.2 reduz o conjunto $C_{\text {corr }}^{e}$ com propriedades correlacionadas até encontrar um conjunto $N_{\text {corr }}$ com propriedades não correlacionadas dentro dele. Depois, o algoritmo verifica se há propriedades correlacionadas entre $N_{\text {corr }}$ e $N_{c o r r}^{e}$, descartando-as caso houver. Por fim, constrói-se um conjunto consolidado de propriedades descorrelacionadas $N_{c o r r}^{s}$. Cada vez que uma propriedade é descartada, uma nova instância do algoritmo 5.2 é criada com novos conjuntos de entrada. Até que, em algum momento depois de algumas iterações (com a criação de uma nova instância a cada uma delas), o conjunto $C_{c o r r}$ se torna vazio, e então cada instância do algoritmo chega ao seu final entregando um conjunto de propriedades não correlacionadas $N_{\text {corr }}$ à instância anterior, até voltar para a instância inicial, entregando o resultado final.

As propriedades remanescentes, que compõem o conjunto $N_{c o r r}^{s}$ do Algoritmo 5.2, formam a base de dados para o próximo procedimento que é a análise de componentes principais (PCA). Pode-se, então, considerar, que as propriedades $p \in N_{\text {corr }}^{s} \subset P_{U}$ são as propriedades resultantes do processo de análise de correlação, cuja quantidade varia para cada condição de combustão $c$ e pode ser expressa pela variável $n_{p, c}$. 


\subsection{Análise de componentes principais (PCA)}

As propriedades resultantes da seção anterior podem ser vistas como diferentes variáveis que descrevem o fenômeno da combustão. Ou seja, essas propriedades podem ser interpretadas como as variáveis de estado de um modelo do fenômeno de combustão através da captura de imagens. No entanto, pode ser difícil trabalhar com um número elevado de variáveis de estado, ainda mais com o intuito de se aplicar as técnicas de identificação que serão vistas mais adiante. A análise de componentes principais (PCA) pode ser utilizada para diminuir o número de variáveis que descrevem um fenômeno com pequena perda de informação.

Imagine que um estado do sistema possa ser representado pelos valores de cada uma das $n_{s}$ variáveis de estado em um determinado instante. Então, esse estado seria um ponto num gráfico em $\mathbb{R}^{n_{s}}$, onde cada coordenada nesse espaço representa uma propriedade, ou uma variável de estado. A PCA é uma técnica útil para a classificação e compressão de dados. Na prática, esta técnica é uma transformação de coordenadas, onde as novas coordenadas são as direções em ordem de variância dos dados (da maior para a menor) e que são ortogonais entre si, e são as chamadas componentes principais. Pelo fato de estar ordenada por variância, é possível descartar a(s) coordenada(s) de baixa variância para diminuir o número de variáveis de estado que descreve o fenômeno.

A PCA foi descrita inicialmente por Pearson (1901), o mesmo autor do coeficiente de correlação, mas foi consolidada, através de uma abordagem diferente, por Hotelling (1933). Hotelling (1936) demonstrou um método mais rápido para se obter componentes principais. Não é o intuito deste trabalho se estender sobre os fundamentos da PCA, recomenda-se Jolliffe (2003) e Jackson (2005) para um maior aprofundamento no assunto.

O primeiro passo é reconhecer que os dados não necessariamente possuem a mesma ordem de grandeza, e uma vez que a PCA se baseia na variância dos dados, caso não seja realizado algum tipo de normalização, os dados com maior ordem de grandeza apresentarão variâncias com números absolutos maiores, o que influencia no estabelecimento do novo conjunto de variáveis a ser encontrado.

Definição 5.3 Seja $f_{p}\left(\tau_{c, t}\right)=\boldsymbol{\delta}_{p}$, conforme Definição 5.1, onde $p \in N_{\text {corr }}^{s} \subset P_{U}$ e $\tau_{c, t}=\tau_{1, t}, \tau_{2, t}, \ldots, \tau_{n_{c}, t}$, então $\boldsymbol{\delta}_{p}$ é um vetor de uma propriedade não correlacionada. $A$ normalização de $\boldsymbol{\delta}_{p}$ é chamada de $\boldsymbol{\delta}_{p}^{n}$, onde o índice $n$ denota normalização. As componentes de $\boldsymbol{\delta}_{p}^{n}$ são dadas por:

$$
\delta_{p}^{n}(i)=\frac{\delta_{p}(i)-\mu_{\delta_{p}}}{\sigma_{\delta_{p}}}
$$

Algoritmo 5.3 (Análise de componentes principais). A partir das propriedades não correlacionadas $p$, os vetores $\boldsymbol{\delta}_{p}^{n}, \forall p \in N_{\text {corr }}^{s} \subset P_{U}$, são utilizados como dados de entrada do algoritmo: 
a) calcular a matriz de covariância entre os vetores $\boldsymbol{\delta}_{p}^{n}, \forall p \in N_{\text {corr }}^{s}$;

b) diagonalizar a matriz de covariância calculada no item (a), onde a matriz $\boldsymbol{\Pi}$ é a matriz transformação de coordenadas que diagonaliza a matriz de covariância;

c) calcular os autovalores da matriz $\boldsymbol{\Pi}$;

d) dividir os autovalores da matriz $\boldsymbol{\Pi}$ pela soma de todos os autovalores para obter a proporção de contribuição na variância total que cada autovalor (componente principal) fornece;

e) definir a porcentagem mínima da variância que se quer manter;

f) verificar quantas componentes principais são necessárias para atingir a porcentagem mínima estabelecida;

g) truncar a matriz $\boldsymbol{\Pi}$ deixando apenas as colunas (autovetores) relacionadas aos autovalores que permanecerão. Dessa forma, se obtém a matriz de transformação que relaciona as propriedades normalizadas com as componentes principais;

h) se for necessário obter de volta as propriedades, deve-se realizar as operações inversas da normalização.

\subsection{O algoritmo de decremento aleatório (RD)}

O ITD, que será visto adiante, requer dados da resposta livre do sistema para conseguir identificar os parâmetros modais. Em muitas situações, obter a resposta livre de um sistema é praticamente impossível. Aplicações em engenharia civil, como pontes e edifícios, recebem excitações aleatórias vindas do meio ambiente a todo momento. No caso do sistema da chama, Silva et al. (2015) citam que para se obter de forma experimental a resposta livre do sistema seria necessário fazer a chama se extinguir, o que é considerado uma condição operacional de risco à segurança do forno. Uma maneira de evitar esse problema e de ampliar o escopo do método ITD foi proposta por Ibrahim (1977) e é utilizar o chamado algoritmo de decremento aleatório, também conhecido como RD, apresentado por Cole Jr. (1968), Cole Jr. (1971).

O RD obtém uma estimativa da resposta livre a partir de respostas com excitação aleatória. Segundo Asmussen (1997), Cole Jr. (1968) explica o conceito da técnica RD com os seguintes argumentos. A resposta aleatória de um sistema no tempo $t_{0}+\Delta t$ é composta por três partes:

1. A resposta ao degrau devida aos deslocamentos iniciais no tempo $t_{0}$.

2. A resposta ao impulso devida às velocidades iniciais no tempo $t_{0}$.

3. Uma parte aleatória (com suposta média nula) que é devida à carga aplicada à estrutura no período entre $t_{0}$ e $t_{0}+\Delta t$. 
Figura 38 - Gráfico ilustrativo da seleção dos segmentos de tempo da resposta $x(t)$.

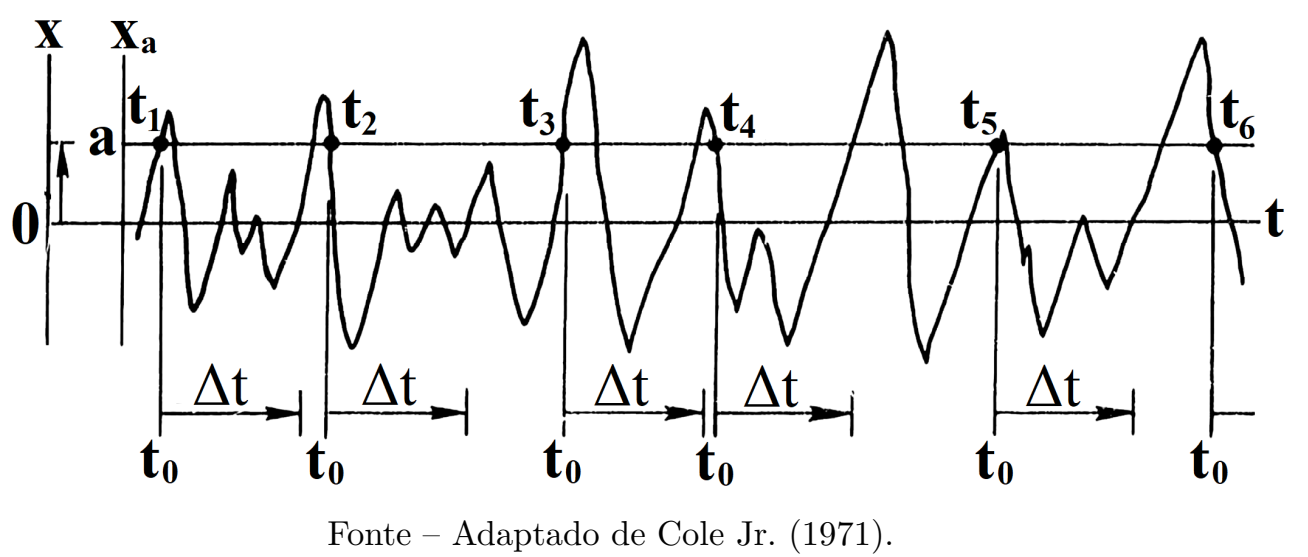

O conceito da técnica RD é selecionar um segmento de tempo da resposta toda vez que a resposta aleatória, $x(t)$, tiver um deslocamento inicial $x(t)=a$, e então fazer a média das respostas de todos estes segmentos de tempo selecionados. À medida que o número de médias aumenta, a parte aleatória devida à carga aleatória irá eventualmente se reduzir à sua média e se tornar desprezível. Além disso, espera-se que o sinal da velocidade inicial varie aleatoriamente com o tempo de forma que a velocidade inicial resultante tenda a zero. A parte que sobra é a resposta livre a partir do deslocamento inicial, $a$. A figura 38 ilustra a seleção dos segmentos de tempo $t_{0}+\Delta t$ de uma resposta aleatória $x(t)$, dada como exemplo por Cole Jr. (1971), quando $x(t)=a$ e as velocidades tenham sinais alternantes.

É comum definir o deslocamento inicial a como sendo o nível de desencadeamento da seleção das medidas, e os pontos $t_{0}$ na linha temporal onde $x=a$ como sendo os pontos de desencadeamento. Definindo-se a média de $x(t)$ como $\mu_{x}=E(x)$, e seu desvio padrão como $\sigma_{x}=\sqrt{E\left[\left(x-\mu_{x}\right)^{2}\right]}$, Asmussen (1997) afirma que um valor comum para o nível de desencadeamento $a$ é:

$$
a=\mu_{x}+\sqrt{2} \cdot \sigma_{x}
$$

O processo de estimativa das funções RD, que Cole Jr. (1971) chamou de assinatura $R D$, pode ser descrito como a soma de segmentos de tempo retirados da resposta $x(t)$ sob a condição que todos os segmentos de tempo tenham o valor a no seu início:

$$
\hat{D}_{x x}(\tau)=\frac{1}{N_{r d}} \sum_{i=1}^{N_{r d}} x\left(t_{i}+\tau\right) \mid x\left(t_{i}\right)=a
$$

onde $\hat{D}_{x x}$ é a função RD estimada, $\tau$ é a variável temporal em $\hat{D}_{x x}$ e $N_{r d}$ é o número total de pontos de desencadeamento. A figura 39 ilustra como fica a assinatura RD após o cálculo da equação (5.14) com um número suficientemente grande de segmentos de tempo computados. Portanto, a assinatura RD tende a se aproximar da resposta livre do sistema. 
Figura 39 - Gráfico ilustrativo da assinatura RD do exemplo da figura 38.

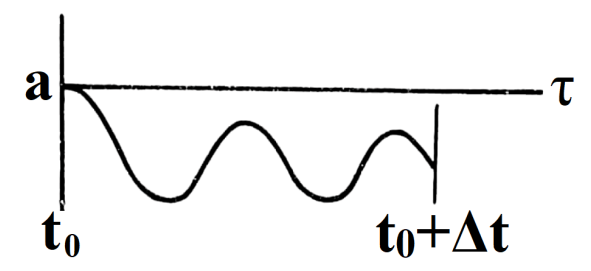

Fonte - Adaptado de Cole Jr. (1971).

A grande desvantagem do algoritmo RD é o fato de necessitar de uma quantidade de dados relativamente grande para que se consiga uma resposta estatisticamente aceitável. Além do fato do RD fazer basicamente uma média e, portanto, já requerer uma quantidade de dados suficiente para levar a média ao valor esperado (esperança matemática), a necessidade de procurar pelo nível de desencadeamento faz com que alguns dados sejam descartados durante essa busca.

A fim de reduzir o desperdício de dados, Asmussen (1997) sugere utilizar um intervalo de desencadeamento, $a+\Delta a$ ao invés de um único valor, o que seria mais razoável para o tratamento numérico do que simplesmente um valor $a$ em que a amostra deveria acertar de forma exata. No entanto, ao admitir um $\Delta a$ na busca por uma amostra que causasse o desencadeamento da coleta, há um erro no instante inicial que pode acarretar num erro no cálculo da equação (5.14). Assim, para garantir maior precisão dos segmentos coletados, escolheu-se por verificar se entre um ponto e outro houve a ultrapassagem de $a$. Caso a ultrapassagem seja detectada, o valor do instante de desencadeamento é calculado via interpolação. Esse método garante melhor precisão na resposta da equação (5.14) ao mesmo tempo que diminui o desperdício de dados. A desvantagem desse método é que como o instante inicial é um ponto interpolado entre duas amostras, e é necessário manter a taxa de amostragem constante, todos os pontos seguintes dessa coleta devem ser interpolados também, o que aumenta o esforço computacional.

\subsection{O método do domínio do tempo de Ibrahim (ITD)}

A identificação de parâmetros modais no domínio do tempo é uma maneira diferente de resolver o problema de identificação em relação a abordagens mais clássicas no domínio da frequência. Há algumas vantagens da identificação no domínio do tempo como, por exemplo, a eliminação da necessidade de executar transformações para o domínio da frequência nas entradas e nas saídas do sistema, o que evita os problemas associados como o fenômeno de vazamento (leakage), truncamento ou resolução na frequência. Por outro lado, a identificação de parâmetros modais no domínio do tempo necessita de um conhecimento a priori do número de graus de liberdade do sistema. Como geralmente não se sabe isso de antemão, métodos iterativos são utilizados para determinar qual o número 
de graus de liberdade resulta num menor grau de erro.

Ibrahim (1999) afirmou que existem duas classes de identificação no domínio do tempo. A primeira classe são as técnicas que requerem medição ou identificação das entradas. A segunda classe, por sua vez, necessita da resposta livre do sistema, eliminando as complexidades envolvidas em medir ou identificar as entradas. No entanto, esse tipo de identificação não possibilita a obtenção dos fatores de participação modal que são necessários para o cálculo dos residuais modais e das massas modais, quando a entrada não é o impulso unitário.

As técnicas de identificação no domínio do tempo que utilizam a resposta livre em conjunto com transformação por decremento aleatório, visto na seção 5.4, oferecem uma ferramenta valiosa para identificar os parâmetros modais de sistemas a partir de respostas operacionais. Quando sistemas são sujeitos a entradas aleatórias não medidas ou desconhecidas, a transformação por decremento aleatório pode reduzir essas respostas para respostas livres equivalentes ou funções de correlação. Estas funções de decremento aleatório podem ser usadas diretamente para identificar parâmetros modais de um sistema.

A técnica denominada ITD foi concebida na década de 1970 e sua aplicação se estabeleceu principalmente na área de mecânica estrutural. Ibrahim e Mikulcik (1973) introduziram a parte teórica do método para respostas livres e Ibrahim e Mikulcik (1977) a estenderam e mostraram seu uso em aplicações práticas. Ibrahim (1977) utilizou o método com a transformação por decremento aleatório a fim de utilizar o método a partir de respostas aleatórias ou operacionais. Ibrahim (1978) apresentou o fator de confiança modal (FCM) como uma maneira de distinguir entre modos reais do sistema e modos identificados a partir de ruído. Pappa e Ibrahim (1981) fizeram uma revisão agregando todos os aspectos da pesquisa sobre ITD até aquele momento. Ibrahim (1984) apresentou uma solução modificada dos mínimos quadrados a fim de eliminar o viés na identificação do fator de amortecimento e melhorar a precisão da identificação.

O grande mérito do ITD é possibilitar, através da abordagem no tempo, a identificação de parâmetros modais em sistemas com vários graus de liberdade de uma só vez. No entanto, além do problema de ter que escolher qual número de graus de liberdade melhor se adequa aos dados, o método necessita da definição de alguns parâmetros próprios, cujas escolhas não são triviais. Além disso, a identificação de um sistema de equações diferenciais homogêneas (apenas resposta livre) também é um limitante quando o objetivo é identificar sistemas em que há termos forçantes importantes para o modelo.

\subsubsection{Base teórica do método do domínio do tempo de Ibrahim (ITD)}

Nesta seção será apresentada a base teórica do método do domínio do tempo de Ibrahim (ITD). A linguagem para descrever o método considera um sistema mecânico 
estrutural, que mais tarde será generalizado para outras aplicações.

Admite-se, por hipótese, que a dinâmica da resposta livre do sistema possa ser descrita pela equação (5.15), que representa um sistema de $2^{a}$ ordem tipo massa-molaamortecedor para cada um dos $n$ graus de liberdade:

$$
M \ddot{\boldsymbol{y}}+\boldsymbol{D} \dot{\boldsymbol{y}}+\boldsymbol{K} \boldsymbol{y}=\mathbf{0}
$$

onde $\boldsymbol{y} \in \mathbb{R}^{n}, \dot{\boldsymbol{y}} \in \mathbb{R}^{n}$ e $\ddot{\boldsymbol{y}} \in \mathbb{R}^{n}$ são respectivamente os vetores de deslocamento, velocidade e aceleração, $\boldsymbol{M} \in \mathbb{R}^{n \times n}$ é matriz de massa do sistema, $\boldsymbol{D} \in \mathbb{R}^{n \times n}$ é a matriz de amortecimento e $\boldsymbol{K} \in \mathbb{R}^{n \times n}$ é a matriz de rigidez. A solução de (5.15) tem a forma

$$
\boldsymbol{y}=\sum_{k=1}^{2 n} \boldsymbol{\psi}_{\boldsymbol{k}} e^{\lambda_{k} t}
$$

isto é, o vetor deslocamento $\boldsymbol{y}$ é a soma das contribuições de todos os $n$ modos de vibrar, onde cada $k$-ésimo modo satisfaz

$$
\left[\lambda^{2} \boldsymbol{M}+\lambda \boldsymbol{D}+\boldsymbol{K}\right] \boldsymbol{\psi}=\mathbf{0}
$$

Na representação por espaço de estados, o sistema (5.15) fica da seguinte forma:

$$
\dot{\boldsymbol{x}}=\boldsymbol{A} \boldsymbol{x}
$$

onde $\boldsymbol{x} \in \mathbb{R}^{2 n}$ é o vetor de variáveis de estado (que pode ser formado por uma combinação linear dos vetores $\boldsymbol{y}$ e $\dot{\boldsymbol{y}}$ ) e $\boldsymbol{A} \in \mathbb{R}^{2 n \times 2 n}$ é matriz do sistema, de forma que o sistema (5.18) é formado por $2 n$ equação diferenciais de $1^{\text {a }}$ ordem. A matriz da dinâmica do sistema $\boldsymbol{A}$ armazena todas as informações de inércia, amortecimento e rigidez do sistema em questão. A partir da equação (5.18), é possível chegar nas mesmas raízes da equação característica de (5.17). Basta aplicar a transformada de Laplace em (5.18).

$$
\lambda \boldsymbol{X}=\boldsymbol{A} \boldsymbol{X}
$$

Uma vez que $\lambda$ é um escalar, a solução de (5.19) é a mesma de um problema de autovalores e autovetores, recaindo numa solução equivalente a (5.17).

$$
\left[\boldsymbol{A}-\lambda \boldsymbol{I}_{2 n}\right] \boldsymbol{\psi}=\mathbf{0}
$$

A equação (5.17) ou (5.20) definem $2 n$ valores para $\lambda$, que são também as raízes da equação característica do sistema. Cada grau de liberdade se comporta como um subsistema de $2^{\mathrm{a}}$ ordem, e por isso apresenta a seguinte equação característica:

$$
\lambda^{2}+2 \zeta \omega_{n} \lambda+\omega_{n}^{2}=0
$$

onde $\omega_{n}$ é frequência natural não amortecida ( $\left.\mathrm{rad} / \mathrm{s}\right)$ e $\zeta$ é o fator de amortecimento do modo de vibrar do grau de liberdade correspondente. As soluções que $\lambda$ pode assumir, ao se resolver a equação (5.21), são:

$$
\lambda_{1,2}=-\zeta \omega_{n} \pm \omega_{n} \sqrt{\zeta^{2}-1}
$$


Para cada par de raízes $\lambda_{1}$ e $\lambda_{2}$ há um par de vetores correspondentes $\boldsymbol{\psi}_{\mathbf{1}}$ e $\boldsymbol{\psi}_{\mathbf{2}}$, respectivamente. Para sistemas superamortecidos, $\lambda_{1,2}$ e $\boldsymbol{\psi}_{\mathbf{1}, \mathbf{2}}$ assumem pares de valores reais para cada modo. Mas para sistemas subamortecidos, $\lambda_{1,2}$ e $\boldsymbol{\psi}_{\mathbf{1 , 2}}$ são valores complexos e ocorrem em pares conjugados para cada modo. Cada par de autovalores e autovetores se combinam para produzir um modo de vibrar correspondente a uma única frequência natural e um fator de amortecimento.

A resposta do sistema varia de acordo com o valor assumido pelo fator de amortecimento. Para $\zeta=0$ a resposta é não amortecida, e para $0<\zeta<1$ a resposta é subamortecida. Para esses dois casos, a fim de unificar a nomenclatura com Pappa e Ibrahim (1981), a equação (5.22) pode ser representada como a equação (5.23):

$$
\lambda_{1,2}=-\sigma \pm i \omega_{d}
$$

onde $\omega_{d}$ é a frequência natural amortecida em rad/s e $\sigma$ é a parte real de $\lambda$. A frequência natural não amortecida ( rad/s) e o fator de amortecimento podem ser calculados, a partir de $\sigma$ e $\omega_{d}$ por $(5.24)$ e $(5.25)$, respectivamente:

$$
\begin{aligned}
\omega_{n} & =\sqrt{\sigma^{2}+\omega_{d}^{2}} \\
\zeta & =\frac{\sigma}{\omega_{n}}
\end{aligned}
$$

Quando $\zeta=1$ a resposta do sistema é chamada de criticamente amortecida e quando $\zeta>1$ a resposta será superamortecida. Em ambos os casos, as soluções de $\lambda$ da equação (5.22) serão números reais. Pappa e Ibrahim (1981) não desenvolvem seu método de identificação para esses casos, mas não é difícil chegar aos valores de $\omega_{n}$ e $\zeta$ para esses casos. A partir da equação de $2^{\circ}$ grau (5.21) deduz-se que as soluções são:

$$
\lambda_{1,2}=-\zeta \omega_{n} \pm \omega_{n} \sqrt{\zeta^{2}-1}
$$

onde $\lambda_{1}$ e $\lambda_{2}$ são números reais quando $\zeta \geq 1$.

Portanto, pode-se chegar nas seguintes relações:

$$
\begin{gathered}
\lambda_{1}+\lambda_{2}=-2 \zeta \omega_{n} \\
\lambda_{1} \cdot \lambda_{2}=\omega_{n}^{2}
\end{gathered}
$$

E assim, os valores da frequência natural $\omega_{n}$ e do fator de amortecimento $\zeta$ são calculados, uma vez que se conhece as raízes de (5.21), da seguinte forma:

$$
\begin{aligned}
\omega_{n} & =\sqrt{\lambda_{1} \cdot \lambda_{2}} \\
\zeta & =-\frac{\lambda_{1}+\lambda_{2}}{2 \sqrt{\lambda_{1} \cdot \lambda_{2}}}
\end{aligned}
$$

Ibrahim e Mikulcik (1977) afirmam que o problema da análise modal consiste em determinar, através de dados medidos, os valores de $\lambda$ e $\boldsymbol{\psi}$ que satisfazem as equações (5.17) 
ou (5.20). A resposta medida, seja deslocamento, velocidade ou aceleração, consiste da soma de contribuições feitas por todos os $n$ modos de vibração, e pode ser escrita como:

$$
\boldsymbol{x}=\sum_{k=1}^{2 n} \boldsymbol{\psi}_{\boldsymbol{k}} e^{\lambda_{k} t}
$$

onde o índice $k$ denota um modo de vibrar arbitrário.

Para uma estação de medição $i$ e um instante de tempo $t_{j}$, a equação (5.31) pode ser modificada para:

$$
\boldsymbol{x}_{\boldsymbol{i}}\left(t_{j}\right)=\boldsymbol{x}_{\boldsymbol{i j}}=\sum_{k=1}^{2 n} \boldsymbol{\psi}_{i k} e^{\lambda_{k} t_{j}}
$$

onde $\boldsymbol{\psi}_{i k}$ e $\lambda_{k}$ são números complexos em geral.

Pappa e Ibrahim (1981) expandem a equação (5.32) para a forma de matrizes, onde são computados valores de $x_{i j}$ para $2 n$ estações de medição e $s$ instantes de tempo.

$$
\left(\begin{array}{cccc}
x_{11} & x_{12} & \ldots & x_{1 s} \\
x_{21} & x_{22} & \ldots & x_{2 s} \\
\vdots & \vdots & \ddots & \vdots \\
x_{2 n, 1} & x_{2 n, 2} & \ldots & x_{2 n, s}
\end{array}\right)=\left(\begin{array}{cccc}
\psi_{11} & \psi_{12} & \ldots & \psi_{1 s} \\
\psi_{21} & \psi_{22} & \ldots & \psi_{2 s} \\
\vdots & \vdots & \ddots & \vdots \\
\psi_{2 n, 1} & \psi_{2 n, 2} & \ldots & \psi_{2 n, s}
\end{array}\right) \times\left(\begin{array}{cccc}
e^{\lambda_{1} t_{1}} & e^{\lambda_{1} t_{2}} & \ldots & e^{\lambda_{1} t_{s}} \\
e^{\lambda_{2} t_{1}} & e^{\lambda_{2} t_{2}} & \ldots & e^{\lambda_{2} t_{s}} \\
\vdots & \vdots & \ddots & \vdots \\
e^{\lambda_{2 n} t_{1}} & e^{\lambda_{2 n} t_{2}} & \ldots & e^{\lambda_{2 n} t_{s}}
\end{array}\right)
$$

A equação (5.33) pode ser representada de forma simplificada por

$$
\Phi=\Psi \Lambda
$$

onde $\boldsymbol{\Phi} \in \mathbb{R}^{2 n \times s}$ é a matriz de respostas livres, $\boldsymbol{\Psi} \in \mathbb{R}^{2 n \times 2 n}$ é a matriz de autovetores e $\boldsymbol{\Lambda} \in \mathbb{R}^{2 n \times s}$ é a matriz de exponenciais complexos.

Numa situação onde se tem as respostas livres do sistema medidas após um intervalo $\Delta t_{1}$ mais tarde que a equação (5.32), medidas nas mesmas estações, a resposta livre do sistema fica:

$$
\begin{aligned}
\boldsymbol{x}_{\boldsymbol{i}}\left(t_{j}+\Delta t_{1}\right)=\hat{\boldsymbol{x}}_{\boldsymbol{i} j} & =\sum_{k=1}^{2 n} \boldsymbol{\psi}_{\boldsymbol{i} \boldsymbol{k}} e^{\lambda_{k}\left(t_{j}+\Delta t_{1}\right)} \\
& =\sum_{k=1}^{2 n}\left(\boldsymbol{\psi}_{\boldsymbol{i k}} e^{\lambda_{k} \Delta t_{1}}\right) e^{\lambda_{k} t_{j}} \\
& =\sum_{k=1}^{2 n} \hat{\boldsymbol{\psi}}_{\boldsymbol{i} \boldsymbol{k}} e^{\lambda_{k} t_{j}}
\end{aligned}
$$

A equação (5.35) pode ser representada de forma de matrizes simplificada por

$$
\hat{\boldsymbol{\Phi}}=\hat{\boldsymbol{\Psi}} \boldsymbol{\Lambda}
$$

onde $\hat{\boldsymbol{\Phi}} \in \mathbb{R}^{2 n \times s}$ é a matriz de $\boldsymbol{\Phi}$ com o atraso de $\Delta t_{1}, \hat{\boldsymbol{\Psi}} \in \mathbb{R}^{2 n \times 2 n}$ é a matriz $\boldsymbol{\Psi}$ com o atraso de $\Delta t_{1}$ e $\boldsymbol{\Lambda} \in \mathbb{R}^{2 n \times s}$ continua sendo a matriz de exponenciais complexos. 
Pode ser verificado no apêndice de Ibrahim e Mikulcik (1977) que as matrizes inversas das matrizes $\boldsymbol{\Psi}$ e $\hat{\boldsymbol{\Psi}}$ existem. E assim, para $s \geq 2 n$, pode-se eliminar a matriz $\boldsymbol{\Lambda}$ relacionando as equações (5.34) e (5.36):

$$
\begin{aligned}
\hat{\boldsymbol{\Phi}} & =\hat{\boldsymbol{\Psi}} \boldsymbol{\Psi}^{-1} \boldsymbol{\Phi} \\
\hat{\boldsymbol{\Phi}} \boldsymbol{\Phi}^{-1} \boldsymbol{\Psi} & =\hat{\boldsymbol{\Psi}}
\end{aligned}
$$

Caso $s=2 n$, ou seja, o número de estações de medida é igual ao dobro do número de graus de liberdade, pode se definir a matriz do sistema $\boldsymbol{A}_{\boldsymbol{I}}$ como sendo

$$
\begin{aligned}
\boldsymbol{A}_{\boldsymbol{I}} & =\hat{\boldsymbol{\Phi}} \boldsymbol{\Phi}^{-1} \\
\boldsymbol{A}_{\boldsymbol{I}} \boldsymbol{\Phi} & =\hat{\boldsymbol{\Phi}} \\
\boldsymbol{\Phi}^{t} \boldsymbol{A}_{\boldsymbol{I}}^{t} & =\hat{\boldsymbol{\Phi}}^{t}
\end{aligned}
$$

pois as matrizes $\hat{\boldsymbol{\Phi}}$ e $\boldsymbol{\Phi}$ são quadradas e a matriz inversa $\boldsymbol{\Phi}^{-1}$ existe. Mas se $s>2 n$, então não é possível calcular $\boldsymbol{\Phi}^{-1}$, pois $\boldsymbol{\Phi}$ não é quadrada. A fim de superar esse problema, a partir da equação (5.40), pré-multiplicam-se os dois lados por $\boldsymbol{\Phi}$ :

$$
\begin{aligned}
\boldsymbol{\Phi} \boldsymbol{\Phi}^{t} \boldsymbol{A}_{\boldsymbol{I}}{ }^{t} & =\boldsymbol{\Phi} \hat{\boldsymbol{\Phi}}^{t} \\
\boldsymbol{A}_{\boldsymbol{I}}{ }^{t} & =\left(\boldsymbol{\Phi} \boldsymbol{\Phi}^{t}\right)^{-1} \boldsymbol{\Phi} \hat{\boldsymbol{\Phi}}^{t}
\end{aligned}
$$

onde $\left(\boldsymbol{\Phi} \boldsymbol{\Phi}^{t}\right)^{-1} \boldsymbol{\Phi}$ é a matriz pseudo-inversa de $\boldsymbol{\Phi}^{t}$. Observa-se que a equação (5.41) nada mais é do que a aplicação do método dos mínimos quadrados para a obtenção da matriz $\boldsymbol{A}_{\boldsymbol{I}}{ }^{t}$, uma vez que $s>2 n$ torna o problema sobredeterminado.

Ibrahim (1986) afirma que quando a identificação modal é implementada com a solução de mínimos quadrados, existe um erro numérico estatístico inerente, que gera polarização dos fatores de amortecimento. Uma alternativa para atenuar esse efeito é utilizar uma abordagem considerando duas soluções para a matriz $\boldsymbol{A}_{\boldsymbol{I}}{ }^{t}$. A primeira foi descrita na equação (5.41). A segunda solução parte da equação (5.40) e pré-multiplicam-se os dois lados por $\hat{\boldsymbol{\Phi}}$ :

$$
\begin{aligned}
\hat{\boldsymbol{\Phi}} \boldsymbol{\Phi}^{t} \boldsymbol{A}_{\boldsymbol{I}}{ }^{t} & =\hat{\boldsymbol{\Phi}} \hat{\boldsymbol{\Phi}}^{t} \\
\boldsymbol{A}_{\boldsymbol{I}}{ }^{t} & =\left(\hat{\boldsymbol{\Phi}} \boldsymbol{\Phi}^{t}\right)^{-1} \hat{\boldsymbol{\Phi}} \hat{\boldsymbol{\Phi}}^{t}
\end{aligned}
$$

Como as duas soluções são opostamente polarizadas, a média das duas reduz a polarização geral, então a solução para a matriz $\boldsymbol{A}_{\boldsymbol{I}}{ }^{t}$ fica:

$$
\boldsymbol{A}_{\boldsymbol{I}}^{t}=\frac{1}{2}\left(\left(\boldsymbol{\Phi} \boldsymbol{\Phi}^{t}\right)^{-1} \boldsymbol{\Phi} \hat{\boldsymbol{\Phi}}^{t}+\left(\hat{\boldsymbol{\Phi}} \boldsymbol{\Phi}^{t}\right)^{-1} \hat{\boldsymbol{\Phi}} \hat{\boldsymbol{\Phi}}^{t}\right)
$$

que é a chamada solução por mínimos quadrados duplos.

Em seguida, após a determinação de $\boldsymbol{A}_{\boldsymbol{I}}$ e aplicando a definição (5.38) na equação (5.37) se tem

$$
\boldsymbol{A}_{\boldsymbol{I}} \boldsymbol{\Psi}=\hat{\boldsymbol{\Psi}}
$$


E, a partir da equação (5.44) e sabendo que as colunas de $\boldsymbol{\Psi}$ e $\hat{\boldsymbol{\Psi}}$ podem ser relacionadas de acordo com a equação (5.35) por $\hat{\boldsymbol{\psi}}_{\boldsymbol{k}}=e^{\lambda_{k} \Delta t_{1}} \boldsymbol{\psi}_{\boldsymbol{k}}$, o sistema completo pode ser colocado como um problema de autovalores:

$$
\boldsymbol{A}_{\boldsymbol{I}} \boldsymbol{\psi}_{\boldsymbol{k}}=e^{\lambda_{k} \Delta t_{1}} \boldsymbol{\psi}_{\boldsymbol{k}}
$$

Apesar de a matriz do sistema $\boldsymbol{A}_{\boldsymbol{I}}$ poder ser considerada uma matriz do sistema, ela não é igual à matriz $\boldsymbol{A}$, que havia sido mencionada em (5.18). Enquanto na equação (5.20) os autovalores de $\boldsymbol{A}$ são chamados por $\lambda$, de onde se obtém os valores de $\omega_{n}$ e $\zeta$ desejados, na equação (5.45) os autovalores de $\boldsymbol{A}_{\boldsymbol{I}}$ são $e^{\lambda_{k} \Delta t_{1}}$ e os valores de $\omega_{n, k}$ e $\zeta_{k}$ desejados derivam de de $\lambda_{k}$.

Para o caso em que $0 \leq \zeta_{k}<1$, se $e^{\lambda_{k} \Delta t_{1}}$ for colocado na forma cartesiana do número complexo

$$
e^{\lambda_{k} \Delta t_{1}}=a_{k}+i b_{k}
$$

e se a forma (5.23) for utilizada para $\lambda_{k}$

$$
\begin{aligned}
e^{\lambda_{k} \Delta t_{1}} & =e^{\left(-\sigma_{k} \pm i \omega_{d, k}\right) \Delta t_{1}} \\
e^{\lambda_{k} \Delta t_{1}} & =e^{-\sigma_{k} \Delta t_{1}} e^{ \pm i \omega_{d, k} \Delta t_{1}} \\
e^{\lambda_{k} \Delta t_{1}} & =C_{k} e^{i \theta_{k}}
\end{aligned}
$$

onde $C_{k}=e^{-\sigma_{k} \Delta t_{1}}$ e $\theta_{k}= \pm \omega_{d, k} \Delta t_{1}$, chega-se na relação entre um número complexo na forma polar e na forma cartesiana:

$$
C_{k} e^{i \theta_{k}}=a_{k}+i b_{k}
$$

Considerando a relação (5.48), decorre que:

$$
\begin{aligned}
C_{k} & =\sqrt{a_{k}^{2}+b_{k}^{2}} \\
\theta_{k} & =\arctan \frac{b_{k}}{a_{k}}
\end{aligned}
$$

Então, a partir das equações (5.47)-(5.50), é possível calcular as frequências naturais e os fatores de amortecimento, para os casos de respostas não amortecidas e subamortecidas, da seguinte maneira:

$$
\begin{aligned}
\omega_{d, k} & =\frac{1}{\Delta t_{1}} \arctan \frac{b_{k}}{a_{k}} \\
\sigma_{k} & =\frac{1}{2 \Delta t_{1}} \ln \left(a_{k}^{2}+b_{k}^{2}\right) \\
\omega_{n, k} & =\sqrt{\sigma_{k}^{2}+\omega_{d, k}^{2}} \\
\zeta_{k} & =\frac{\sigma_{k}}{\omega_{n, k}}
\end{aligned}
$$

e os autovetores $\boldsymbol{\psi}_{\boldsymbol{k}}$ associados aos autovalores da $\boldsymbol{A}_{\boldsymbol{I}}$ são os modos de vibração do sistema. 
Por sua vez, para o caso $\zeta_{k} \geq 1$, definem-se os autovalores reais de $\boldsymbol{A}_{\boldsymbol{I}}$ como:

$$
\begin{aligned}
& c_{k}=e^{\lambda_{1, k} \Delta t_{1}} \\
& d_{k}=e^{\lambda_{2, k} \Delta t_{1}}
\end{aligned}
$$

Assim, utilizando as definições (5.55)-(5.56) em conjunto com as equações (5.29) e (5.30), tem-se as frequências naturais e fatores de amortecimento para os casos de respostas criticamente amortecidas e superamortecidas:

$$
\begin{aligned}
\lambda_{1, k} & =\frac{1}{\Delta t_{1}} \ln c_{k} \\
\lambda_{2, k} & =\frac{1}{\Delta t_{1}} \ln d_{k} \\
\omega_{n, k} & =\sqrt{\lambda_{1, k} \cdot \lambda_{2, k}} \\
\zeta_{k} & =-\frac{\lambda_{1, k}+\lambda_{2, k}}{2 \sqrt{\lambda_{1, k} \cdot \lambda_{2, k}}}
\end{aligned}
$$

Em resumo, as equações (5.43) e (5.45) formam a base da solução da análise modal: as funções de resposta livre são colocadas nas linhas das matrizes $\boldsymbol{\Phi}$ e $\hat{\boldsymbol{\Phi}}$. Depois, a matriz $\boldsymbol{A}_{\boldsymbol{I}}$ é obtida através da solução de (5.43) por mínimos quadrados duplos. E então, os autovalores e autovetores de $\boldsymbol{A}_{\boldsymbol{I}}$ são obtidos e os parâmetros modais do sistema são extraídos dessa matriz através das equações (5.51)-(5.54), para $0 \leq \zeta_{k}<1$, ou (5.57)-(5.60), para $\zeta_{k} \geq 1$.

\subsubsection{Solução da matriz do sistema por SVD}

Pappa e Ibrahim (1981) argumentam que a solução da matriz $\boldsymbol{A}_{\boldsymbol{I}}$ da equação (5.40) através da pré-multiplicação por $\boldsymbol{\Phi}$, conforme mostrado na equação (5.41), apresenta problemas de precisão quando a matriz de medidas $\boldsymbol{\Phi}$ for mal condicionada. O mau condicionamento de $\boldsymbol{\Phi}$ leva o termo $\left(\boldsymbol{\Phi} \boldsymbol{\Phi}^{t}\right)$ à singularidade, o que cria problemas na sua inversão em (5.41). Então, a solução dada por (5.43) para a obtenção da matriz $\boldsymbol{A}_{\boldsymbol{I}}{ }^{t}$ será substituída por um método onde não se usa inversão de matrizes, a decomposição em valores singulares (SVD, sigla em inglês).

Partindo novamente da equação (5.40), se $s>2 n$ haverá várias soluções para a matriz $\boldsymbol{A}_{\boldsymbol{I}}{ }^{t}$. O interesse reside na matriz $\boldsymbol{A}_{\boldsymbol{I}}{ }^{t}$ que melhor se ajusta a todas as $s$ medidas. Logo, pode-se formular o problema de mínimos quadrados da seguinte forma: de todas as matrizes $\boldsymbol{A}_{\boldsymbol{I}}{ }^{t}$ que minimizam a soma de quadrados $\left\|\hat{\boldsymbol{\Phi}}^{t}-\boldsymbol{\Phi}^{t} \boldsymbol{A}_{\boldsymbol{I}}{ }^{t}\right\|_{2}$, qual a que apresenta o menor valor para $\left\|\boldsymbol{A}_{\boldsymbol{I}}{ }^{t}\right\|_{2}$ ? $^{3}$ A solução

$$
\boldsymbol{A}_{\boldsymbol{I}}{ }^{t}=\boldsymbol{\Phi}^{I} \hat{\boldsymbol{\Phi}}^{t}
$$

3 O operador $\|\cdot\|_{2}$ é a norma matricial induzida pela norma euclidiana de vetores. 
onde

$$
\boldsymbol{\Phi}^{I}=\left(\boldsymbol{\Phi} \boldsymbol{\Phi}^{t}\right)^{-1} \boldsymbol{\Phi}
$$

foi a solução apresentada em (5.41). Mas se $\boldsymbol{\Phi} \boldsymbol{\Phi}^{t}$ for (praticamente) singular, então haverá infinitas matrizes $\boldsymbol{A}_{\boldsymbol{I}}^{t}$ que (praticamente) minimizam $\left\|\hat{\boldsymbol{\Phi}}^{t}-\boldsymbol{\Phi}^{t} \boldsymbol{A}_{\boldsymbol{I}}{ }^{t}\right\|_{2}$.

Golub e Kahan (1965) elaboraram um algoritmo para o cálculo da decomposição em valores singulares (SVD) de uma matriz, ou seja, uma matriz é descrita como o produto de três matrizes com propriedades específicas para facilitar sua manipulação algébrica, sem a necessidade da operação de inversão de matrizes. Ao invés de (5.62), a matriz pseudo-inversa $\boldsymbol{\Phi}^{I}$ é obtida por

$$
\boldsymbol{\Phi}^{I}=\boldsymbol{V} \boldsymbol{\Sigma}^{I} \boldsymbol{U}^{*}
$$

onde $\boldsymbol{V}, \boldsymbol{\Sigma}$ e $\boldsymbol{U}$ são obtidas da decomposição em valores singulares de $\boldsymbol{\Phi}^{t}$ que satisfazem a seguinte equação:

$$
\Phi^{t}=\boldsymbol{U} \boldsymbol{\Sigma} \boldsymbol{V}^{*}
$$

onde $\boldsymbol{U}$ e $\boldsymbol{V}$ são matrizes unitárias (e portanto ortogonais) e $\boldsymbol{\Sigma}$ é uma matriz retangular diagonal do mesmo tamanho de $\boldsymbol{\Phi}^{t}$ com valores reais não negativos na sua diagonal.

Para se ter uma ideia de como as matrizes $\boldsymbol{U}, \boldsymbol{\Sigma}$ e $\boldsymbol{V}$ são obtidas, sem a pretenção de provar matematicamente a validade do algoritmo da decomposição em valores singulares, e tomando-se como hipótese que a equação (5.64) seja verdadeira, observa-se que $\boldsymbol{\Phi}^{t} \boldsymbol{\Phi}$ fica

$$
\boldsymbol{\Phi}^{t} \boldsymbol{\Phi}=\boldsymbol{U} \boldsymbol{\Sigma} \boldsymbol{V}^{*} \boldsymbol{V} \boldsymbol{\Sigma}^{t} \boldsymbol{U}^{*}
$$

como $\boldsymbol{V}$ e $\mathbf{U}$ são ortogonais, então $\boldsymbol{V}^{*}=\boldsymbol{V}^{-1}$ e $\boldsymbol{U}^{*}=\boldsymbol{U}^{-1}$, e como as matrizes no meio $\boldsymbol{V}^{-1} \boldsymbol{V}=\boldsymbol{I}, \log \mathrm{O}$

$$
\boldsymbol{\Phi}^{t} \boldsymbol{\Phi}=\boldsymbol{U} \boldsymbol{\Sigma} \boldsymbol{\Sigma}^{t} \boldsymbol{U}^{-1}
$$

E, uma vez que $\boldsymbol{\Sigma}$ é diagonal, $\boldsymbol{\Sigma} \boldsymbol{\Sigma}^{t}$ também será diagonal. Nota-se claramente que a equação (5.66) representa a forma de diagonalização de matrizes, onde $\boldsymbol{U}$ é a matriz de autovetores de $\boldsymbol{\Phi}^{t} \boldsymbol{\Phi}$ e $\boldsymbol{\Sigma} \boldsymbol{\Sigma}^{t}$ é a matriz de autovalores de $\boldsymbol{\Phi}^{t} \boldsymbol{\Phi}$. Então, a matriz $\boldsymbol{U}$ e a matriz $\boldsymbol{\Sigma}$ são determinadas pelos autovetores e autovalores de $\boldsymbol{\Phi}^{t} \boldsymbol{\Phi}$, respectivamente. A matriz $\boldsymbol{\Sigma}$ possui o mesmo tamanho de $\boldsymbol{\Phi}^{t}$, e os elementos na sua diagonal principal são chamados de valores singulares, e são a raiz quadrada dos autovalores de $\boldsymbol{\Phi}^{t} \boldsymbol{\Phi}$.

A matriz $\boldsymbol{V}$ pode ser obtida computando-se o valor de $\boldsymbol{\Phi} \boldsymbol{U}$ :

$$
\begin{aligned}
& \boldsymbol{\Phi} \boldsymbol{U}=\boldsymbol{V} \boldsymbol{\Sigma}^{t} \boldsymbol{U}^{*} \boldsymbol{U} \\
& \boldsymbol{\Phi} \boldsymbol{U}=\boldsymbol{V} \boldsymbol{\Sigma}^{t} \boldsymbol{U}^{-1} \boldsymbol{U} \\
& \boldsymbol{\Phi} \boldsymbol{U}=\boldsymbol{V} \boldsymbol{\Sigma}^{t}
\end{aligned}
$$

uma vez que já se conhecem as matrizes $\boldsymbol{U}$ e $\boldsymbol{\Sigma}^{t}$. Para um maior detalhamento matemático da decomposição de matrizes em valores singulares, consultar Golub e Van Loan (2013). 
No MATLAB ${ }^{\circledast}$ o comando svd é utilizado para obter as matrizes $\boldsymbol{U}, \boldsymbol{\Sigma}$ e $\boldsymbol{V}$ a partir da matriz $\boldsymbol{\Phi}^{t}$. A matriz $\boldsymbol{\Sigma}^{I}$ é obtida de $\boldsymbol{\Sigma}$ substituindo os valores positivos da diagonal por seus valores recíprocos e transpondo a matriz resultante.

Com essas informações é possível calcular $\boldsymbol{\Phi}^{I}$ por (5.63) e, depois, achar a solução de $\boldsymbol{A}_{\boldsymbol{I}}{ }^{t}$ utilizando (5.61). Após achar $\boldsymbol{A}_{\boldsymbol{I}}$, o método ITD continua, conforme descrito na seção 5.5.1, a partir da equação (5.44), página 108 .

\subsubsection{Aplicação do ITD para quantidade limitada de medidas disponíveis}

De acordo com as seções anteriores, é necessário construir a matriz $\boldsymbol{\Phi}$ para se determinar a matriz $\boldsymbol{A}_{\boldsymbol{I}}$ do sistema. Além disso, na equação (5.33), viu-se que a matriz $\boldsymbol{\Phi}$ havia sido construída com valores da resposta $x_{i j}$ com $2 n$ estações de medidas e $s$ instantes de tempo. Mas e se não houver a disponibilidade de todas as $2 n$ estações de medidas? Pappa e Ibrahim (1981) explicam que é possível construir a matriz $\boldsymbol{\Phi}$ utilizando mais dados de uma ou mais estações de medidas para completar os dados faltantes.

Supõe-se que o número disponível de medidas seja $m<n$. As $n-m$ medidas faltantes são completadas com as $m$ medidas disponíveis deslocadas no tempo de um parâmetro $\Delta t_{2}$. Caso não sejam necessárias todas as $m$ medidas para completar até as $n$ primeiras linhas, então utiliza-se só o necessário. Caso sejam necessárias mais do que $m$ para completar as $n$ primeiras linhas, então as medidas disponíveis devem ser deslocadas de um valor $2 \Delta t_{2}$. E ainda, caso necessário, continua-se o processo com $3 \Delta t_{2}, 4 \Delta t_{2}, \ldots,(n-a) \Delta t_{2}$. A vantagem desse processo é que ele não altera os autovalores da matriz $\boldsymbol{A}_{\boldsymbol{I}}$.

As últimas $n$ linhas são completadas adicionando um terceiro parâmetro de tempo $\Delta t_{3}$. Logo, as medidas utilizadas na parte superior da matriz são deslocadas de um valor de tempo $\Delta t_{3}$, mesmo se, eventualmente, algumas linhas já estiverem deslocadas com múltiplos de $\Delta t_{2}$.

\subsubsection{Ferramentas para comparar o sucesso da identificação do ITD com o modelo teórico}

O método ITD possui três parâmetros relacionados ao tempo decorrido na aquisição das medidas: $\Delta t_{1}, \Delta t_{2}$ e $\Delta t_{3}$. O primeiro já foi apresentado na equação (5.35) e os outros dois foram apresentados na seção 5.5.3. Apesar de algumas sugestões dadas por Pappa e Ibrahim (1981) para limitar as escolhas desses parâmetros, eles não foi propõem uma metodologia para obtê-los de forma direta.

A fim de analisar melhor as implicações das escolhas dos parâmetros $\Delta t_{1}, \Delta t_{2} \mathrm{e}$ $\Delta t_{3}$ no resultado da identificação, algumas ferramentas serão apresentadas com o objetivo de facilitar a comparação dos resultados com diversos valores combinados de $\Delta t_{1}, \Delta t_{2}$ e $\Delta t_{3}$. A identificação modal de um sistema se resume à identificação das frequências 
naturais, fatores de amortecimento e modos de vibrar. Assim, as ferramentas apresentadas a seguir visam dar um valor maior aos resultados que mais se aproximam de um valor ideal de referência para as frequências naturais, fatores de amortecimento e modos de vibrar.

\subsubsection{Constante de correlação de modos de vibrar/Critério de garantia modal}

A constante de correlação de modos de vibrar (MSCC, sigla em inglês), muitas vezes também chamada de critério de garantia modal (MAC, em inglês), foi desenvolvida com o intuito de resolver a necessidade de um indicador que garantisse que vetores modais experimentais obtidos através de funções de resposta em frequência estivessem corretos.

Allemang (2003) descreve que o MAC surgiu a partir do desenvolvimento de um cálculo da função de coerência associada ao processamento da função de resposta em frequência. Ele serve para fornecer uma medida de consistência (grau de linearidade) entre vetores modais. E pode ser visto como um índice de uma comparação da análise de regressão linear entre dois (ou mais) vetores modais realizada pelo método dos mínimos quadrados. O cálculo do MAC resulta num método de garantia modal que é insensível a pequenas variações e/ou pequenas magnitudes.

O MAC assume valores de zero a um, onde "zero" representa falta total de consistência na correspondência entre os modos de vibrar e "um", por sua vez, representa total consistência na correspondência entre eles. O índice do MAC é definido na equação (5.70):

$$
M A C_{k}^{i r}=\frac{\left|\left(\boldsymbol{\psi}_{k}^{i}\right)^{T}\left(\boldsymbol{\psi}_{k}^{r}\right)^{*}\right|^{2}}{\left[\left(\boldsymbol{\psi}_{k}^{i}\right)^{T}\left(\boldsymbol{\psi}_{k}^{i}\right)^{*}\right]\left[\left(\boldsymbol{\psi}_{k}^{r}\right)^{T}\left(\boldsymbol{\psi}_{k}^{r}\right)^{*}\right]}
$$

onde $\boldsymbol{\psi}_{k}^{i}$ é o vetor do $k$-ésimo modo de vibrar identificado (ou qualquer outro que se queira comparar com uma referência) e $\boldsymbol{\psi}_{k}^{r}$ é o vetor do $k$-ésimo modo de vibrar de referência. O símbolo * de um vetor $\left(\boldsymbol{\psi}_{k}\right)^{*}$ denota um vetor formado pelos elementos conjugados de $\left(\boldsymbol{\psi}_{k}\right)$, de forma que o MAC também possa ser utilizado com modos formados por números complexos.

Allemang (1981) aponta algumas aplicações para o uso do MAC, sendo uma das mais usuais verificar ou comparar um vetor modal experimental (ou obtido por simulação) em relação a um vetor modal teórico.

Neste trabalho, o MAC será utilizado para avaliar a estimação de parâmetros modais pelo método ITD ao se variar os seus próprios parâmetros, ou a função de entrada, seja uma resposta livre natural do sistema ou um resposta livre obtida através do algoritmo $\mathrm{RD}$, que foi analisado na seção 5.4. Uma desvantagem do MAC é a necessidade de dispor de uma referência para que um modo seja comparado. Em casos onde não há como se obter uma referência de comparação, este índice não pode ser utilizado. Logo, o MAC será utilizado nos exemplos a seguir, onde se sabe os parâmetros modais de forma analítica, como uma ferramenta de análise do sucesso de identificação do algoritmo do ITD. 


\subsubsection{2 Índices de sucesso da identificação}

Comparar o sucesso de uma identificação de parâmetros modais para cada diferente conjunto de parâmetros utilizados pode ser uma tarefa árdua, uma vez que cada identificação fornece $2 n$ frequências naturais, $2 n$ fatores de amortecimentos e $2 n$ modos de vibrar.

Com esse intuito, nas equações (5.71) a (5.73) são propostos, neste trabalho, índices que sumarizam o sucesso da identificação de todas as frequências, fatores de amortecimento e modos de vibrar para todos os modos do sistema.

$$
\begin{aligned}
i_{\omega} & = \begin{cases}\frac{1}{2 n} \sum_{k=1}^{2 n}\left(\frac{\omega_{n, k}^{i}}{\omega_{n, k}^{r}}\right) & \text { se } \omega_{n, k}^{i} \leq \omega_{n, k}^{r} \\
\frac{1}{2 n} \sum_{k=1}^{2 n}\left(\frac{\omega_{n, k}^{i}}{\omega_{n, k}^{r}}\right)^{-1} & \text { se } \omega_{n, k}^{i}>\omega_{n, k}^{r}\end{cases} \\
i_{\zeta} & = \begin{cases}\frac{1}{2 n} \sum_{k=1}^{2 n}\left(\frac{\zeta_{k}^{i}}{\zeta_{k}^{r}}\right) & \text { se } \zeta_{k}^{i} \leq \zeta_{k}^{r} \\
\frac{1}{2 n} \sum_{k=1}^{2 n}\left(\frac{\zeta_{k}^{i}}{\zeta_{k}^{r}}\right)^{-1} & \text { se } \zeta_{k}^{i}>\zeta_{k}^{r}\end{cases} \\
i_{M A C} & =\frac{1}{2 n} \sum_{k=1}^{2 n} M A C_{k}^{i r}
\end{aligned}
$$

onde $i_{\omega}$ é o índice de sucesso da identificação das frequências naturais, $i_{\zeta}$ é o índice de sucesso da identificação dos fatores de amortecimento e $i_{M A C}$ é o índice de sucesso da identificação dos modos de vibrar.

Todos esses índices possuem, dentro da somatória, fatores que variam de "zero" a "um" para cada um dos $2 n$ valores obtidos na identificação. Portanto, cada índice não passa de uma média aritmética desses $2 n$ valores, por onde se deduz que os índices também ficam dentro do intervalo $[0,1]$.

Por fim, define-se também um índice que agrupa todas as três propriedades da analise modal, frequência natural, fator de amortecimento e modos de vibrar, num único número, chamado de índice de sucesso da identificação geral $i_{s}$. A frequência natural e o fator de amortecimento são grandezas escalares, enquanto que os modos de vibrar são grandezas vetoriais. Então, faz-se uma média ponderada entre os índices apresentados nas equações (5.71) a (5.73), colocando-se um peso maior na identificação dos modos de vibrar e pesos iguais para as identificações das frequências naturais e fatores de amortecimento, para manter um certo equilíbrio nos pesos entre grandezas escalares e vetoriais que formam o índice.

$$
i_{s}=p_{M A C} i_{M A C}+p_{\omega} i_{\omega}+p_{\zeta} i_{\zeta}
$$

onde os valores adotados para $p_{M A C}, p_{\omega}$ e $p_{\zeta}$ estão dispostos na tabela 9 .

Outro motivo que justifica um maior peso para os modos de vibrar é que um erro em um modo de vibrar de um sistema identificado em relação à referência afeta mais a resposta do sistema do que um erro na frequência natural ou no fator de amortecimento. 
Tabela 9 - Valores adotados para os pesos na equação (5.74).

\begin{tabular}{ll}
\hline Parâmetro & Valor \\
\hline$p_{M A C}$ & 0,50 \\
$p_{\omega}$ & 0,25 \\
$p_{\zeta}$ & 0,25 \\
Fonte- Elaborado pelo autor.
\end{tabular}

Da mesma forma, um erro na frequência natural afeta a resposta de maneira comparável ao que um erro no fator de amortecimento causa, o que justifica a atribuição de pesos iguais para essas propriedades.

\subsubsection{Exemplo da aplicação do método com as $2 n$ medidas disponíveis}

O método ITD será aplicado a um caso de um sistema simples em que se pode obter as características modais analiticamente. O modelo a ser utilizado é um sistema massa-mola-amortecedor de dois graus de liberdade, cujo esquema está mostrado na figura 40.

Figura 40 - Desenho esquemático de um sistema massa-mola-amortecedor de 2 graus de liberdade.

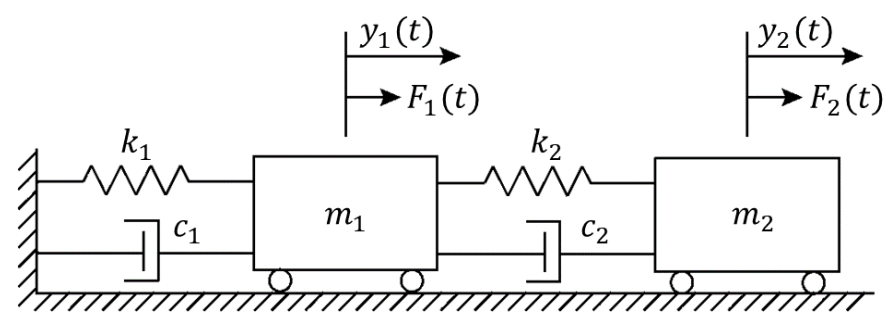

Fonte - Elaborado pelo autor.

Os parâmetros utilizados neste exemplo são mostrados na tabela 10. As forças $\vec{F}_{1}(t)$ e $\vec{F}_{2}(t)$ são forças externas aplicadas a cada uma das massas, aplicadas nas direções $\vec{y}_{1}(t)$ e $\vec{y}_{2}(t)$ respectivamente, que são as coordenadas de posição de cada uma das massas.

A equação (5.15) para o exemplo fica:

$$
\left(\begin{array}{ll}
1 & 0 \\
0 & 1
\end{array}\right)\left(\begin{array}{l}
\ddot{y}_{1} \\
\ddot{y}_{2}
\end{array}\right)+\left(\begin{array}{cc}
2,1 & -1,2 \\
-1,2 & 1,2
\end{array}\right)\left(\begin{array}{l}
\dot{y}_{1} \\
\dot{y}_{2}
\end{array}\right)+\left(\begin{array}{cc}
500 & -300 \\
-300 & 300
\end{array}\right)\left(\begin{array}{l}
y_{1} \\
y_{2}
\end{array}\right)=\left(\begin{array}{l}
0 \\
0
\end{array}\right)
$$

Em seguida definimos $\boldsymbol{x}=\left(\begin{array}{llll}y_{1} & y_{2} & \dot{y}_{1} & \dot{y}_{2}\end{array}\right)^{T}$ para que se obtenha a equação (5.75) na 
Tabela 10 - Parâmetros utilizados no exemplo de 2 graus de liberdade.

\begin{tabular}{lcr}
\hline Parâmetro & Símbolo & \multicolumn{1}{c}{ Valor } \\
\hline Massa 1 & $m_{1}$ & $1,0 \mathrm{~kg}$ \\
Massa 2 & $m_{2}$ & $1,0 \mathrm{~kg}$ \\
Coeficiente de amortecimento viscoso 1 & $c_{1}$ & $0,9 \mathrm{~N} \mathrm{~s} / \mathrm{m}$ \\
Coeficiente de amortecimento viscoso 2 & $c_{2}$ & $1,2 \mathrm{~N} \mathrm{~s} / \mathrm{m}$ \\
Constante de rigidez da mola 1 & $k_{1}$ & $200 \mathrm{~N} / \mathrm{m}$ \\
Constante de rigidez da mola 2 & $k_{2}$ & $300 \mathrm{~N} / \mathrm{m}$ \\
\hline
\end{tabular}

Fonte - Elaborado pelo autor.

forma da equação (5.18) na notação de espaço de estados:

$$
\underbrace{\left(\begin{array}{l}
\dot{y}_{1} \\
\dot{y}_{2} \\
\ddot{y}_{1} \\
\ddot{y}_{2}
\end{array}\right)}_{\dot{\boldsymbol{x}}}=\underbrace{\left(\begin{array}{cccc}
0 & 0 & 1 & 0 \\
0 & 0 & 0 & 1 \\
-500 & 300 & -2,1 & 1,2 \\
300 & -300 & 1,2 & -1,2
\end{array}\right)}_{\boldsymbol{A}_{\boldsymbol{t}}} \underbrace{\left(\begin{array}{l}
y_{1} \\
y_{2} \\
\dot{y}_{1} \\
\dot{y}_{2}
\end{array}\right)}_{\boldsymbol{x}}
$$

A matriz $\boldsymbol{A}$ do sistema na equação (5.76) será chamada de matriz $\boldsymbol{A}_{\boldsymbol{t}}$ em referência a matriz do sistema obtida analiticamente por um modelo teórico. Nota-se que as forças externas $\vec{F}_{1}(t)$ e $\vec{F}_{2}(t)$ foram zeradas para corresponder apenas à resposta livre do sistema. Ela permite que se determinem as propriedades modais, como descrito nas equações (5.19)(5.25), cujos resultados são mostrados na tabela 11 e na equação (5.77).

Tabela 11 - Propriedades modais do sistema (5.76) obtidas analiticamente.

\begin{tabular}{lcc}
\hline $\begin{array}{l}\text { Modo } \\
\text { de vibrar }\end{array}$ & $\begin{array}{c}\text { Frequência } \\
\text { natural }[\mathrm{Hz}]\end{array}$ & $\begin{array}{c}\text { Fator de } \\
\text { amortecimento }\end{array}$ \\
\hline Modo 1 & 1,46 & 0,020 \\
Modo 2 & 4,26 & 0,055 \\
\hline \multicolumn{3}{c}{ Fonte - Elaborado pelo autor. }
\end{tabular}

$$
\boldsymbol{\Psi}=\left(\begin{array}{cccc}
-0,0014+0,0635 \mathrm{i} & -0,0014-0,0635 \mathrm{i} & -0,0017+0,0302 \mathrm{i} & -0,0017-0,0302 \mathrm{i} \\
-0,0018+0,0881 \mathrm{i} & -0,0018-0,0881 \mathrm{i} & 0,0013-0,0218 \mathrm{i} & 0,0013+0,0218 \mathrm{i} \\
0,5812+0,0008 \mathrm{i} & 0,5812-0,0008 \mathrm{i} & 0,8107 & 0,8107 \\
-0,8064 & -0,8064 & -0,5842-0,0025 \mathrm{i} & -0,5842+0,0025 \mathrm{i}
\end{array}\right)
$$

Num sistema de $2^{\text {a }}$ ordem com $n=2$ graus de liberdade, obtêm-se $2 n$ soluções, ou seja 4 soluções para se representar 2 modos de vibrar com 2 frequências naturais e 2 fatores 
de amortecimento. Os dados da tabela 11 mostram as frequências naturais e os fatores de amortecimento dos dois modos de vibrar do sistema (5.76) obtidas analiticamente. E a equação (5.77) exprime os vetores modais nas colunas da matriz $\boldsymbol{\Psi}$. Cada par de vetores modais com componentes complexas conjugadas se refere a um respectivo modo de vibrar.

Agora, com o objetivo de se descobrir os parâmetros modais via ITD, é necessário dispor de dados simulados que seriam obtidos na aquisição dos sinais do sistema real. Para tanto, utiliza-se o modelo (5.76) para a geração desses dados. A resposta livre do sistema vem da sua excitação não forçada, apenas se aplicando condições iniciais diferentes do ponto de equilíbrio do sistema. As condições iniciais escolhidas foram $\boldsymbol{x}_{\boldsymbol{i}}=\left(\begin{array}{llll}y_{1 i} & y_{2 i} & \dot{y}_{1 i} & \dot{y}_{2 i}\end{array}\right)^{T}=$ $\left(\begin{array}{llll}1 & 1 & 0 & 0\end{array}\right)^{T}$. Simulou-se a resposta por $10 s$ a uma taxa de aquisição de $100 \mathrm{~Hz}$, embora os gráficos das figuras 41 e 42 mostrem apenas $7 s$ da simulação.

Figura 41 - Gráficos das posições das massas 1 e 2 em função do tempo na simulação com as condições iniciais $\boldsymbol{x}_{\boldsymbol{i}}$.

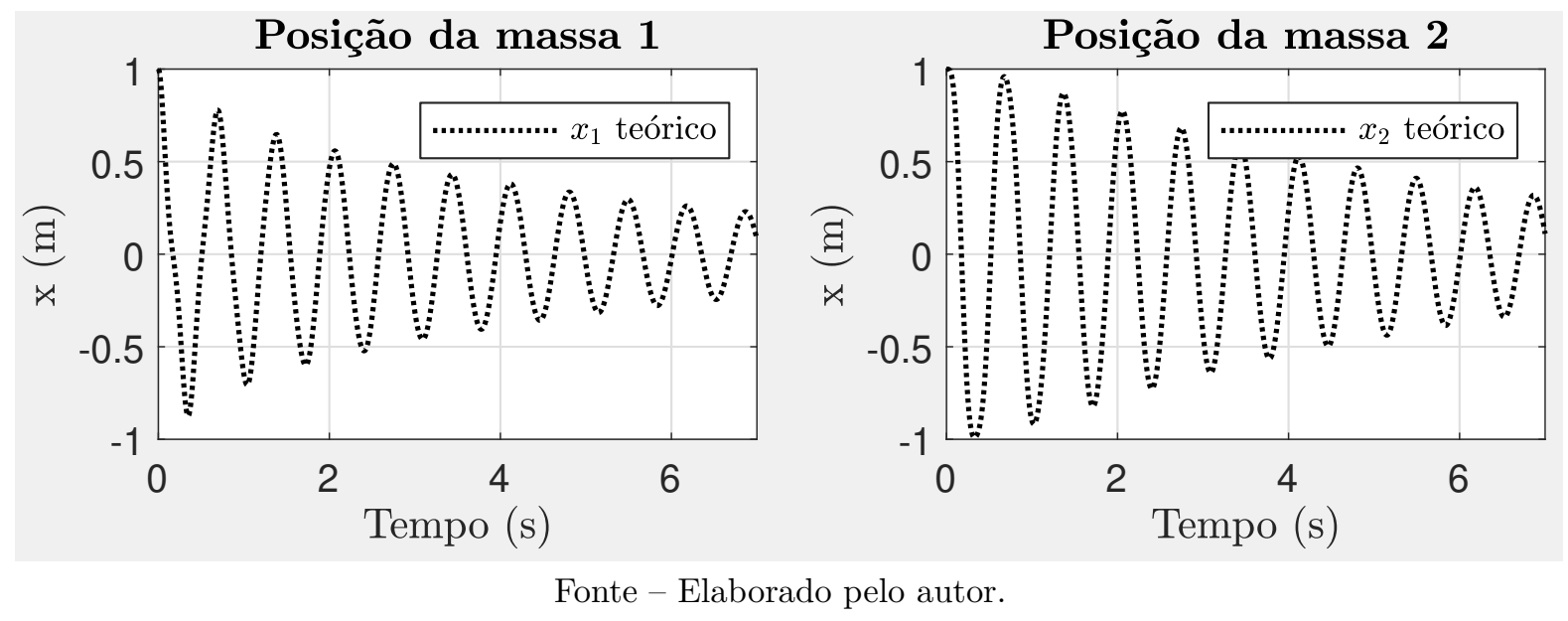

A matriz $\boldsymbol{A}$ do sistema é estimada a partir das medidas simuladas de $\boldsymbol{x}=$ $\left(\begin{array}{llll}y_{1} & y_{2} & \dot{y}_{1} & \dot{y}_{2}\end{array}\right)^{T}$, através da equação (5.61), pelo método do SVD, descrito na seção 5.5.2 (página 110). Lançando-se mão das equações (5.44)-(5.54), obtêm-se parâmetros modais da tabela 12. A figura 43 mostra o resultado do MAC entre os modos de vibrar teóricos e os modos de vibrar identificados pelo ITD com $2 n$ medidas disponíveis. Tanto pela comparação dos parâmetros modais da tabela 12 quanto pelos modos de vibrar da figura 43 entre o identificação modal teórica e a identificação modal por ITD, conclui-se que houve uma identificação perfeita do sistema, pois as frequências naturais e os fatores de amortecimento dos dois modos identificados foram iguais aos teóricos e o MAC apresentou valor 1,0 na diagonal principal.

Por último, para este exemplo, uma análise da qualidade da identificação com a variação do parâmetro $\Delta t_{1}$ é realizada. Nesta análise, os parâmetros $\Delta t_{1}$ e $\Delta t_{2}$ e $\Delta t_{3}$ do método ITD serão definidos conforme a tabela 13. Para este exemplo em específico, o 
Figura 42 - Gráficos das velocidades das massas 1 e 2 em função do tempo na simulação com as condições iniciais $\boldsymbol{x}_{\boldsymbol{i}}$.

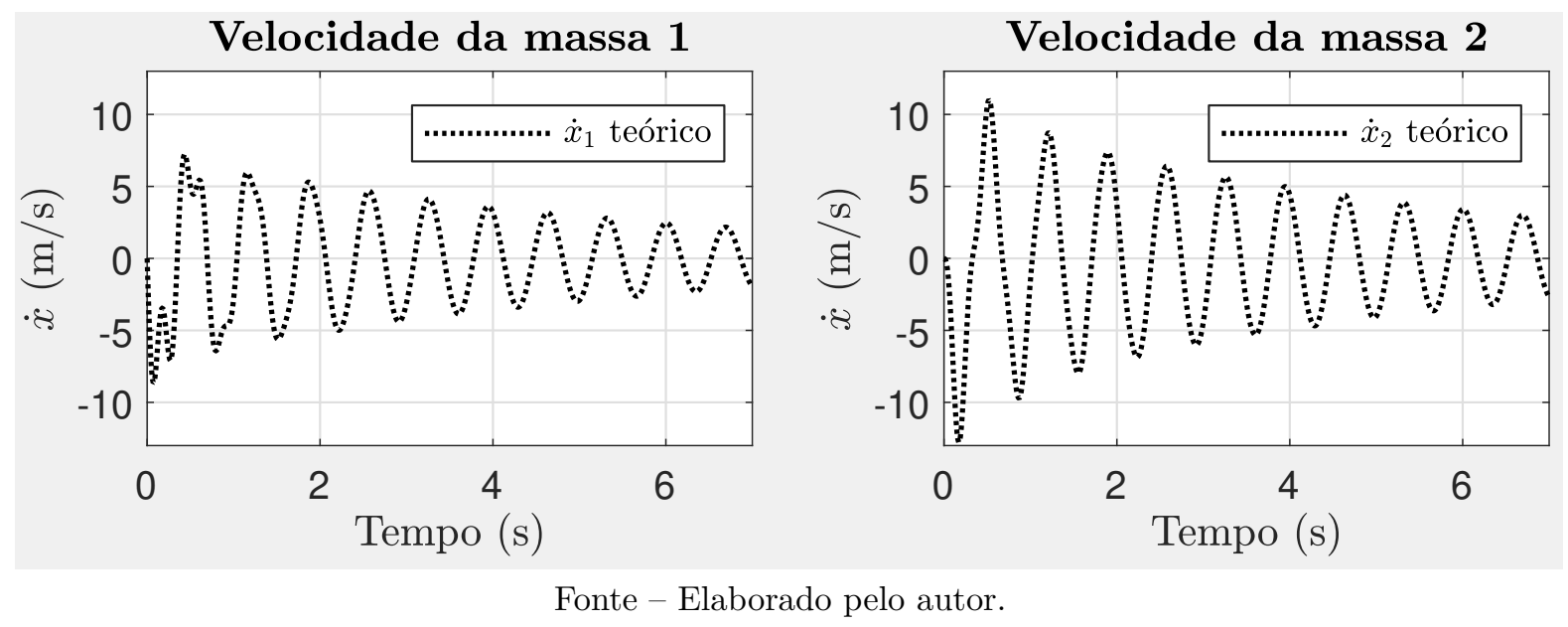

Tabela 12 - Propriedades modais do sistema (5.76) obtidas pelo ITD com $2 n$ medidas disponíveis.

\begin{tabular}{lcccc}
\hline Modo & $\begin{array}{c}\text { Frequência } \\
\text { natural } \\
\text { (teórico) }[\mathrm{Hz}]\end{array}$ & $\begin{array}{c}\text { Frequência } \\
\text { natural } \\
\text { (ITD 2n med.) }[\mathrm{Hz}]\end{array}$ & $\begin{array}{c}\text { Fator de } \\
\text { amortecimento } \\
\text { (teórico) }\end{array}$ & $\begin{array}{c}\text { Fator de } \\
\text { amortecimento } \\
\text { (ITD 2n med.) }\end{array}$ \\
\hline Modo 1 & 1,46 & 1,46 & 0,020 & 0,020 \\
Modo 2 & 4,26 & 4,26 & 0,055 & 0,055 \\
\hline
\end{tabular}

Fonte - Elaborado pelo autor.

parâmetro $\Delta t_{2}$ não aparece na formulação do método de identificação, pois já existem $2 n$ medidas disponíveis. Então, é natural que a variação desse parâmetro não cause alteração nos resultados obtidos.

Tabela 13 - Amplitude de variação dos parâmetros $\Delta t_{1}, \Delta t_{2}$ e $\Delta t_{3}$, a fim de verificar as limitações nas suas escolha.

\begin{tabular}{lcc}
\hline Parâmetro & Valor mínimo & Valor máximo \\
\hline$\Delta t_{1}$ & 0,02 & 0,20 \\
$\Delta t_{2}$ & 0,02 & 0,20 \\
$\Delta t_{3}$ & 0,02 & 0,02 \\
\hline
\end{tabular}

Fonte - Elaborado pelo autor.

Os índices de sucesso apresentados na seção 5.5.4.2 são calculados para cada combinação de valores de $\Delta t_{1}, \Delta t_{2}$ e $\Delta t_{3}$ conforme tabela 13. Nota-se da tabela 13 que 
Figura 43 - Gráfico dos índices MAC entre os modos teóricos e os modos identificados via ITD com $2 n$ medidas disponíveis.

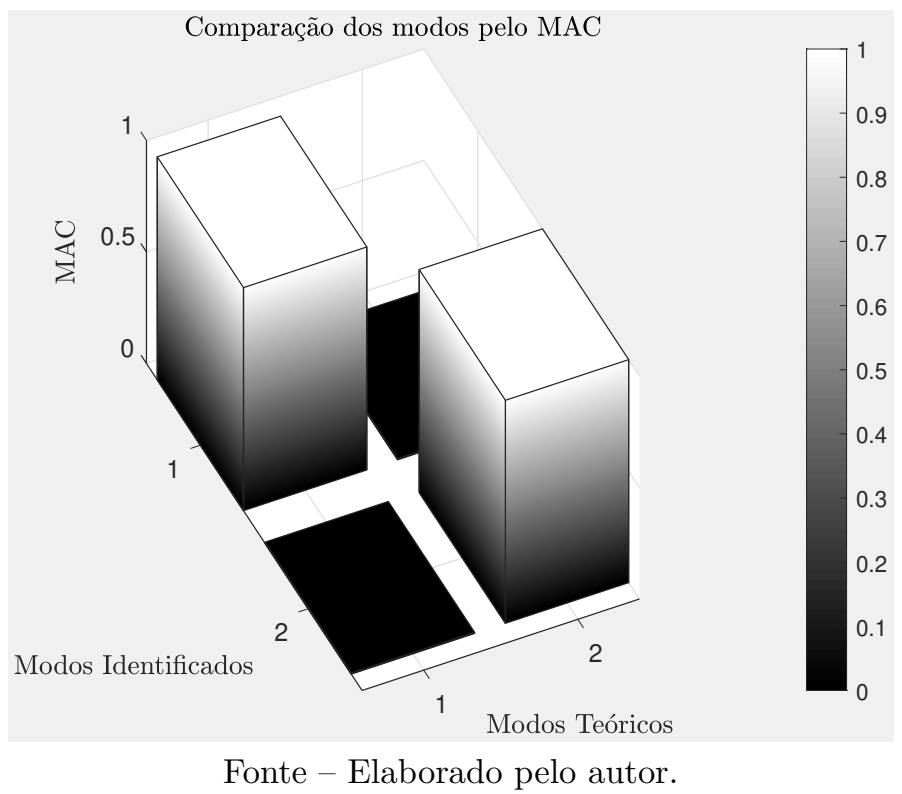

o valor de $\Delta t_{3}$ é constante, portanto, os gráficos (a) a (d) da figura 44 mostram apenas variação nos parâmetros $\Delta t_{1}$ e $\Delta t_{2}$ para os índices de sucesso da identificação $i_{\omega}, i_{\zeta}, i_{M A C}$ e $i_{s}$.

A figura 44(c) destaca que a identificação dos modos não são afetados com a variação de $\Delta t_{1}$. Por outro lado, frequência natural e fator de amortecimento apresentam degradação na identificação a partir de $\Delta t_{1}=0,12 \mathrm{~s}$. É interessante perceber que o índice de sucesso geral $i_{s}$ captura a degradação na identificação da frequência natural e fator de amortecimento, mesmo com $i_{M A C}$ obtendo o valor 1,0 para todos os valores assumidos de $\Delta t_{1}$. A degradação da identificação tem explicação a partir do teorema de amostragem de Nyquist-Shannon, que afirma que um sinal amostrado pode ser recuperado se a taxa de amostragem for maior que o dobro da maior frequência do sinal original. Esta taxa de amostragem limite é comumente chamada de frequência de Nyquist (NYQUIST, 1928).

A maior frequência natural do sistema é $\omega_{n, 2}=4,26 \mathrm{~Hz}$, conforme visto na tabela 11 , o que faz com que o maior período de amostragem que satisfaça o teorema de NyquistShannon seja $1 /\left(2 \omega_{n, 2}\right)=0,117 \mathrm{~s}$. Apesar dos dados terem sido simulados a uma taxa de $100 \mathrm{~Hz}$ (período de $0,01 \mathrm{~s}$ ), a introdução do parâmetro $\Delta t_{1}$ faz com que a taxa de amostragem, para fins do sucesso de identificação, se torne $1 / \Delta t_{1}$. Assim, quando $\Delta t_{1}$ se torna maior que $0,117 \mathrm{~s}$, a identificação fica comprometida. 
Figura 44 - Comparação de índice de sucesso para diferentes valores de $\Delta t_{1}$ e $\Delta t_{2}$

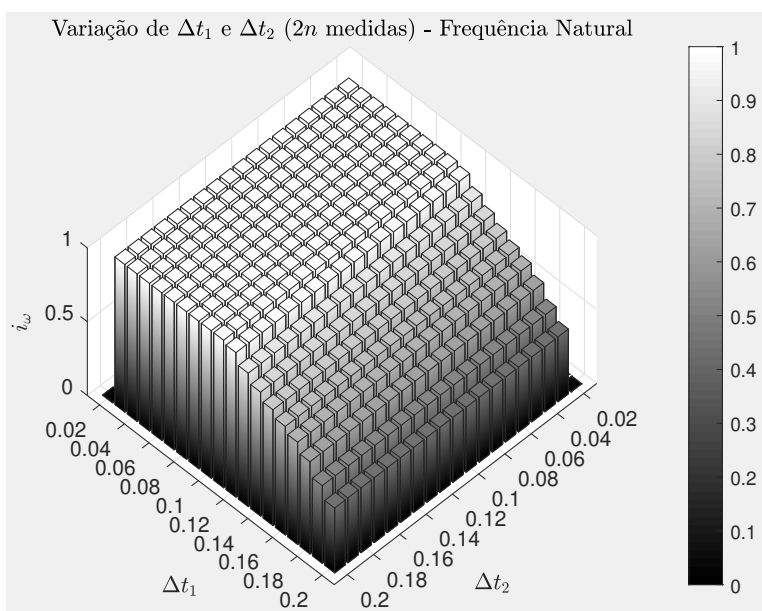

(a) Frequência natural

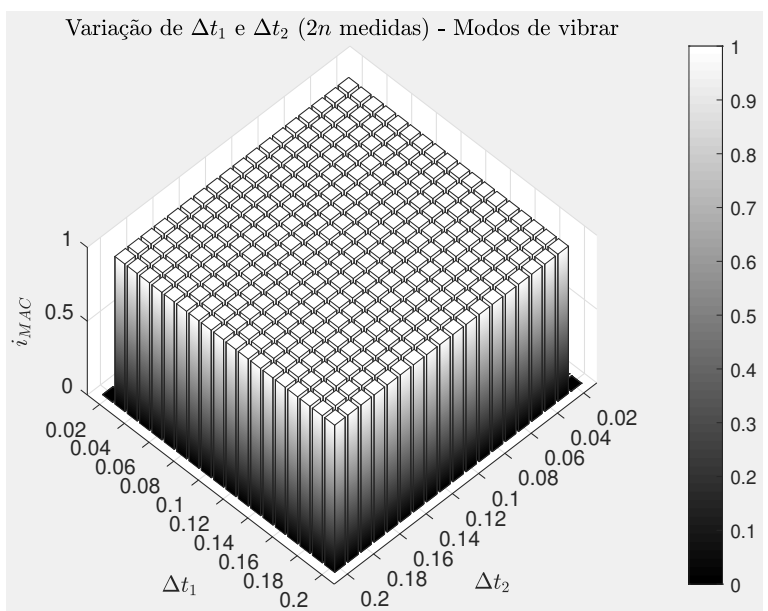

(c) Modos de vibrar

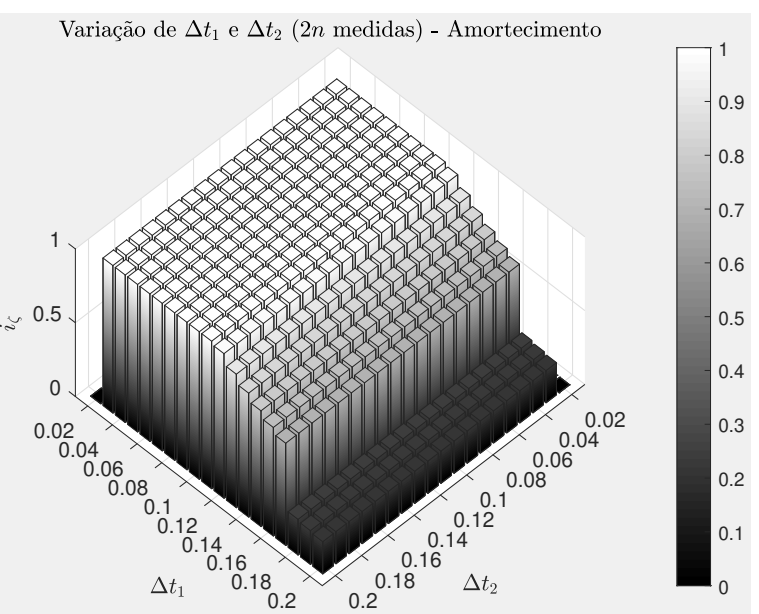

(b) Fator de amortecimento

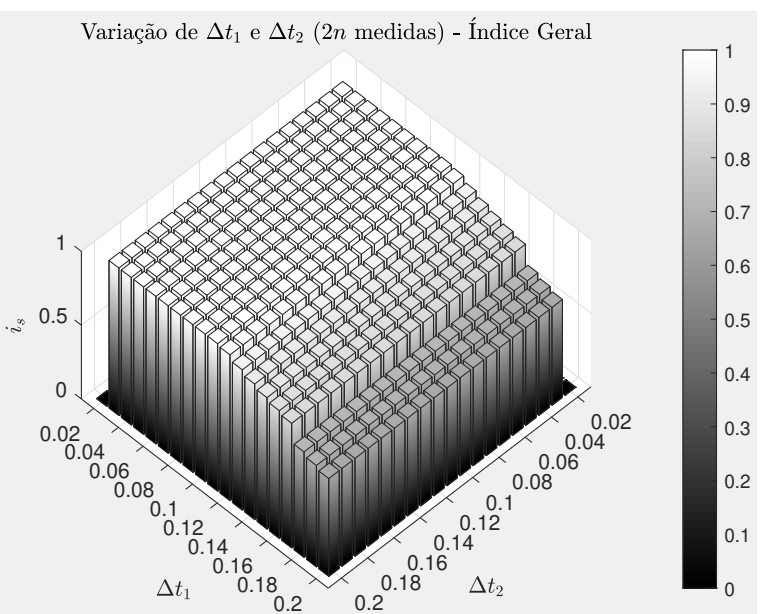

(d) Índice de sucesso geral

Fonte - Elaborado pelo autor.

\subsubsection{Método iterativo para obtenção de $\Delta t_{1}, \Delta t_{3}$ e $P_{t}$}

Já foi citado que o fluxograma da metodologia na figura 23 do capítulo 3 (página 71) exibe uma iteração dos parâmetros $N_{1}, N_{3}$ e $P_{t}$. Como mencionado na seção 5.1 , a variável $P_{t}$ determina a porcentagem em relação a quantidade de dados em cada condição de combustão, $n_{\tau_{c}}$ que será utilizada para treinamento. $\mathrm{O}$ valor complementar serão os dados de validação, conforme equação (5.1), na página 95.

Os parâmetros $N_{1}, N_{2}$ e $N_{3}$ derivam dos parâmetros de tempo do ITD: $\Delta t_{1}, \Delta t_{2}$ e $\Delta t_{3}$. Pappa e Ibrahim (1981) citam que uma boa escolha desses parâmetros é fundamental para uma identificação satisfatória. A frequência de aquisição das amostras (imagens) está fixada em $f_{s}=30 \mathrm{~Hz}$, e os parâmetros $\Delta t_{1}, \Delta t_{2}$ e $\Delta t_{3}$ podem ser escritos em função do 
tempo de amostragem $t_{s}=1 / f_{s}$ :

$$
\begin{aligned}
& \Delta t_{1}=N_{1} \cdot t_{s} \\
& \Delta t_{2}=N_{2} \cdot t_{s} \\
& \Delta t_{3}=N_{3} \cdot t_{s}
\end{aligned}
$$

onde $N_{1}, N_{2}, N_{3} \in \mathbb{N}$ são índices que podem substituir $\Delta t_{1}, \Delta t_{2}$ e $\Delta t_{3}$, respectivamente, uma vez que $t_{s}$ é constante.

Como foi avaliado na seção 5.5 .5 (página 119), os parâmetros $\Delta t_{1}, \Delta t_{2}$ e $\Delta t_{3}$ influenciam na identificação na medida em que, quanto maiores eles forem, menor a frequência de Nyquist e mais difícil se torna a identificação de frequências mais altas. $\mathrm{O}$ parâmetro $\Delta t_{2}$ é o mais sensível no desempenho do método tendo em vista os múltiplos dele próprio que podem ser utilizados, e dessa forma é escolhido com uma constante $N_{2}=1$. Os valores de $N_{1}$ e $N_{3}$ são escolhidos entre 1 e 12.

Esses três parâmetros, $N_{1}, N_{3}$ e $P_{t}$ foram submetidos a um algoritmo iterativo que minimiza o erro da equação (5.40), da página 108.

Definição 5.4 (Erro quadrático médio). Se $\boldsymbol{v}$ e $\hat{\boldsymbol{v}}$ são dois vetores com $n_{v}$ componentes cada, o erro médio quadrático, $M S E(\boldsymbol{v}, \hat{\boldsymbol{v}})$ é definido como

$$
M S E(\boldsymbol{v}, \hat{\boldsymbol{v}})=\frac{1}{n_{v}} \sum_{i=1}^{n_{v}}(v(i)-\hat{v}(i))^{2}
$$

No caso de matrizes, o MSE é computado entre as colunas correspondentes de ambas as matrizes e, então, o maior valor é escolhido como o MSE das duas matrizes em comparação.

Como a matriz $\boldsymbol{A}_{\boldsymbol{I}}$ é encontrada pelo método dos mínimos quadrados, a equação (5.40) se torna uma aproximação ao invés de uma igualdade. O MSE é utilizado entre as matrizes $\boldsymbol{\Phi}^{t} \boldsymbol{A}_{\boldsymbol{I}}{ }^{t}$ e $\hat{\boldsymbol{\Phi}}^{t}$ para avaliar o tamanho do erro dessa aproximação. Logo, o algoritmo itera todas as possíveis combinações para os parâmetros $N_{1}, N_{3}$ e $P_{t}$ dentro dos limites estabelecidos, calcula o MSE das soluções encontradas e escolhe a solução em que o MSE é mínimo.

\subsection{Identificação da dinâmica das imagens de chama}

Fleury, Trigo e Martins (2013) propuseram um modelo de passeio aleatório para a chama que pode ser expresso, em tempo discreto, por:

$$
\dot{\boldsymbol{x}}(t)=\boldsymbol{\nu}(t)
$$

onde $\boldsymbol{x}(t) \in \mathbb{R}^{2 n}$ é o vetor de estados e $\boldsymbol{\nu}(t) \sim N(0, \boldsymbol{R}(\boldsymbol{x}(t))) \in \mathbb{R}^{2 n}$ é um vetor de ruído branco gaussiano com matriz de covariância simétrica positiva semi-definida $\boldsymbol{R}(\boldsymbol{x}(t)) \in$ $\mathbb{R}^{2 n \times 2 n}$, que representa a dinâmica aleatória da chama. 
Por outro lado, Silva et al. (2015) desenvolveram outro modelo identificado através de RD e ITD para apenas uma condição de combustão, que pode ser escrito, em tempo discreto, por:

$$
\dot{\boldsymbol{x}}(t)=\boldsymbol{A x}(t)
$$

onde $\mathbf{A}$ é a matriz identificada do sistema, que já mostrava que caso não haja nenhuma excitação, o sistema tende à estabilidade, o que, por sua vez, poderia ser interpretado como a extinção da chama. A quantidade de amostras reduzidas limitaram a extensão do modelo proposto, mas esse trabalho permitiu um amadurecimento das ideias que são desenvolvidas aqui.

Neste trabalho, os modelos sugeridos por Fleury, Trigo e Martins (2013) e Silva et al. (2015) são combinados para formar uma proposta inovadora de modelo para a chama de fornos industriais. Além disso, o processo de identificação é aplicado, não apenas a uma, mas a sete condições de combustão, de forma que é possível compará-las e analisar suas diferenças e similaridades. Os testes experimentais foram realizados com diferentes razões de equivalência, mas que eram mantidos constantes durante o tempo de coleta de dados. Mesmo assim, quando o RD é aplicado, Silva et al. (2015) afirma que a excitação sobre as características da imagem são aleatórias. É um argumento possível de se afirmar pois, apesar da entrada física ser constante para cada condição de combustão, a chama está sujeita a pressões termoacústicas, velocidades diferentes para combustíveis e comburentes, e reações químicas que interagem e produzem efeitos micro e macroscópicos, ou seja, diversos fatores não controlados e não conhecidos a priori. Logo, todos esses efeitos não modelados interferem na resposta da chama de forma aleatória, uma vez que não são causadas por variações nas entradas. Portanto, é razoável assumir que as propriedades características da imagem da chama também reproduzam essas respostas aleatórias.

Quando o RD é aplicado às características da imagem da chama, a parte aleatória desaparece e apenas a resposta a degrau da razão de equivalência de entrada permanece. Assim, a matriz A, que é obtida via ITD, reflete, consequentemente, na resposta dinâmica à entrada determinística da razão de equivalência, e é exatamente o que o modelo de Silva et al. (2015) representa. O modelo de Fleury, Trigo e Martins (2013) é dividido entre uma parte determinística e outra aleatória, no entanto, a parte determinística, que é descrita apenas pelo estado $\boldsymbol{x}(t)$ no instante presente na equação (5.82), não carrega nenhuma informação intrínseca do sistema, e delega a função de modelagem para a parte aleatória.

O modelo apresentado na equação (5.84) leva em consideração as vantagens dos dois modelos previamente discutidos, uma vez que possui uma contribuição determinística que carrega informação sobre o sistema através da identificação da matriz $\mathbf{A}$, e também uma contribuição aleatória que completa a modelagem com o que não foi considerado na parte determinística:

$$
\dot{\boldsymbol{x}}(t)=\boldsymbol{A} \boldsymbol{x}(t)+\boldsymbol{\nu}(t)
$$


onde $\boldsymbol{x}(t) \in \mathbb{R}^{2 n}$ é o vetor de estados, A é a matriz do sistema identificada e $\boldsymbol{\nu}(t) \sim$ $N(0, \boldsymbol{R}(\boldsymbol{x}(t))) \in \mathbb{R}^{2 n}$ é um vetor de ruído branco gaussiano com matriz de covariância simétrica positiva semi-definida $\boldsymbol{R}(\boldsymbol{x}(t)) \in \mathbb{R}^{2 n \times 2 n}$.

\subsubsection{Transformação de coordenadas para propriedades da chama}

Nesta seção, alguns desdobramentos de procedimentos já realizados serão tratados para facilitar o entendimento da modelagem da matriz de covariância, que será apresentada na próxima seção.

O conceito de variáveis de estado foi introduzido, no modelo (5.84), devido ao resultado obtido através da identificação via ITD. Cada variável de estado do vetor $\boldsymbol{x}(t)$ representa a dinâmica de uma componente principal das propriedades das imagens selecionadas pela análise de correlação e transformadas pela PCA, para uma condição de combustão $c$ arbitrária. É interessante que se defina também um sistema com as variáveis de estado sendo as próprias propriedades da imagem selecionadas pela análise de correlação da seção 5.2 (página 95), que selecionou as propriedades $p \in N_{\text {corr }}^{s}=\left\{p_{1}, p_{2}, \ldots, p_{n_{p, c}}\right\} \subset P_{U}$.

Definição 5.5 Sabendo que $n_{p, c}$ (ver página 99) é a quantidade de propriedades não correlacionadas selecionadas no processo de análise de correlação numa condição de combustão c arbitrária, o modelo da dinâmica das imagens da chama é representado pelo vetor de estados $\boldsymbol{z}(t)=\left(\begin{array}{llll}z_{1}(t) & z_{2}(t) & \cdots & z_{n_{p, c}}(t)\end{array}\right)^{t}$, onde cada variável de estado corresponde a uma propriedade da imagem da chama.

Um vetor de estados com os dados experimentais de treinamento $\boldsymbol{z}_{\boldsymbol{t}}(t)$ pode ser construído relacionando cada variável de estado com a função $f_{p}\left(\tau_{c, t}\right)$ da definição 5.1 (página 95).

$$
\boldsymbol{z}_{\boldsymbol{t}}(t)=\left(\begin{array}{c}
z_{1, t}(t) \\
z_{2, t}(t) \\
\vdots \\
z_{n_{p, c}, t}(t)
\end{array}\right)=\left(\begin{array}{c}
f_{p_{1}}\left(\tau_{c, t}\right) \\
f_{p_{2}}\left(\tau_{c, t}\right) \\
\vdots \\
f_{p_{n_{p, c}}}\left(\tau_{c, t}\right)
\end{array}\right)
$$

Por outro lado, um vetor de estados estimados $\hat{\boldsymbol{z}}(t)$ deve ser obtido através do modelo (5.84). O item (h) do algoritmo 5.3 (página 101) já sinalizava sobre a possibilidade da transformação inversa do PCA para se obter as propriedades da imagem a partir das componentes principais. Primeiramente, obtém-se o vetor de estados estimados normalizado $\hat{z}_{n}(t)$ :

$$
\hat{\boldsymbol{z}}_{\boldsymbol{n}}(t)=\boldsymbol{x}(t) \boldsymbol{\Pi}^{t}
$$

onde a matriz $\boldsymbol{\Pi}$ é a matriz truncada de transformação de coordenadas que diagonaliza a a matriz de covariância, e havia sido definida no item (b) do algoritmo 5.3 (página 101), e $\boldsymbol{x}(t)$ vem da equação (5.84). 
Em seguida, inverte-se o processo de normalização (ver definição 5.3), o que resulta nas variáveis de estado estimadas $\hat{\boldsymbol{z}}(t)$ :

$$
\hat{\boldsymbol{z}}(t)=\left(\begin{array}{c}
\hat{z}_{1}(t) \\
\hat{z}_{2}(t) \\
\vdots \\
\hat{z}_{n_{p, c}}(t)
\end{array}\right)=\left(\begin{array}{c}
\hat{z}_{1, n}(t) \sigma_{\delta_{p_{1}}}+\mu_{\delta_{p_{1}}} \\
\hat{z}_{2, n}(t) \sigma_{\delta_{p_{2}}}+\mu_{\delta_{p_{2}}} \\
\vdots \\
\hat{z}_{n_{p, c}, n}(t) \sigma_{\delta_{p_{n_{p}, c}}}+\mu_{\delta_{p_{n, c}}}
\end{array}\right)
$$

onde foram aplicadas as equações (5.6) e (5.7), da página 96, com $p \in N_{\text {corr }}^{s}=\left\{p_{1}, p_{2}, \ldots, p_{n_{p, c}}\right\} \subset$ $P_{U}$.

\subsubsection{Modelagem da matriz de covariância}

As variáveis de estado estimados obtidas em (5.87) possuem variância muito menor, se comparadas com os dados experimentais de treinamento originais. Isso ocorre pois, até a identificação do modelo pelo ITD, há passos do procedimento de identificação fazem com que os dados percam parte da sua variância. Especialmente, quando o algoritmo RD é aplicado, boa parte da variância desaparece devido ao cálculo de média que esse algoritmo realiza na equação (5.14), da página 102. Logo, quando é feita a transformação de coordenadas de volta para restabelecer as propriedades da imagem, não é possível recuperar toda a variância do sinal original.

Portanto, para determinar a variável aleatória $\boldsymbol{\nu}(t)$ de (5.84), que modelará a dinâmica aleatória do sistema, a matriz de covariância $\boldsymbol{R}(\boldsymbol{x}(t))$ requer ser modelada também.

Definição 5.6 Seja $\boldsymbol{R}^{(e s t)}(\boldsymbol{x}(t))$ uma matriz de covariância dos dados estimados pelo ITD, após todo o processo de identificação. A matriz de covariância $\boldsymbol{R}(\boldsymbol{x}(t))$ da variável aleatória $\boldsymbol{\nu}(t)$ é determinada por:

$$
\boldsymbol{R}(\boldsymbol{x}(t))=\boldsymbol{f}_{\boldsymbol{R}} \cdot \boldsymbol{R}^{(e s t)}(\boldsymbol{x}(t))
$$

onde $\boldsymbol{f}_{\boldsymbol{R}} \in \mathbb{R}^{2 n \times 2 n}$ é chamado de fator de correção de variância.

O fator de correção de variância, $\boldsymbol{f}_{\boldsymbol{R}}$, é calculado comparando a matriz de covariância das propriedades de imagem extraídas do conjunto de treinamento dos dados experimentais com a matriz de covariância das propriedades de imagem estimadas. O algoritmo 5.4 traça os passos para determinar $\boldsymbol{f}_{\boldsymbol{R}}$.

Algoritmo 5.4 Este algoritmo descreve o procedimento para se obter o fator de correção de variância $\boldsymbol{f}_{\boldsymbol{R}}$ :

a) transformar os dados $\boldsymbol{z}_{\boldsymbol{t}}(t)$ nas coordenadas PCA para encontrar $\boldsymbol{x}_{\boldsymbol{t}}(t)$ :

$$
\boldsymbol{x}_{\boldsymbol{t}}(t)=\boldsymbol{z}_{t}(t) \boldsymbol{\Pi}
$$


b) calcular a matriz de covariância das propriedades dos dados experimentais de treinamento, $\boldsymbol{R}^{(\exp )}\left(\boldsymbol{x}_{\boldsymbol{t}}(t)\right)$ :

$$
\boldsymbol{R}^{(e x p)}\left(\boldsymbol{x}_{t}(t)\right)=\left(\begin{array}{cccc}
r_{1,1}^{(e x p)} & r_{1,2}^{(e x p)} & \cdots & r_{1,2 n}^{(e x p)} \\
r_{2,1}^{(e x p)} & r_{2,2}^{(e x p)} & \cdots & r_{2,2 n}^{(e x p)} \\
\vdots & \vdots & \ddots & \vdots \\
r_{2 n, 1}^{(e x p)} & r_{2 n, 2}^{(e x p)} & \cdots & r_{2 n, 2 n}^{(e x p)}
\end{array}\right)
$$

c) obter soluções estimadas $\boldsymbol{x}(t)$ a partir do modelo (5.84);

d) calcular a matriz de covariância das propriedades dos dados estimados, $\boldsymbol{R}^{(\text {est })}(\boldsymbol{x}(t))$ :

$$
\boldsymbol{R}^{(e s t)}(\boldsymbol{x}(t))=\left(\begin{array}{cccc}
r_{1,1}^{(e s t)} & r_{1,2}^{(e s t)} & \cdots & r_{1,2 n}^{(e s t)} \\
r_{2,1}^{(e s t)} & r_{2,2}^{(e s t)} & \cdots & r_{2,2 n}^{(e s t)} \\
\vdots & \vdots & \ddots & \vdots \\
r_{2 n, 1}^{(e s t)} & r_{2 n, 2}^{(e s t)} & \cdots & r_{2 n, 2 n}^{(e s t)}
\end{array}\right)
$$

e) obter a matriz do fator de correção de variância $\boldsymbol{f}_{\boldsymbol{R}}$, onde cada componente é calculada como:

$$
f_{R}(i, j)=\sqrt{\frac{r_{i, j}^{(e x p)}}{r_{i, j}^{(e s t)}}}, \quad \forall i, j \in\{1,2, \ldots, 2 n\}
$$

A variável $\boldsymbol{x}(t)$ é uma variável estocástica, logo para obter valores representativos estatisticamente de $\boldsymbol{x}(t)$, é necessário executar o Algoritmo 5.4 diversas vezes e após uma quantidade suficiente de amostras, avaliar sua média e desvio padrão de $\boldsymbol{f}_{\boldsymbol{R}}$. Um vez obtido $\boldsymbol{f}_{\boldsymbol{R}}$, basta aplicar a equação (5.88) para encontrar a matriz de covariância $\mathbf{R}$ desejada.

Portanto, depois de encontrar a matriz da dinâmica do sistema $\boldsymbol{A}$ e obter a matriz de covariância $\boldsymbol{R}$, o modelo da equação (5.84) está completamente identificado.

\subsection{Validação do modelo identificado}

O processo de validação consiste em comparar dados estimados com o modelo recém obtido com dados experimentais que não foram usados no processo de identificação. Essa necessidade de validação causou a necessidade de, na seção 5.1, definir a repartição da massa de dados em dois grupos: um grupo com $P_{t}$ dados para treinamento e outro com $P_{v}$ dados para validação.

Devido ao procedimento pelo qual o modelo foi obtido, com a parte aleatória sendo construída a partir de um ruído branco, a correlação de seu sinal com qualquer outro tipo de sinal tende a ser baixa, uma vez que, por definição, um ruído branco não é 
correlacionado com nenhum sinal. Logo, utilizar diretamente o coeficiente de Pearson não traz resultados conclusivos.

Uma comparação no domínio da frequência aparece como uma solução alternativa para o processo de validação. De fato, no domínio da frequência um ruído branco é uma reta constante. A mudança de paradigma na representação do sinal torna possível o uso do coeficiente de correlação de Pearson na comparação de ambos os sinais.

Ryder (2002) avalia alguns métodos para comparar respostas em frequência de diferentes sinais e conclui que dois métodos podem ser usados: o coeficiente de correlação e o desvio espectral. Os dois métodos apresentam pontos positivos e negativos e, por isso, devem ser usados, de preferência, de maneira complementar. Por um lado, o coeficiente de correlação diz se as tendências das curvas em geral apresentam alguma similaridade. Por outro lado, o desvio espectral trata de como a variância de ambas as curvas se relacionam. O coeficiente de correlação de Pearson já havia sido definido na equação (5.9), e seu resultado havia sido interpretado através de conceitos qualitativos, conforme tabela 8. O desvio espectral, por sua vez, é definido a seguir:

Definição 5.7 (Desvio espectral estocástico, (MIKKELSEN et al., 1993)). O desvio espectral estocástico, $\sigma_{\omega}$ é definido por

$$
\sigma_{\omega}=\frac{100}{N_{f}} \sum_{j=1}^{N_{f}} \sqrt{\frac{1}{N_{m}-1} \sum_{i=1}^{N_{m}}\left(\frac{\bar{r}_{j}-r_{i j}}{\bar{r}_{j}}\right)^{2}}
$$

onde $N_{f}$ é o número total de frequências discretas e $N_{m}$ é a quantidade total de medidas a serem comparadas. Os diferentes sinais a serem comparados são $r_{i}$, com $i=1,2, \ldots, N_{m}$. Cada medida $r_{i}$ é formada por $N_{f}$ pontos, de forma que $r_{i j}$ é um ponto específico da medida $i$ com frequência $j$. A média $\bar{r}_{j}$ é calculada dos valores de todas as $N_{m}$ medidas para a mesma frequência $j$. É multiplicada por 100 para dar respostas em porcentagem.

Quando apenas dois sinais são comparados ao mesmo tempo, $N_{m}=2$ e a equação (5.93) se torna:

$$
\sigma_{\omega}=\frac{100 \sqrt{2}}{N_{f}} \sum_{j=1}^{N_{f}}\left|\frac{r_{2 j}-r_{1 j}}{r_{2 j}+r_{1 j}}\right|
$$

Quanto mais perto de zero o desvio espectral, menor será a diferença entre a média de todas as medidas com cada medida, para uma mesma frequência, logo, melhor será o resultado da identificação.

\subsection{Unificação dos modelos identificados}

Os modelos propostos estão restritos a condições de chama específicas, além disso, a forma da equação (5.84) não admite entradas, o que dificulta sua utilização para sistemas 
de controle. Segue, então, uma proposta para a unificação dos modelos, de forma a fazer com que a razão de equivalência se torne a entrada do sistema.

Definição 5.8 Sejam, para cada condição de combustão, as matrizes $\boldsymbol{A}_{\boldsymbol{c}}$, com c= $1,2, \ldots, n_{c}$, as matrizes identificadas, e as matrizes $\boldsymbol{R}_{\boldsymbol{c}}$, com $c=1,2, \ldots, n_{c}$, as matrizes de covariância da variável aleatória, para os modelos do tipo:

$$
\dot{\boldsymbol{x}}_{\boldsymbol{c}}(t)=\boldsymbol{A}_{\boldsymbol{c}} \boldsymbol{x}_{\boldsymbol{c}}(t)+\boldsymbol{\nu}_{\boldsymbol{c}}(t)
$$

Cada componente da matriz média $\boldsymbol{A}_{\boldsymbol{\mu}} \in \mathbb{R}^{2 n \times 2 n}$ é definida como:

$$
a_{\mu}(i, j)=\frac{1}{n_{c}} \sum_{c=1}^{n_{c}} a_{c}(i, j), \quad \forall i, j \in\{1,2, \ldots, 2 n\}
$$

Cada componente da matriz média $\boldsymbol{R}_{\boldsymbol{\mu}} \in \mathbb{R}^{2 n \times 2 n}$ é definida como:

$$
r_{\mu}(i, j)=\frac{1}{n_{c}} \sum_{c=1}^{n_{c}} r_{c}(i, j), \quad \forall i, j \in\{1,2, \ldots, 2 n\}
$$

As matrizes diferenças são:

$$
\begin{aligned}
\boldsymbol{A}_{c}^{\prime} & =\boldsymbol{A}_{c}-\boldsymbol{A}_{\mu} \\
\boldsymbol{R}_{c}^{\prime} & =\boldsymbol{R}_{c}-\boldsymbol{R}_{\mu}
\end{aligned}
$$

Então, o novo modelo fica:

$$
\dot{\boldsymbol{x}}_{\boldsymbol{c}}(t)=\boldsymbol{A}_{\boldsymbol{\mu}} \boldsymbol{x}_{\boldsymbol{c}}(t)+\boldsymbol{A}_{c}^{\prime} \boldsymbol{x}_{c}(t)+\boldsymbol{\nu}_{c}(t)
$$

As matrizes $\boldsymbol{A}_{\boldsymbol{c}}^{\prime}$ e $\boldsymbol{R}_{\boldsymbol{c}}^{\prime}$ podem ser imaginadas variando continuamente na medida em que varia cada condição de combustão $c$. A figura 45 ilustra, de forma esquemática, que as componentes das matrizes $\boldsymbol{A}_{c}^{\prime}$ e $\boldsymbol{R}_{\boldsymbol{c}}^{\prime}$ variam com a variação da condição de combustão $c$, caso esta variasse de forma contínua. Essas matrizes foram identificadas para as condições de combustão específicas em que houveram ensaios (representadas por retângulos quadriculados na figura 45).

A fim de encontrar os parâmetros aproximados de modelos intermediários àqueles identificados, pode-se interpolar as componentes das matrizes $\boldsymbol{A}_{\boldsymbol{c}}^{\prime}$ e $\boldsymbol{R}_{\boldsymbol{c}}^{\prime}$. Para isso, as hipóteses de que as matrizes $\boldsymbol{A}_{\boldsymbol{c}}$ e as matrizes $\boldsymbol{R}_{\boldsymbol{c}}$ são descritas na mesma base de coordenadas, para qualquer $c=1,2, \ldots, n_{c}$ e correspondem às mesmas propriedades das imagens são assumidas. Assume-se também que as razões de equivalência $0,42 \leq u_{c} \leq 1,12$ estão organizadas em ordem crescente para $c=1,2, \ldots, n_{c}$.

Sempre existem dois valores de $u_{c}$ seguidos e arbitrários: $u_{k}$ e $u_{k+1}$, onde $c=k$ e $c=(k+1)$, respectivamente, são valores de razões de equivalência em que há medidas 
Figura 45 - Ilustração esquemática de como variam as matrizes $\boldsymbol{A}_{c}^{\prime}$ e $\boldsymbol{R}_{\boldsymbol{c}}^{\prime}$ com a variação de $c$.

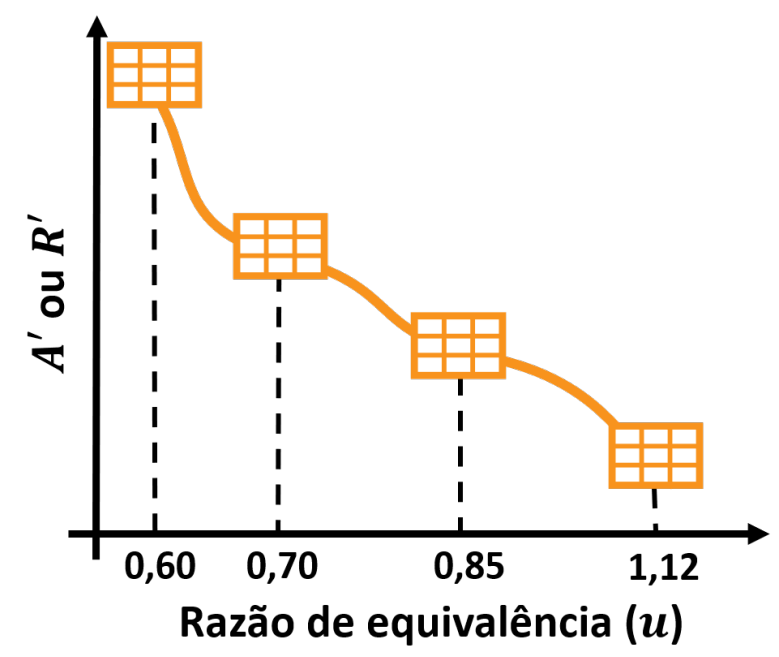

Fonte - Elaborado pelo autor.

disponíveis. Para $u \in\left\{\mathbb{R} \mid 0,42 \leq u_{k} \leq u \leq u_{k+1} \leq 1,12\right\}$, os valores das componentes das matrizes $\boldsymbol{A}^{\prime}(u)$ e $\boldsymbol{R}^{\prime}(\boldsymbol{x}(t), u)$, podem ser calculados da seguinte maneira:

$$
\begin{aligned}
a^{\prime}(i, j) & =\left(a_{k+1}^{\prime}(i, j)-a_{k}^{\prime}(i, j)\right)\left(\frac{u-u_{k}}{u_{k+1}-u_{k}}\right)+ \\
& +a_{k}^{\prime}(i, j), \quad \forall i, j \in\{1,2, \ldots, 2 n\} \\
r^{\prime}(i, j) & =\left(r_{k+1}^{\prime}(i, j)-r_{k}^{\prime}(i, j)\right)\left(\frac{u-u_{k}}{u_{k+1}-u_{k}}\right)+ \\
& +r_{k}^{\prime}(i, j), \quad \forall i, j \in\{1,2, \ldots, 2 n\}
\end{aligned}
$$

onde $a_{k}^{\prime}(i, j), a_{k+1}^{\prime}(i, j)$ são componentes das matrizes $\boldsymbol{A}_{k}^{\prime}$ e $\boldsymbol{A}_{k+1}^{\prime}$, respectivamente, e $r_{k}^{\prime}(i, j), r_{k+1}^{\prime}(i, j)$ são componentes das matrizes $\boldsymbol{R}_{k}^{\prime}$ e $\boldsymbol{R}_{k+1}^{\prime}$, respectivamente.

As equações (5.101) e (5.102) se prestam a interpolar as matrizes $\boldsymbol{A}_{\boldsymbol{c}}^{\prime}$ e $\boldsymbol{R}_{\boldsymbol{c}}^{\prime}$ identificadas com os dados dos ensaios experimentais. Numa hipotética aplicação industrial, esses ensaios seriam realizados na fase de calibração do modelo do forno. Essa interpolação permite unificar os modelos identificados e estendê-los, de forma que a equação (5.100) possa ser reescrita da seguinte forma:

$$
\dot{\boldsymbol{x}}(t)=\boldsymbol{A}_{\boldsymbol{\mu}} \boldsymbol{x}(t)+\boldsymbol{A}^{\prime}(u) \boldsymbol{x}(t)+\boldsymbol{\nu}(u, t)
$$

onde a entrada $u \in[0,42 ; 1,12] \subset \mathbb{R}$ e $\boldsymbol{\nu}(u, t) \sim N\left(0, \boldsymbol{R}^{\prime}(\boldsymbol{x}(t), u)\right)$.

O modelo da equação (5.103) é o modelo unificado de chama, que tem como entrada a razão de equivalência do processo de combustão. Caso fosse identificado que valores intermediários de ensaios realizados possuíssem valor significativamente diferentes dos valores interpolados, um novo valor de set point na curva da firgura 46 deveria ser adicionado. 
Figura 46 - Ilustração esquemática da aproximação das matrizes $\boldsymbol{A}_{c}^{\prime}$ e $\boldsymbol{R}_{c}^{\prime}$ através de interpolação linear.

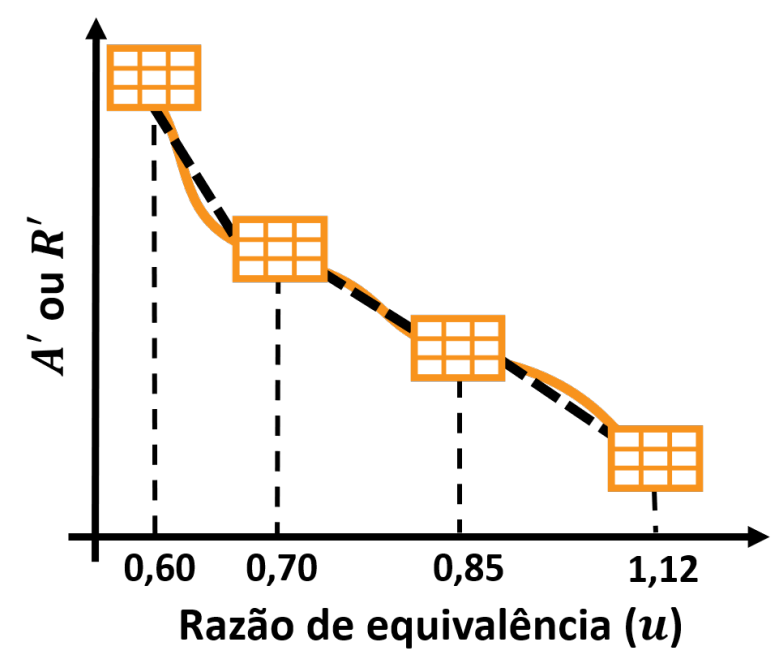

Fonte - Elaborado pelo autor. 


\section{RESULTADOS E DISCUSSÕES}

Este capítulo é organizado de forma a apresentar e discutir os resultados obtidos na mesma ordem em que a metodologia se deu, conforme o fluxograma na figura 23 do capítulo 3. Na seção 6.1 são discutidas as etapas da coleta e processamento de imagens, bem como é feita uma comparação entre os três limiares calculados, a fim de justificar a escolha da média dos pontos P e T. As seções 6.2 e 6.3 mostram os resultados dos processos de análise de correlação e análise de componentes principais, respectivamente. As seções 6.4 e 6.5 detalham os resultados da identificação dos modelos por análise modal operacional com os métodos RD e ITD, respectivamente. A seção 6.6 apresenta os resultados do cálculo do fator de correção de variância para a identificação da matriz de covariância da parte aleatória do modelo. Os resultados dos modelos finais são apresentados na seção 6.7. Por fim, na seção 6.8, os resultados do processo de validação são discutidos.

\subsection{Discussões sobre a coleta e o processamento das imagens de chama}

No capítulo 4, enquanto os passos do processamento de imagens eram explicados, amostras de imagens foram ilustradas, como exemplos, a fim de garantir um maior entendimento ao leitor. Além disso, o apêndice A mostra de forma prática as imagens intermediárias do processamento, bem como o histograma da imagem com a indicação do limiar utilizado. Logo, os resultados do processamento de imagens em si já foram exibidos, mas ainda há alguns pontos importantes a serem discutidos e comentados.

Durante a execução do experimento com a aquisição das imagens, durante a fase considerada como período transitório, as configurações do ganho do brilho e contraste do vídeo eram revistos. Essa ação permitiu obter imagens com aproximadamente o mesmo padrão de brilho do fundo para todas as condições. Infelizmente, houve uma exceção na aquisição das imagens da condição 1, que não foram muito bem configuradas e é perceptível que o fundo ficou mais claro nessas imagens.

Na medida do possível, o algoritmo criado para a limiarização contornou o problema e as imagens em branco e preto obtidas evidenciam uma separação satisfatória entre a chama e o fundo. Essa dificuldade se dá pois o histograma das imagens da condição 1 não apresenta um segundo pico tão evidenciado quanto as outras condições. Por outro lado, o resultado fornecido pelo algoritmo proposto para a determinação do limiar, mesmo sem os picos pronunciados no histograma, possibilitou a identificação de um modelo para essa condição de chama, o que demonstra uma certa robustez do algoritmo para imagens que 
Figura 47 - Comparações entre limiares para condição 1.

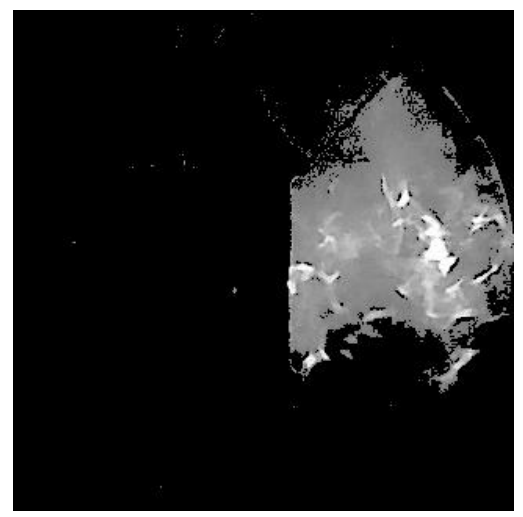

(a) Ponto P.

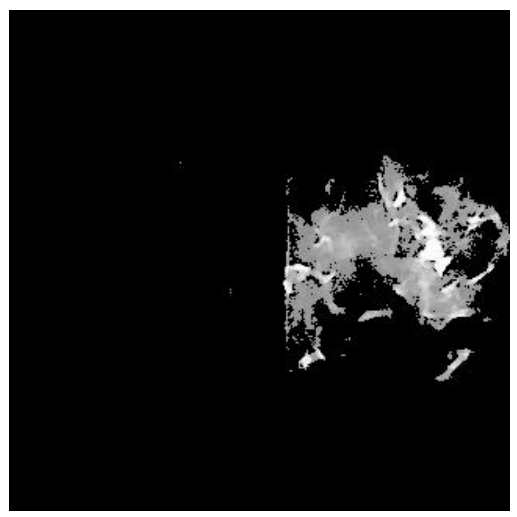

(b) Média entre $\mathrm{P}$ e $\mathrm{T}$.

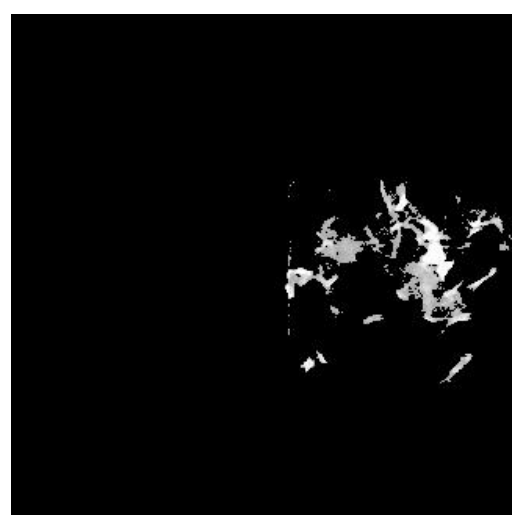

(c) Ponto T.

Fonte - Elaborado pelo autor.

não seguem de maneira ideal o padrão de histograma mostrado na figura 31.

Figura 48 - Comparações entre limiares para condição 2.

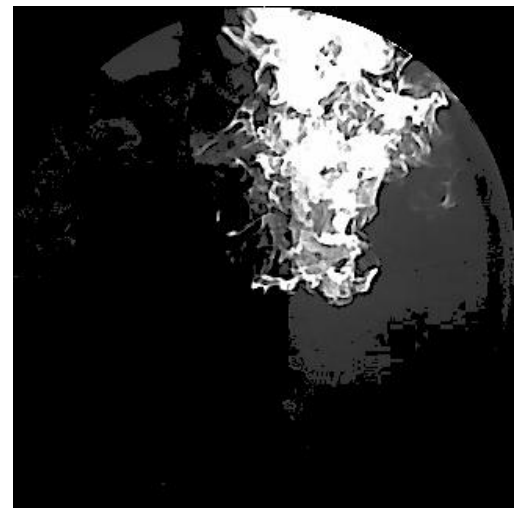

(a) Ponto P.

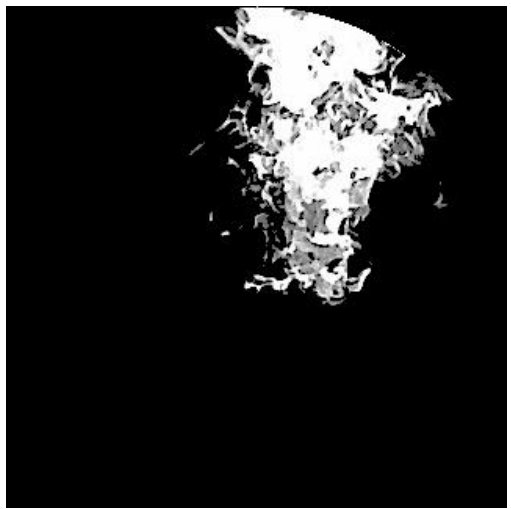

(b) Média entre P e T.

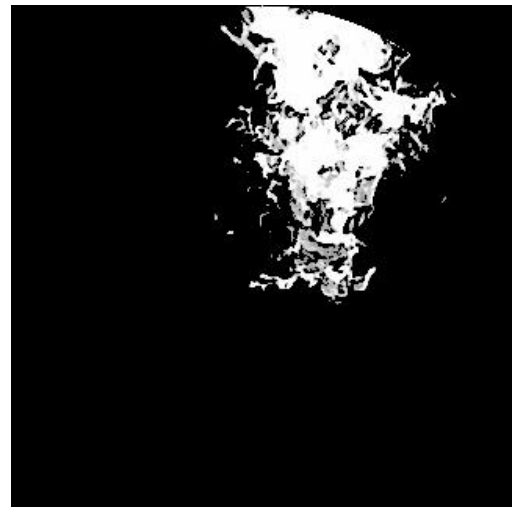

(c) Ponto T.

Fonte - Elaborado pelo autor.

As figuras 47 a 53 de imagens segmentadas, em todas as condições, comparam a escolha do limiar entre os pontos $\mathrm{P}$ e $\mathrm{T}$ da figura 31, na seção 4.4 .2 (página 85), e da média entre os pontos $\mathrm{P}$ e $\mathrm{T}$, que foi o ponto adotado no processamento das imagens. $\mathrm{Na}$ condição 6, a condição de combustão é tão pobre em combustível que a chama está bem escura, quase apagada, e qualquer um dos limiares dá resultados muito parecidos. Com exceção dela, a escolha do ponto P causa o aparecimento de porções do fundo na imagem.

A porção do fundo na imagem distorce os valores das propriedades características pois muitas delas se baseiam na imagem em preto e branco $I^{p b}$. Consequentemente, haverá a interpretação que o fundo faz parte da chama, caso isso ocorra. As diferenças entre a média do ponto P e T e o próprio ponto T são mais sutis. Contudo, é possível notar que as imagens com limiar no ponto T perdem o detalhamento das bordas da chama, onde há 
Figura 49 - Comparações entre limiares para condição 3.

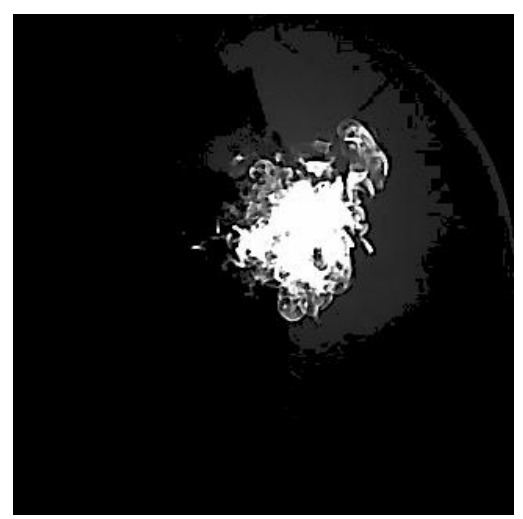

(a) Ponto P.

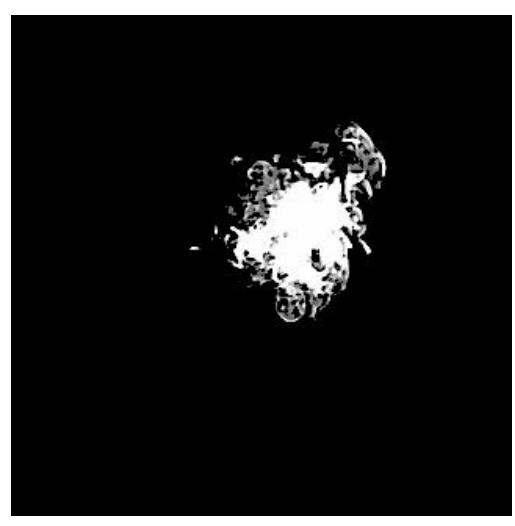

(b) Média entre P e T.

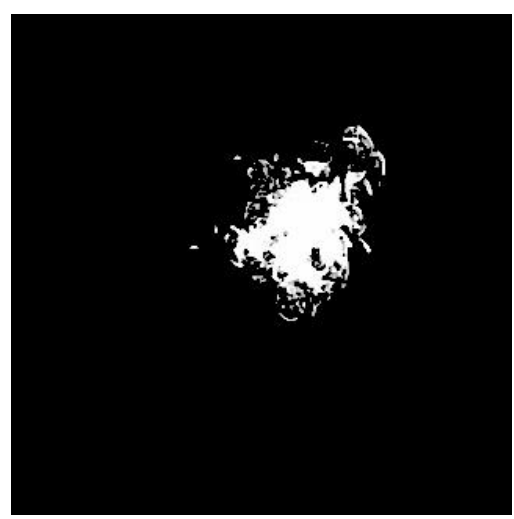

(c) Ponto T.

Fonte - Elaborado pelo autor.

Figura 50 - Comparações entre limiares para condição 4.

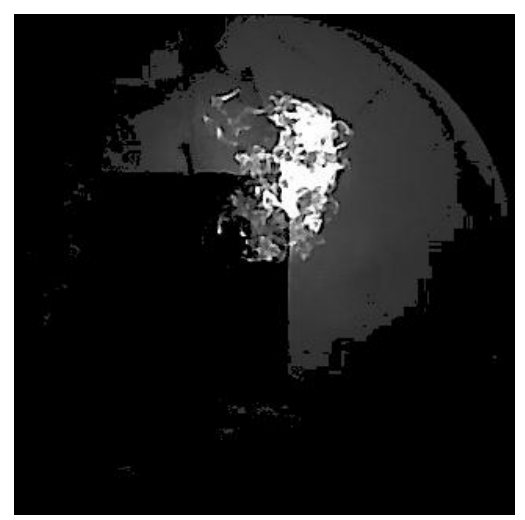

(a) Ponto P.

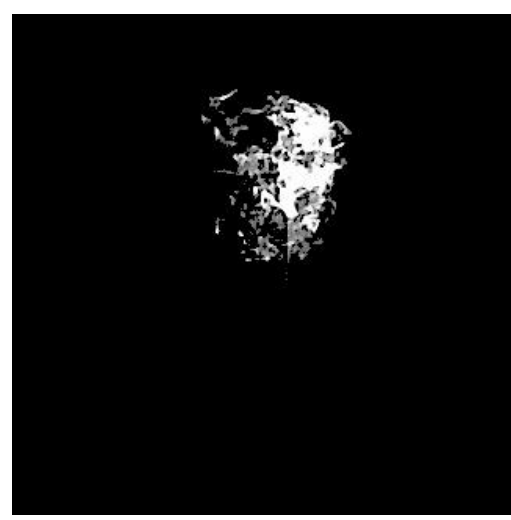

(b) Média entre $\mathrm{P}$ e T.

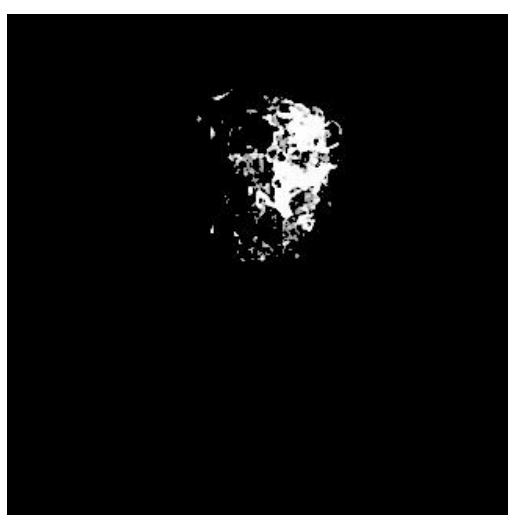

(c) Ponto T.

Fonte - Elaborado pelo autor.

fumaça com partes mais escuras que ainda são chamas, mas provavelmente numa condição incompleta de queima. As imagens com limiar no ponto T são quase imagens em preto e branco pois seus níveis de cinza já são muito altos.

Os tons intermediários de cinza, que ainda são da chama, são importantes para a caracterização das medidas relacionadas ao brilho da chama, pois dá mais textura à imagem. Portanto, a escolha do ponto $\mathrm{P}$ acarreta em considerar parte do fundo como chama, e a escolha do ponto T faz perder detalhes das bordas da chama. Quando se escolhe a média entre P e T como limiar, há um maior equilíbrio entre esses dois critérios, mesmo que em alguns casos haja um pouco de fundo na imagem, como pode ser observado nas imagens da condição 1, por motivos já discutidos.

A proposta de utilização da média entre P e T como solução para a escolha do limiar viabilizou um processamento de imagens que garantisse maior detalhamento na 
Figura 51 - Comparações entre limiares para condição 5.

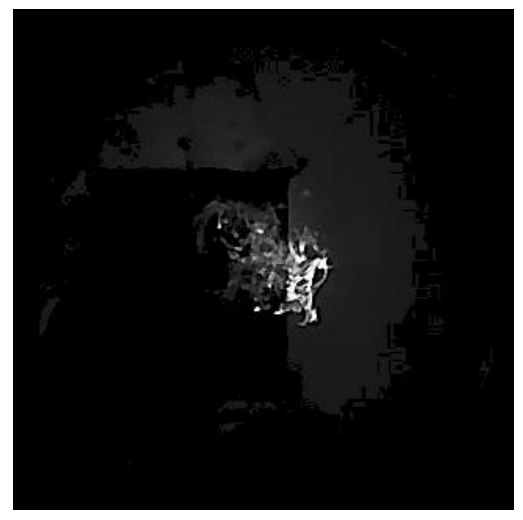

(a) Ponto P.

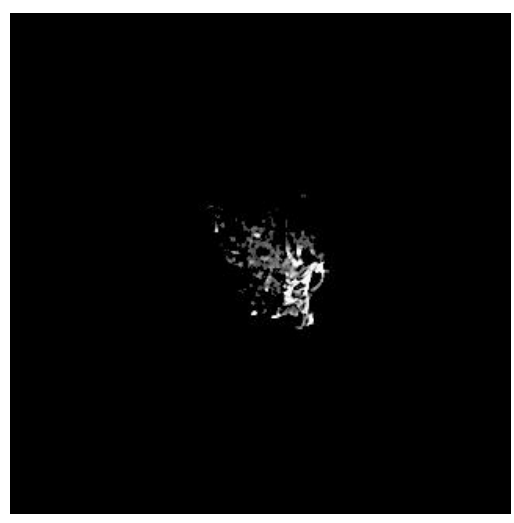

(b) Média entre P e T.

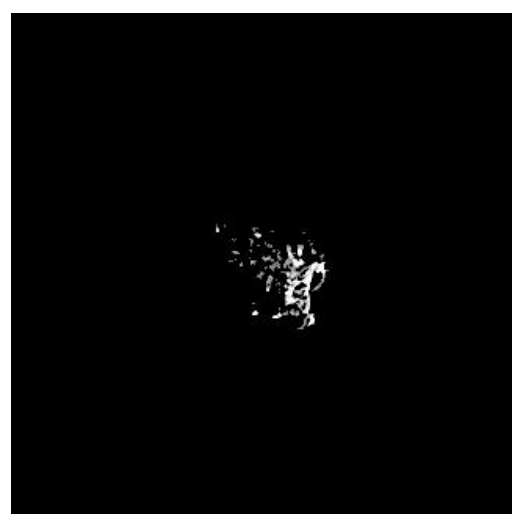

(c) Ponto T.

Fonte - Elaborado pelo autor.

Figura 52 - Comparações entre limiares para condição 6 .

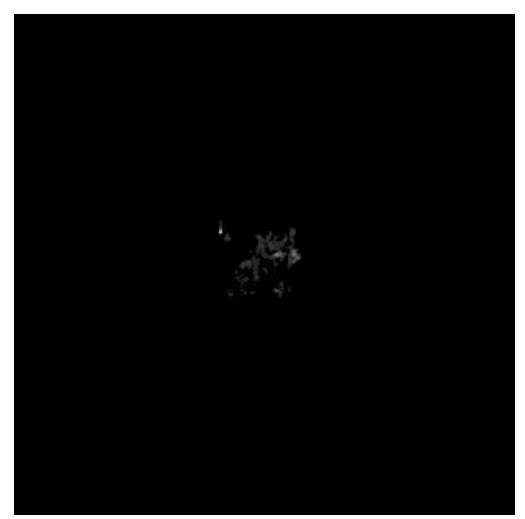

(a) Ponto P.

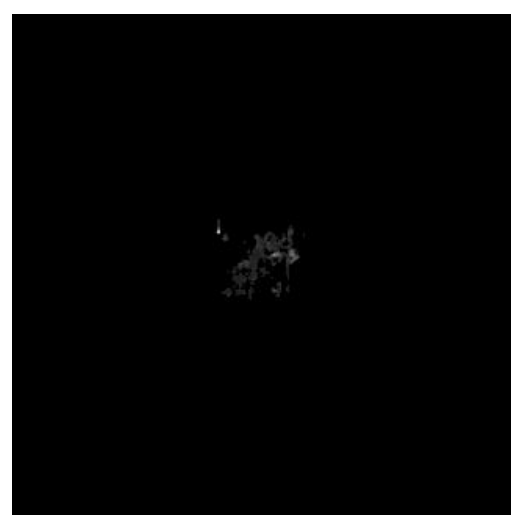

(b) Média entre P e T.

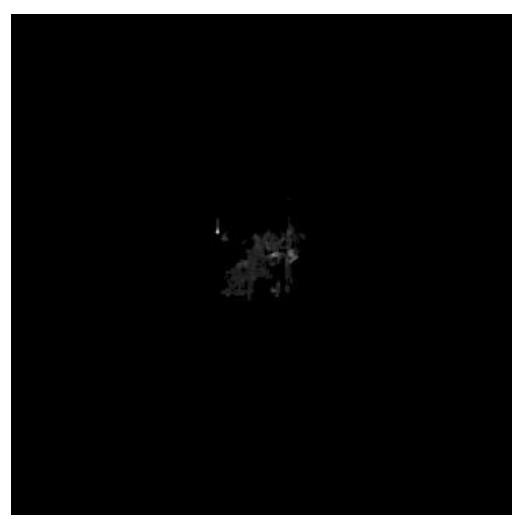

(c) Ponto T.

Fonte - Elaborado pelo autor.

Figura 53 - Comparações entre limiares para condição 7.

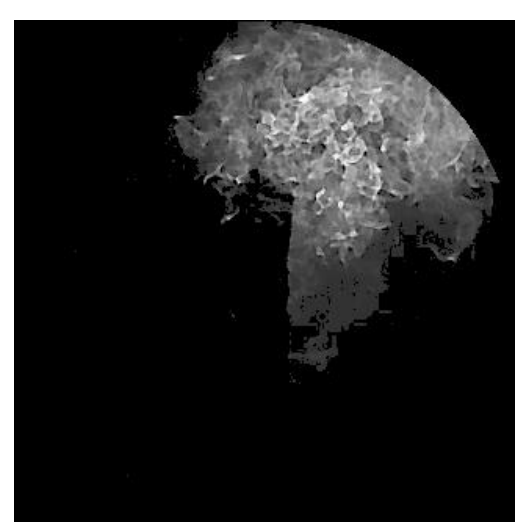

(a) Ponto P.

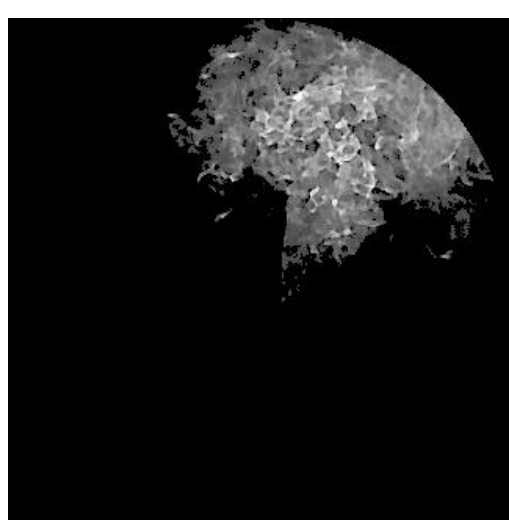

(b) Média entre P e T.

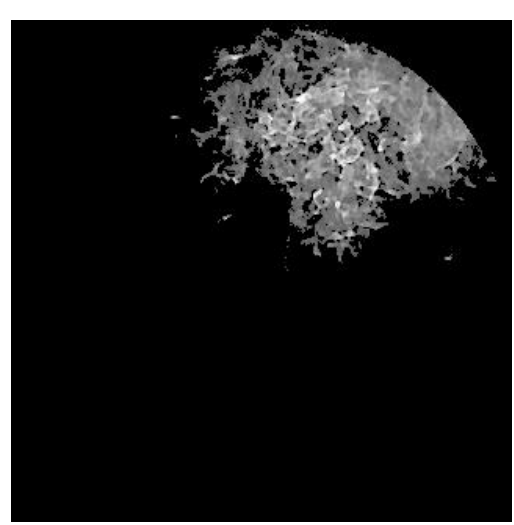

(c) Ponto T.

Fonte - Elaborado pelo autor. 
dinâmica das propriedades, uma vez que conseguiu encontrar uma solução simples que separasse, de forma mais otimizada, o objeto de interesse na imagem, no caso, a chama, do seu fundo.

\subsection{Resultados da análise de correlação}

A análise de correlação foi realizada com o objetivo de garantir que as propriedades escolhidas para a modelagem fossem pouco correlacionadas, dentre as $N_{p}=15$ propriedades definidas na seção 4.6 (página 92). A tabela 8 (página 97) é utilizada como referência para a escolha do valor do limite $L_{c o r r}$, que é o limite que divide as propriedades entre correlacionadas e não correlacionadas. Conforme discutido na seção 5.2 (página 95), escolheu-se $L_{\text {corr }}=0,4$ para que, de acordo com a convenção da tabela 8, as propriedades remanescentes do processo possuíssem correlação fraca ou muito fraca. As propriedades escolhidas, de acordo com a condição de combustão, estão detalhadas na tabela 14 .

Tabela 14 - Propriedades não correlacionadas obtidas através da análise de correlação.

\begin{tabular}{lcccccr}
\hline Condição de & \multicolumn{9}{c}{ Propriedades características } & Qtd. total de \\
combustão, $c$ & 1 & 2 & 3 & 4 & 5 & propriedades \\
\hline 1 & $C_{x}$ & $C_{y}$ & $L_{y}$ & & & 3 \\
2 & $C_{x}$ & $C_{y}$ & $L_{y}$ & $H_{x}$ & & 4 \\
3 & $C_{x}$ & $C_{y}$ & $L_{y}$ & $H_{x}$ & $B$ & 5 \\
4 & $C_{x}$ & $C_{y}$ & $L_{y}$ & $H_{x}$ & & 4 \\
5 & $C_{x}$ & $C_{y}$ & $L_{y}$ & & & 3 \\
6 & $C_{x}$ & $C_{y}$ & $L_{y}$ & & \\
7 & $C_{x}$ & $C_{y}$ & $L_{y}$ & $H_{x}$ & $B$ & 5 \\
\hline \multicolumn{7}{c}{ Fonte - Elaborado pelo autor. }
\end{tabular}

O processo recursivo proposto se mostrou uma ferramenta eficaz para realizar a análise de correlação entre uma grande quantidade de propriedades duas a duas. A partir de uma quantidade inicial de 15 propriedades, o algoritmo diminuiu para um valor entre 3 a 5 propriedades, ou seja, uma diminuição de $67 \%$ a $80 \%$ das propriedades iniciais, o que facilitará sobremaneira a manipulação do sistema a ser identificado. Nota-se que as propriedades $C_{x}, C_{y}$ e $L_{y}$ estão presentes em todas as condições de chama.

\subsection{Resultados da análise de componentes principais}

A partir das propriedades que restaram aplica-se a PCA para reduzir um pouco mais a dimensionalidade das variáveis de estado, mas mantendo boa parte da informação. 
O critério escolhido para se determinar a quantidade de componentes a serem escolhidas foi:

a) manter ao menos $80 \%$ da variância total dos dados originais;

b) escolher no mínimo três componentes principais.

O estabelecimento da restrição ao mínimo de três componentes principais $(\mathrm{CP})$ se deve à validação do resultado final e será discutido mais adiante, na seção 6.8. A tabela 15 mostra o resultado alcançado com a aplicação da PCA nas propriedades das imagens.

Tabela 15 - Resultados da aplicação da PCA.

\begin{tabular}{lccc}
\hline $\begin{array}{c}\text { Condição de } \\
\text { combustão, c }\end{array}$ & $\begin{array}{c}\text { Qtd. original de } \\
\text { propriedades }\end{array}$ & $\begin{array}{c}\text { Qtd. de } \\
\text { CP }\end{array}$ & $\begin{array}{c}\text { Variância das CP } \\
\text { selecionadas (\%) }\end{array}$ \\
\hline 1 & 3 & 3 & 100,0 \\
2 & 4 & 3 & 88,1 \\
3 & 5 & 3 & 87,6 \\
4 & 4 & 3 & 84,1 \\
5 & 3 & 3 & 100,0 \\
6 & 3 & 3 & 100,0 \\
7 & 5 & 3 & 90,4 \\
\hline
\end{tabular}

Fonte - Elaborado pelo autor.

Apesar de haver algumas condições que mantiveram o mesmo número de componentes principais do que tinham em propriedades, essa transformação é importante para padronizar a mesma quantidade de componentes principais para todas as condições de chama, o que facilita na análise dos resultados do processo de identificação RD/ITD. Além disso, o método da PCA garante a ortogonalidade das variáveis de estado, o que ajuda no desempenho do método de identificação utilizado.

\subsection{Resultados do algoritmo RD}

O único parâmetro a ser escolhido para o RD é a variável temporal $\tau$, que define o tamanho da janela de coleta da assinatura RD, expressa na equação (5.14), na página 102. O valor selecionado foi de $\tau=8 \mathrm{~s}$. Cada janela de coleta se inicia quando o nível de desencadeamento $a$ é alcançado em cada sequência de dados, e finaliza tendo decorrido o tempo $\tau$. A quantidade de janelas encontradas é um valor interessante de se analisar, uma vez que indica quantas sequências de dados serão utilizadas para que se calcule a média que trata a assinatura RD resultante. Entre o instante que uma janela de coleta acaba e o instante em que o sinal ultrapassa novamente $a$, há um intervalo de tempo cujas 
amostras são descartadas. Assim, também foi calculada a porcentagem de dados utilizados para a geração da assinatura RD em relação à quantidade total de imagens do conjunto de treinamento. A tabela 16 sumariza esses resultados.

Tabela 16 - Resultados do algoritmo RD.

\begin{tabular}{lcccc}
\hline $\begin{array}{l}\text { Condição de } \\
\text { combustão, } c\end{array}$ & $\begin{array}{c}\text { Total de } \\
\text { imagens }\end{array}$ & $\begin{array}{c}\text { Qtd. de janelas } \\
\text { encontradas }\end{array}$ & $\begin{array}{c}\text { Qtd. de imagens } \\
\text { por janela }\end{array}$ & $\begin{array}{c}\text { Porcentagem de } \\
\text { dados utilizados (\%) }\end{array}$ \\
\hline 1 & 4590 & 10 & 459 & 55,6 \\
2 & 4020 & 11 & 365 & 68,8 \\
3 & 4710 & 18 & 262 & 94,7 \\
4 & 5520 & 20 & 276 & 90,9 \\
5 & 4170 & 14 & 298 & 82,4 \\
6 & 3600 & 13 & 277 & 92,9 \\
7 & 1590 & 5 & 318 & 83,3 \\
\hline
\end{tabular}

Fonte - Elaborado pelo autor.

No geral, houve boa utilização da massa de dados, com porcentagem que varia entre aproximadamente $80 \%$ e $95 \%$ de uso dos dados. As exceções são as condições 1 e 2 , nas quais houve um descarte um pouco maior de amostras. Uma razão para a diferença no nível do descarte se dá devido ao nível de desencadeamento a escolhido. Mesmo com um valor que é função do desvio padrão da série temporal, pode ser que ele esteja sendo menos ativado do que seria se um a menor fosse escolhido. Mesmo assim, no geral, o número de janelas encontradas está condizente com a quantidade de amostras disponíveis, e já possibilita uma caracterização da resposta livre do sistema, apesar de não apresentarem curvas suaves.

\subsection{Resultados do método ITD}

Através do método iterativo descrito na seção 5.5.6 os parâmetros de tempo do método ITD, $N_{1}$ e $N_{3}$, e a porcentagem de dados utilizados para o treinamento, $P_{t}$, foram determinados. A tabela 17 mostra os resultados dos parâmetros encontrados. Para conveniência do leitor, o parâmetro $N_{2}$, que é definido como constante, também foi incluso na tabela. É interessante notar que os valores de $N_{3}$ encontrados foram todos iguais a 1 , o que ajuda manter a frequência de Nyquist mais alta, e consequentemente, melhora a identificação das frequências mais altas.

O algoritmo RD forneceu ao ITD três sinais, supostamente de respostas livres de cada variável. Por serem três variáveis provenientes do PCA, podem ser consideradas 
Tabela 17 - Parâmetros encontrados no processo iterativo.

\begin{tabular}{lcccc}
\hline Condição, $c$ & $N_{1}$ & $N_{2}$ & $N_{3}$ & $P_{t}(\%)$ \\
\hline 1 & 7 & 1 & 1 & 63 \\
2 & 4 & 1 & 1 & 57 \\
3 & 3 & 1 & 1 & 65 \\
4 & 3 & 1 & 1 & 77 \\
5 & 3 & 1 & 1 & 58 \\
6 & 4 & 1 & 1 & 58 \\
7 & 5 & 1 & 1 & 67 \\
\hline
\end{tabular}

Fonte - Elaborado pelo autor.

linearmente independentes, e portanto, três variáveis de estado, o que resulta na identificação de um sistema com $n=3$ graus de liberdade, em que cada grau representa um sistema linear de $2^{\mathrm{a}}$ ordem. Os resultados da identificação modal realizada pelo método ITD são exibidos na tabela 18. Nota-se que os dados modais obtidos para cada condição

Tabela 18 - Resultados da identificação dos modelos modais para cada condição de combustão.

\begin{tabular}{lcccccc}
\hline Condição de & \multicolumn{2}{c}{ Modo 1} & \multicolumn{2}{c}{ Modo 2} & \multicolumn{2}{c}{ Modo 3 } \\
combustão, $c$ & $\omega_{n 1}[\mathrm{~Hz}]$ & $\zeta_{1}$ & $\omega_{n 2}[\mathrm{~Hz}]$ & $\zeta_{2}$ & $\omega_{n 3}[\mathrm{~Hz}]$ & $\zeta_{3}$ \\
\hline 1 & 0,85 & 1,02 & 1,60 & 0,86 & 1,83 & 0,97 \\
2 & 0,53 & 1,21 & 1,50 & 1,04 & 3,59 & 0,86 \\
3 & 0,91 & 0,97 & 4,68 & 1,02 & 4,76 & 0,91 \\
4 & 1,09 & 1,04 & 3,57 & 1,19 & 4,35 & 0,84 \\
5 & 0,73 & 1,19 & 2,46 & 1,01 & 4,49 & 0,98 \\
6 & 0,59 & 1,11 & 2,72 & 1,02 & 4,37 & 0,98 \\
7 & 0,62 & 2,15 & 1,85 & 0,99 & 3,02 & 0,94 \\
\hline
\end{tabular}

de combustão não são comparáveis, pois foram gerados com matrizes de transformação $\boldsymbol{\Pi}$ da PCA diferentes umas das outras, isto é, a base de coordenadas das componentes principais da condição 1 é diferente da base da condição 2, e assim por diante.

Para todas as condições de chama, houve modos subamortecidos e modos superamortecidos identificados, mas que na maioria dos casos possui um amortecimento próximo ao amortecimento crítico. Esses resultados são consistentes com o que se espera a partir do senso comum, pois demonstram que a chama estabiliza rapidamente, com pouca ou 
nenhuma oscilação em torno da posição de equilíbrio. De fato, a partir de uma variação na razão de equivalência, a chama entra num novo equilíbrio de reações químicas e iterações termoacústicas muito rapidamente. As oscilações da chama devido aos fenômenos estocásticos permanecem em qualquer razão de equivalência, em maior ou menor grau, característica que é captada pelo modelo proposto nesta tese.

\subsection{Resultados da modelagem da matriz de covariância}

A partir da matriz $\boldsymbol{A}$ identificada para cada condição de combustão, é possível simular uma situação que remete aos dados experimentais existentes. Inicia-se a simulação com as mesmas condições iniciais dos dados experimentais e se troca o modelo nos mesmos instantes em que há alteração de razão de equivalência nos dados experimentais. Ao se tratar os dados simulados dessa forma, viabiliza-se a sua comparação com os dados experimentais. Nesse primeiro momento, como foi descrito na seção 5.6.2, o fator de correção de variância $\boldsymbol{f}_{\boldsymbol{R}} \in \mathbb{R}^{2 n \times 2 n}$, onde $f_{R}(i, j)=1$, com $i, j=1,2, \ldots, 2 n$.

Figura 54 - Comparação entre dados experimentais de treinamento e dados estimados sem a correção da variância (Propriedade $C_{x}$ para todas as condições).

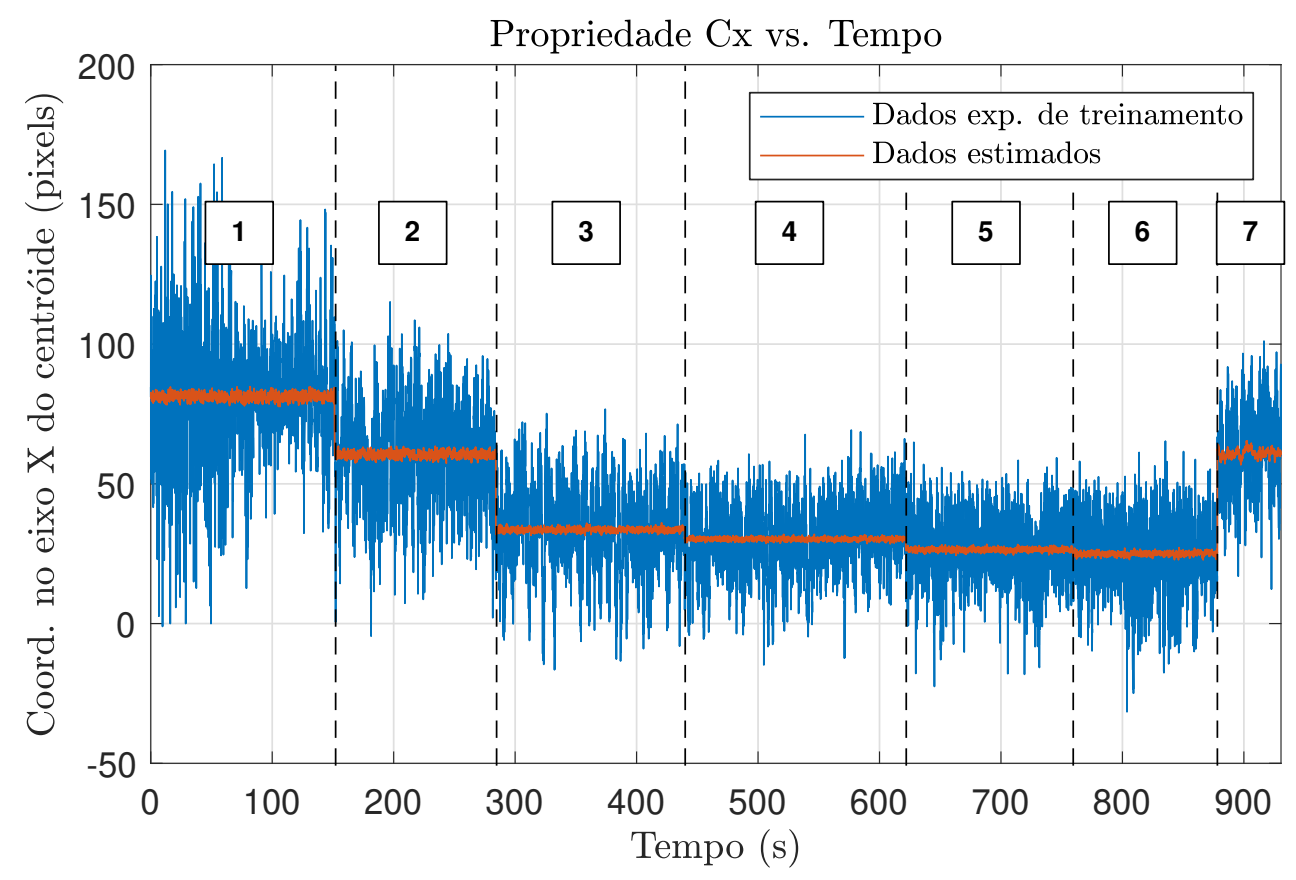

Fonte - Elaborado pelo autor.

A figura 54 mostra no mesmo gráfico, para a propriedade $C_{x}$, a evolução temporal dos dados experimentais de treinamento e a evolução temporal dos dados estimados, para todas as sete condições de combustão (cada condição está marcada com um número e delimitada por linhas tracejadas $)^{1}$. Como previsto na seção 5.6.2, pode ser observado que

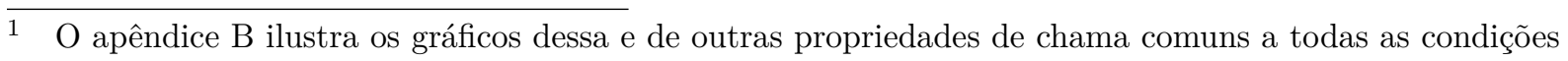


a variância dos dados experimentais é maior que a dos dados estimados, e é justamente este fato que justifica a determinação do fator de correção da variância.

Conforme citado na seção 5.6.2, é necessário iterar o cálculo de $\boldsymbol{f}_{\boldsymbol{R}}$ por um número suficiente de vezes para que se obtenha a média e o desvio padrão do vetor, e assim determiná-lo. A figura 55 mostra um gráfico do tipo boxplot ${ }^{2}$ para os valores de $\boldsymbol{f}_{\boldsymbol{R}}$ para todas as variáveis de estado, para a condição de combustão $c=1$, obtidos com 200 iterações ${ }^{3}$. A tabela 19 detalha todos os valores das médias e desvios padrão de $\boldsymbol{f}_{\boldsymbol{R}}$ para

Figura 55 - Gráfico boxplot do fator de correção de variância para a condição $c=1$.

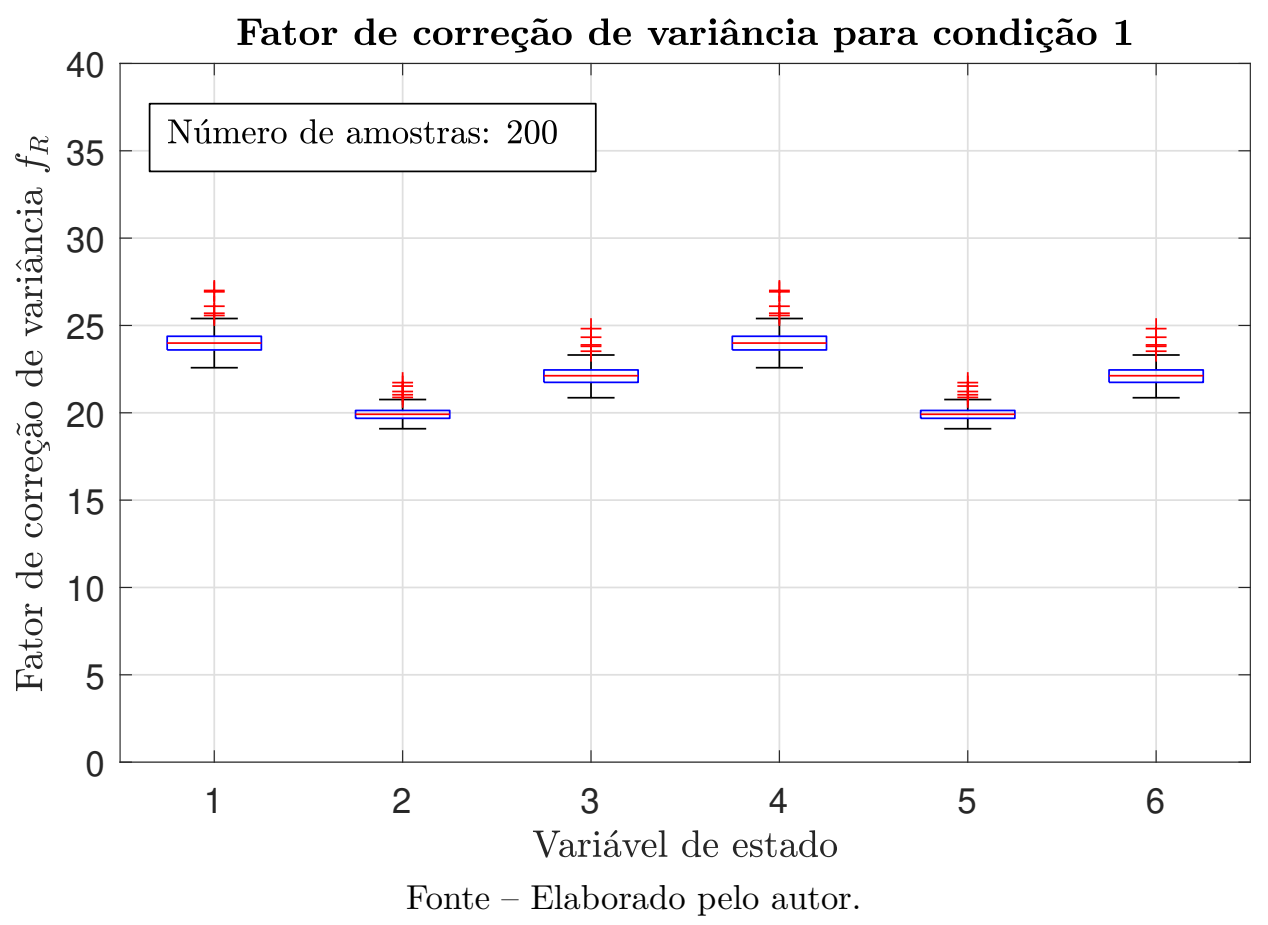

todas as condições. Da mesma forma que pode ser avaliado pelo gráfico na figura 74(b) do Apêndice $\mathrm{C}$, o valor de $\boldsymbol{f}_{\boldsymbol{R}}$ na condição $c=2$ para as variáveis 2 e 5 deveria ser analisado para entender a causa de sua disparidade em relação aos outros. No entanto, como para todas as outras condições de combustão, e também para as outras variáveis, essas disparidades não foram encontradas, assume-se que a causa deve ser algo pontual, e não afeta a metodologia como um todo.

O conhecimento dos valores de $\boldsymbol{f}_{\boldsymbol{R}}$ permite encontrar a matriz de covariância desejada, conforme equação (5.88).

de combustão, com e sem a aplicação do fator de correção de variância $\boldsymbol{f}_{\boldsymbol{R}}$, justamente para destacar a função desse fator.

2 Boxplot é uma forma padronizada de se representar uma distribuição de dados. São mostrados 5 números diferentes: mínimo, primeiro quartil, mediana, terceiro quartil e máximo. Os dados assinalados como cruzes são os outliers.

3 O apêndice $\mathrm{C}$ mostra o restante dos gráficos box plot dos valores obtidos para $\boldsymbol{f}_{\boldsymbol{R}}$ para as outras condições de combustão. 
Tabela 19 - Resultados da determinação dos valores para $\boldsymbol{f}_{\boldsymbol{R}}$ após 200 iterações.

\begin{tabular}{lrrr}
\hline $\begin{array}{l}\text { Condição de } \\
\text { combustão, } c\end{array}$ & $\begin{array}{r}\text { Variáveis de } \\
\text { estado 1 e 4 }\end{array}$ & $\begin{array}{r}\text { Variáveis de } \\
\text { estado 2 e } 5\end{array}$ & $\begin{array}{c}\text { Variáveis de } \\
\text { estado 3 e 6 }\end{array}$ \\
\hline 1 & $24,02 \pm 0,64$ & $19,93 \pm 0,40$ & $22,14 \pm 0,56$ \\
2 & $15,52 \pm 0,49$ & $70,00 \pm 50,91$ & $12,95 \pm 0,68$ \\
3 & $26,82 \pm 0,68$ & $21,06 \pm 0,44$ & $17,89 \pm 0,48$ \\
4 & $23,44 \pm 0,44$ & $22,04 \pm 0,40$ & $26,00 \pm 0,74$ \\
5 & $16,13 \pm 0,49$ & $10,29 \pm 0,42$ & $13,96 \pm 0,56$ \\
6 & $21,15 \pm 0,52$ & $12,21 \pm 0,53$ & $17,91 \pm 0,83$ \\
7 & $18,31 \pm 1,76$ & $8,03 \pm 0,73$ & $19,95 \pm 1,13$ \\
\hline
\end{tabular}

Fonte - Elaborado pelo autor.

\subsection{Resultados do modelo identificado}

Uma vez que se conhece a matriz da dinâmica do sistema $\boldsymbol{A}$ e a matriz de covariância $\boldsymbol{R}$, a equação (5.84) pode ser utilizada para estimar as propriedades das imagens de cada uma das condições de combustão $c=1,2, \ldots, n_{c}$. A figura 56 mostra uma comparação entre os dados experimentais de validação e os dados estimados, para a propriedade $C_{x}$, e em todas as sete condições de combustão ${ }^{4}$. É interessante notar que em termos gerais o modelo consegue capturar a essência das diferenças da propriedade da imagem entre as diferentes condições. Obviamente, não basta apenas a inspeção visual, logo, na próxima seção a validação do modelo é fundamentada com critérios mais quantitativos.

Apesar de ser necessária uma adaptação do algoritmo de processamento para cada tipo de forno, combustível e ângulo da câmera em relação à chama, os procedimentos gerais propostos nesse trabalho podem ser replicados para fornos com configurações diferentes.

\subsection{Validação do modelo identificado}

A seção 5.7 explicou que a validação é realizada com os sinais no domínio da frequência. A figura 57 compara os sinais, no domínio da frequência, da propriedade $C_{x}$ quando $c=1$, dos dados experimentais de validação e dos dados estimados com o modelo proposto $^{5}$. Após a transformação dos sinais das propriedades da imagem no domínio da frequência, foram calculados os coeficientes de correlação e os desvios espectrais, conforme definidos na seção 5.7, para 200 iterações de estimação. As figuras 58 e 59 mostram as

\footnotetext{
4 Conforme citado anteriormente, o apêndice B ilustra este e outros gráficos de comparação das propriedades que são comuns a todas as condições de combustão.

5 O apêndice D apresenta os gráficos das comparações de sinal no espectro da frequência para as propriedades de todas as condições de combustão.
} 
Figura 56 - Comparação entre dados experimentais de validação e dados estimados com variância corrigida (Propriedade $C_{x}$ para todas as condições).

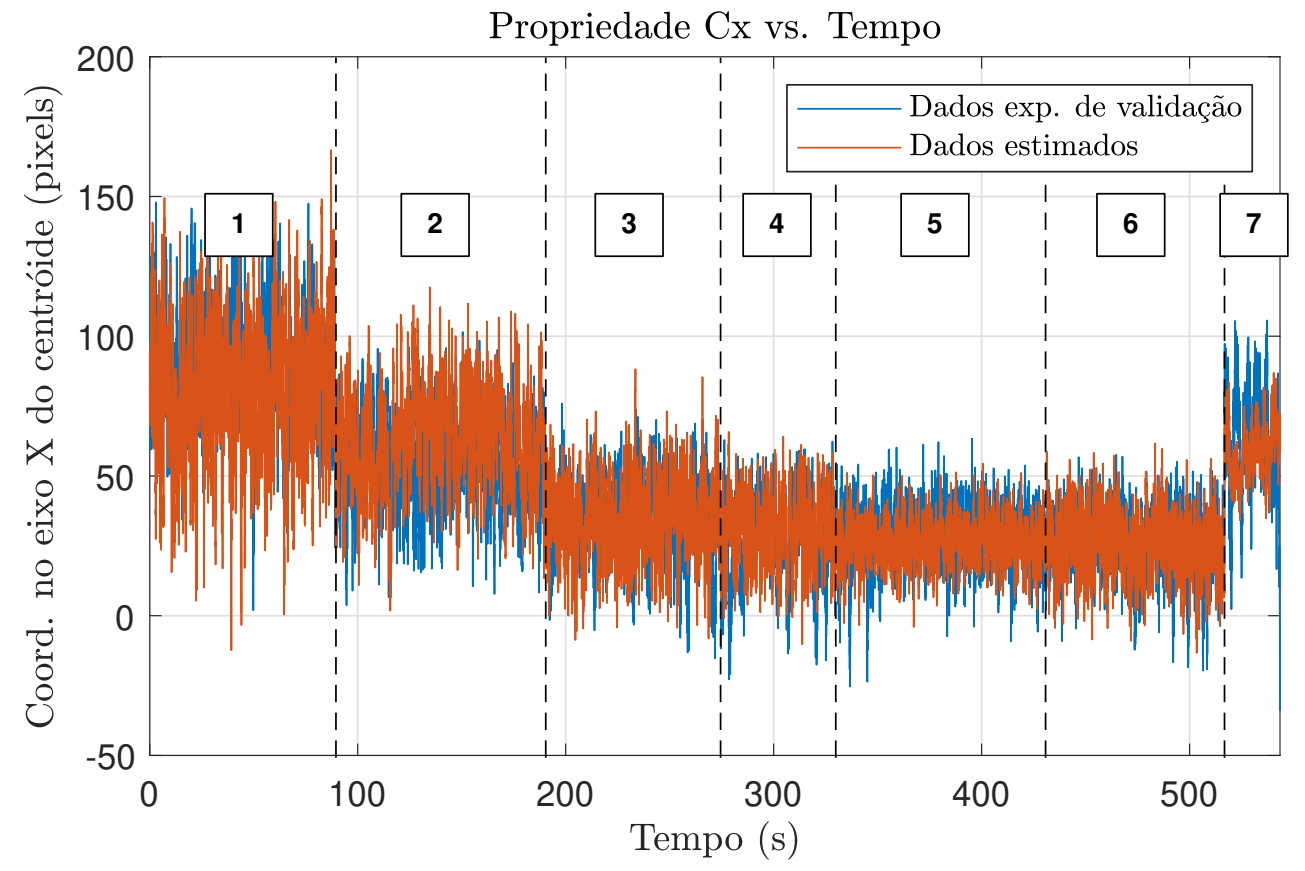

Fonte - Elaborado pelo autor.

Figura 57 - Espectro de frequência da propriedade $C_{x}$ na condição $c=1$.

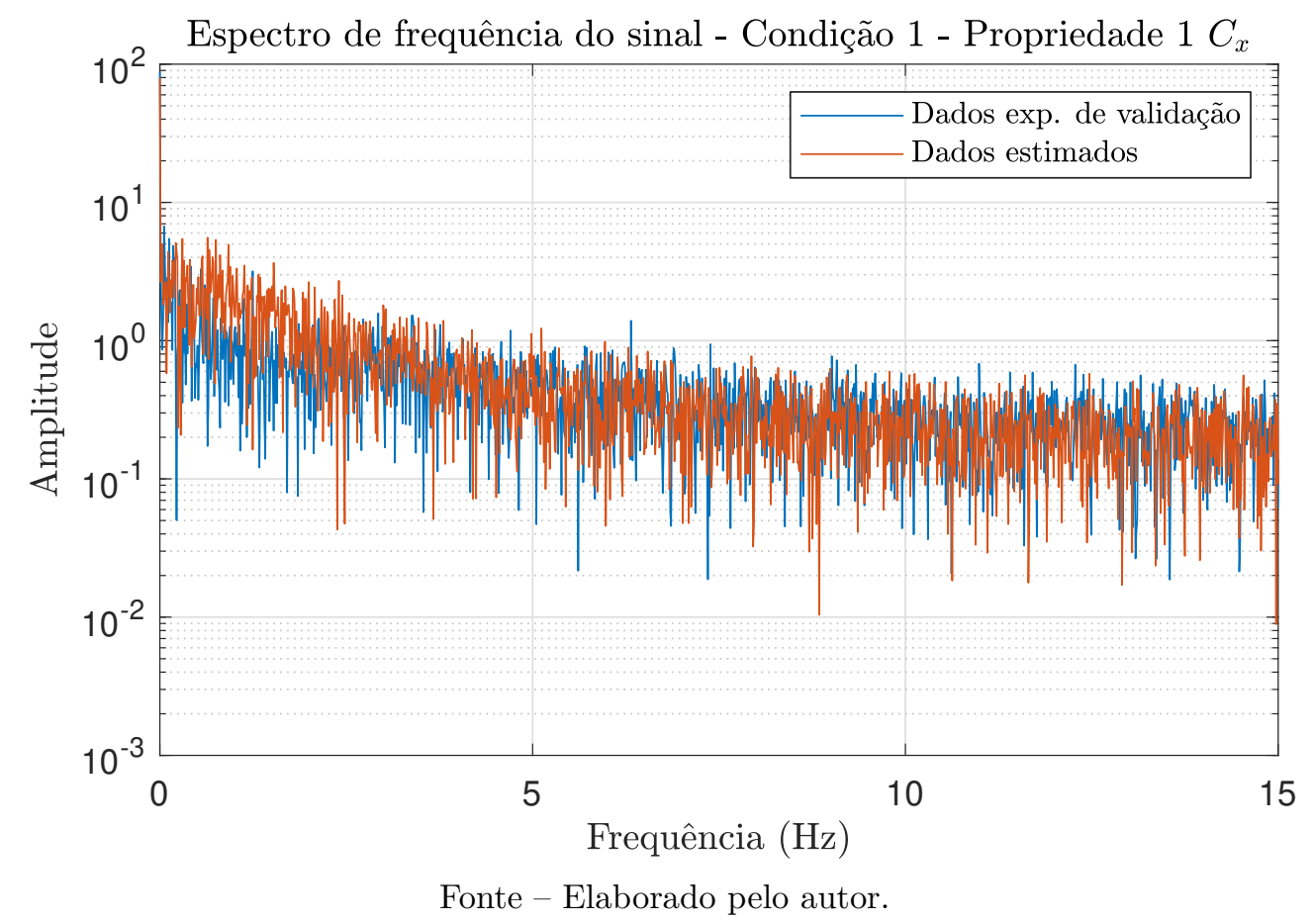


Figura 58 - Média dos coeficientes de correlação das propriedades da imagem por cada condição de combustão.

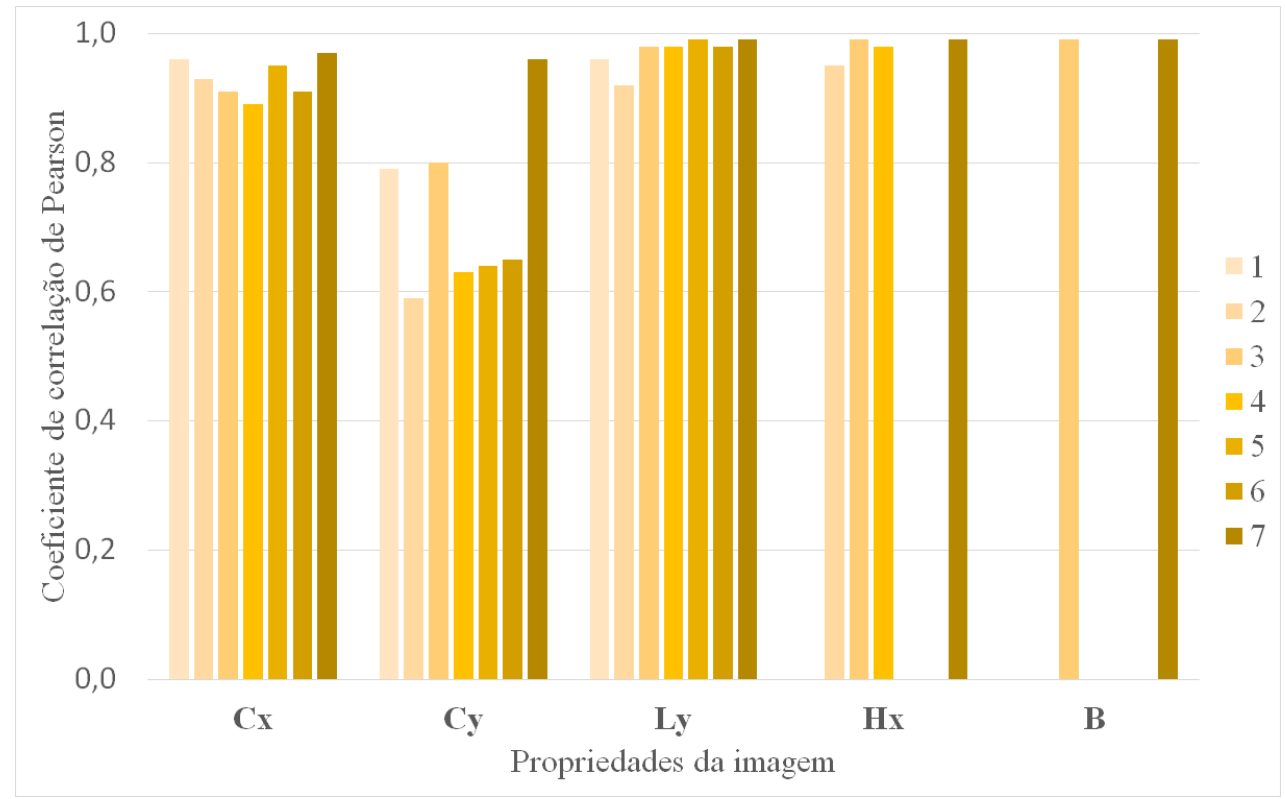

Fonte - Elaborado pelo autor.

Figura 59 - Média dos desvios espectrais das propriedades da imagem por cada condição de combustão.

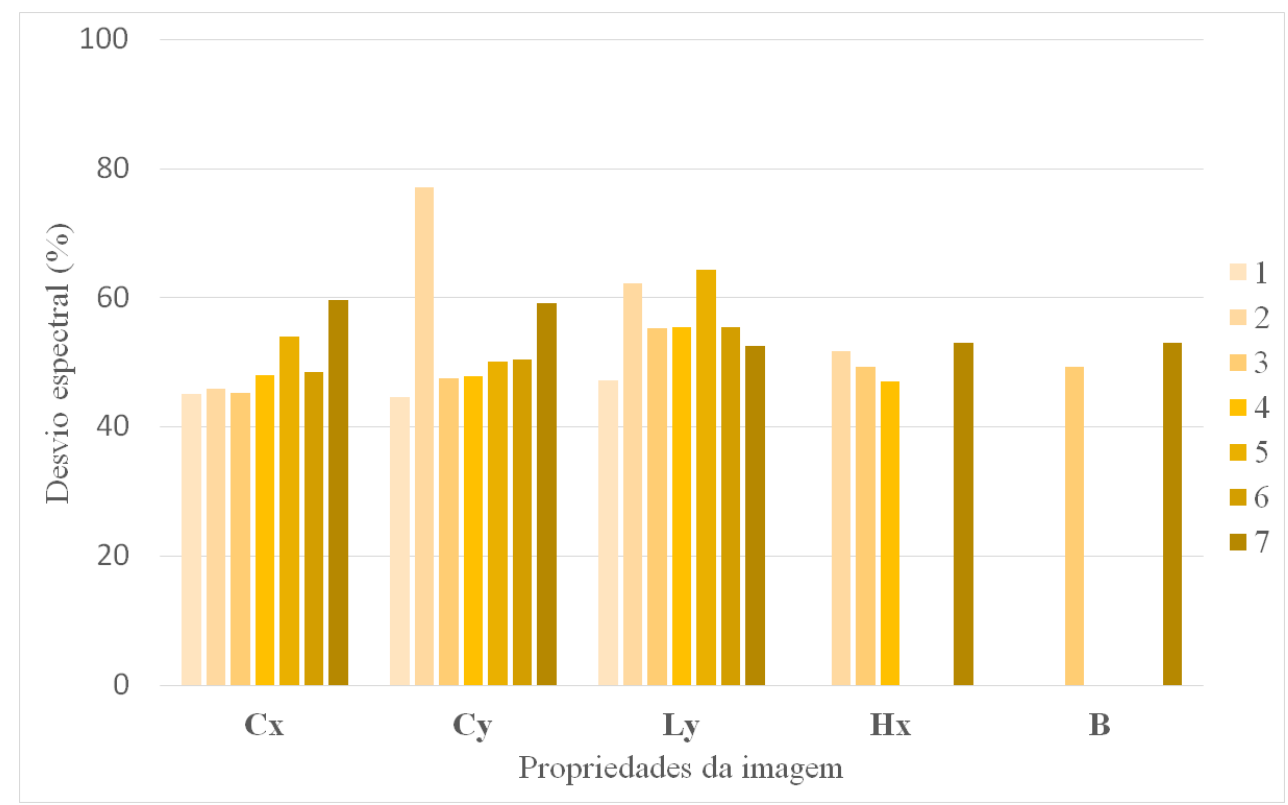

Fonte - Elaborado pelo autor. 
médias dos coeficientes de correlação e desvio espectral para todas as propriedades de todas condições identificadas, respectivamente.

Os resultados dos coeficientes de correlação indicam que existe um grau de correlação excelente entre dados experimentais e dados estimados com a grande maioria de propriedades, de acordo com o critério de Evans (1996) (ver tabela 8, página 97). Entre as 27 propriedades identificadas entre todas as sete condições de combustão, 21 (78\%) apresentam correlação muito forte, 5 (18\%) possuem correlação forte e 1 (4\%) ficou com correlação moderada. Esta última, porém, com coeficiente de correlação 0,59, isto é, muito próximo do limite de 0,60 para correlação forte. Ou seja, se os conceitos de correlação forte e muito forte forem agrupados para formar o que se admite como dados efetivamente correlacionados, 26 de 27 propriedades, ou $96 \%$ do total, possuem correlação efetiva entre dados experimentais e dados estimados.

Na seção 6.3 estabeleceu-se uma quantidade mínima de três componentes principais por modelo de condição de chama. Isto se deu pois, caso não houvesse essa restrição, haveria pelo menos duas condições com modelos com apenas duas componentes principais. Verificou-se que alguns coeficientes de correlação das propriedades descritas por apenas duas componentes principais apresentavam grau de correlação fraco. Desse fato pode-se concluir, mesmo garantindo um mínimo de variância total pelas componentes principais, que a ausência de um grau de liberdade extra estaria prejudicando a descrição da dinâmica das propriedades. Portanto, uma solução encontrada para contornar esse problema foi restringir o número mínimo de componentes principais escolhidas.

Os resultados dos desvios espectrais encontrados indicam um valor entre $40 \%$ e $60 \%$ para as propriedades identificadas. Esses valores indicam que existe uma diferença razoável entre as variâncias das frequências das propriedades. Uma possível interpretação desses dados é que a variável estocástica que foi assumida como um ruído branco, não seja tão branco assim. Estes resultados demonstram que esta pesquisa tem espaços para aprimoramentos no que se refere à determinação da matriz de covariância da parte aleatória do modelo. Se, por um lado, a variância estimada não representa tão bem aquela dos dados experimentais, a correlação indica que o modelo descreve bem a tendência dos dados experimentais, o que pode ser observado nas figuras do apêndice B. Portanto, pode se considerar que os modelos identificados conseguem descrever razoavelmente bem os dados experimentais. 


\section{CONCLUSÕES}

Em fornos industriais, o monitoramento do processo de combustão é essencial para se manter uma operação segura. Para garantir segurança e qualidade do processo de combustão, sistemas supervisórios elaborados, com sensores que detectam vários aspectos do processo, como, por exemplo, taxas de vazões, temperaturas ou medições de concentração de gases de escape, geralmente estão disponíveis em tais fornos. Porém instrumentos convencionais costumam medir apenas variáveis globais, que fornecem informação limitada sobre o que acontece dentro da câmara de combustão. Um diagnóstico preciso necessitaria de informações mais completas sobre as propriedades da chama. Logo, imprevistos ou falhas podem passar despercebidos pelos sensores até se tornarem muito significativos.

O monitoramento da chama por imagem surge como uma forma de obter informações sobre a chama que não estão disponíveis por instrumentos convencionais. Diversas pesquisas, que trataram de problemas de monitoramento de falhas específicas através da imagem da chama, apresentam resultados animadores para a área. E a possibilidade de realizar controles avançados sobre a chama começa a ser investigado. No entanto, um dos principais entraves para um sistema de controle de chama é a falta de modelos disponíveis. Métodos de discretização do tipo método dos elementos finitos ou dinâmica dos fluidos computacional são inadequados para obter informações em tempo real, e modelos analíticos disponíveis não captam a complexidade do processo termoacústico de forma satisfatória para a aplicação em nível industrial.

Neste trabalho, objetivou-se identificar um modelo para a chama, em diversos níveis diferentes de razão de equivalência, de um forno em escala industrial a gás natural a partir de imagens de uma câmera CCD. Primeiramente, a imagem capturada foi processada para que a imagem da chama fosse separada de seu fundo. Para isso, foi proposto um método que utiliza informações características do histograma de chamas em conjunto com o método de limiarização de Otsu. O método proposto forneceu imagens de chama separadas de seu fundo com o detalhamento suficiente para que fossem evidenciadas propriedades das imagens que variavam com a mudança de razão de equivalência. Em seguida, foram então gerados vetores com informações representativas da chama, como propriedades geométricas e de luminosidade. Esses vetores, colocados em sequência temporal formaram séries temporais das propriedades, cujas dinâmicas poderiam ser identificadas.

A princípio foram propostas quinze propriedades candidatas a descreverem a chama. Elas foram sujeitas a uma análise de correlação proposta num algoritmo recursivo para que se verificasse o grau de correlação entre elas. O desejável era que se trabalhasse com propriedades o menos correlacionadas possível, para evitar redundância de informação. 
Após essa análise, sobraram de três a cinco propriedades, dependendo da condição de razão de equivalência. A quantidade de variáveis foi padronizada em três com a aplicação de uma análise de componentes principais.

Para cada condição de combustão, os três sinais foram submetidos a um processo de análise modal operacional para identificação de sistemas. Primeiramente, aplicou-se o algoritmo de decremento aleatório, para converter a resposta aleatória exibida pelas propriedades, para uma resposta livre do sistema. Em seguida, a resposta livre foi utilizada no método do domínio do tempo de Ibrahim para a identificação dos parâmetros modais da dinâmica das propriedades da chama ou, de forma equivalente, para a obtenção da matriz $\boldsymbol{A}$ da dinâmica do sistema. Foram identificados modos subamortecidos e superamortecidos, em sua maioria com fatores de amortecimento próximos do amortecimento crítico. Esse fato demonstra que os modos oscilam pouco ou não oscilam antes de alcançarem o valor de equilíbrio da parte determinística.

O modelo proposto para a chama é composto por duas partes. A primeira, determinística, é formada pela contribuição da dinâmica identificada pela matriz $\boldsymbol{A}$. A segunda, aleatória, as partes não modeladas pela parte determinística, cuja matriz de covariância foi identificada através de características estatísticas das próprias propriedades das imagens.

O modelo obtido foi validado através do desvio espectral e da correlação, no domínio da frequência, entre dados estimados pelo modelo e dados experimentais não utilizados no processo de identificação. O bom resultado da correlação permite afirmar que o modelo estimado apresenta a mesma tendência dos dados experimentais. Por outro lado, o resultado do desvio espectral mostra que existem oportunidades de melhorias na correção da matriz de covariância da parte aleatória, mas que é um resultado aceitável para um primeiro modelo de chama.

Além disso, foi proposto um método para realizar a unificação dos modelos nas diversas condições de chama. Nesse modelo unificado, a entrada do modelo é justamente a razão de equivalência. Conforme foi citado no fluxograma da metodologia, na figura 23 do capítulo 3, obter um modelo que permite atuação através de uma entrada sempre foi um dos objetivos de pesquisa do grupo. Logo, uma possibilidade natural para se expandir a pesquisa é sintetizar um controlador regulador e se possível implementá-lo num forno experimental.

O fato de poder contar com algum modelo, diferentemente da situação que se tinha anteriormente, abre diversas possibilidades para o monitoramento de fornos industriais. $\mathrm{O}$ modelo fornece estimativas das propriedades das imagens que podem ser relacionadas com medidas físicas, isto é, ao se obter um modelo que relaciona as propriedades das imagens com as emissões dos gases de exaustão, por exemplo, seria possível, através apenas do monitoramento das imagens da chama, estimar a exaustão dos gases de emissão. 
Aliás, é importante salientar que, sem um termo forçante, as chamas se atenuariam até a extinção. Como isto não acontece, uma das possíveis explicações é que as matrizes de covariância estimadas não englobam apenas ruído, mas também não linearidades não inclusas no modelo determinístico, que agem como termos forçantes. A adequação de um modelo cúbico para explicar as não-linearidades do sistema, do tipo do oscilador de Van-der-Pol, traz uma boa perspectiva para a continuidade do trabalho. Ou até mesmo a incorporação de medidas de pressão sonora dentro da câmara de combustão às medidas através das imagens. Isso ajudaria a aumentar as frequências identificadas dos modelos, uma vez que as medidas com pressão sonora permitem aquisição com taxas de amostragem muito maiores que câmeras de vídeo digital.

Outra possibilidade para novas pesquisas seria o de realizar o sentido inverso do que foi feito e, a partir de um modelo, estimar ou reconstruir a própria imagem da chama, que poderia trazer visões diferentes dos resultados tradicionais em dinâmica dos fluidos computacional. Ainda na linha do processamento de imagens, uma outra possibilidade para trabalhos futuros é o aprofundamento do processo de limiarização para imagens de chama, podendo também trabalhar com imagens coloridas, o que poderia mostrar características não captadas pelos tons de cinza e facilitaria na identificação do modelo de cada condição de combustão. A dificuldade em se utilizar imagens coloridas está na velocidade de processamento necessária para fazer com três cores o que nas imagens em tons de cinza se faz apenas uma vez. A robustez da aquisição das imagens e a consequente variação na identificação do modelo também podem ser estudadas simulando ruídos nas imagens ou variações nos parâmetros da câmera.

Neste trabalho, utilizamos apenas um método de identificação que é o método no domínio do tempo de Ibrahim em conjunto com o algoritmo de decremento aleatório. Um próximo desenvolvimento seria identificar esse sistema de chama com outro método de identificação, por exemplo, o ERA (eigensystem realization algorithm), que permite identificar modelos com matrizes de entrada, diferentemente do método ITD. 


\section{REFERÊNCIAS}

ALLEMANG, R. J. Investigation of some multiple input/output frequency response function experimental modal analysis techniques. 1981. 358 p. Tese (Ph.D.) - Department of Mechanical and Industrial Engineering, College of Engineering, University of Cincinnati, Cincinnati, USA, 1981. Citado na página 113.

ALLEMANG, R. J. The modal assurance criterion-twenty years of use and abuse. Sound and vibration, v. 37, n. 8, p. 14-23, 2003. Citado na página 113.

ARMSTRONG, B.; NEEVEL, D.; KUSIK, T. New results in NPID control: tracking, integral control, friction compensation and experimental results. IEEE Transactions on Control Systems Technology, IEEE, v. 9, n. 2, p. 399-406, 2001. Citado na página 33.

ASMUSSEN, J. C. Modal analisys based on the random decrement technique. 1997. 215 p. Tese (Ph.D. on Dynamics of Structures) — Department of Building Technology and Structural Engineering, University of Aalborg, Aalborg, Denmark, 1997. Citado 3 vezes nas páginas 101, 102 e 103.

BALLESTER, J.; GARCÍA-ARMINGOL, T. Diagnostic techniques for the monitoring and control of practical flames. Progress in Energy and Combustion Science, Elsevier, v. 36, n. 4, p. 375-411, 2010. Citado 2 vezes nas páginas 37 e 38.

BERTUCCO, L.; FICHERA, A.; NUNNARI, G.; PAGANO, A. A cellular neural networks approach to flame image analysis for combustion monitoring. In: IEEE. Proceedings of the 2000 6th IEEE International Workshop on Cellular Neural Networks and their Applications (CNNA 2000)(Cat. No. 00TH8509). [S.l.], 2000. p. 455-459. Citado na página 42.

BOYLE, W. S.; SMITH, G. E. Charge coupled semiconductor devices. Bell System Technical Journal, Wiley Online Library, v. 49, n. 4, p. 587-593, 1970. Citado na página 40.

CHEN, J.; CHAN, L. L. T.; CHENG, Y.-C. Gaussian process regression based optimal design of combustion systems using flame images. Applied energy, Elsevier, v. 111, p. 153-160, 2013. Citado na página 41.

CHRISTENSEN, C. M.; RAYNOR, M. E.; MCDONALD, R. What is disruptive innovation. Harvard Business Review, Boston, v. 93, n. 12, p. 44-53, 2015. Citado na página 38.

COLE JR., H. A. On-the-line analysis of random vibrations. In: 9th Structural Dynamics and Materials Conference. [S.l.: s.n.], 1968. p. 288. Citado na página 101.

COLE JR., H. A. Failure detection of a space shuttle wing flutter model by random decrement. NASA Technical Memorandum, NASA, n. TM X-62041, 1971. Citado 3 vezes nas páginas 101, 102 e 103.

CULICK, F. E. C. Non-linear growth and limiting amplitude of acoustic oscillations in combustion chambers. Combustion Science and Technology, Taylor \& Francis, v. 3, n. 1, p. 1-16, 1971. Citado na página 34. 
DUNSTAN, W. J.; BITMEAD, R. R.; SAVARESI, S. M. Fitting nonlinear low-order models for combustion instability control. Control Engineering Practice, Elsevier, v. 9, n. 12, p. 1301-1317, 2001. Citado na página 35.

EVANS, J. D. Straightforward statistics for the behavioral sciences. [S.l.]: Thomson Brooks/Cole Publishing Co, 1996. Citado 3 vezes nas páginas 96, 97 e 143.

FLEURY, A. T. Estimadores de estado de sistemas dinâmicos baseados no conceito de dualidade. 1985. Tese (Doutorado) — Escola Politécnica, Universidade de São Paulo, São Paulo, 1985. Citado na página 52.

FLEURY, A. T.; CHUI, D. S.; TRIGO, F. C.; MARTINS, F. P. R. Modelling, identification and a first control approach on the quality of flames in oil furnaces. In: BRUZZONE, A. G.; DAUPHIN-TANGUY, G.; JUNCO, S.; LONGO, F. (Ed.). Proceedings of the $8^{\text {th }}$ International Conference on Integrated Modeling and Analysis in Applied Control and Automation (IMAACA 2015). Bergeggi, Italy: Curran Associates, Inc., 2015. p. 79-88. Citado 7 vezes nas páginas 46, 57, 59, 60, 61, 62 e 63 .

FLEURY, A. T.; TRIGO, F. C.; MARTINS, F. P. R. Application of computer vision and Kalman filtering techniques to identify oil flames nebulization quality. In: NEGRI, V. J. de; PERONDI, E. A.; CUNHA, M. A. B.; HORIKAWA, O. (Ed.). ABCM Symposium Series in Mechatronics. Rio de Janeiro: ABCM - Brazilian Society of Mechanical Sciences and Engineering, 2010. v. 4, p. 1-10. Citado na página 45.

FLEURY, A. T.; TRIGO, F. C.; MARTINS, F. P. R. Identificação da qualidade de nebulização de chamas de óleo em fornos de refino utilizando técnicas de visão computacional e filtro de Kalman. In: XVIII Congresso Brasileiro de Automática (CBA). Bonito: SBA Sociedade Brasileira de Automática, 2010. p. 3750-3757. Citado 3 vezes nas páginas 42, 43 e 44.

FLEURY, A. T.; TRIGO, F. C.; MARTINS, F. P. R. A new approach based on computer vision and non-linear Kalman filtering to monitor the nebulization quality of oil flames. Expert Systems with Applications, Elsevier, v. 40, n. 12, p. 4760-4769, 2013. Citado 5 vezes nas páginas 48, 49, 52, 121 e 122.

FLEURY, A. T.; TRIGO, F. C.; PACIFICO, A.; MARTINS, F. P. R. An inference model for the diagnostics of the combustion state in an experimental oil furnace. Expert Systems with Applications, Elsevier, 2017. Citado 2 vezes nas páginas 46 e 63.

FOSSUM, E. R.; HONDONGWA, D. B. A review of the pinned photodiode for ccd and cmos image sensors. IEEE Journal of the electron devices society, 2014. Citado na página 40 .

GOLUB, G.; KAHAN, W. Calculating the singular values and pseudo-inverse of a matrix. Journal of the Society for Industrial and Applied Mathematics, Series B: Numerical Analysis, SIAM, v. 2, n. 2, p. 205-224, 1965. Citado na página 111.

GOLUB, G.; VAN LOAN, C. Matrix Computations. Johns Hopkins University Press, 2013. (Johns Hopkins Studies in the Mathematical Sciences). ISBN 9781421407944. Disponível em: < https://books.google.com.br/books?id=X5YfsuCWpxMC > . Citado na página 111. 
GÓMEZ, H. O.; CALLEJA, M. C.; FERNÁNDEZ, L. A.; KIEDRZYŃSKA, A.; LEWTAK, $\mathrm{R}$. Application of the CFD simulation to the evaluation of natural gas replacement by syngas in burners of the ceramic sector. Energy, Elsevier, v. 185, p. 15-27, 2019. Citado na página 34.

GONZÁLEZ-CENCERRADO, A.; PEÑA, B.; GIL, A. Coal flame characterization by means of digital image processing in a semi-industrial scale pf swirl burner. Applied energy, Elsevier, v. 94, p. 375-384, 2012. Citado na página 41.

GONZALEZ, R. C.; WOODS, R. E. Digital image processing. 2. ed. New Jersey: PrenticeHall Inc., 2001. 793 p. ISBN 0-201-18075-8. Citado 6 vezes nas páginas 54, 74, 81, 82, 86 e 91.

HERNANDEZ, R.; BALLESTER, J. Flame imaging as a diagnostic tool for industrial combustion. Combustion and flame, Elsevier, v. 155, n. 3, p. 509-528, 2008. Citado na página 41.

HOTELLING, H. Analysis of a complex of statistical variables into principal components. Journal of educational psychology, Warwick \& York, v. 24, n. 6, p. 417, 1933. Citado na página 100.

HOTELLING, H. Simplified calculation of principal components. Psychometrika, Springer, v. 1, n. 1, p. 27-35, 1936. Citado na página 100.

IBRAHIM, S. R. Random decrement technique for modal identification of structures. Journal of Spacecraft and Rockets, v. 14, n. 11, p. 696-700, 1977. Citado 2 vezes nas páginas 101 e 104.

IBRAHIM, S. R. Modal confidence factor in vibration testing. Journal of Spacecraft and Rockets, v. 15, n. 5, p. 313-316, 1978. Citado na página 104.

IBRAHIM, S. R. A modal identification algorithm for higher accuracy requirements. In: AIAA Proceeding of the 25 $5^{\text {th }}$ Structures, Structural Dynamics and Materials Conference. Palm Springs: AIAA - American Institute of Aeronautics and Astronautics, 1984. p. 117-122. Citado na página 104.

IBRAHIM, S. R. Double least squares approach for use in structural modal identification. AIAA journal, v. 24, n. 3, p. 499-503, 1986. Citado na página 108.

IBRAHIM, S. R. Fundamentals of time domain modal identification. In: SILVA, J. M. M.; MAIA, N. M. M. (Ed.). Modal Analysis and Testing. Dordrecht: Kluwer Academic Publishers, 1999, (NATO ASI series: E). p. 241-250. ISBN 978-0-7923-5894-7. Disponível em: <https://books.google.com.br/books?id=31nFQgAACAAJ>. Citado na página 104.

IBRAHIM, S. R.; MIKULCIK, E. C. A time domain modal vibration test technique. The Shock and Vibration Bulletin, v. 43, n. 4, p. 21-37, 1973. Citado na página 104.

IBRAHIM, S. R.; MIKULCIK, E. C. A method for the direct identification of vibration parameters from the free response. The Shock and Vibration Bulletin, v. 47, n. 4, p. 183-198, 1977. Citado 3 vezes nas páginas 104, 106 e 108. 
IPCC. Climate Change 2014: Synthesis Report. Geneva, Switzerland, 2014. Contribution of Working Groups I, II and III to the Fifth Assessment Report of the Intergovernmental Panel on Climate Change [Core Writing Team, R.K. Pachauri and L.A. Meyer (eds.)]. 151 p. Citado na página 32.

JACKSON, J. E. A user's guide to principal components. [S.l.]: John Wiley \& Sons, 2005. v. 587. Citado na página 100.

JAZWINSKI, A. H. Stochastic processes and filtering theory. 1. ed. New York: Dover Publications Inc., 2007. 376 p. ISBN 978-0-486-46274-5. Citado 2 vezes nas páginas 50 e 51.

JOLLIFFE, I. Principal component analysis. Technometrics, American Society for Quality, v. 45, n. 3, p. 276, 2003. Citado na página 100.

JÓŹWIAK, P.; HERCOG, J.; KIEDRZYŃSKA, A.; BADYDA, K. CFD analysis of natural gas substitution with syngas in the industrial furnaces. Energy, Elsevier, v. 179, p. 593-602, 2019. Citado na página 34.

KRYLOV, N. M.; BOGOLIUBOV, N. N. Introduction to non-linear mechanics. [S.l.]: Princeton University Press, 1949. Citado na página 35.

KURIHARA, N.; NISHIKAWA, M.; WATANABE, A.; SATOH, Y.; OHTSUKA, K.; MIYAGAKI, H.; HIGASHI, T.; MASAI, T. A combustion diagnosis method for pulverized coal boilers using flame-image recognition technology. IEEE Transactions on Energy conversion, IEEE, n. 2, p. 99-103, 1986. Citado na página 39.

LAERA, D.; CAMPA, G.; CAMPOREAlE, S. M.; BERTOLOTTO, E.; RIZZO, S.; BONZANI, F.; FERRANTE, A.; SAPONARO, A. Modelling of thermoacoustic combustion instabilities phenomena: Application to an experimental test rig. Energy Procedia, Elsevier, v. 45, p. 1392-1401, 2014. Citado 3 vezes nas páginas 33, 35 e 37.

LANDAU, I. D.; BOUZIANI, F.; BITMEAD, R. R. A nonlinear model for combustion instability: Analysis and quenching of the oscillations. In: Analysis and design of nonlinear control systems. [S.l.]: Springer, 2008. p. 161-181. Citado 2 vezes nas páginas 34 e 35.

MAMDANI, E. H.; ASSILIAN, S. An experiment in linguistic synthesis with a fuzzy logic controller. International journal of man-machine studies, Elsevier, v. 7, n. 1, p. 1-13, 1975. Citado na página 42.

MARQUES FILHO, O.; VIEIRA NETO, H. Processamento digital de imagens. [S.l.]: Brasport, 1999. Citado 4 vezes nas páginas 79, 81, 86 e 91.

MARTINS, S. B. Introdução ao processamento digital de imagens: Parte 1 - definiçoẽs, espaço de cores e histogramas. 2014. Disponível em: < https://www.ic.unicamp.br/ ra144681/ misc/files/ApostilaProcDeImagesParteI.pdf>. Acesso em: 12 nov. 2019. Citado na página 73.

MIKKELSEN, S.; BAK-JENSEN, J.; BAK-JENSEN, B.; SORENSEN, J. T. Sensitivity of identified transfer functions in transformer diagnosis. In: IEEE. Proceedings of Electrical/Electronics Insulation Conference. [S.1.], 1993. p. 533-537. Citado na página 126. 
NYQUIST, H. Certain topics in telegraph transmission theory. Transactions of the American Institute of Electrical Engineers, IEEE, v. 47, n. 2, p. 617-644, 1928. Reprint as classic paper in: Proc. IEEE, Vol. 90, N. 2, Feb. 2002. Citado na página 119.

OLIVEIRA, A. R. E. History of krylov-bogoliubov-mitropolsky methods of nonlinear oscillations. Advances in Historical Studies, Scientific Research Publishing, v. 6, n. 1, p. 40-55, 2017. Citado na página 35.

OTSU, N. A threshold selection method from gray-level histograms. IEEE transactions on systems, man, and cybernetics, IEEE, v. 9, n. 1, p. 62-66, 1979. Citado 4 vezes nas páginas 46, 82, 83 e 84 .

PAPPA, R. S.; IBRAHIM, S. R. A parametric study of the Ibrahim time domain modal identification algorithm. The Shock and Vibration Bulletin, v. 51, n. 3, p. 43-72, 1981. Citado 6 vezes nas páginas 104, 106, 107, 110, 112 e 120.

PARKER, M. Digital Signal Processing 101: Everything you need to know to get started. [S.l.]: Newnes, 2017. Citado na página 45.

PEARSON, K. Liii. on lines and planes of closest fit to systems of points in space. The London, Edinburgh, and Dublin Philosophical Magazine and Journal of Science, Taylor \& Francis, v. 2, n. 11, p. 559-572, 1901. Citado na página 100.

PEARSON, K.; GALTON, F. Vii. note on regression and inheritance in the case of two parents. Proceedings of the Royal Society of London, The Royal Society London, v. 58, n. 347-352, p. 240-242, 1895. Citado na página 96.

PERACCHIO, A.; PROSCIA, W. Nonlinear heat-release/acoustic model for thermoacoustic instability in lean premixed combustors. Journal of Engineering for gas Turbines and Power, American Society of Mechanical Engineers Digital Collection, v. 121, n. 3, p. 415-421, 1999. Citado 2 vezes nas páginas 34 e 35.

RIOS NETO, A.; KUGA, H. Kalman filtering state noise adaptive estimation. In: SOUZA, J. A. M. F. de (Ed.). Proceedings of Second IASTED International Conference on Telecommunication and Control, TELECON'85. Rio de Janeiro: INPE, 1985. p. 210-213. Citado na página 52.

RYDER, S. A. Methods for comparing frequency response analysis measurements. In: IEEE. Conference Record of the the 2002 IEEE International Symposium on Electrical Insulation (Cat. No. 02CH37316). [S.1.], 2002. p. 187-190. Citado na página 126.

SANTOS-VICTOR, J. A.; COSTEIRA, J. P.; TOMÉ, J. A. B.; SENTIEIRO, J. J. S. A computer vision system for the characterization and classification of flames in glass furnaces. IEEE Transactions on Industry Applications, IEEE, v. 29, n. 3, p. 470-478, 1993. Citado 2 vezes nas páginas 32 e 41.

SHAH, P.; AGASHE, S. Review of fractional pid controller. Mechatronics, Elsevier, v. 38, p. 29-41, 2016. Citado na página 33.

SILVA NETO, G. C. da; CHUI, D. S.; TRIGO, F. C.; MARTINS, F. P. R.; FLEURY, A. T. Fuzzy inference of oil furnace combustion state through computer vision information. In: SAVI, M. A.; RITTO, T. G.; BESSA, W. M. (Ed.). Proceedings of the XVIII International Symposium on Dynamic Problems of Mechanics (DINAME 2019). Buzios, RJ, Brazil: ABCM, 2019. Citado 2 vezes nas páginas 46 e 63. 
SILVA, R. P.; FLEURY, A. T.; MARTINS, F. P. R.; PONGE-FERREIRA, W. J. A.; TRIGO, F. C. Identification of the state-space dynamics of oil flames through computer vision and modal techniques. Expert Systems with Applications, Elsevier, v. 42, n. 5, p. 2421-2428, 2015. Citado 11 vezes nas páginas 14, 36, 46, 53, 54, 55, 56, 57, 62, 101 e 122.

SILVA, R. T. da. Aplicações da teoria de controle em uma refinaria de petróleo: Estudo de caso: REVAP. 2009. Monografia (Bacharelado). Instituto de Matemática e Estatística, Universidade de São Paulo. Citado na página 32.

SREEDHANYA, L.; VARGHESE, A.; NAIR, M. S.; WILSCY, M. Temperature mapping of a rotary kiln using fuzzy logic. Journal of Intelligent $\&$ Fuzzy Systems, IOS Press, v. 32, n. 4, p. 3059-3067, 2017. Citado na página 42.

STADLMAIR, N. V.; HUMMEL, T.; SATTELMAYER, T. Thermoacoustic damping rate determination from combustion noise using bayesian statistics. Journal of Engineering for Gas Turbines and Power, American Society of Mechanical Engineers, v. 140, n. 11, p. 111501, 2018. Citado na página 35.

STEMMER IMAGING. CCD sensor types. [s.d.]. Disponível em: <https://www. stemmer-imaging.com/en/knowledge-base/ccd/>. Acesso em: 26 out. 2019. Citado na página 40.

TERANISHI, N.; KOHONO, A.; ISHIHARA, Y.; ODA, E.; ARAI, K. No image lag photodiode structure in the interline ccd image sensor. In: IEEE. 1982 International Electron Devices Meeting. [S.l.], 1982. p. 324-327. Citado na página 40.

TÓTH, P.; GARAMI, A.; CSORDÁS, B. Image-based deep neural network prediction of the heat output of a step-grate biomass boiler. Applied energy, Elsevier, v. 200, p. 155-169, 2017. Citado na página 42.

WALSH, L.; DYCK, R. A new charge-coupled area imaging device. In: Proc. CCD Applicat. Conf. [S.l.: s.n.], 1973. p. 21-22. Citado na página 40.

ZADEH, L. A. A simple view of the dempster-shafer theory of evidence and its implication for the rule of combination. AI magazine, v. 7, n. 2, p. 85-85, 1986. Citado na página 63.

ZUCHERMAN, L.; KAWALL, J.; KEFFER, J. Digital image analysis of a turbulent flame. Experiments in fluids, Springer, v. 6, n. 1, p. 16-24, 1988. Citado 2 vezes nas páginas 38 e 39. 
Apêndices 


\section{APÊNDICE A - AMOSTRAS DE IMAGENS PROCESSADAS}

No capítulo 4 foram exibidas as figuras 25(a) a 25(u) para ilustrar três amostras de imagens de cada condição de chama testada. No entanto, ao longo do mesmo capítulo, várias passagens de processamento de imagens foram realizadas nas imagens, mas apenas algumas foram exibidas no capítulo 4. Aqui serão exibidas todas as imagens para cada passo de processamento para as 21 amostras. Cada conjunto de imagens ilustra as três transformações ocorridas em uma amostra de chama, ou seja, há uma imagem recortada, uma imagem em preto e branco após a limiarização e uma imagem segmentada gerada utilizando-se a imagem em preto e branco como máscara da imagem recortada. O histograma da imagem recortada completa o conjunto evidenciando na barra indicada por uma pequena flecha onde está o limite de limiarização utilizado para a geração da imagem em preto e branco.

Figura 60 - Transformações da imagem da chama da amostra 1 na condição 1.

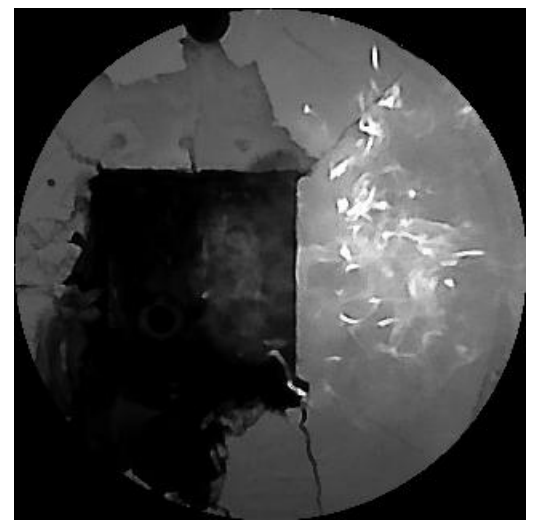

(a) Imagem recortada.

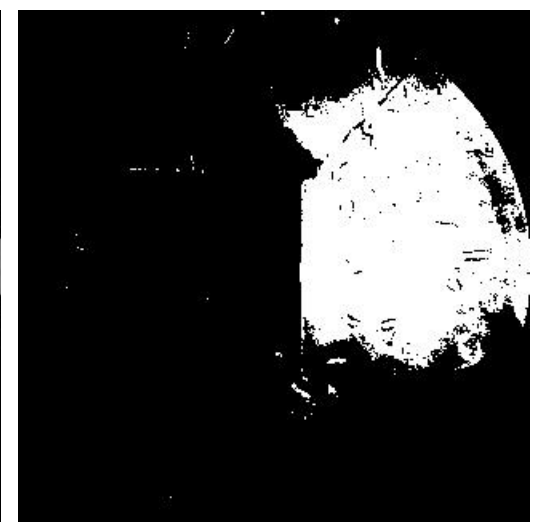

(b) Imagem em preto e branco.

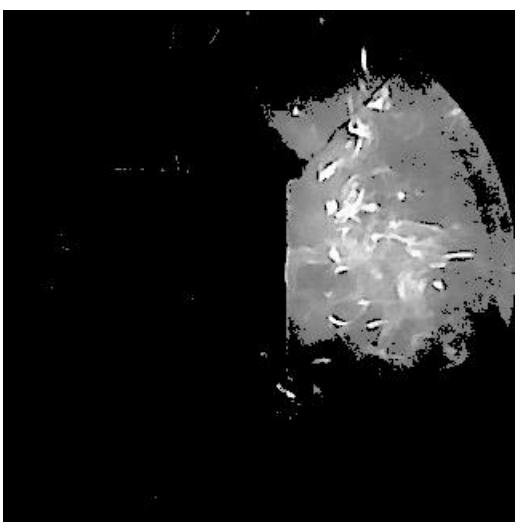

(c) Imagem segmentada.

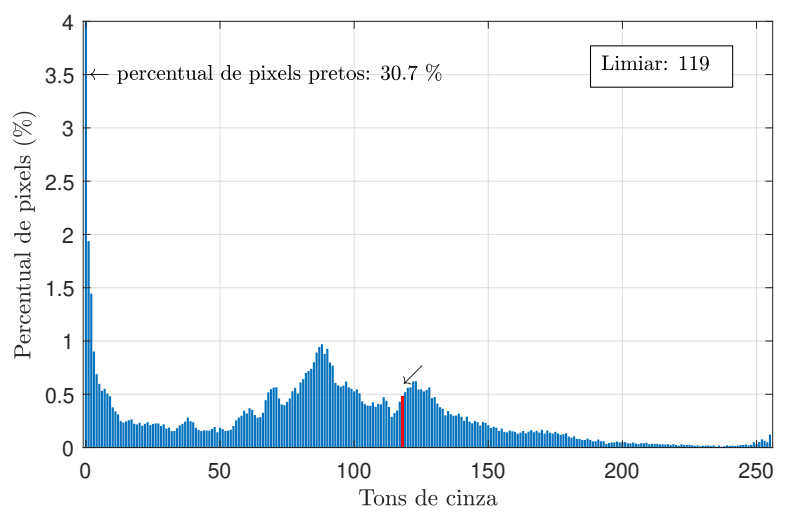

(d) Histograma.

Fonte - Elaborado pelo autor. 
Figura 61 - Transformações das imagens da chama das amostras 2 e 3 na condição 1. Imagens da amostra 2 na condição 1

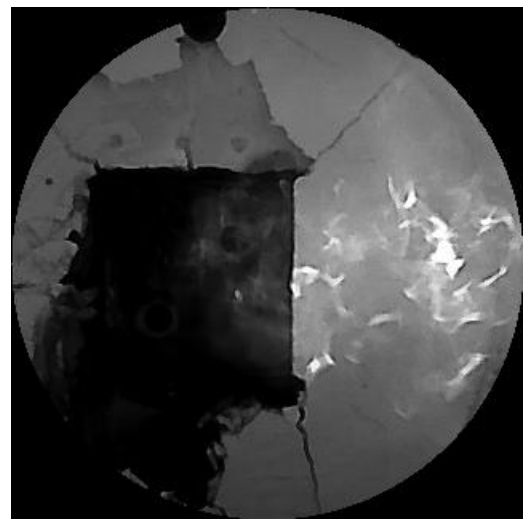

(a) Imagem recortada.

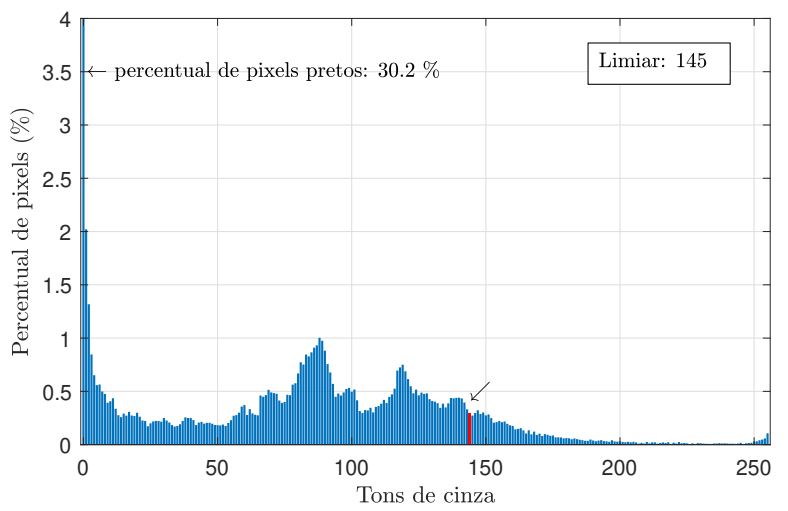

(d) Histograma da amostra 2.

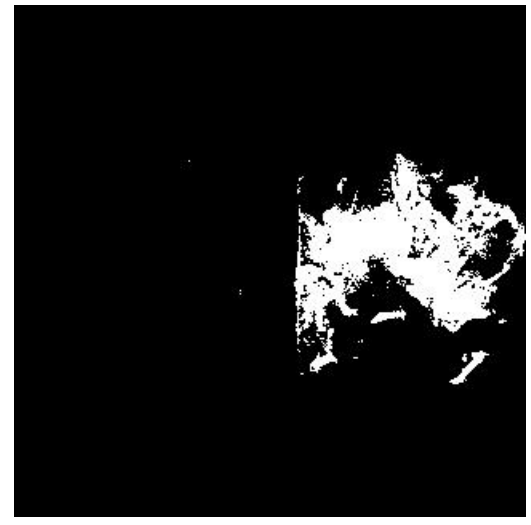

(b) Imagem em preto e branco.

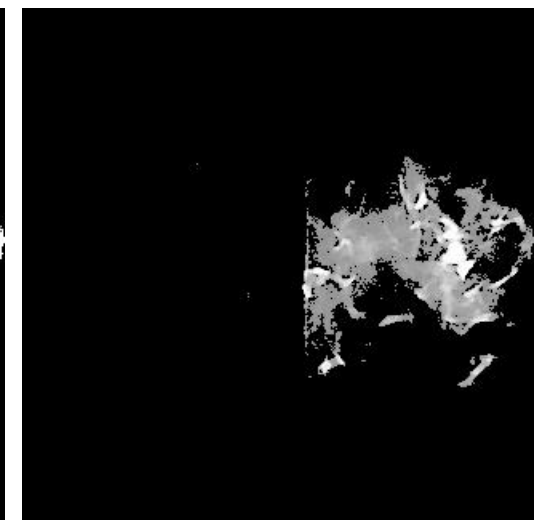

(c) Imagem segmentada.

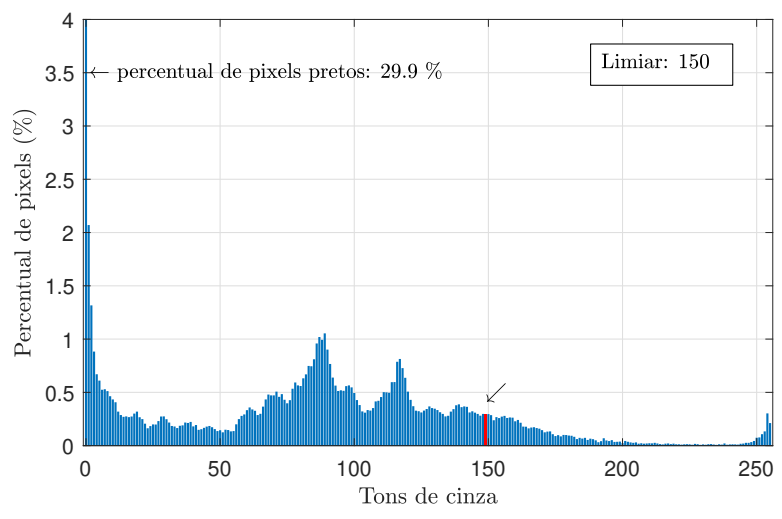

(e) Histograma da amostra 3 .

Imagens da amostra 3 na condição 1

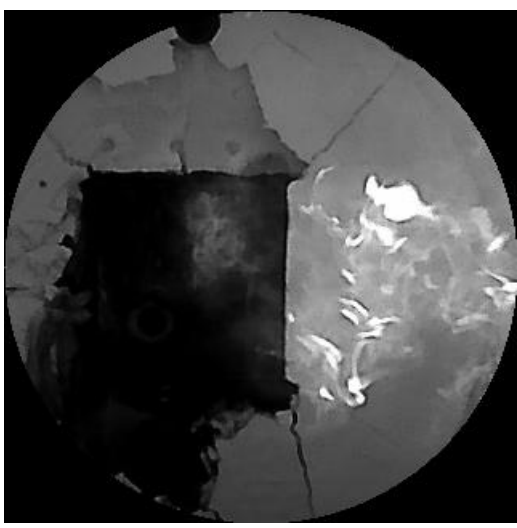

(f) Imagem recortada.

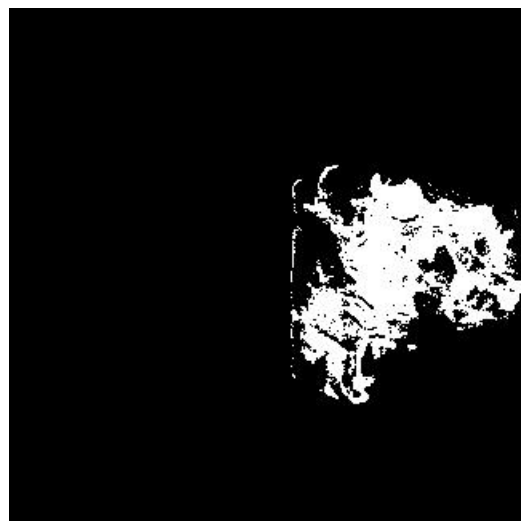

(g) Imagem em preto e branco.

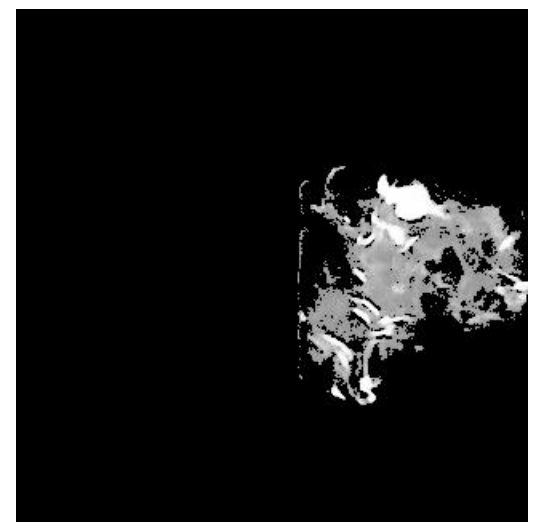

(h) Imagem segmentada. Fonte - Elaborado pelo autor. 
Figura 62 - Conjuntos das transformações das imagens da chama das amostras 1 e 2 na condição 2 .

Imagens da amostra 1 na condição 2

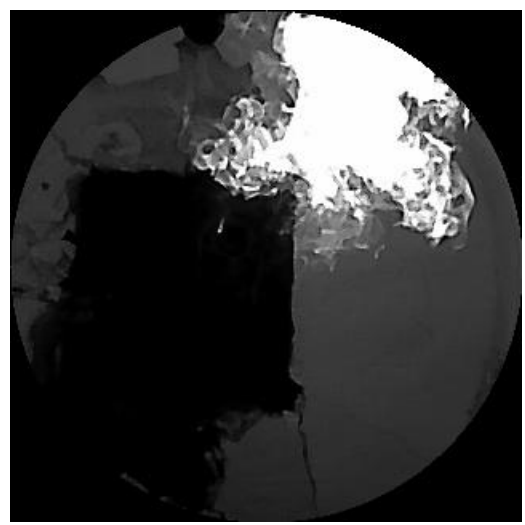

(a) Imagem recortada.

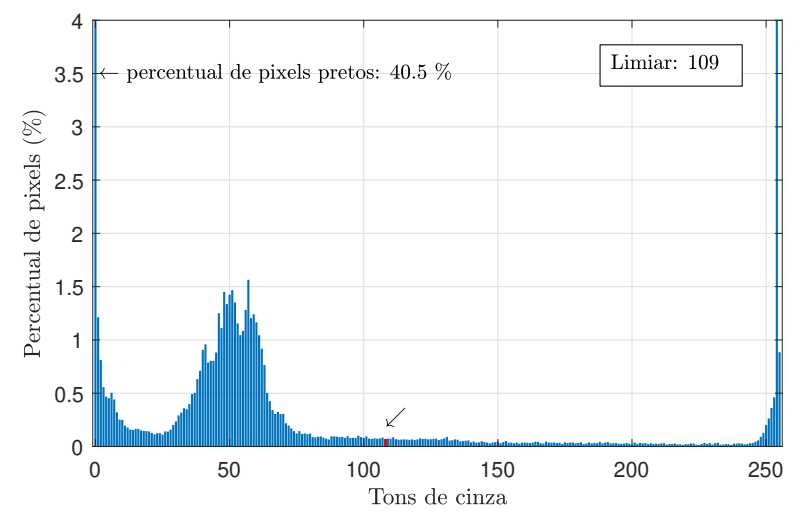

(d) Histograma da amostra 1.

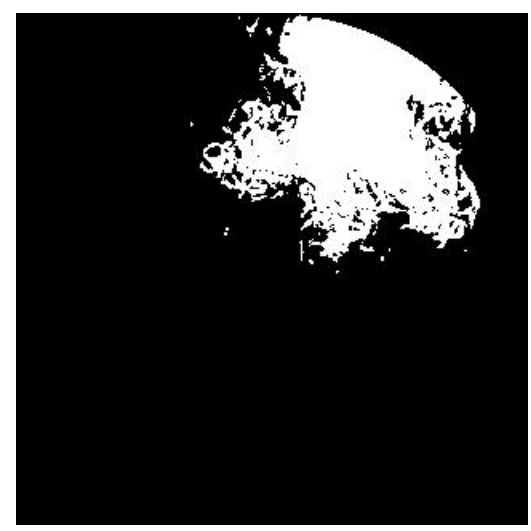

(b) Imagem em preto e branco.

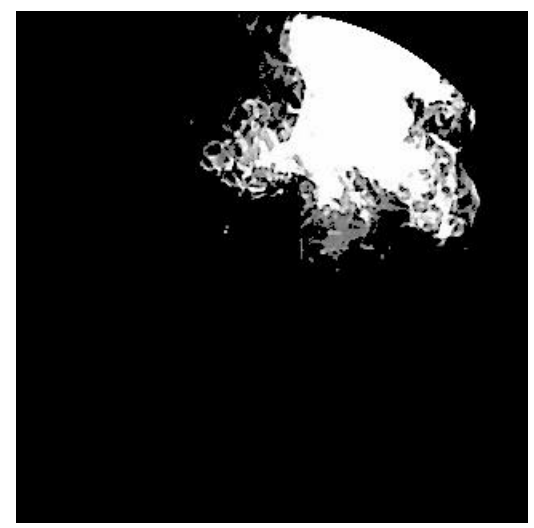

(c) Imagem segmentada.

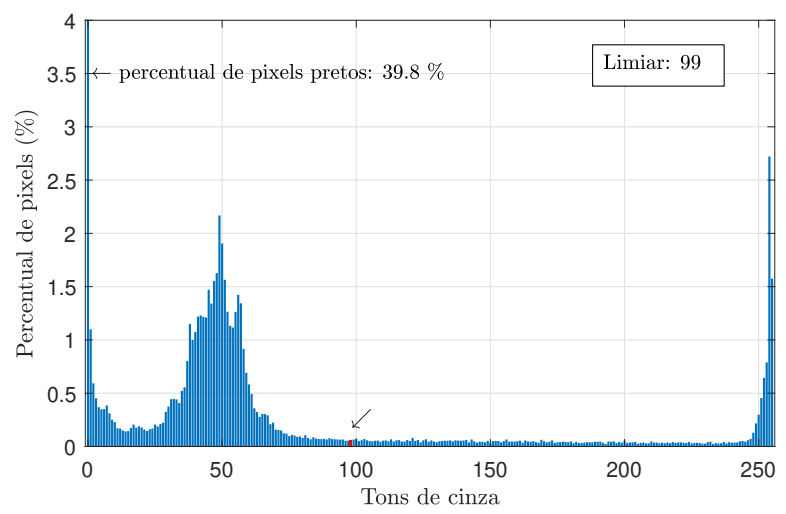

(e) Histograma da amostra 2.

Imagens da amostra 2 na condição 2

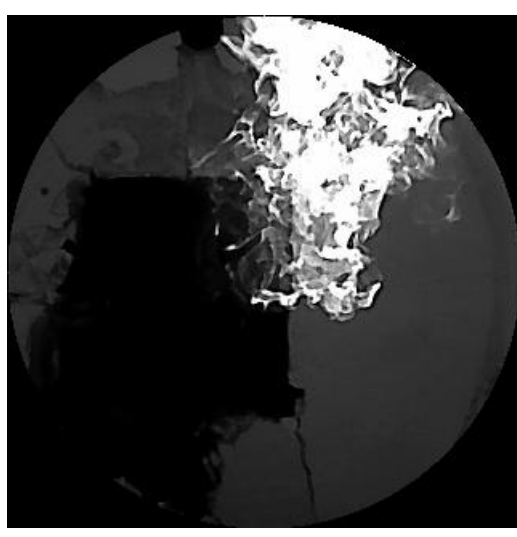

(f) Imagem recortada.

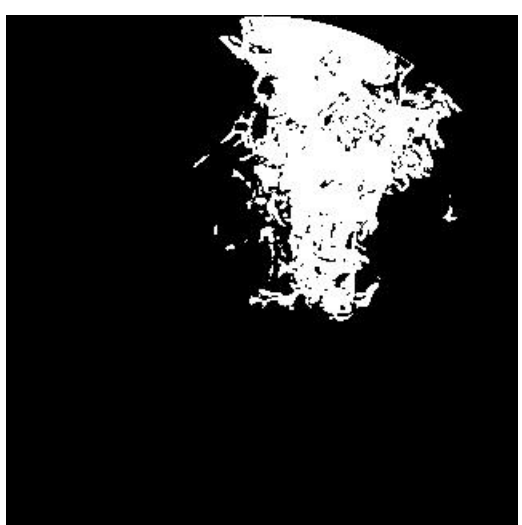

(g) Imagem em preto e branco.

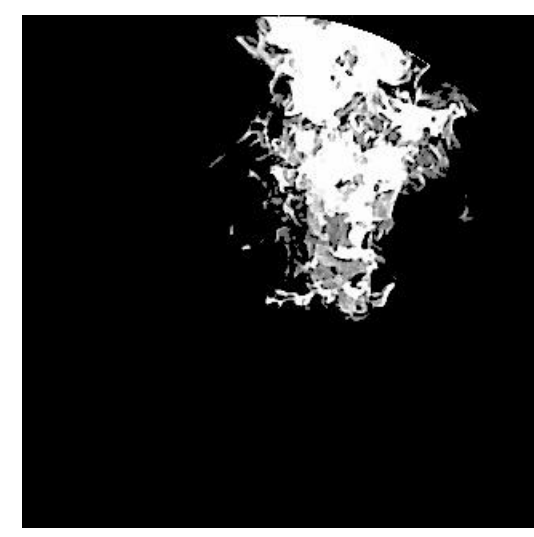

(h) Imagem segmentada.

Fonte - Elaborado pelo autor. 
Figura 63 - Conjuntos das transformações das imagens da chama da amostra 3 na condição 2 e da amostra 1 na condição 3 .

Imagens da amostra 3 na condição 2

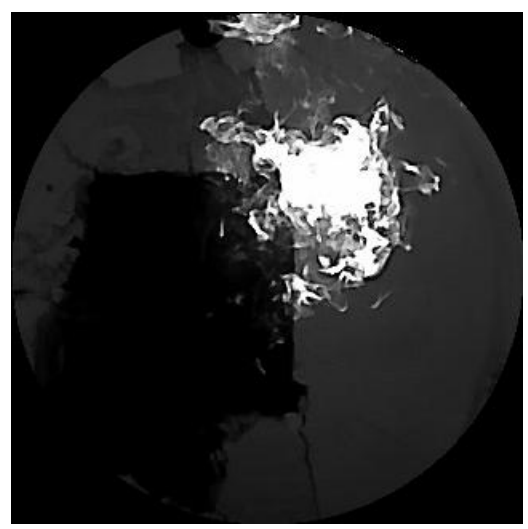

(a) Imagem recortada.

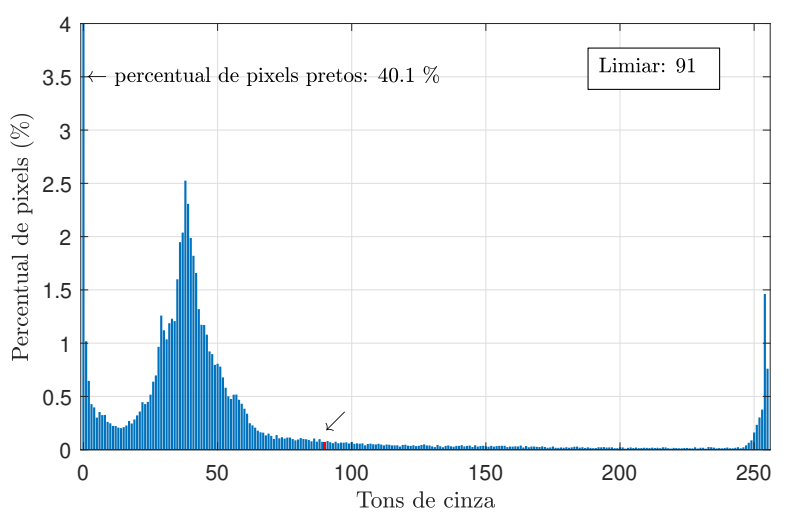

(d) Histograma da amostra 3 na condição 2.

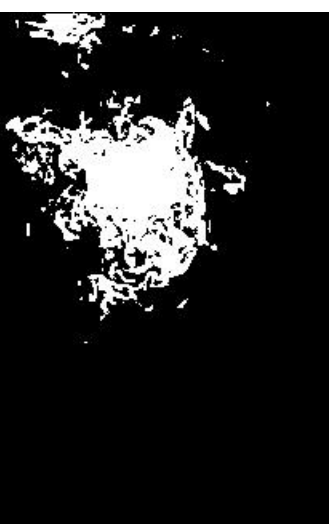

(b) Imagem em preto e branco.

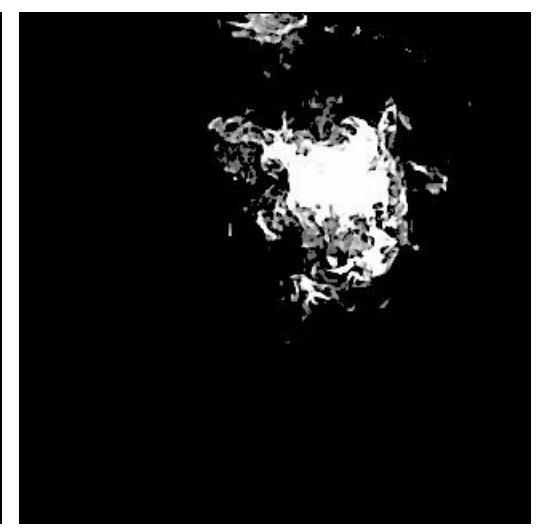

(c) Imagem segmentada.

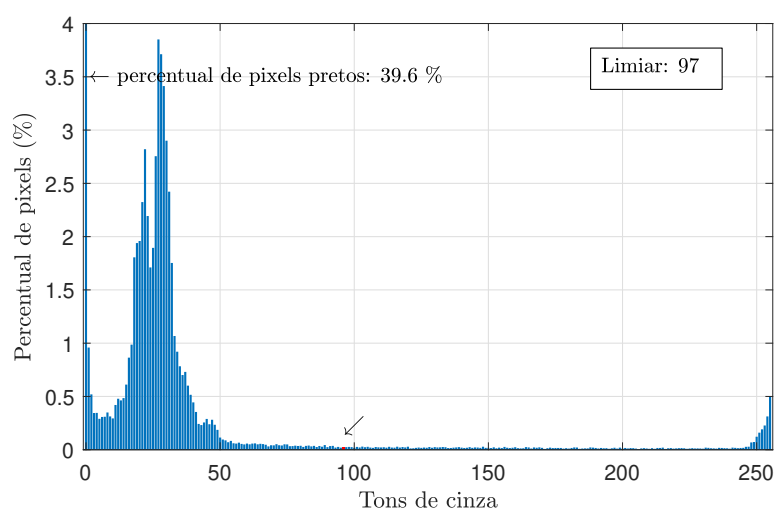

(e) Histograma da amostra 1 na condição 3.

Imagens da amostra 1 na condição 3

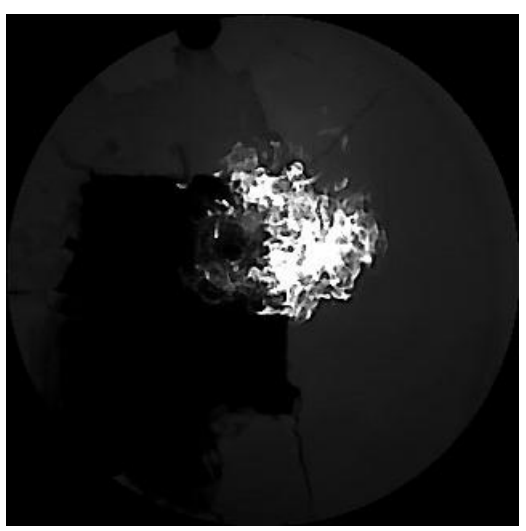

(f) Imagem recortada.

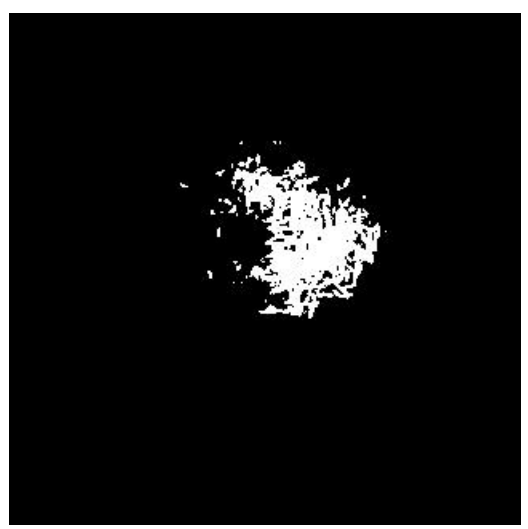

(g) Imagem em preto e branco.

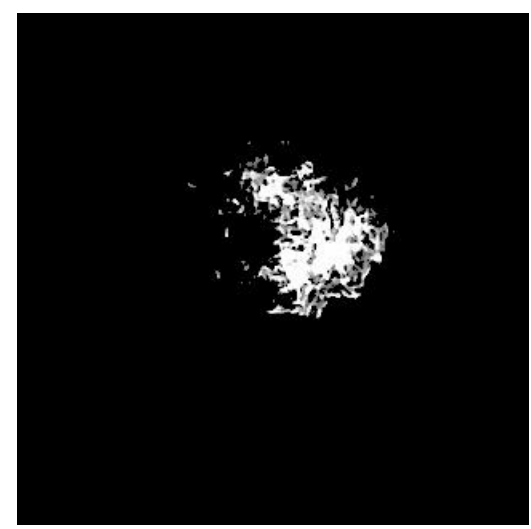

(h) Imagem segmentada. Fonte - Elaborado pelo autor. 
Figura 64 - Conjuntos das transformações das imagens da chama das amostras 2 e 3 na condição 3 .

Imagens da amostra 2 na condição 3

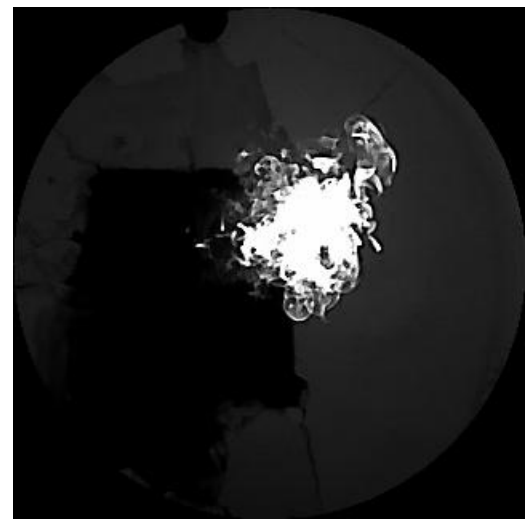

(a) Imagem recortada.

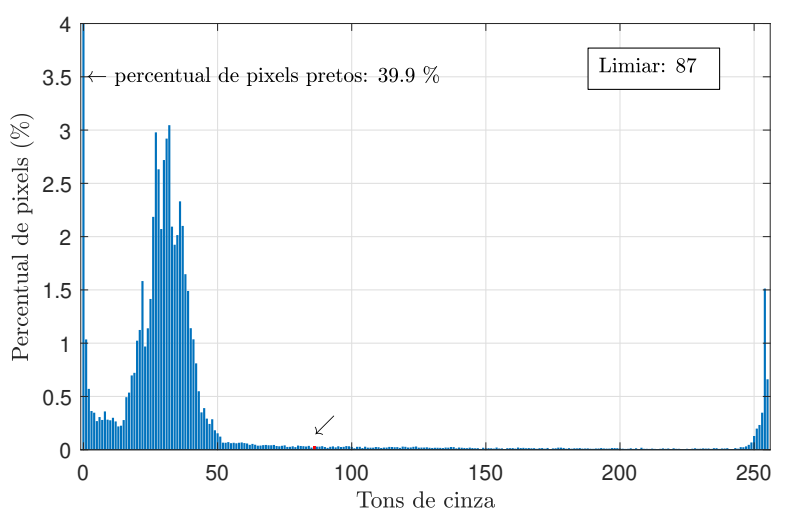

(d) Histograma da amostra 2.

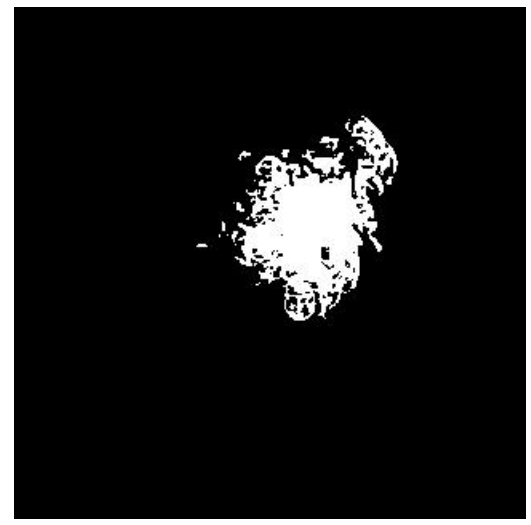

(b) Imagem em preto e branco.

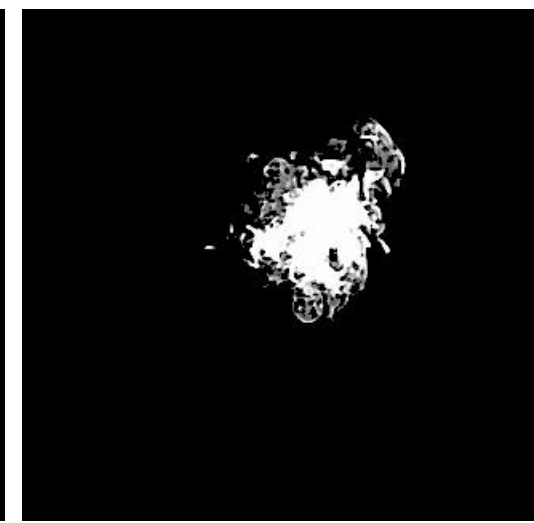

(c) Imagem segmentada.

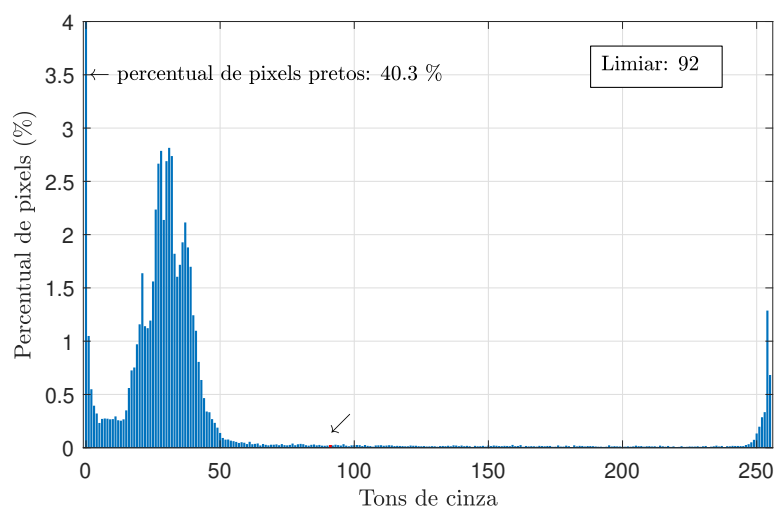

(e) Histograma da amostra 3.

Imagens da amostra 3 na condição 3

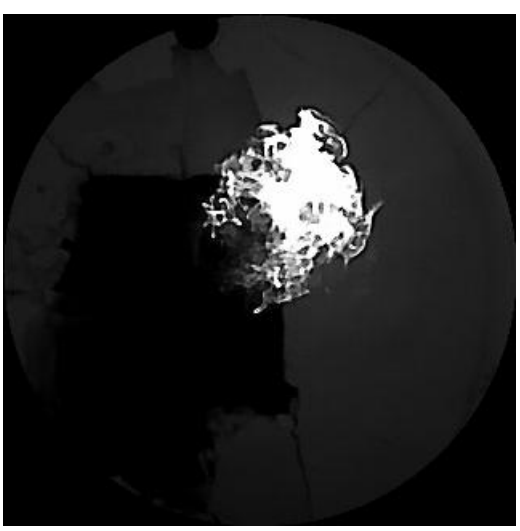

(f) Imagem recortada.

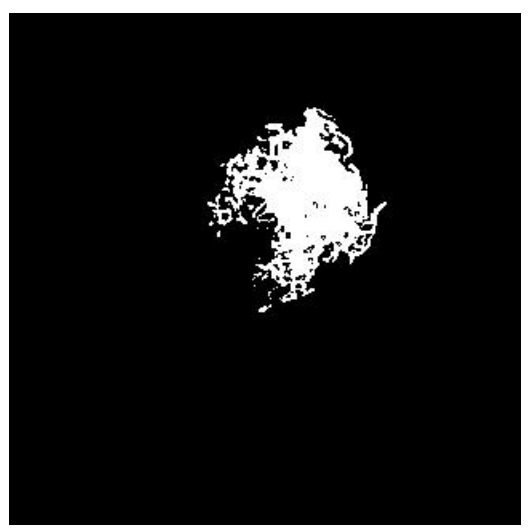

(g) Imagem em preto e branco.

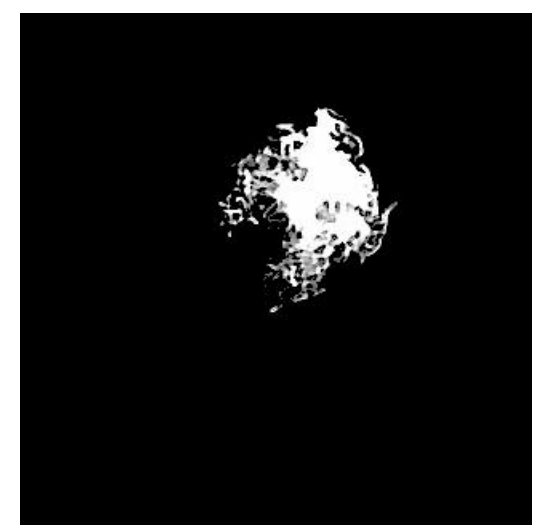

(h) Imagem segmentada. Fonte - Elaborado pelo autor. 
Figura 65 - Conjuntos das transformações das imagens da chama das amostras 1 e 2 na condição 4 .

Imagens da amostra 1 na condição 4

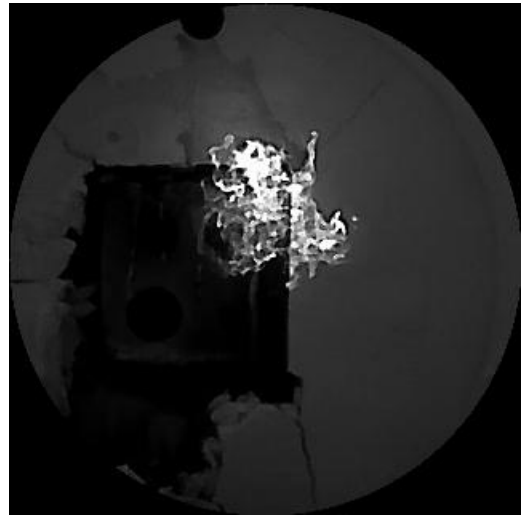

(a) Imagem recortada.

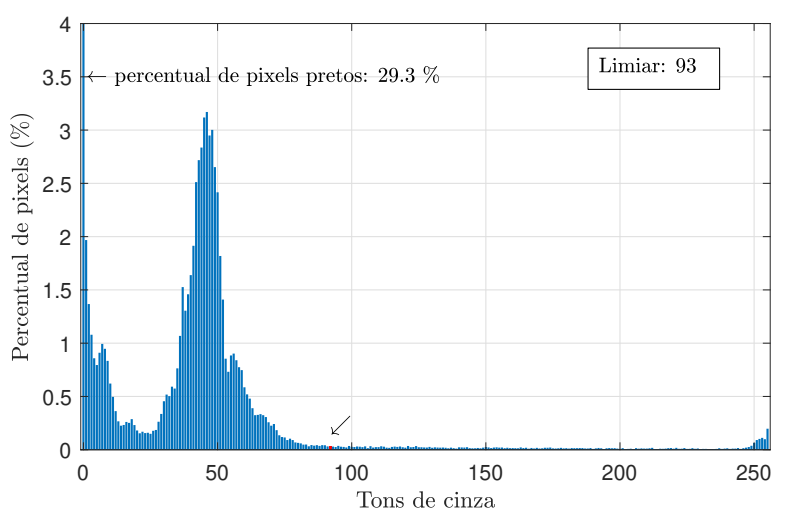

(d) Histograma da amostra 1.

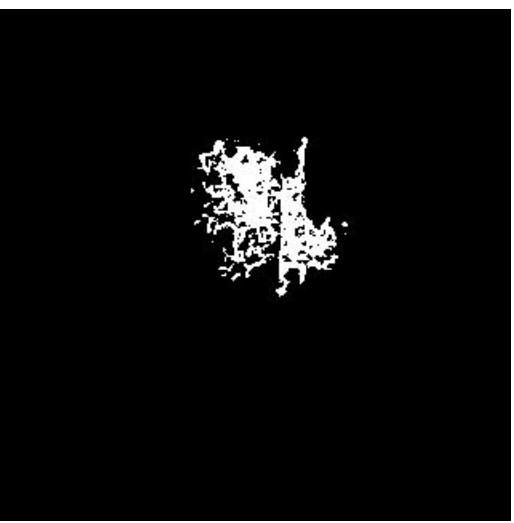

(b) Imagem em preto e branco.

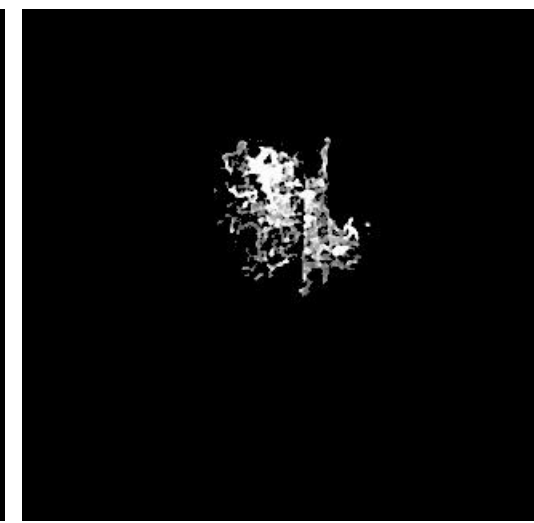

(c) Imagem segmentada.

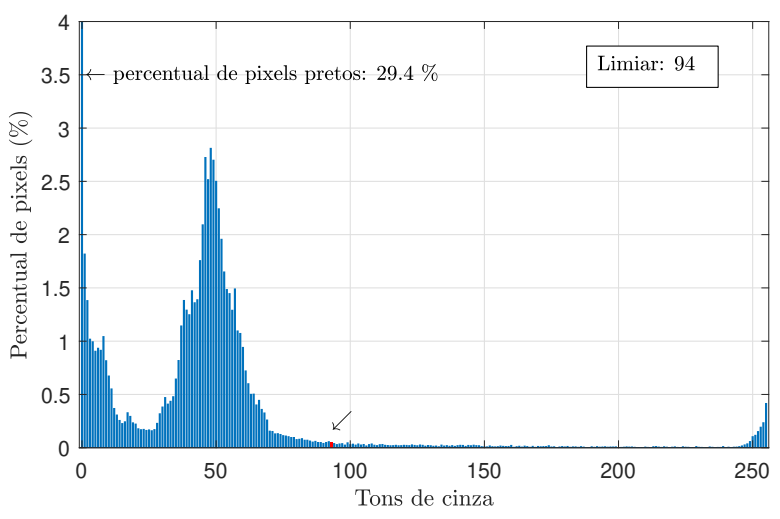

(e) Histograma da amostra 2.

Imagens da amostra 2 na condição 4

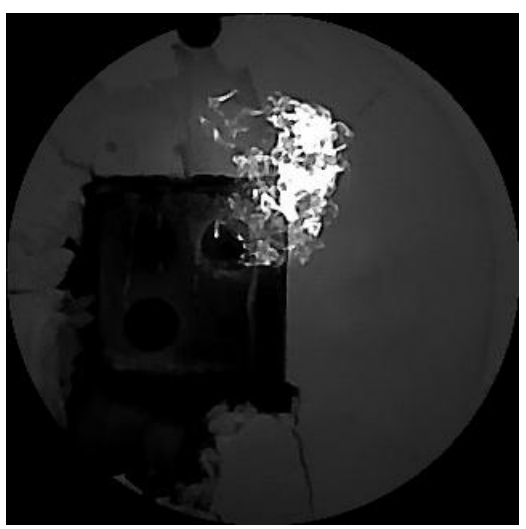

(f) Imagem recortada.

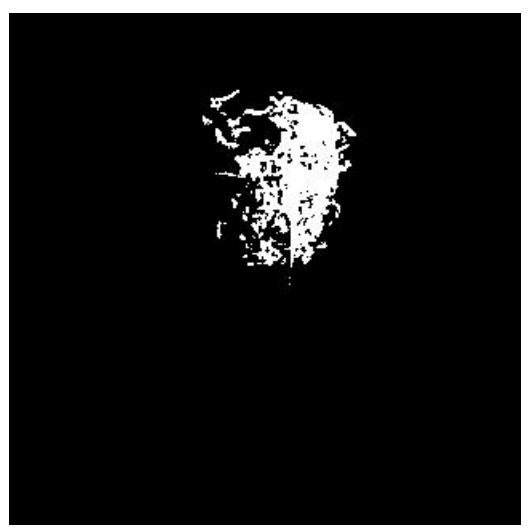

(g) Imagem em preto e branco.

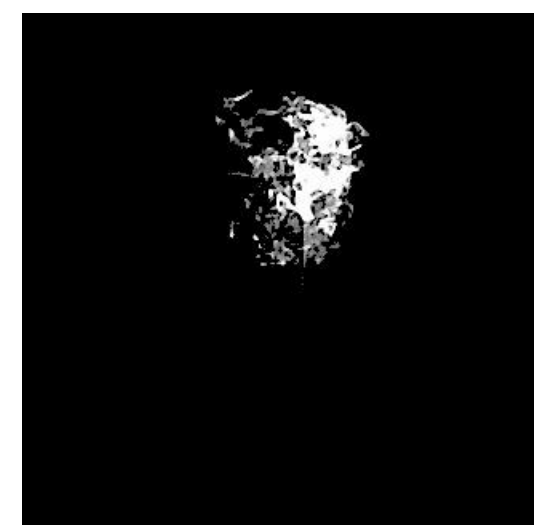

(h) Imagem segmentada.

Fonte - Elaborado pelo autor. 
Figura 66 - Conjuntos das transformações das imagens da chama da amostra 3 na condição 4 e da amostra 1 na condição 5 .

Imagens da amostra 3 na condição 4

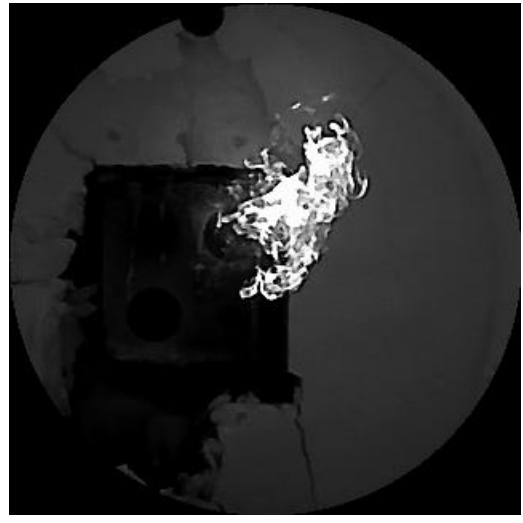

(a) Imagem recortada.

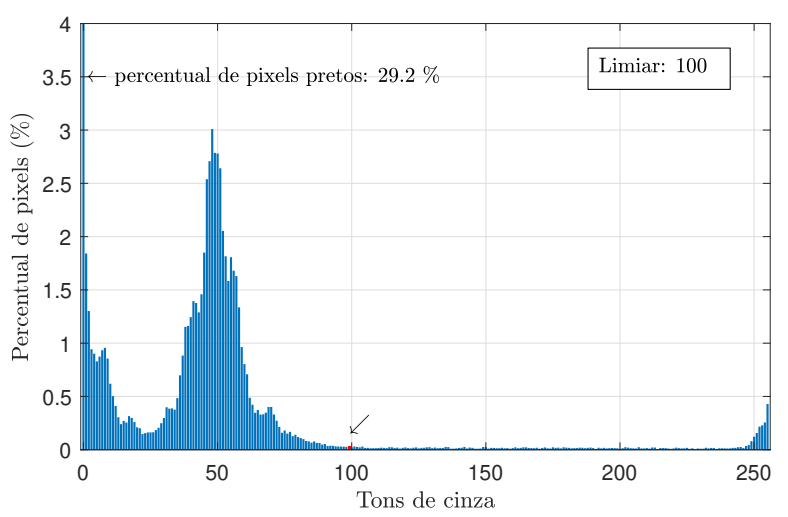

(d) Histograma da amostra 3 na condição 4.

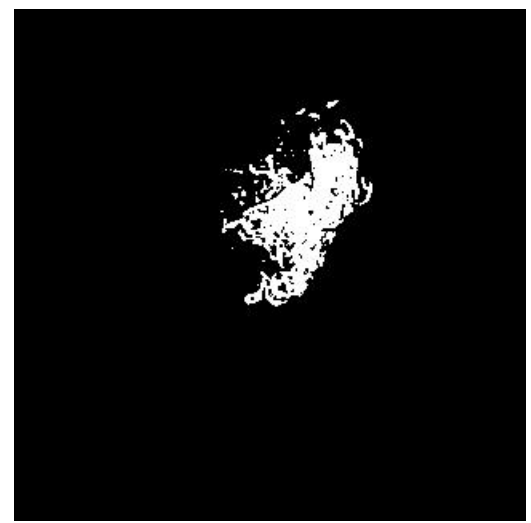

(b) Imagem em preto e branco.

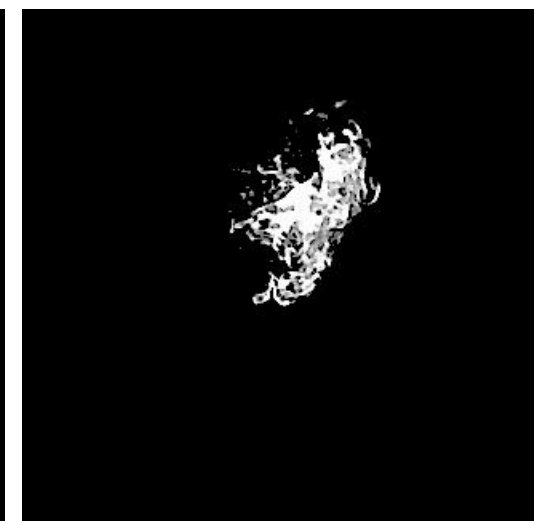

(c) Imagem segmentada.

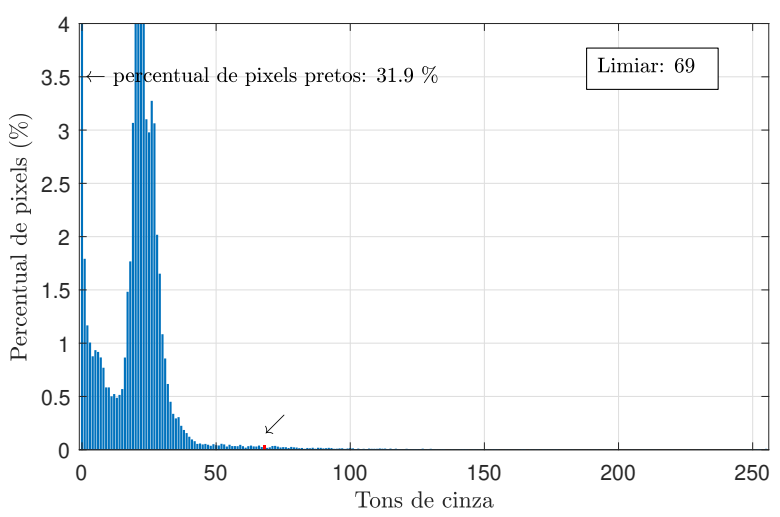

(e) Histograma da amostra 1 na condição 5.

Imagens da amostra 1 na condição 5

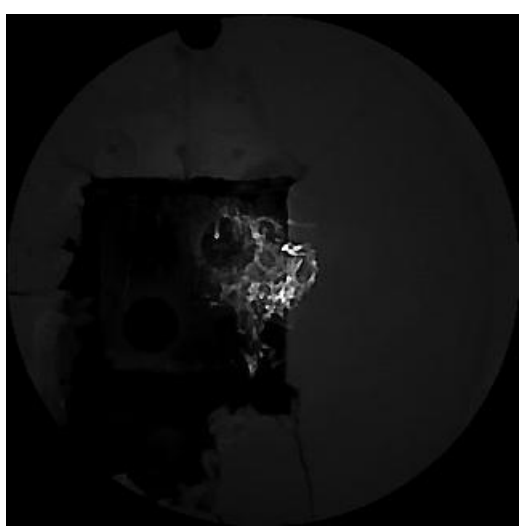

(f) Imagem recortada.

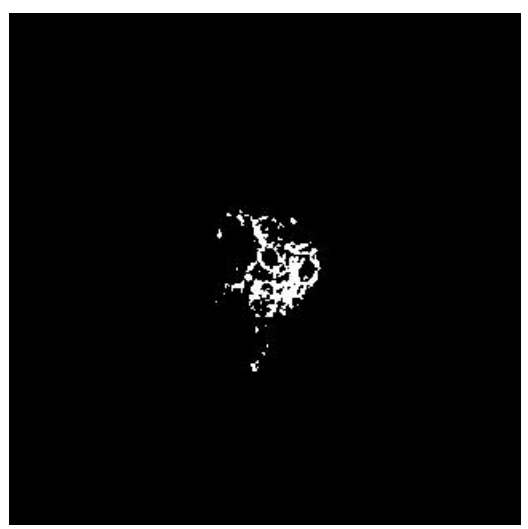

(g) Imagem em preto e branco.

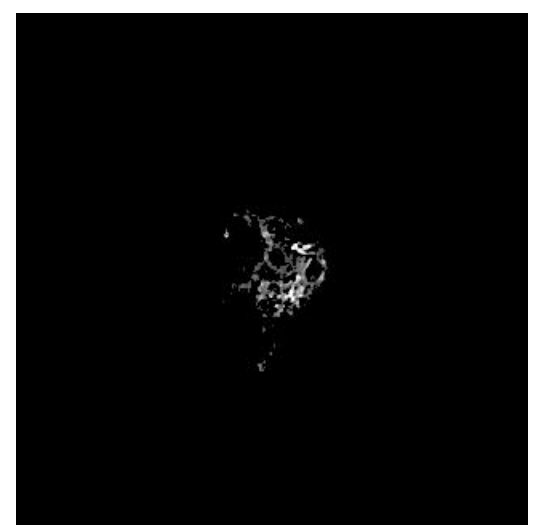

(h) Imagem segmentada.

Fonte - Elaborado pelo autor. 
Figura 67 - Conjuntos das transformações das imagens da chama das amostras 2 e 3 na condição 5 .

Imagens da amostra 2 na condição 5

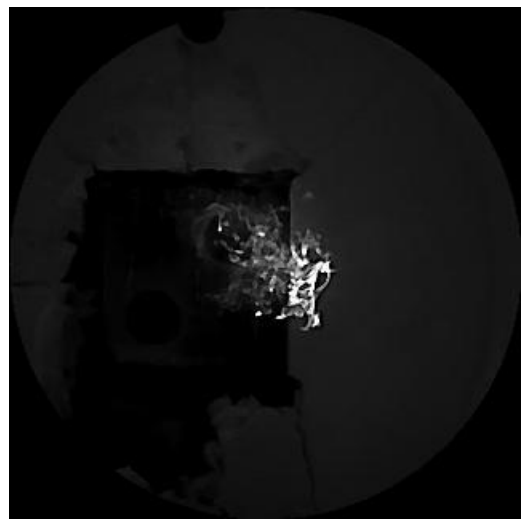

(a) Imagem recortada.

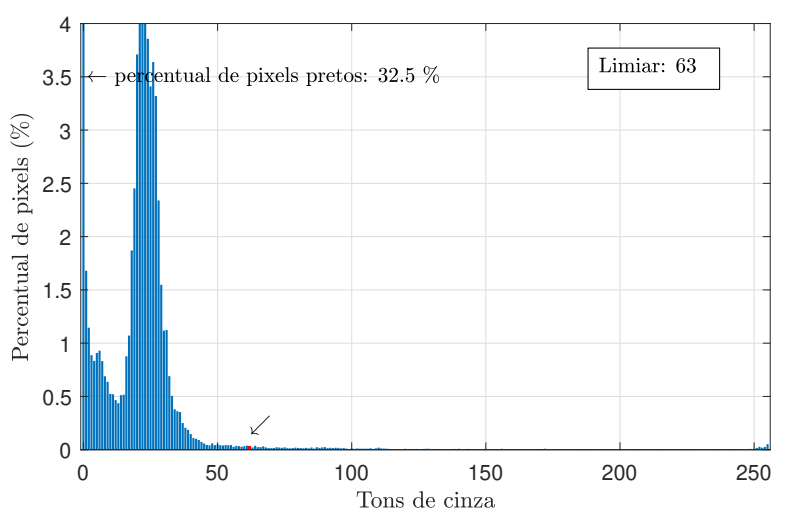

(d) Histograma da amostra 2.

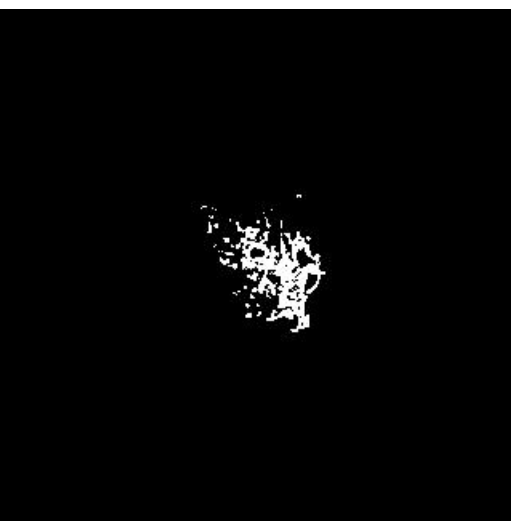

(b) Imagem em preto e branco.

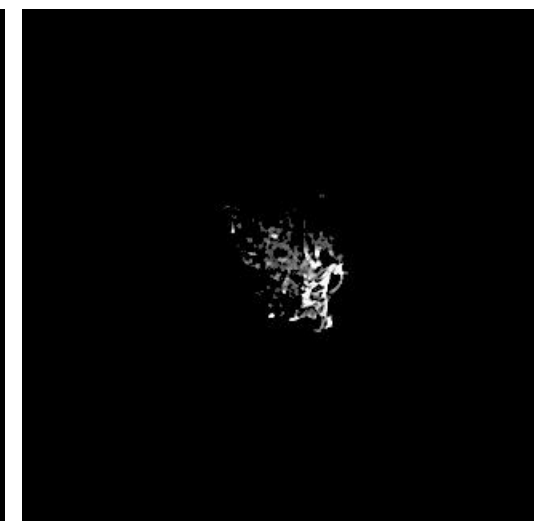

(c) Imagem segmentada.

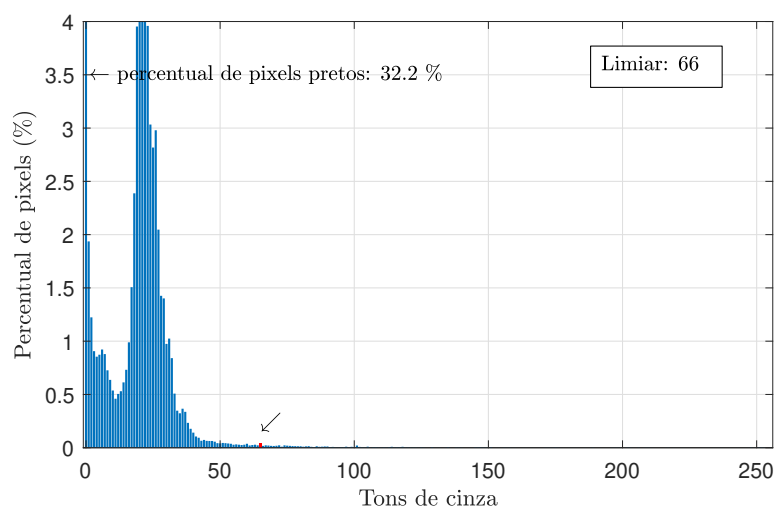

(e) Histograma da amostra 3.

Imagens da amostra 3 na condição 5

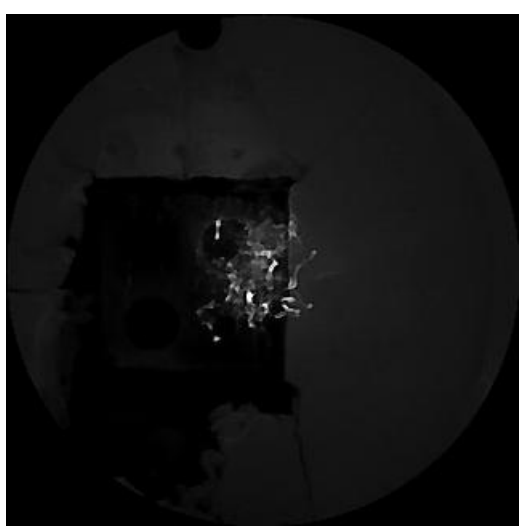

(f) Imagem recortada.

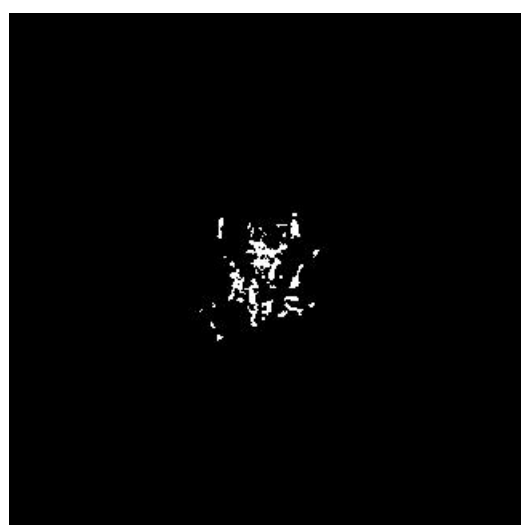

(g) Imagem em preto e branco.

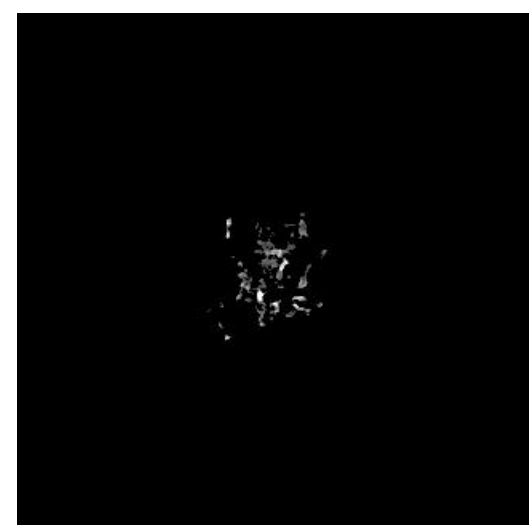

(h) Imagem segmentada.

Fonte - Elaborado pelo autor. 
Figura 68 - Conjuntos das transformações das imagens da chama das amostras 1 e 2 na condição 6 .

Imagens da amostra 1 na condição 6

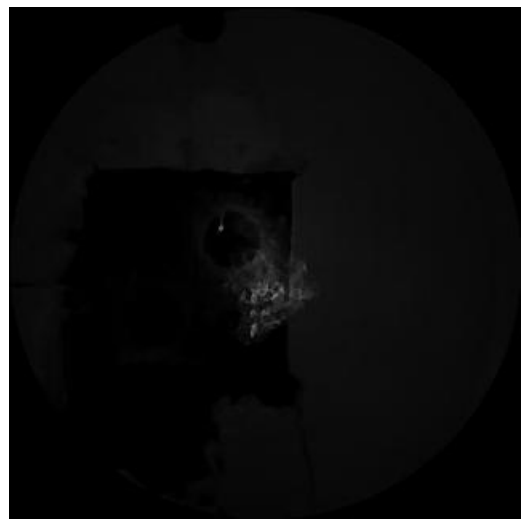

(a) Imagem recortada.

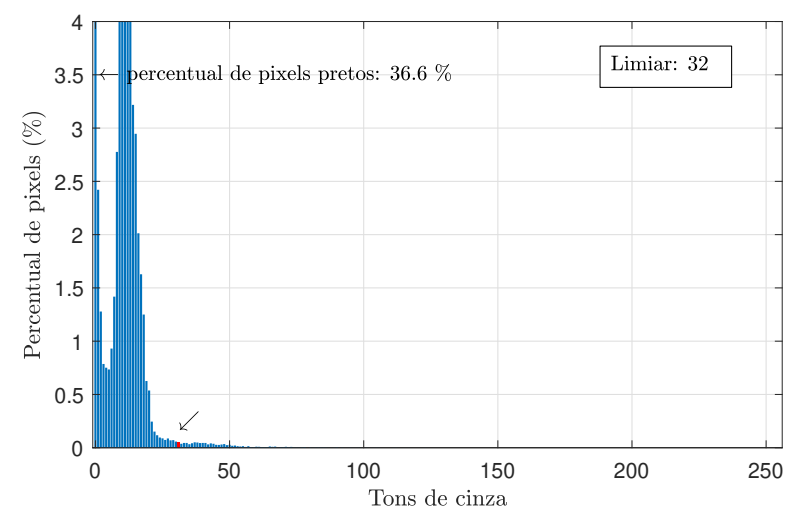

(d) Histograma da amostra 1.

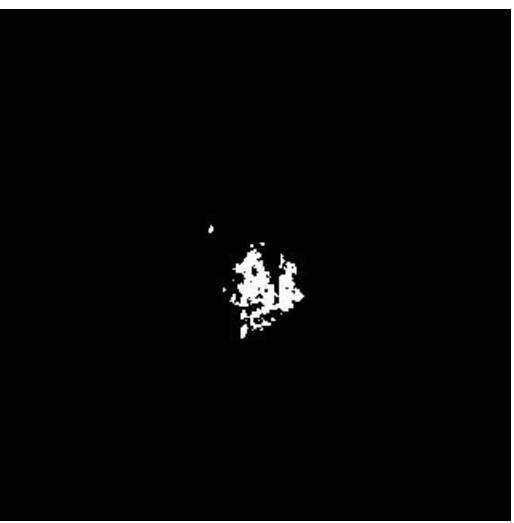

(b) Imagem em preto e branco.

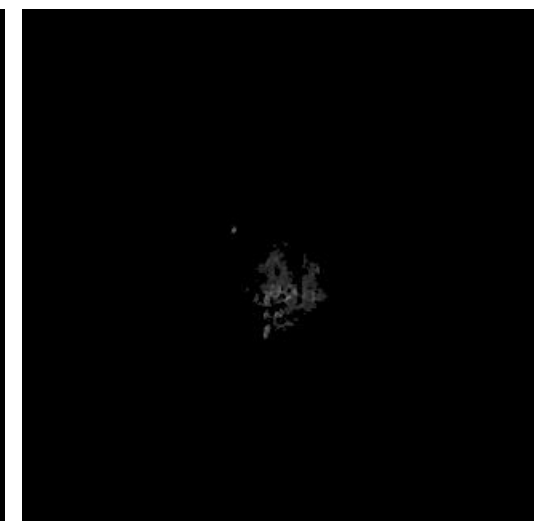

(c) Imagem segmentada.

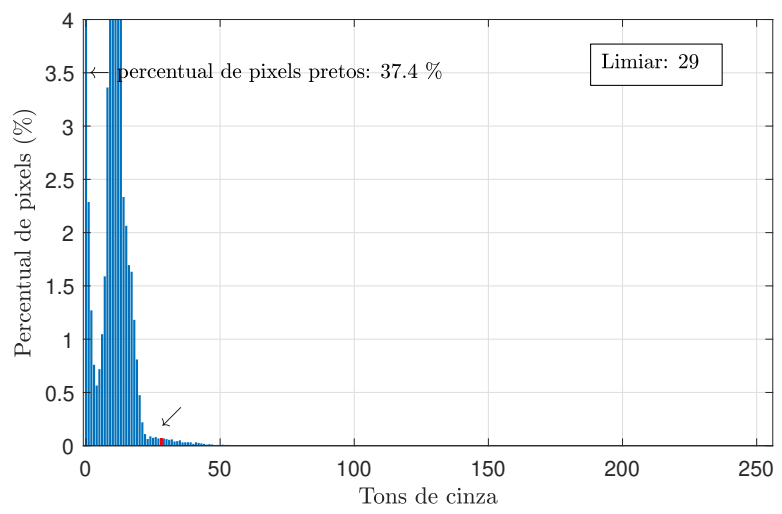

(e) Histograma da amostra 2.

Imagens da amostra 2 na condição 6

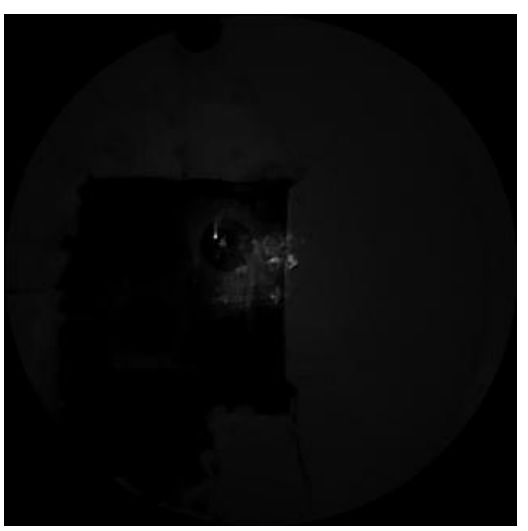

(f) Imagem recortada.

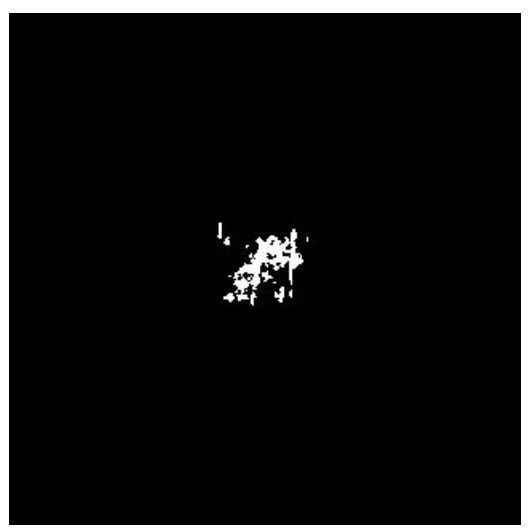

(g) Imagem em preto e branco.

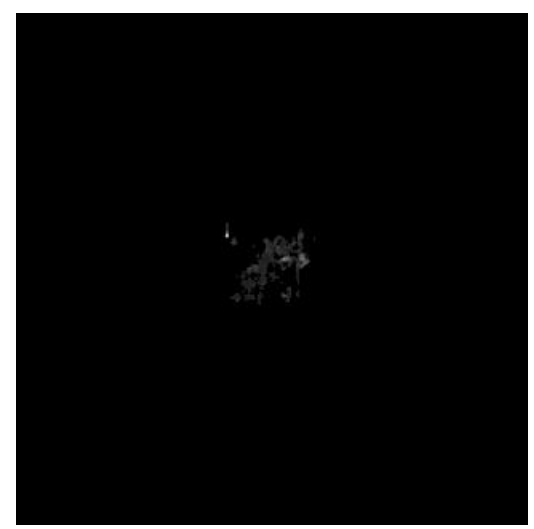

(h) Imagem segmentada. Fonte - Elaborado pelo autor. 
Figura 69 - Conjuntos das transformações das imagens da chama da amostra 3 na condição 6 e da amostra 1 na condição 7 .

Imagens da amostra 3 na condição 6

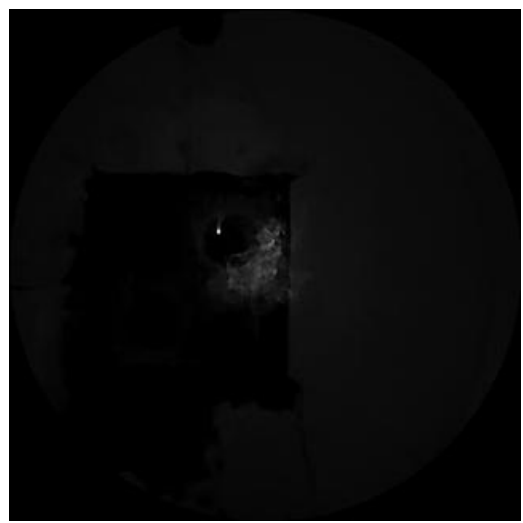

(a) Imagem recortada.

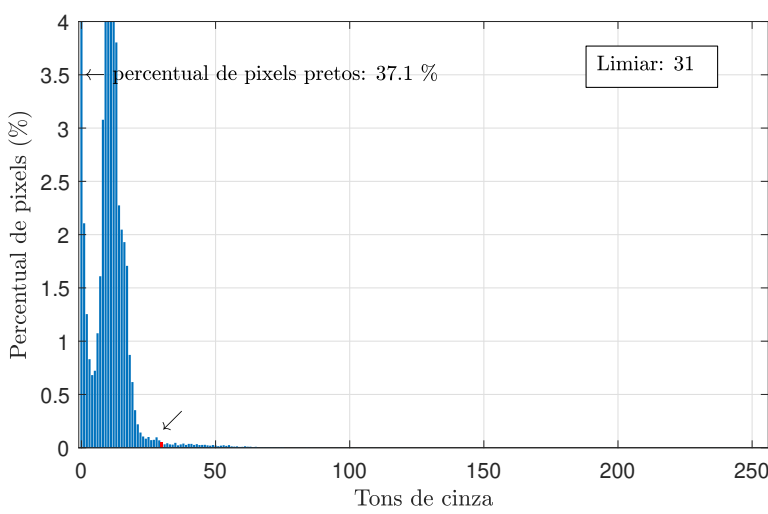

(d) Histograma da amostra 3 na condição 6 .

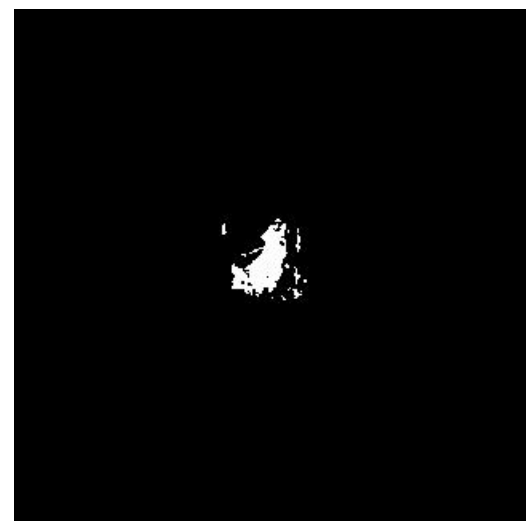

(b) Imagem em preto e branco.

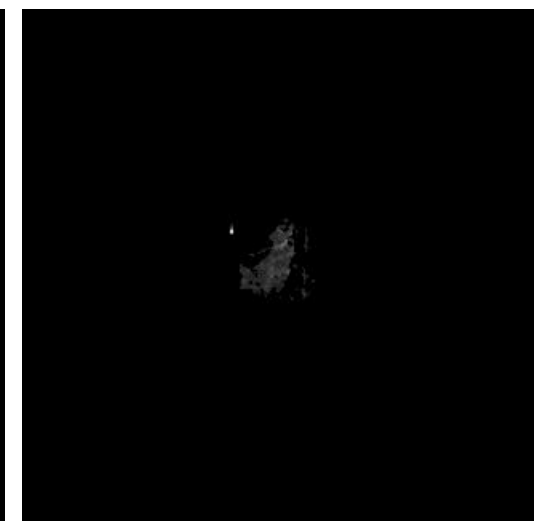

(c) Imagem segmentada.

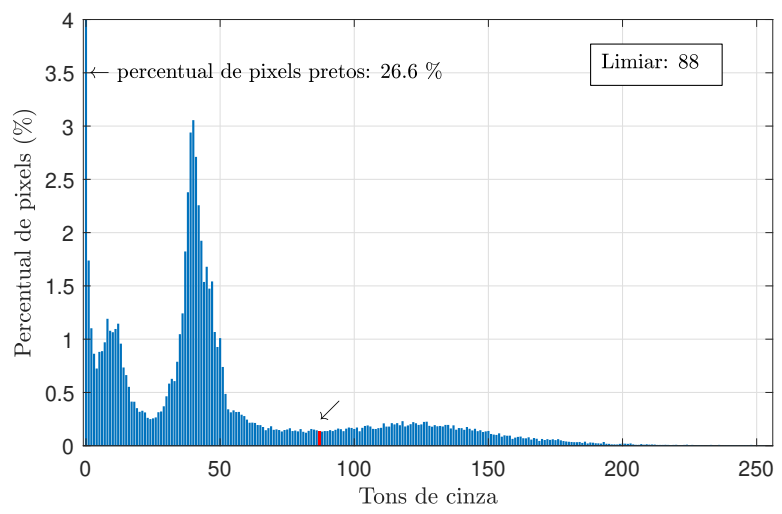

(e) Histograma da amostra 1 na condição 7.

Imagens da amostra 1 na condição 7

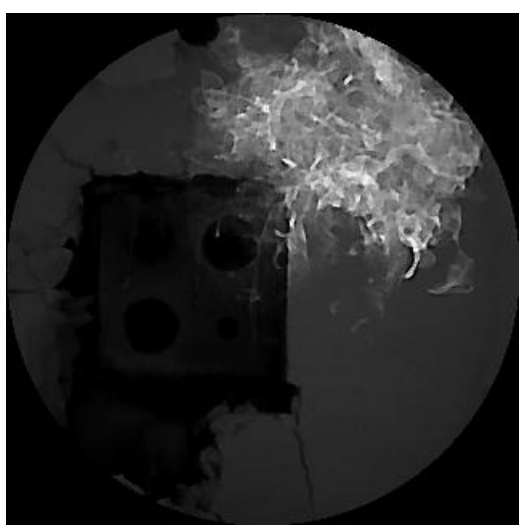

(f) Imagem recortada.

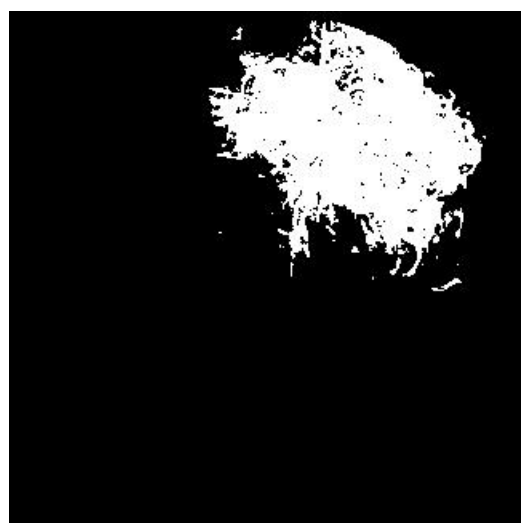

(g) Imagem em preto e branco.

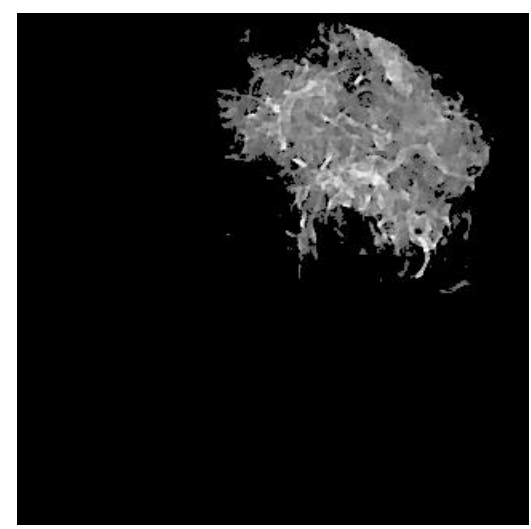

(h) Imagem segmentada.

Fonte - Elaborado pelo autor. 
Figura 70 - Conjuntos das transformações das imagens da chama das amostras 2 e 3 na condição 7 .

Imagens da amostra 2 na condição 7

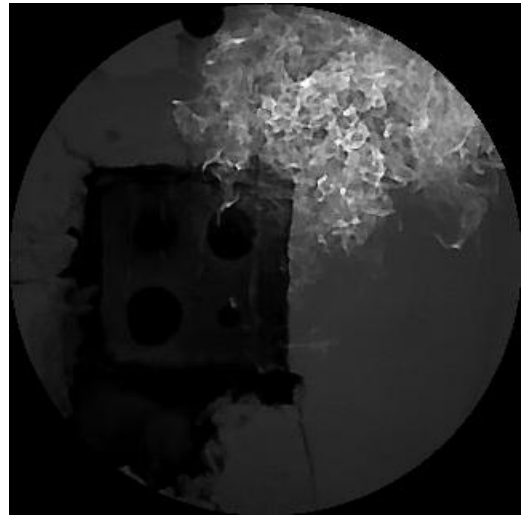

(a) Imagem recortada.

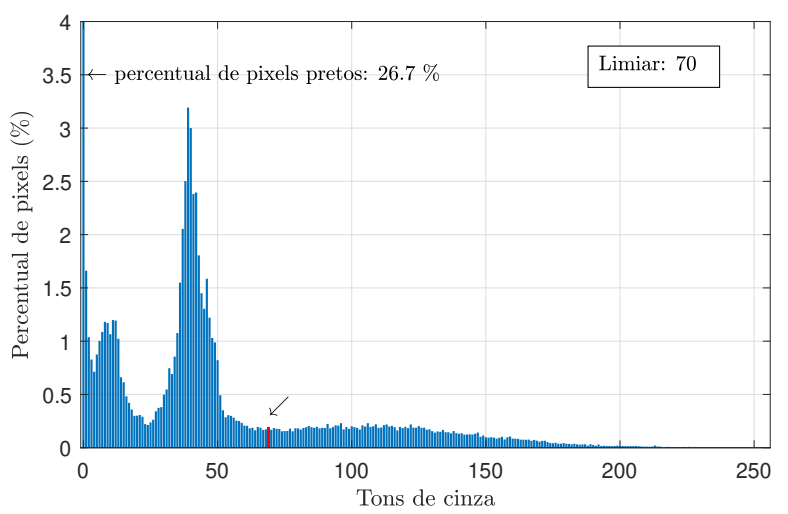

(d) Histograma da amostra 2.

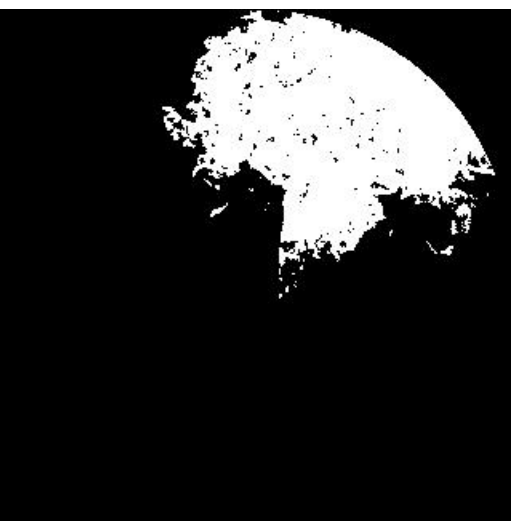

(b) Imagem em preto e branco.

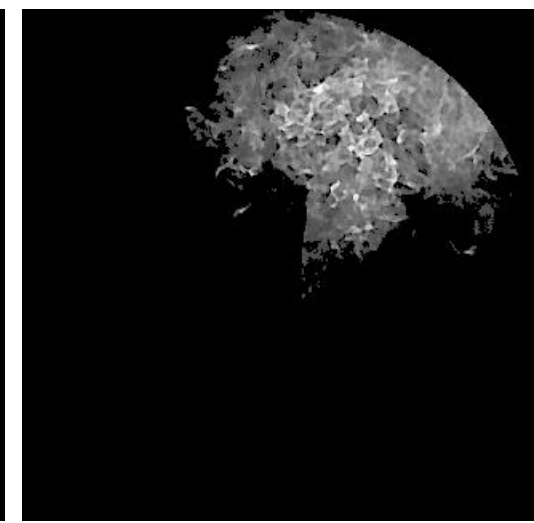

(c) Imagem segmentada.

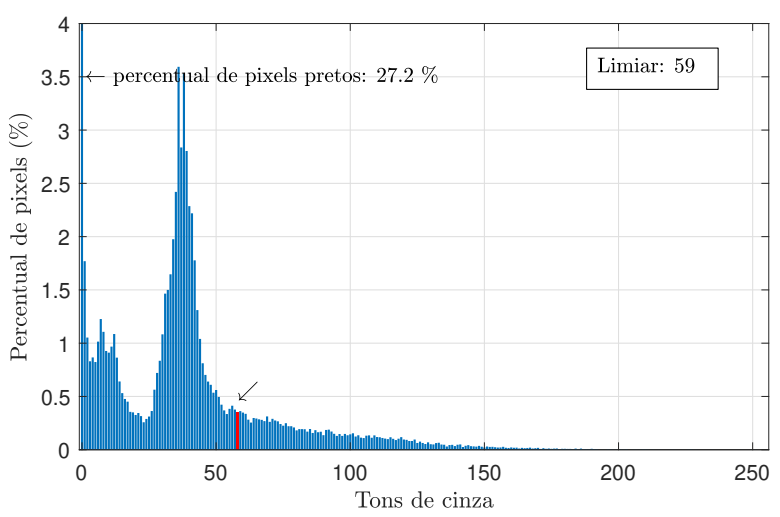

(e) Histograma da amostra 3.

Imagens da amostra 3 na condição 7

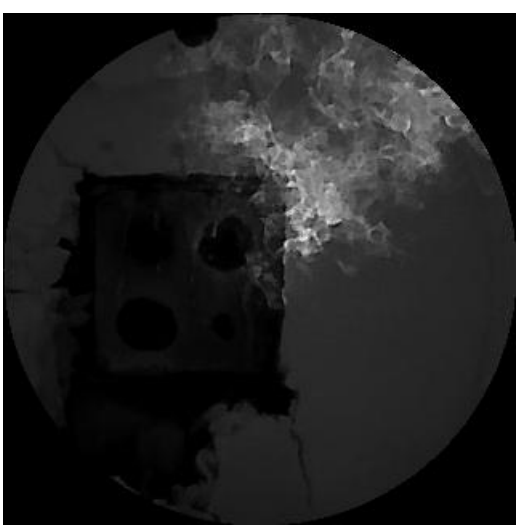

(f) Imagem recortada.

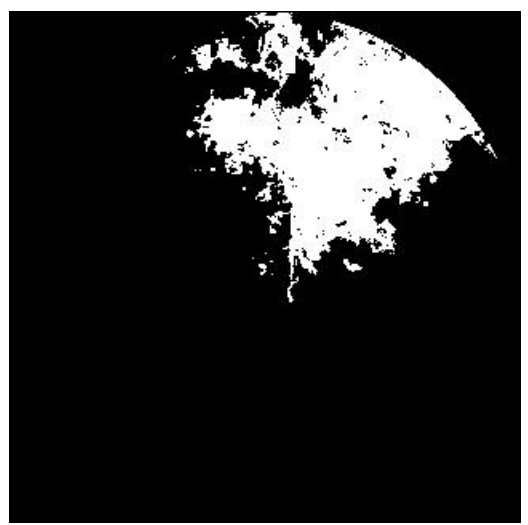

(g) Imagem em preto e branco.

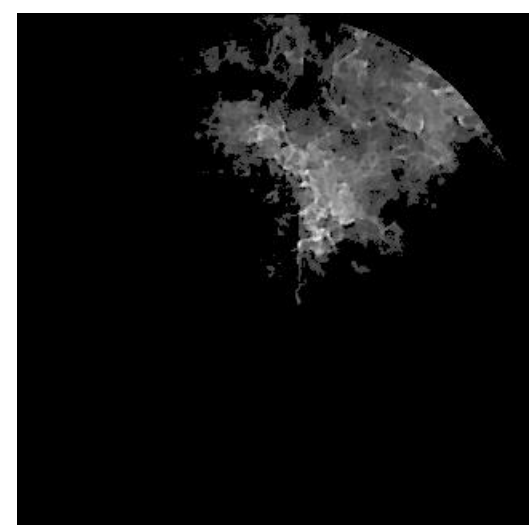

(h) Imagem segmentada.

Fonte - Elaborado pelo autor. 


\section{APÊNDICE B - COMPARAÇÃO ENTRE DADOS EXPERIMENTAIS E ESTIMADOS}

No capítulo 6 foram exibidas comparações entre os dados estimados e experimentais de apenas uma propriedade. Aqui, são mostrados gráficos das três propriedades que são comuns a todas as condições de chama: $C_{x}, C_{y}$ e $L_{y}$. Este apêndice tem o objetivo de Figura 71 - Comparações de $C_{x}$ entre dados experimentais e dados estimados sem e com $f_{R}$.

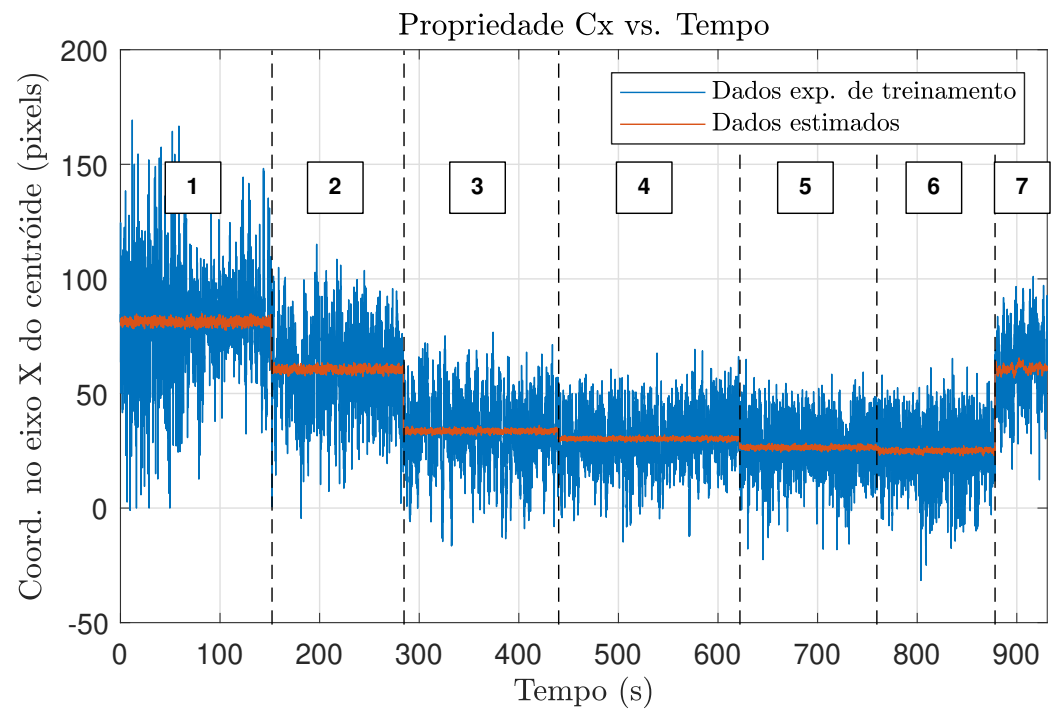

(a) Sem $\boldsymbol{f}_{\boldsymbol{R}}$.

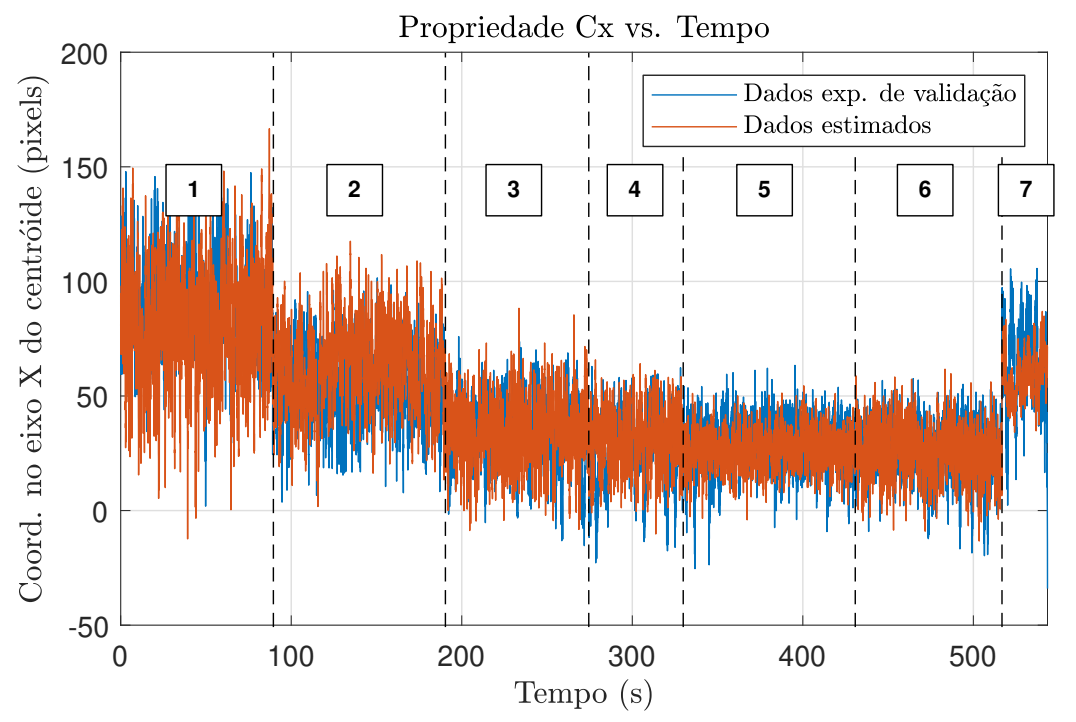

(b) $\operatorname{Com} \boldsymbol{f}_{\boldsymbol{R}}$.

Fonte - Elaborado pelo autor. 
agregar os gráficos com dados experimentais de treinamento (sem a aplicação de $\boldsymbol{f}_{\boldsymbol{R}}$ ) com os dados experimentais de validação (com a aplicação de $\boldsymbol{f}_{\boldsymbol{R}}$ ) a fim de melhorar a comparação entre os dois. É importante salientar que os dados experimentais de treinamento e os dados Figura 72 - Comparações de $C_{y}$ entre dados experimentais e dados estimados sem e com $f_{R}$.

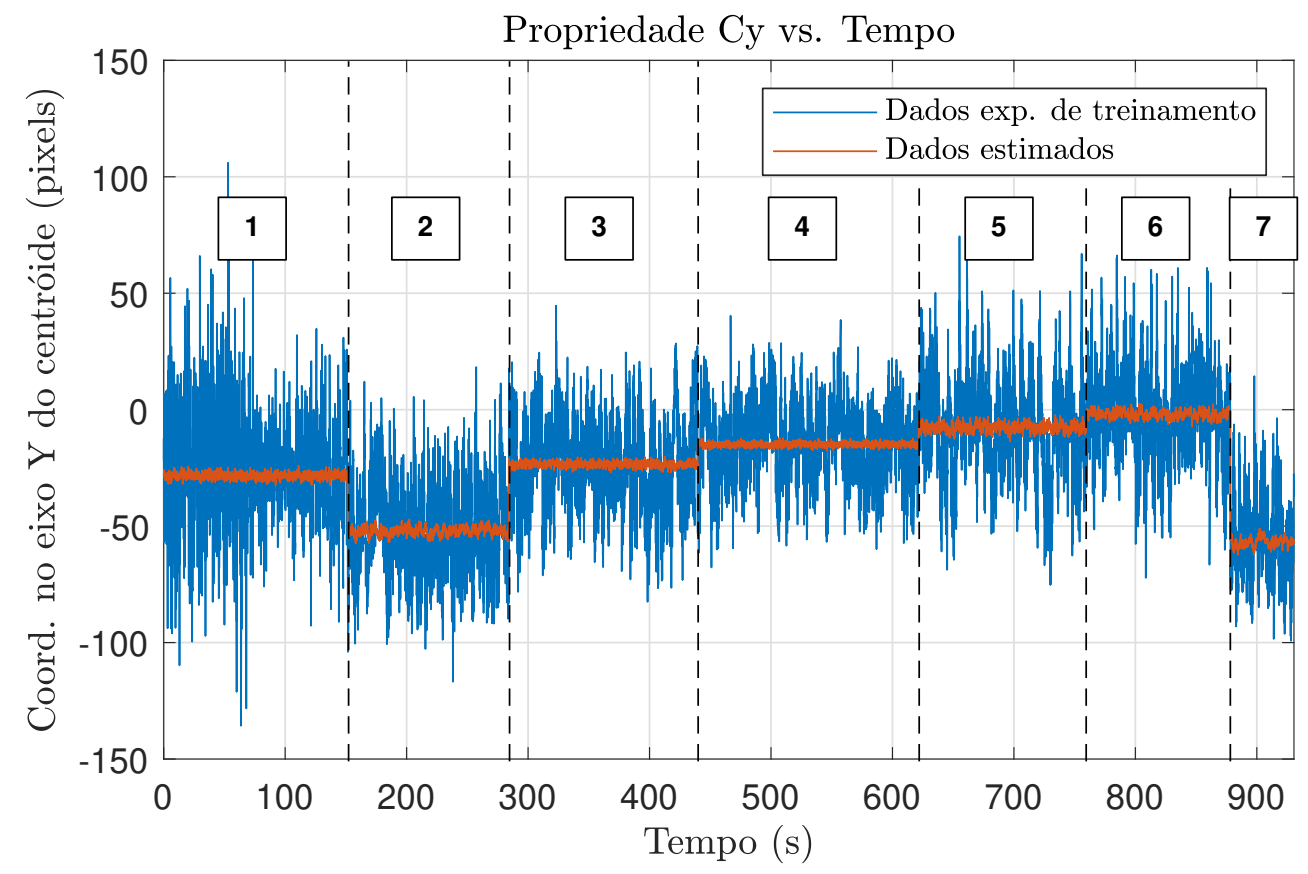

(a) Sem $\boldsymbol{f}_{\boldsymbol{R}}$.

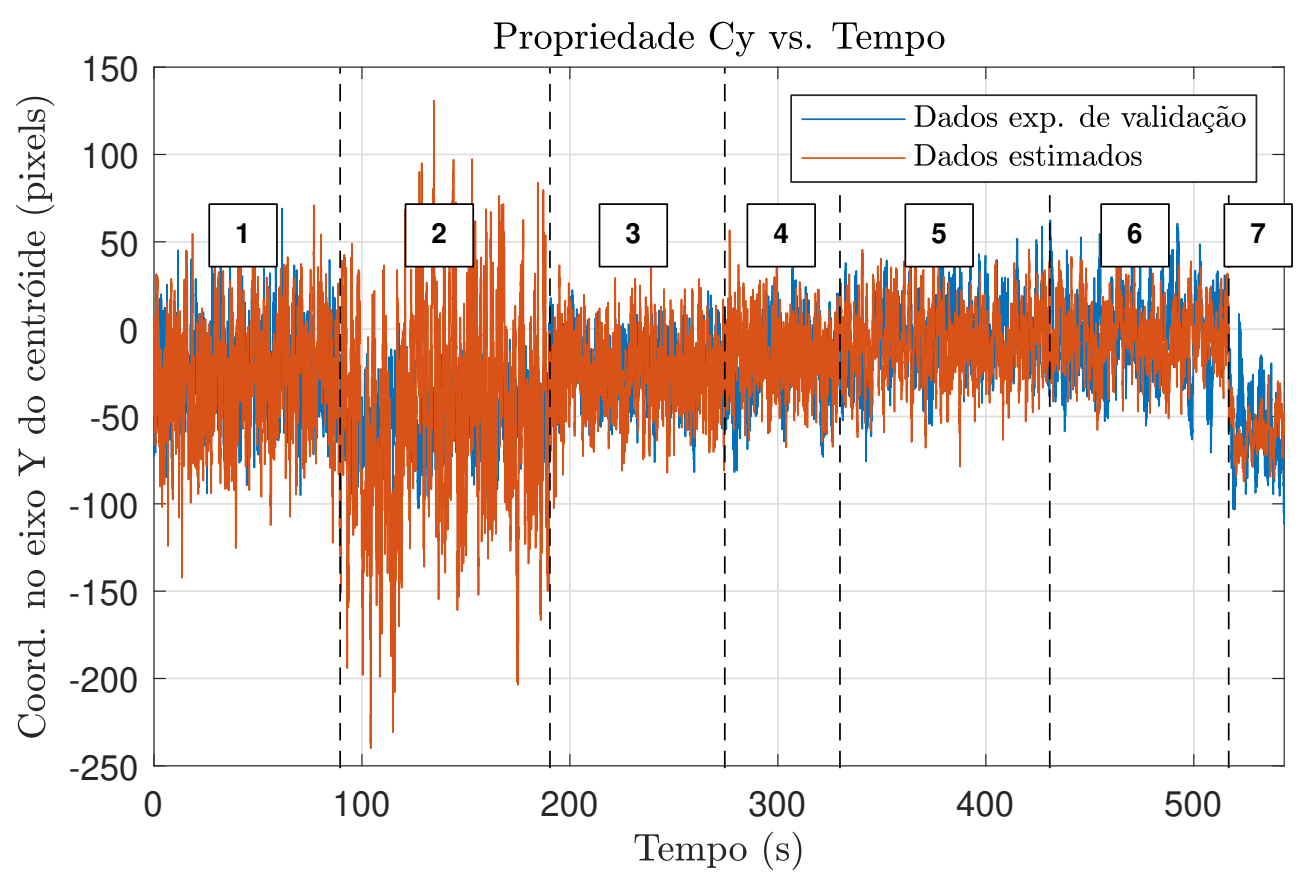

(b) $\operatorname{Com} \boldsymbol{f}_{\boldsymbol{R}}$.

Fonte - Elaborado pelo autor.

estimados sem o fator de correção da variância são utilizados para os cálculos dos próprios 
fatores $\boldsymbol{f}_{\boldsymbol{R}}$. Além disso, nos gráficos com os dados experimentais de validação, os fatores calculados com os dados de treinamento são utilizados para a correção da variância dos dados estimados com os modelos propostos, e é justamente esse fator que faz o modelo apresentar comportamento próximo ao dos dados experimentais.

Figura 73 - Comparações de $L_{y}$ entre dados experimentais e dados estimados sem e com $\boldsymbol{f}_{\boldsymbol{R}}$.

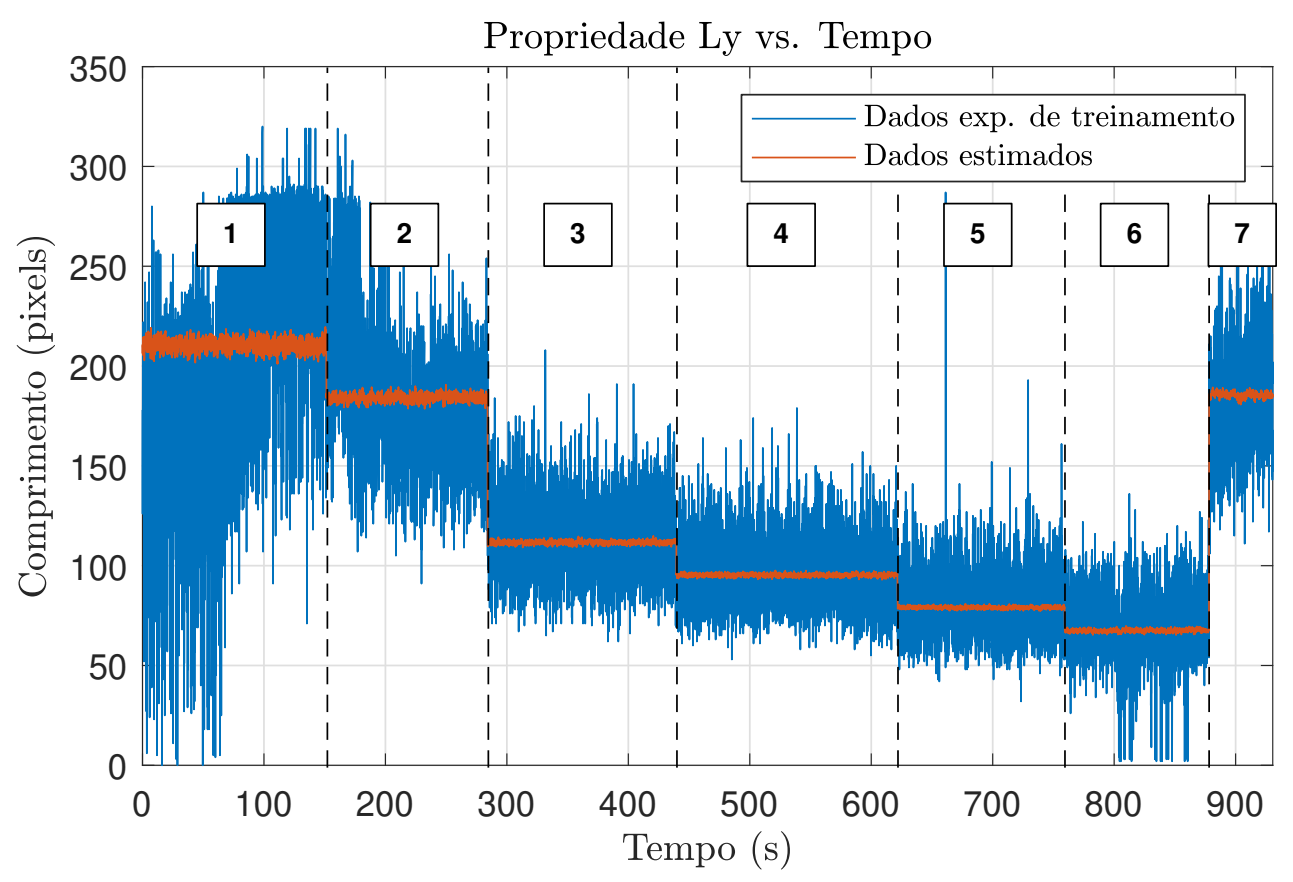

(a) Sem $\boldsymbol{f}_{\boldsymbol{R}}$

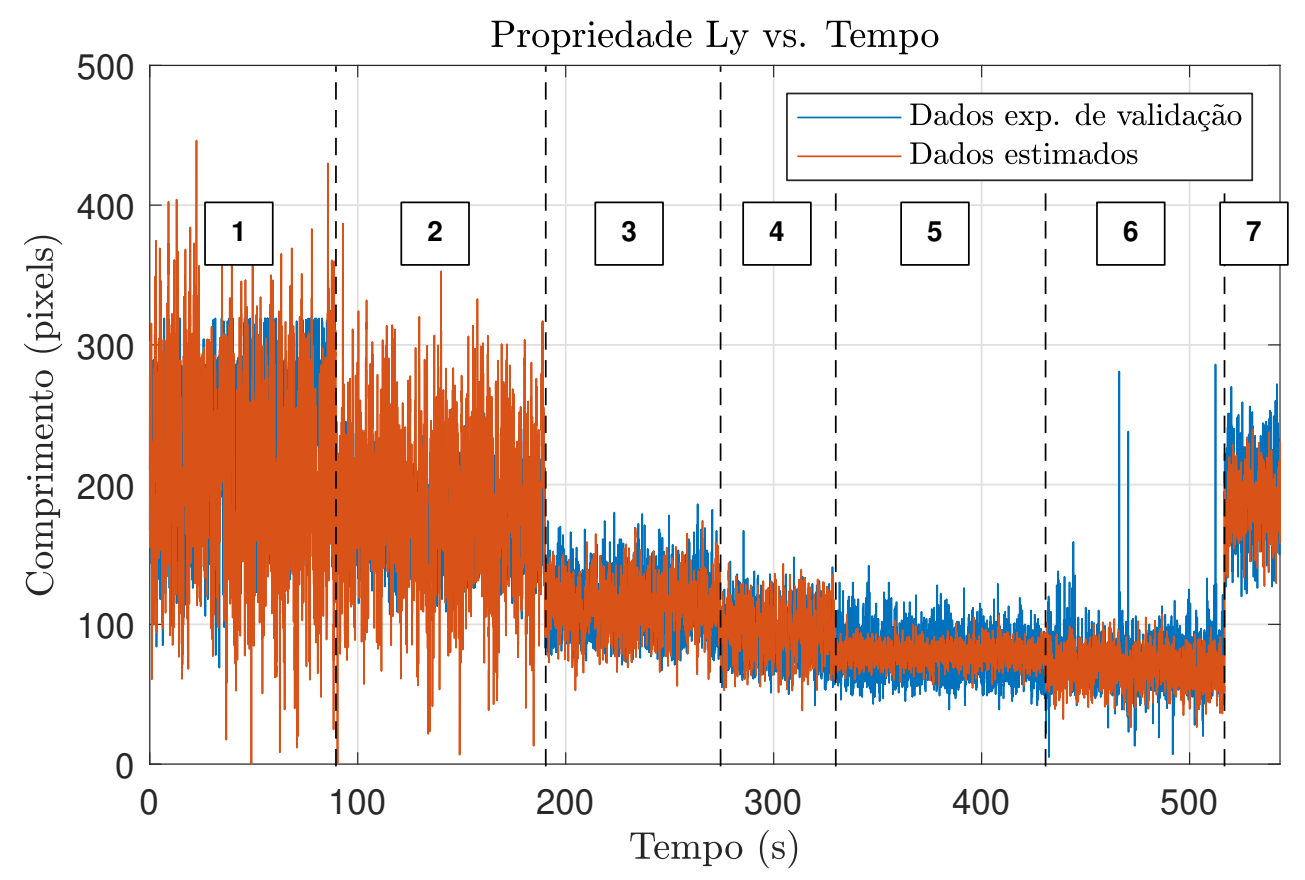

(b) $\operatorname{Com} \boldsymbol{f}_{\boldsymbol{R}}$.

Fonte - Elaborado pelo autor. 


\section{APÊNDICE C - FATORES DE CORREÇÃO DE VARIÂNCIA}

No capítulo 6 foi exibido o gráfico boxplot dos fatores de correção de variância, $\boldsymbol{f}_{\boldsymbol{R}}$, para a condição $c=1$. Neste apêndice, todos os gráficos dos fatores de correção da variância de todas as condições de combustão são apresentados.

Figura 74 - Gráficos boxplot dos fatores de correção de variância para as condições $c=1$

$$
\text { e } c=2 \text {. }
$$

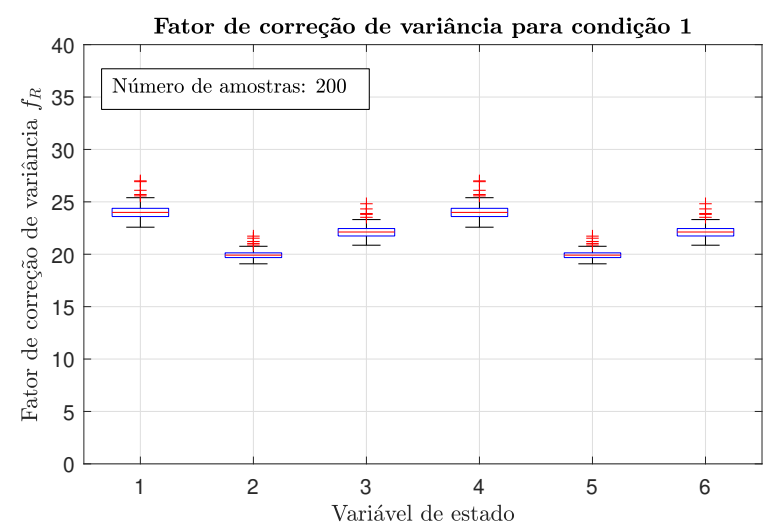

(a) Condição de combustão $c=1$.

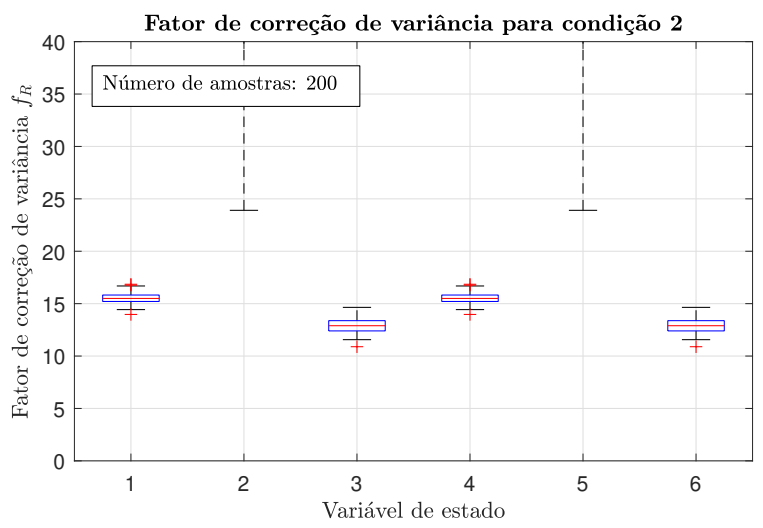

(b) Condição de combustão $c=2$.

Fonte - Elaborado pelo autor.

Figura 75 - Gráficos boxplot dos fatores de correção de variância para as condições $c=3$ e $c=4$.

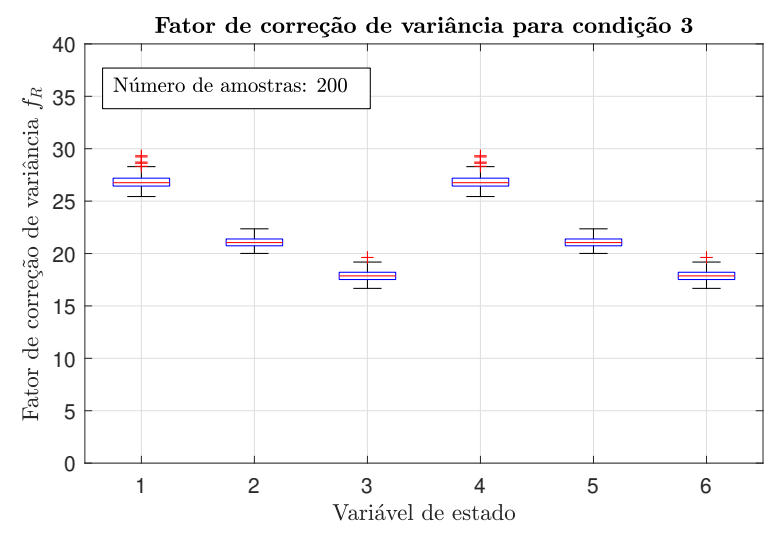

(a) Condição de combustão $c=3$.

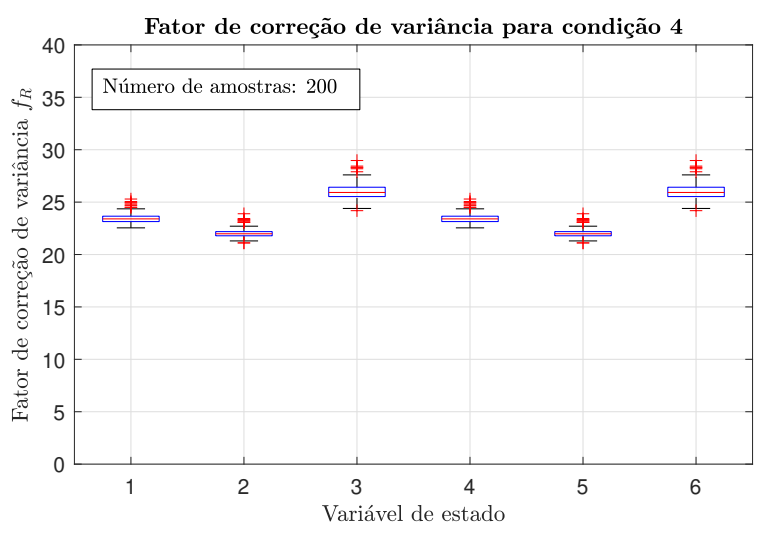

(b) Condição de combustão $c=4$.

Fonte - Elaborado pelo autor. 
Figura 76 - Gráficos boxplot dos fatores de correção de variância para as condições $c=5$, $c=6$ e $c=7$.

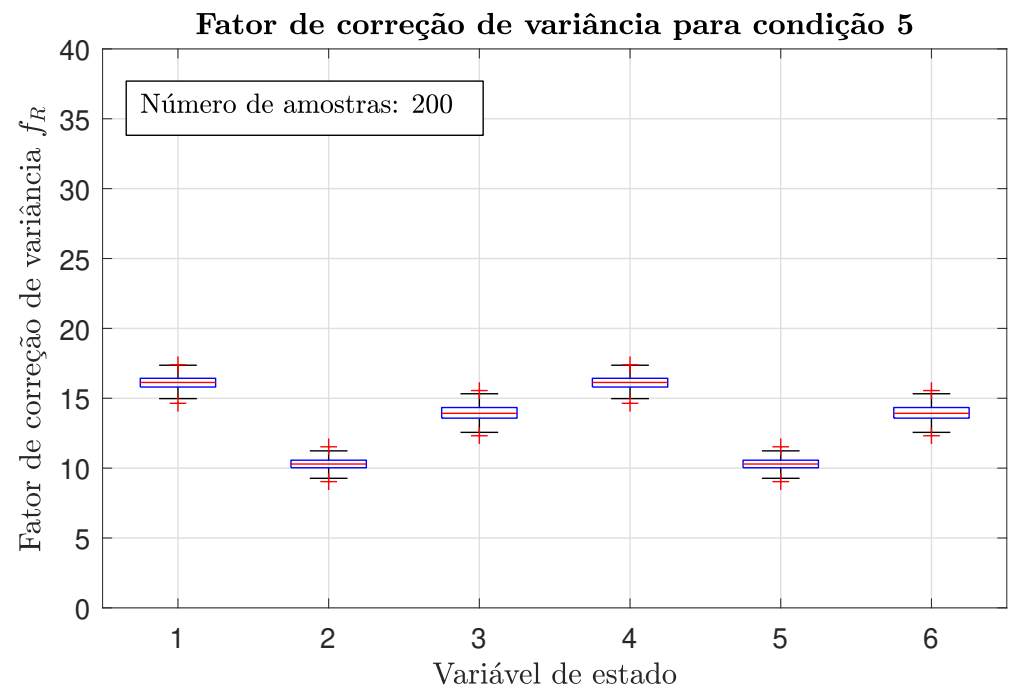

(a) Condição de combustão $c=5$.

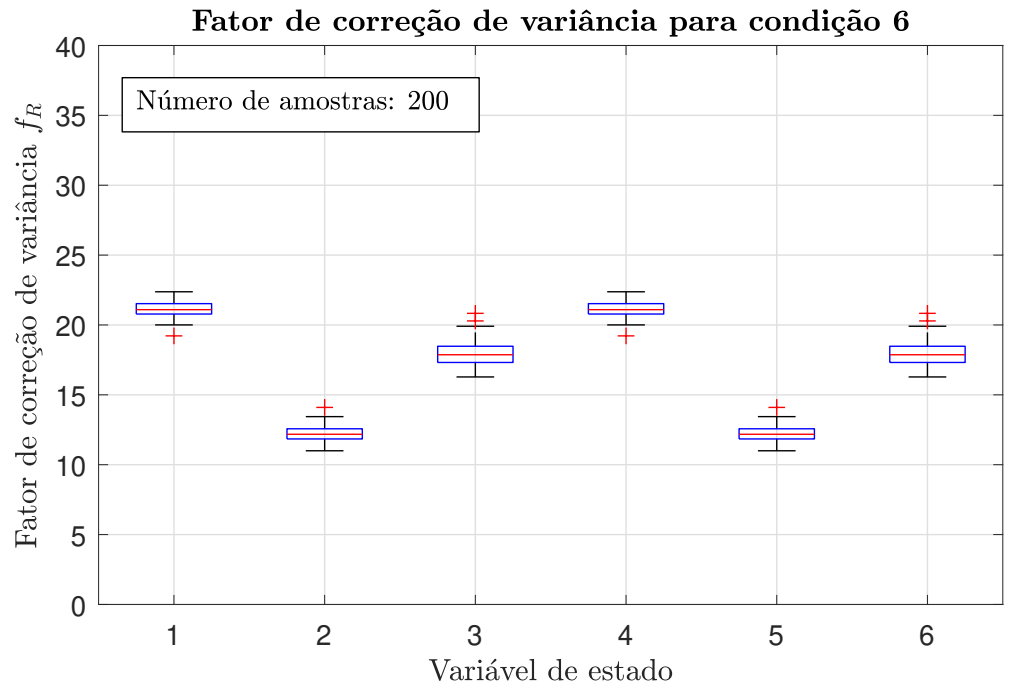

(b) Condição de combustão $c=6$.

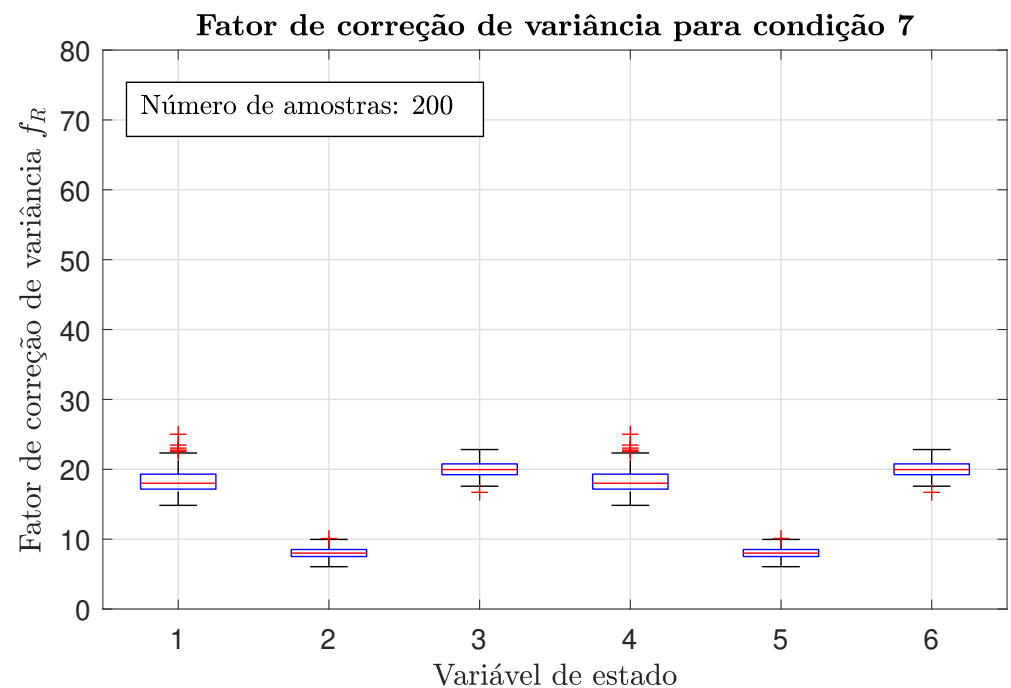

(c) Condição de combustão $c=7$.

Fonte - Elaborado pelo autor. 


\section{APÊNDICE D - COMPARAÇÕES DE SINAIS NO DOMÍNIO DA FREQUÊNCIA}

Na seção 6.8 do capítulo 6 foi exibido apenas o gráfico de comparação dos sinais, no domínio da frequência, entre os dados experimentais de validação e os dados estimados do modelo proposto para propriedade $C_{x}$ na condição $c=1$. Neste apêndice, todos os gráficos comparativos entre os sinais de propriedades no domínio da frequência são apresentados.

Figura 77 - Comparação no domínio da frequência entre sinais dos dados experimentais de validação e dados estimados com o modelo proposto.

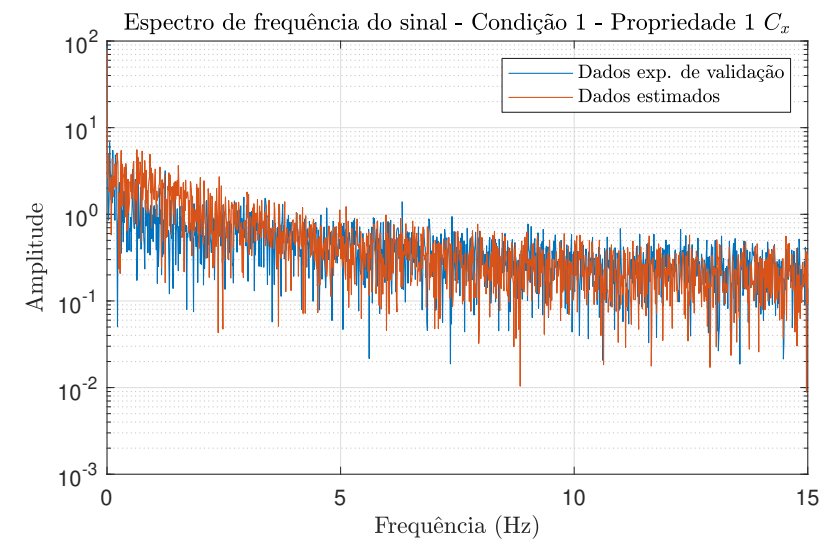

(a) Condição 1, propriedade $C_{x}$.

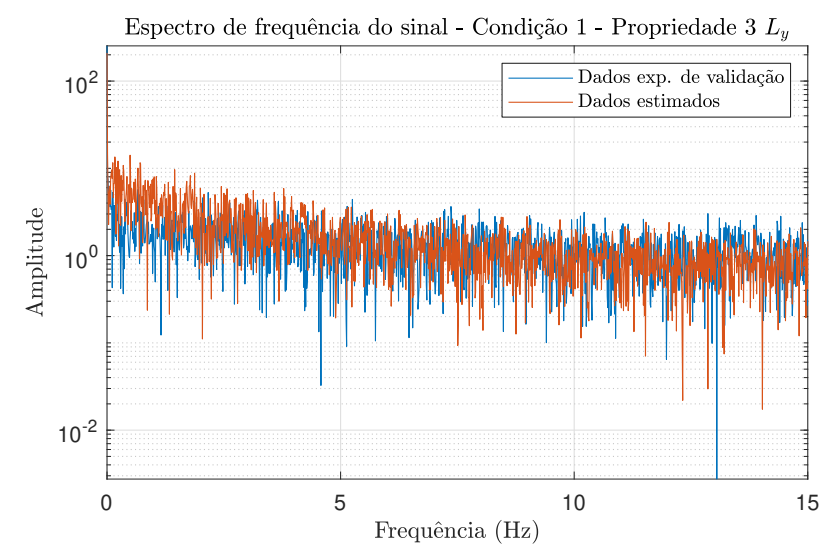

(c) Condição 1, propriedade $L_{y}$.

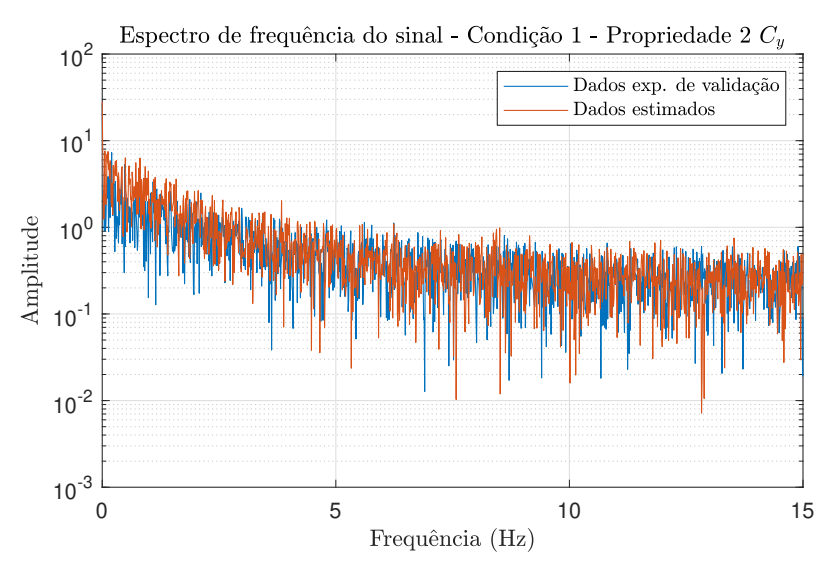

(b) Condição 1 , propriedade $C_{y}$.

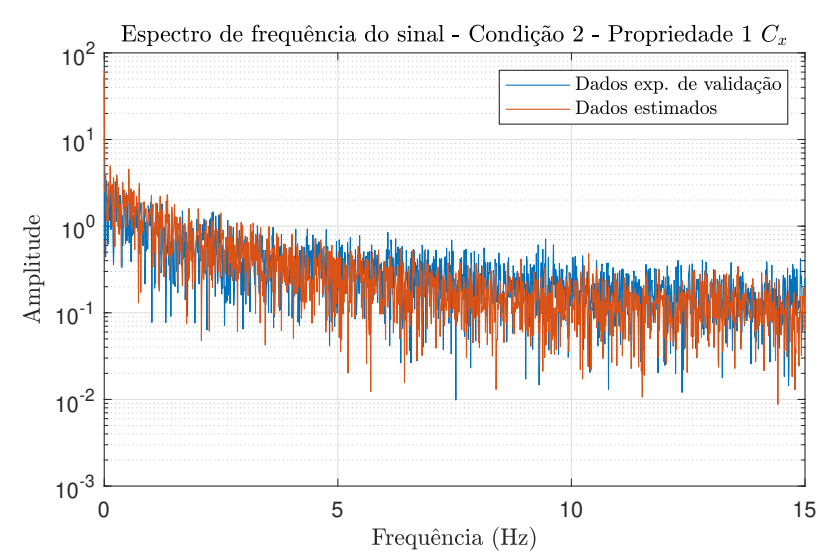

(d) Condição 2, propriedade $C_{x}$.

Fonte - Elaborado pelo autor. 
Figura 77 - Comparação no domínio da frequência entre sinais dos dados experimentais de validação e dados estimados com o modelo proposto (continuação).

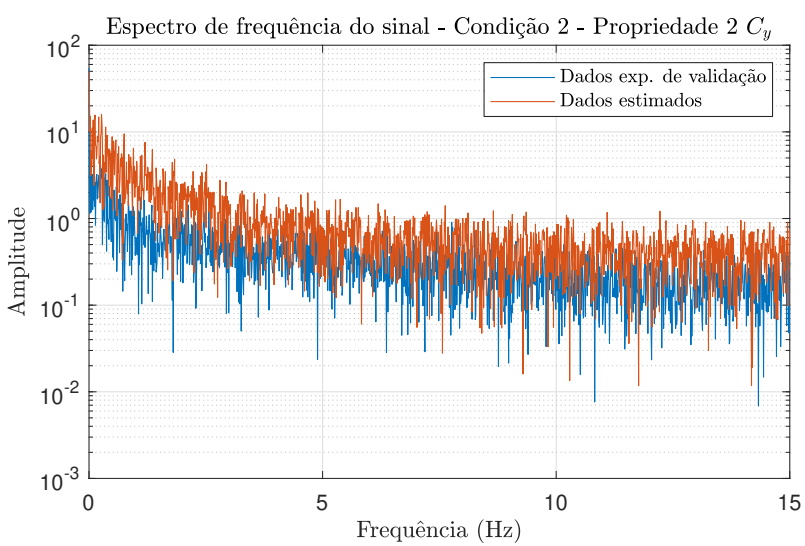

(e) Condição 2, propriedade $C_{y}$.

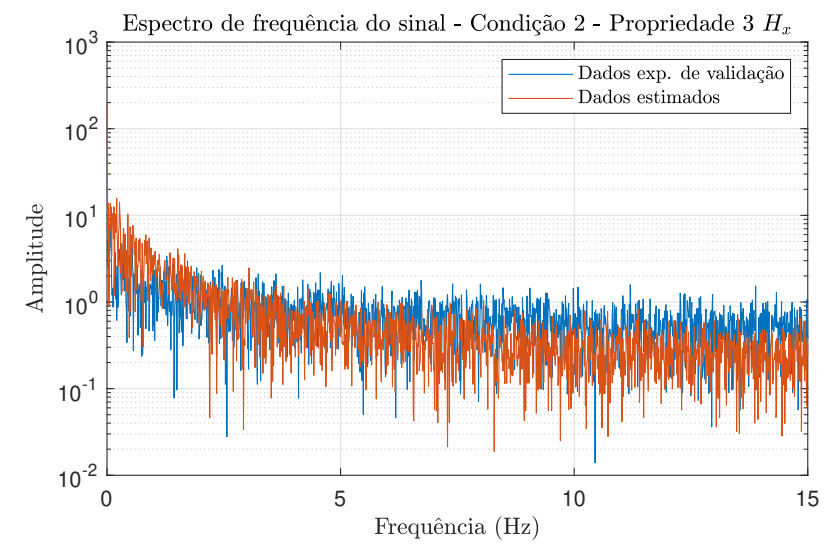

(g) Condição 2, propriedade $H_{x}$.

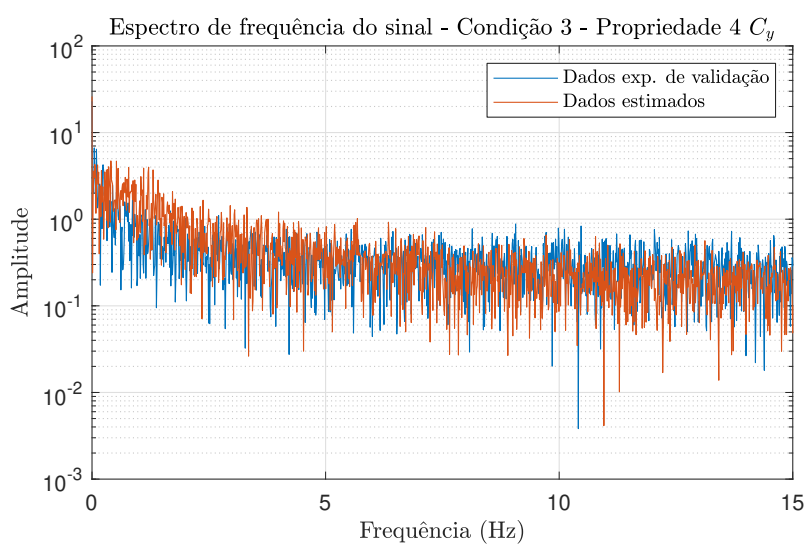

(i) Condição 3 , propriedade $C_{y}$.

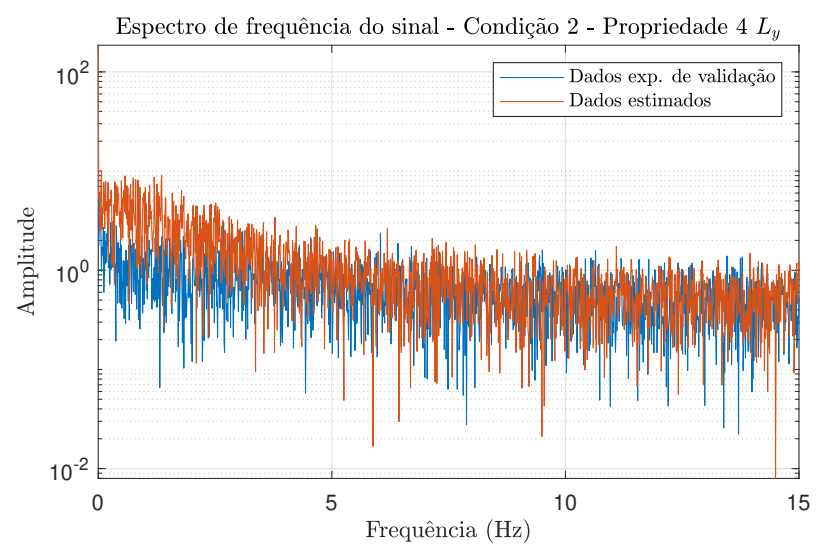

(f) Condição 2, propriedade $L_{y}$.

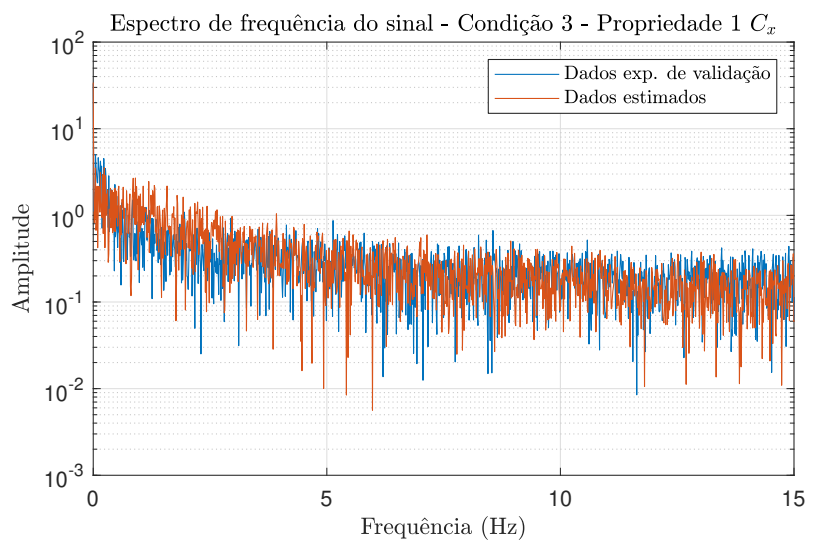

(h) Condição 3 , propriedade $C_{x}$.

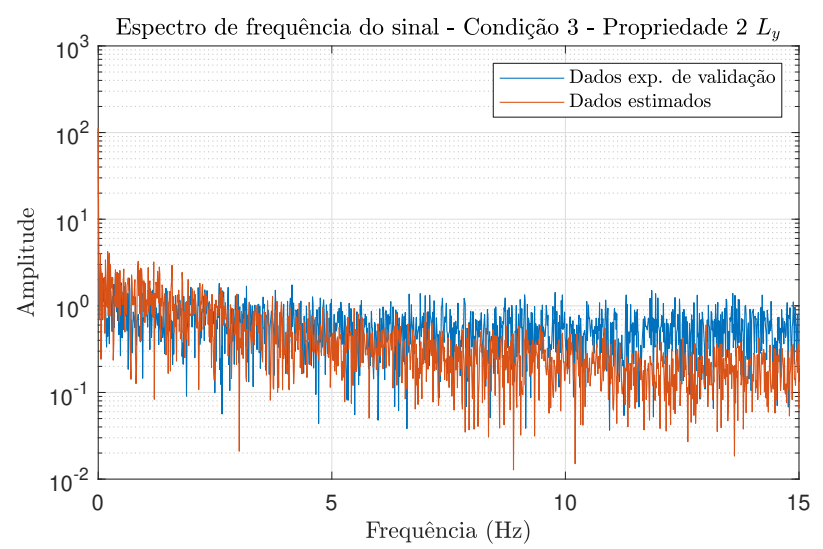

(j) Condição 3 , propriedade $L_{y}$.

Fonte - Elaborado pelo autor. 
Figura 77 - Comparação no domínio da frequência entre sinais dos dados experimentais de validação e dados estimados com o modelo proposto (continuação).

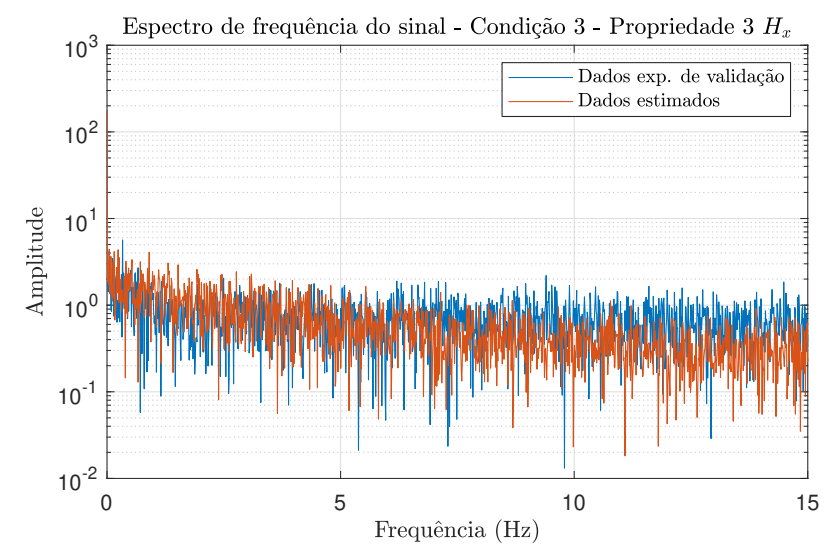

(k) Condição 3, propriedade $H_{x}$.

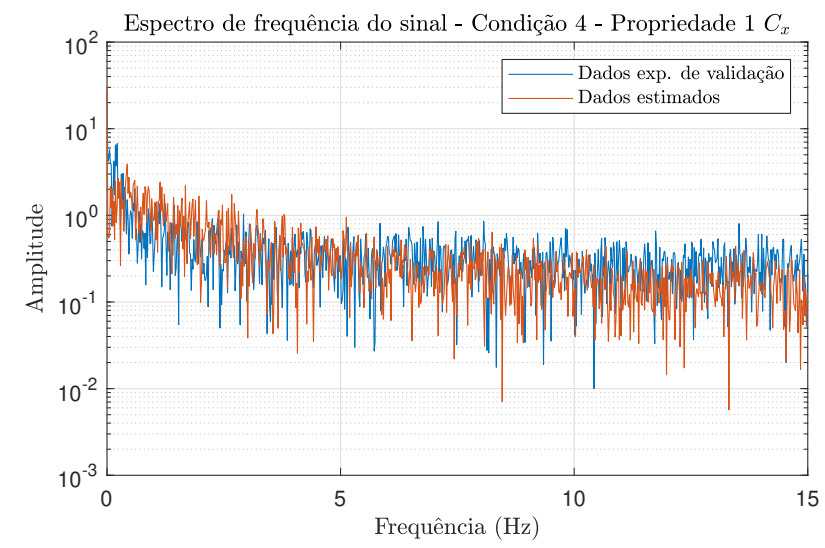

(m) Condição 4 , propriedade $C_{x}$.

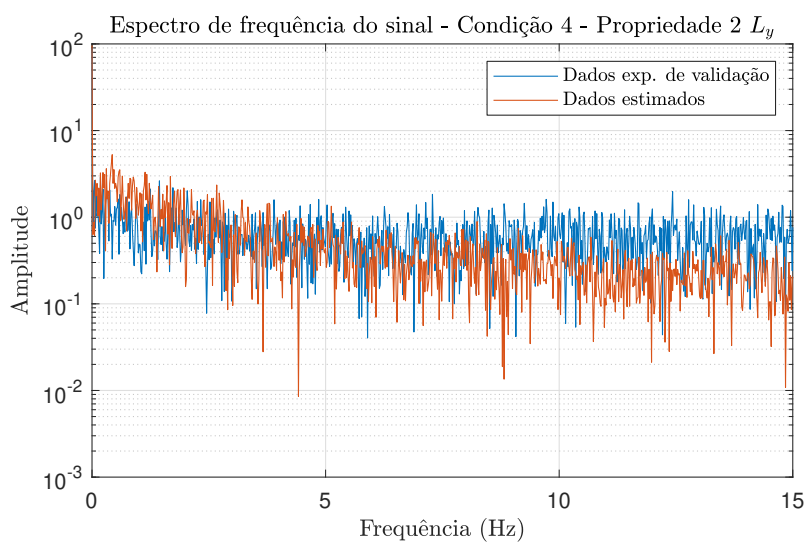

(o) Condição 4 , propriedade $L_{y}$.

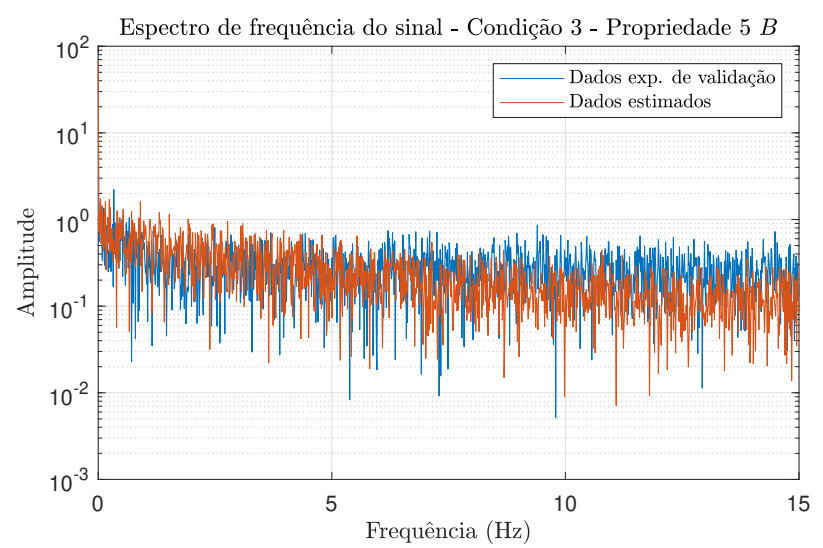

(l) Condição 3, propriedade $B$.

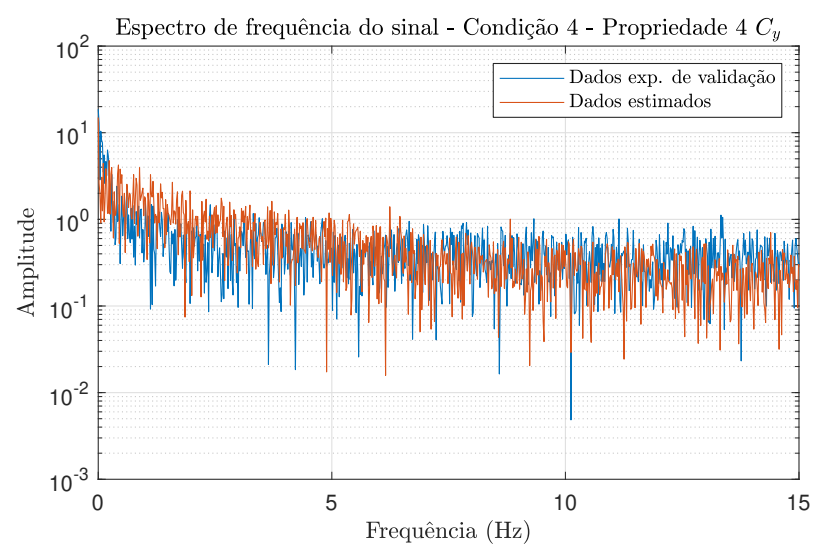

(n) Condição 4 , propriedade $C_{y}$.

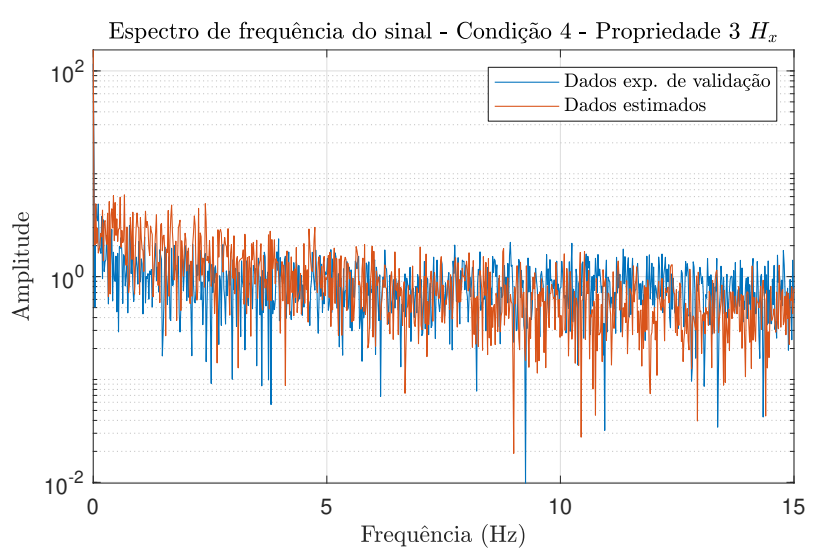

(p) Condição 4, propriedade $H_{x}$.

Fonte - Elaborado pelo autor. 
Figura 77 - Comparação no domínio da frequência entre sinais dos dados experimentais de validação e dados estimados com o modelo proposto (continuação).

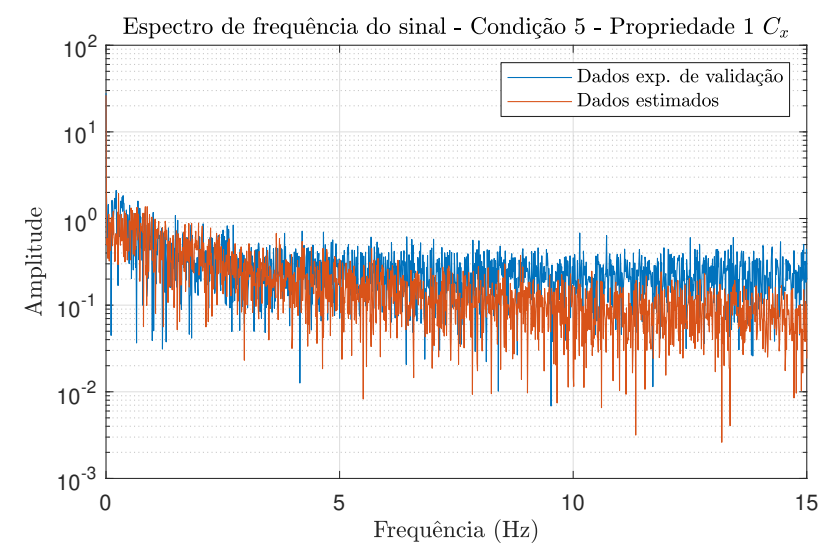

(q) Condição 5, propriedade $C_{x}$.

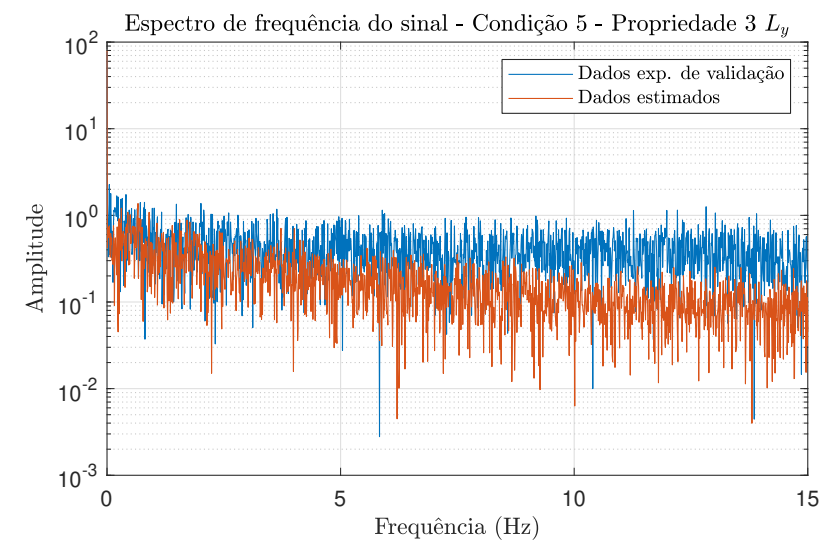

(s) Condição 5, propriedade $L_{y}$.

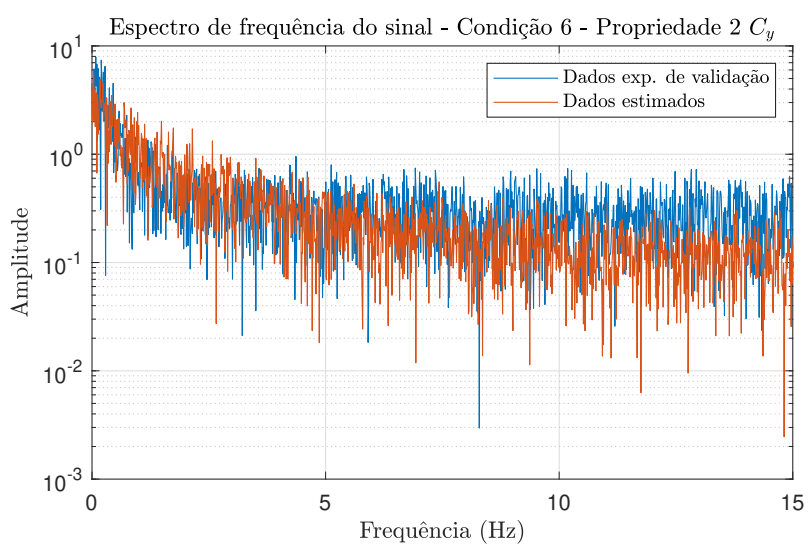

(u) Condição 6 , propriedade $C_{y}$.

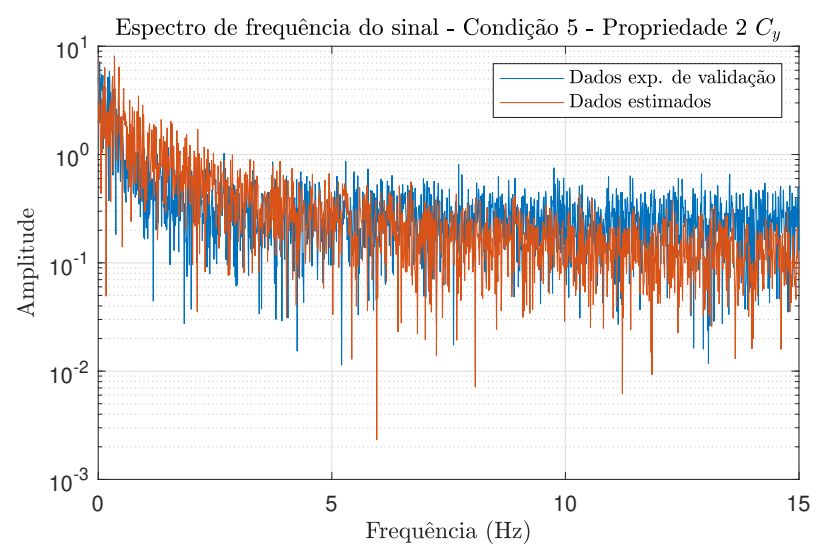

(r) Condição 5 , propriedade $C_{y}$.

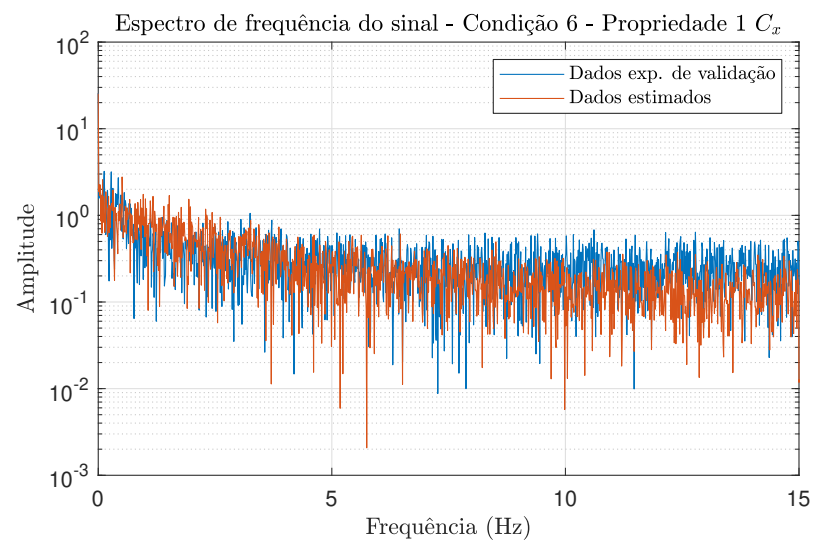

(t) Condição 6, propriedade $C_{x}$.

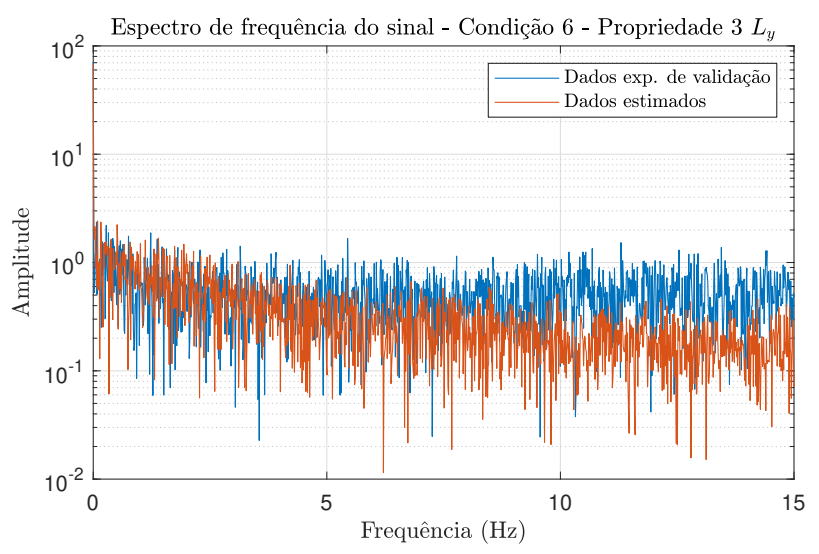

(v) Condição 6, propriedade $L_{y}$.

Fonte - Elaborado pelo autor. 
Figura 77 - Comparação no domínio da frequência entre sinais dos dados experimentais de validação e dados estimados com o modelo proposto (continuação).

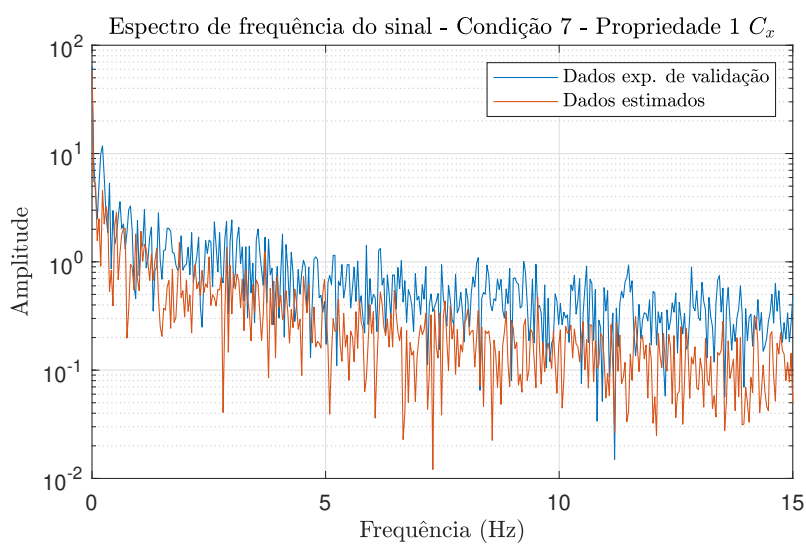

(w) Condição 7, propriedade $C_{x}$.

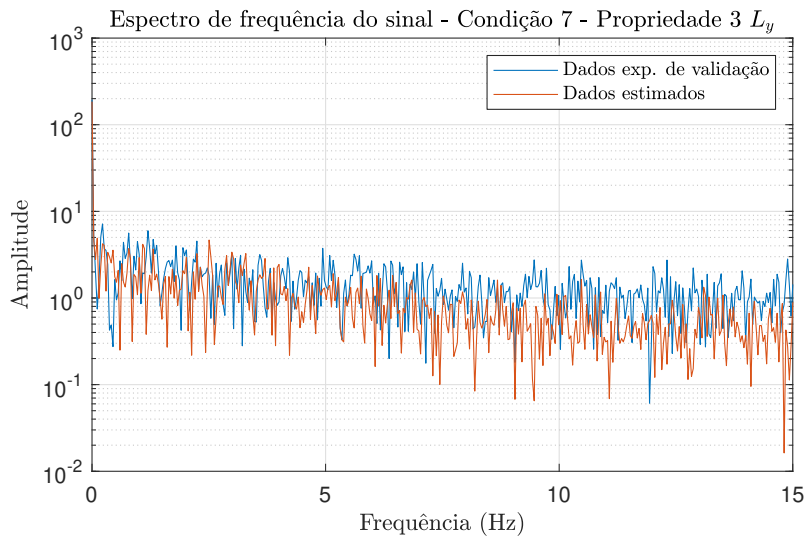

(y) Condição 7, propriedade $L_{y}$.

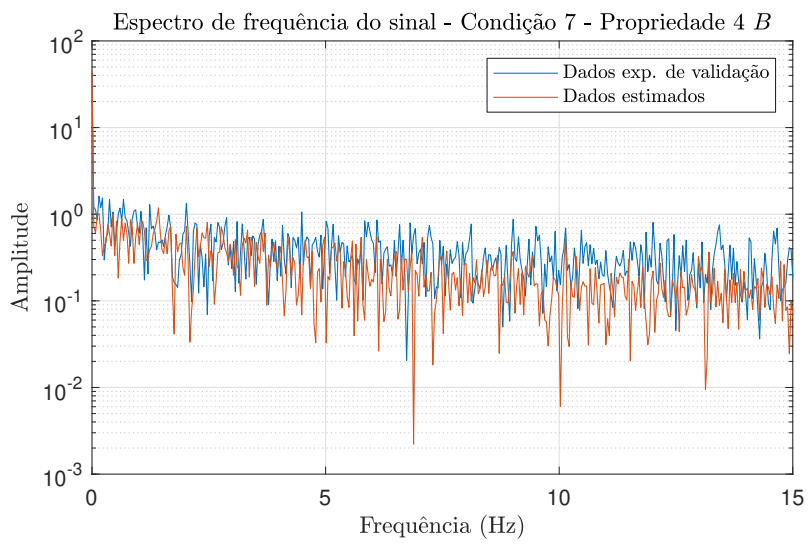

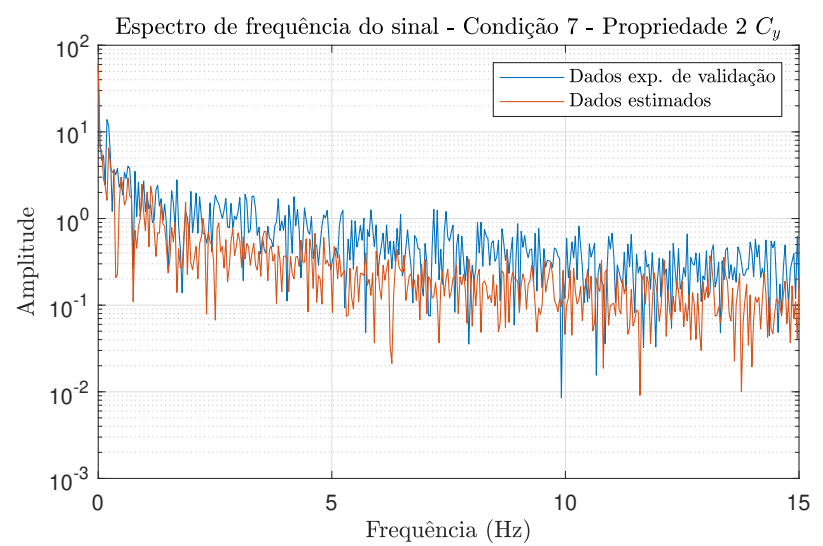

(x) Condição 7, propriedade $C_{y}$.

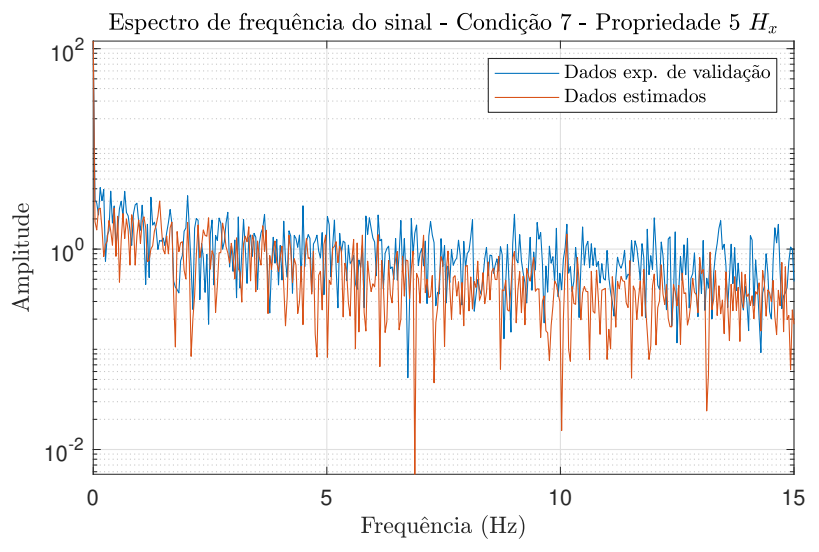

(z) Condição 7, propriedade $H_{x}$.

(aa) Condição 7, propriedade $B$.

Fonte - Elaborado pelo autor. 